\title{
Navigating barriers to gender equality in the European Union context
}

Citation for published version (APA):

Kalaitzi, S. (2019). Navigating barriers to gender equality in the European Union context: The case of healthcare sector. [Doctoral Thesis, Maastricht University]. Open Line, Digital Printing. https://doi.org/10.26481/dis.20191217sk

Document status and date:

Published: 01/01/2019

DOI:

10.26481/dis.20191217sk

Document Version:

Publisher's PDF, also known as Version of record

\section{Please check the document version of this publication:}

- A submitted manuscript is the version of the article upon submission and before peer-review. There can be important differences between the submitted version and the official published version of record.

People interested in the research are advised to contact the author for the final version of the publication, or visit the DOI to the publisher's website.

- The final author version and the galley proof are versions of the publication after peer review.

- The final published version features the final layout of the paper including the volume, issue and page numbers.

Link to publication

\footnotetext{
General rights rights.

- You may freely distribute the URL identifying the publication in the public portal. please follow below link for the End User Agreement:

www.umlib.nl/taverne-license

Take down policy

If you believe that this document breaches copyright please contact us at:

repository@maastrichtuniversity.nl

providing details and we will investigate your claim.
}

Copyright and moral rights for the publications made accessible in the public portal are retained by the authors and/or other copyright owners and it is a condition of accessing publications that users recognise and abide by the legal requirements associated with these

- Users may download and print one copy of any publication from the public portal for the purpose of private study or research.

- You may not further distribute the material or use it for any profit-making activity or commercial gain

If the publication is distributed under the terms of Article $25 \mathrm{fa}$ of the Dutch Copyright Act, indicated by the "Taverne" license above, 
NAVIGATING BARRIERS

TO GENDER EQUALITY IN THE EUROPEAN UNION CONTEXT

The case of healthcare sector

Stavroula Kalaitzi 
NAVICATING BARRIERS

TO CENDER EQUALITY IN THE EUROPEAN UNION CONTEXT

The case of healthcare sector

By

Stavroula Kalaitzi 
The research for this dissertation was performed at the Department of International Health within CAPHRI, the Care and Public Health Research Institute, Faculty of Health, Medicine and Life Sciences, Maastricht University

Dissertation: Navigating barriers to gender equality in the European Union context : The case of healthcare sector

Author: Stavroula Kalaitzi

Cover design: loulia Karavasiloglou \& Stavroula Kalaitzi

Layout design and typesetting: loulia Karavasiloglou

(c) Copyright: Stavroula Kalaitzi, Maastricht 2019

All rights reserved. No part of this publication may be reproduced without permission of the copyright owner.

ISBN:978-94-6380-637-4

Printed by Open Line, Alkamenous 18, 10439 Athens, Greece 


\section{NAVIGATING BARRIERS \\ TO CENDER EQUALITY IN THE EUROPEAN UNION CONTEXT}

The case of healthcare sector

\section{DISSERTATION}

To obtain the degree of Doctor at Maastricht University, on the authority of the Rector Magnificus Prof. dr. Rianne M. Letschert, in accordance with the decision of the Board of Deans to be defended in public on Tuesday, 17 December 2019, at 14:45 hours

by

Stavroula Kalaitzi 


\section{Supervisor}

Prof. dr. Helmut Brand

\section{Co-supervisor}

Dr. Katarzyna Czabanowska

\section{Assessment Committee}

Prof. dr. Leopold Curfs (Chair)

Dr. Milena Pavlova

Prof. dr. Marielle G. Heijltjes

Prof. dr. dr. Bettina Pfleiderer (Universität Münster, Germany)

Prof. dr. Anastasia Vlachou (University of Thessaly, Greece) 


\section{TABLE OF CONTENTS}

Chapter 1 Introduction

Chapter 2 Women leadership barriers in healthcare, academia and business

Chapter 3 Exploring women healthcare leaders' perceptions on barriers to leadership in Greek context

Chapter 4 Women, healthcare leadership and societal culture: a qualitative study

Chapter 5 The sustainable development thinking in gender equality policy in EU:

misplaced priorities and unmet challenges

Chapter 6 Gender mainstreaming toolkits towards achieving organizational change: a qualitative analysis

Chapter 7 General discussion

Valorization Addendum. 161

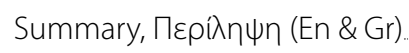

Acknowledgments 175

Curriculum Vitae. 177

List of publications 179 



\section{Chapter}

INTRODUCTION 



\subsection{Background}

Progress towards achieving gender equality in the European Union context is reported slow, fragmented and uneven. Albeit EU's and Member States' high level political and legal commitment to the principle of gender equality as a fundamental block to an egalitarian social order and social cohesion, women remain significantly under-represented at the highest echelons and their talents remain untapped. Despite the adopted sophisticated strategies and the laudable efforts to bring about change, gendered barriers are persistent and poorly addressed compromising, thus, the sustainable future for the EU.

Equality between men and women is key for Europe Union's future. Currently, gender equality lies at the heart of EU public debate and commitment to continue to make progress towards true equality between women and men in Europe (European Commission, 2019a). Hence, the EU cannot afford to fail on making use of the huge potential lying in half of its population (EC, 2019b). Open files on equality between women and men have been put forward, such as negotiations on work/life balance legislation, addressing blockages on women on boards, sectoral initiatives for gender sensitive policies (e.g. European Network on Women in Digital, Women to the transport sector) (EC, 2019b). The intent of the EU to deliver on the legal commitment and on the promise of gender equality has been also emphasized by the recent alignment with sustainable development goals (SDGs) (UN 2030 Agenda; Eurostat, 2018), and in particular with SDG5 (Achieve gender equality and empower all women and girls). In that line, the immediate past Presidency trio [Estonia, Bulgaria and Austria (July 2017 - January 2019)] called upon a standalone, distinct from other policy areas, EU gender equality strategy and highlighted the importance of EU's guiding role for national strategies (Bulgarian Presidency, 2019; EC, 2019b).

However, the centrality of gender equality in EU's legal and policy commitments has not yet translated in adequate gender equality outcomes across Member States (EC, 2019c). The European Commission and its agencies keep fighting against gendered barriers, such as stereotypes and gender gap especially at higher levels of public and private sectors, aiming to bring behavioral and social change and, gratefully, some achievements have been made (EC, 2019d). For example, employment rates have reached historically the highest levels in the EU and more women are in leading positions than ever, whereas the gender gap in education is being closed and even reversed in some disciplines. Yet, women participate in labor market at about 11,5\% less than men, are paid at an average $16 \%$ lower than men and they hardly reach an equal share on the highest decisionmaking echelons assuming only 6,3\% of CEO positions in major companies across EU (EC, 2019b). Many indicators on gender equality are stagnating, while others are worsened in several Member States (EIGE, 2017). Thereby, progress has been uneven and fragmented across economic sectors and Member States. The reality is that equality between women and men remains not a tangible reality for too many EU citizens.

Arguably, gender inequalities are socially constructed, whereas challenging norms, attitudes and deeply rooted patterns of behavior are uncomfortable, difficult and time demanding. And this 
generates slowness in progress; it also shows the need for consistent commitment and collective action by all actors for driving gender balance and inclusivity in social reality. Thereby, the debates among policy, scholars and civil society grew more complex and, in some instances, less effective. For example, several perspectives, such as policy inconsistencies and misplaced priorities, the varied meaning of gender equality for involved actors and stakeholders, the barriers holding back any possible progress have been debated extensively.

Research on gender equality and women's leadership is productive in dispelling myths and facts about several forms of gender inequalities, yet shedding light in a scattered and fragmented way on gendered barriers. The manifestation of barriers within an organization or a sector on a comprehensive and prevalence basis has received scant attention so far. For example, stereotypes, gender pay gap, bias, sexual harassment have been explored on a one to one basis, but rarely through the big picture perspective and how each barrier contributes to shape this picture (Eagly and Steffen, 1984; Diekman and Eagly, 2000; Rubery et al, 2005; Ely et al, 2011; Bismark et al, 2015; Linkova, 2017; McLaughlin et al, 2017; Lerch et al, 2018). Being aware of the big picture of all visible and invisible barriers, understanding the context within which they are developed, the underlying mechanisms that feed the durability and transferability of each barrier within socio-cultural and economic reality may be the missing link between policy and practice. Understanding the barriers that make up the labyrinth of women's leadership (Eagly and Carli, 2007) will provide us with deeper insights and will help us to explore the knowledge on how to address effectively the complexities of gender inequality challenges, such as cross-cutting inequalities, at both the social and economy level. It will make it easier to understand how to dismantle and de-power deeply rooted gendered perceptions, and to develop effective and gender responsive policies. From the broader social change perspective, it is important aspiring women leaders to count on enjoying genuine equal opportunities when competing on attaining influential leadership positions; organizations and decision makers should also count on the possibility to access the greatest, untapped talent pool when selecting leaders by achieving gender equality and inclusion objectives, which is linked to organizational and societal progress (Acker, 2012; Ellemers, 2014; World Economic Forum, 2018)

Hence, this thesis aims to explore the following overarching research question:

\section{What are the barriers to gender equality in the EU context?}

Which may be subsumed under the following, more granular questions:

What are the barriers to gender equality?

Are the barriers to gender equality similar across sectors? Do barriers manifest themselves differently across sectors? For example, what are the barriers in healthcare, academia and business sectors? Is the barriers' prevalence similar across sectors? Across countries? Why? Why not?

How important are the socio-economic and cultural contexts to the manifestation and prevalence of barriers to gender equality?

What is the relation of women's leadership to gender equality? Does gender equality involve women's leadership advancement? In what way? 
Does the EU's sustainable development thinking aligns with the adopted gender equality policy objectives? What is the European Union's policy agenda to gender equality? What are the objectives? To what extent do the EU gender equality policy objectives relate to gender equality challenges faced by Member States' citizens?

What is the EU strategy towards achieving gender equality objectives? How does EU support implementation of gender equality policy objectives at Member States level? Are EU efforts considered effective? Is there any room for improvement at both EU and Member States level?

Hence, the research topic lies on the triangle of the EU gender equality policy, gendered barriers and sector perspective (Figure 1.1).

Figure 1.1 The triangle of research topic (own concept)

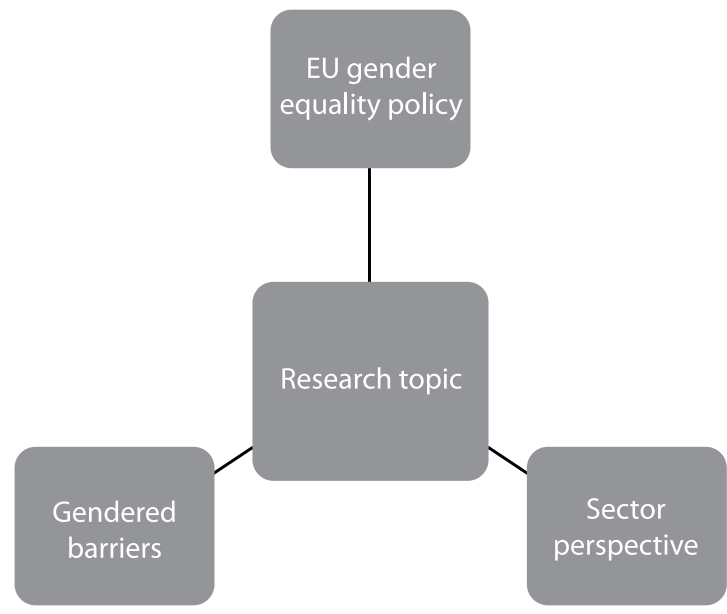

The research, which follows in the next chapters, focuses on the barriers to gender equality and, in particular, to women's leadership in healthcare sector at European Union level. This thesis uses empirical evidence to examine, in the first place, the barriers to women's leadership and their prevalence and then, moving to gender equality policy and implementation sphere, to identify potential gaps and solutions to explored phenomenon.

In the following, this introductory chapter provides a description of theoretical considerations as a starting point to understand the concepts of gender equality and women's leadership; secondly, it turns to the European Union aiming to explore the concept of gender equality and women's leadership at policy making and implementation level, and how these concepts are perceived and operationalized at the EU and Member States level. Thirdly, the added value of gender equality and women's leadership in healthcare sector is described arguing for the focus of the study in the field. Then, towards the end of this chapter, the study design is detailed followed by the methodological commitments of the applied qualitative research methods in order to address rigorously the formulated research questions. 


\subsection{THEORETICAL AND CONCEPTUAL CONSIDERATIONS}

The explored topic involves several aspects and thus requires an all-encompassing approach which may not fall easily into a single theoretical framework. The study applies theories of gender equality, women's leadership, policy and implementation at EU level. To better serve the research objectives of this thesis, the study focused on healthcare sector; three main healthcare facets, academic - clinical - medical, have been explored. Thereby, to address pertinently the overarching research question on "barriers to gender equality in the EU context" the content of this thesis lies in the heart of the combination of three individual conceptual frameworks : "gendered barriers", "EU gender equality policy" and "healthcare sector". The aim of combining the conceptual frameworks is to contextualize better the findings and gain in depth understanding of barriers to gender equality through the perspective of barriers to women's leadership in healthcare sector at country level; then to deduce conclusions for other sectors and the broader EU social reality (Collins et al, 2007) (Figure 1.2):

Figure 1.2 Combination of theoretical frameworks of the research (own concept)

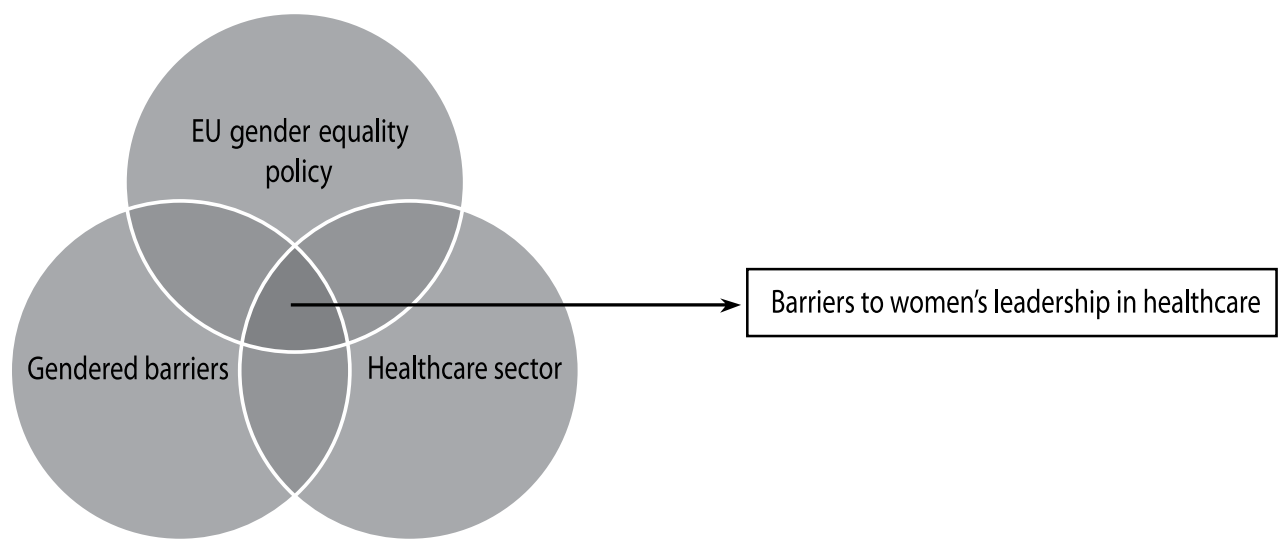

This research adopted centrality of women's leadership to the explored phenomenon to frame and interpret clearly the experiences and practices at top ranks of decision-making level through immersion of data (Holloway, 2005, p 260). Therefore, it is deemed important to provide a description of the adopted conceptual frameworks starting from gender equality and gender equality policy at the EU level and then turn to the component of women's leadership and its relationship to the broader framework of gender equality; lastly, women's leadership in healthcare sector is also considered.

\section{Gender equality}

In this thesis the concept of gender is approached as a cross-cutting socio-cultural and economic variable (Parsons, 1964; Helman, 2007; Hoyt, 2010). In the first place, gender is understood as "the socially constructed roles, behaviors, activities and attributes that a given society considers appropriate for women and men" (Council of Europe, Article 3c, Istanbul Convention, 2011) in 
contrast to "sex" referring to "the different biological and physiological characteristics of males and females such as reproductive organs, chromosomes, hormones, etc" (WHO, 2019a). These characteristics tend to differentiate humans as men and women, whereas gender refers to a socially acquired identity connected to "being male or female in a given society at a given time and as a member of a specific community within that society" (EIGE, 2019; MIGS, 2019). Hence, gender identity prescribes what is expected, allowed or valued in a woman or a man within a given context (Parsons, 1964; Helman, 2007). In societies, inequalities and differences between women and men do exist in activities, attributed responsibilities, opportunities in decision making or control over resources, and are further influenced by additional socio-cultural criteria, such as age, ethnicity, economic empowerment or profession (Hoyt, 2010; Toh and Leonardelli, 2012).

Gender equality refers to "equal visibility, empowerment, responsibility and participation of women and men in all spheres of public and private life. It also means an equal access to and distribution of resources between women and men and valuing them equally" (Council of Europe, 2019). Also known as "equality of opportunity" (Booth \& Bennett, 2002), it implies that women's and men's interests, needs and priorities are taken into consideration irrelevant to their gender. Thus, it is recognized that gender equality is not a women's issue but should interest and fully engage men and women in the sense of supporting women's capacity to make life choices in a context where this capacity was previously denied to them (MIGS, 2019; Kabeer, 2001; Council of Europe, 2019). Gender equality is deeply entrenched in EU constitutional law in the context of human rights and anti-discrimination law (Chalmers, 2004; EUR-lex, 2019a; EUR-lex, 2019b), yet, it is beyond the scope of this research to explore gender equality from the human rights perspective.

\section{Gender equality policy in the EU context}

European Union anchored firmly the concept of gender equality in the European Treaties and expressed its commitment with policies on economic development, social cohesion and democratic societies (EC, 2017). The milestones of the trajectory of gender equality policy agendas arrayed from the Treaty of Rome (1957, Art 141) focusing on "equal pay for equal work" to the Treaty of Amsterdam (1997, Art 3.2) "to eliminate inequalities and to promote equality between men and women" in all EU activities (EUR-lex, 2019c; EUR-lex, 2019d; EC, 2018). Later, in the Treaty of Lisbon (2009) (EUR-lex, 2019a) EU broadened its binding commitment to observe gender equality principle and pursuit gender equality objectives; to that end, EU adopted the strategy of gender mainstreaming in all policy areas within EU involving the gender perspective into all stages of policy making, regulatory measures and spending programs (EIGE, 2019; EC, 2019c). In 2010 the Women's Charter was presented by the EU Commission in the form of policy declaration aiming to reinforce Commission's obligation to gender mainstreaming in the form of targeted support in all policy areas (EUR-lex, 2019b; EC, 2019e). In 2015 EU committed to fully integrate the UN sustainable development goal towards achieving gender equality and women's empowerment (SDG5) in EU policy framework under the concept of social and economic development; the focus was on four sub-themes: "employment", "leadership positions", "education" and "gender based violence" aiming to a more inclusive and fair Europe for both women and men (Eurostat, 2018; EC, 2018). Women's empowerment was understood as a multidimensional social process that enables women (in 
general, disadvantaged groups) to challenge existing power allocations, to gain control over their lives and make strategic decisions in a context where this ability was previously denied to them (EC, 2019e; Kabeer, 2001).

\section{Gender equality and women's leadership}

In that context, women's leadership was perceived as central component towards achieving gender equality and women's empowerment objectives within EU sustainable development policy framework (EC, 2018). In particular, the target of women's leadership advancement was embedded directly to the theme of "leadership positions" ("seats held by women in national parliaments and governments" and "positions held by women in senior management"), but was also related indirectly to themes of "education" ("gender gap for tertiary educational attainment", "gender gap for employment rate of recent graduates"), and "employment" ("gender employment gap", "gender pay gap in unadjusted form") (Eurostat, 2018, p. 107). Hence, women's leadership advancement was approached to a certain extent by EU policy agenda as a driver to equal opportunities for full and effective participation to leading positions at all levels of decision making, in all employment areas and in all societal spheres (EC, 2019b).

Scholars explored women's leadership from several perspectives, such as sociologic (Eagly and Chin, 2010; Hoss et al, 2006; Acker, 2006), sociocultural (Schuh et al., 2014; Riska, 2001; Madsen, 2010;), cultural (Ely et al, 2011; Toh and Leonardelli, 2012; Ingelhart et al, 2003), organizational (Bismark et al, 2015; Newman et al, 2016; Acker, 2012; Carnes et al., 2008; McTavish and Miller, 2009; Young, 2004) and economic (McTavish \& Miller, 2009; Kodama and Dugan, 2013). Literature has also dealt extensively with the concept of leadership; among several well-educated definitions of leadership, the description offered by Bennis et al (2001) touches upon the concept of leadership as perceived for the purposes of this study:

"... a function of knowing yourself, having a vision that is well communicated, building trust among colleagues and taking effective action to realize your own leadership potential" (Bennis, 1984, p. 15).

Women's leadership journey was often described using metaphors such as "labyrinth" reflecting a complex, riddled journey, full of challenges throughout the career advancement or "sticky floors" implying that women are prevented from any advancement beyond entry level (Eagly and Carli, 2007; Carli and Eagly, 2011). In sum, women's leadership potential was vested by various persisting constraints hindering personal, professional and social progress. In the present study, the term "barriers" to women's leadership advancement was adopted in the meaning of a "concrete wall, visible or invisible" constraining women's career advancement (Eagly and Carli, 2007, p. 2).

\section{Women's leadership in the healthcare sector}

The healthcare sector is regarded as an investment driver across European Union (Mossialos, 2005; Economou et al, 2014) which, amongst others, safeguards the right to health for EU 
citizens; it also enjoys a prominent position among the biggest employers in EU (Eurostat, 2018). Healthcare is populated mainly by women; seventy four percent (74\%) of health workforce are women but only $14 \%$ assume high level positions in decision making (OECD, 2018). Health systems miss female talent and perspectives, especially in higher echelons and turn weaker, underperformed since the women who deliver them do not have an equal say in the management and leadership of the systems they know best (WHO, 2019b) Thereby, a substantial share of talents pool remains untapped, whereas the deficit for transformative leaders in healthcare grows bigger.

The growing importance of women's leadership advancement in healthcare has been also reflected in the increasing body of academic literature and policy reports (indicatively, Coe et al, 2019; OECD, 2018; Kuhlman et al, 2017; HRH, 2017; Newman et al, 2016; McDonagh et al, 2014). Research argues that the durability and transferability of gendered barriers have compromised any steps forward (Newman et al, 2017; Lerch-Pieper et al, 2018; Downs et al, 2016; Toh and Leonardelli, 2012). In addition, the cross-pathing identities, such as gendered identity, health professional, decision maker at a leading position, increased the complexity of gendered relationships and interactions holding back distinct policy objectives and implementation practices (Kapilashrami and Hankivsky, 2018; Acker, 2012). On the other note, women's added value in the healthcare sector is widely acknowledged; scholars contend that health professions are of high social regard and considered a potential driver for social change offering an array of role models (Czabanowska et al, 2017; OECD, 2018; HRH, 2017; Riska, 2001; Acker, 2006). However, the social respect towards women does not seem to exert the expected positive influence to women's career advancement, fostering thus the paradox of women leaders' underrepresentation in healthcare.

Nonetheless, despite the scholarship and policy's attention, any progress made has been deemed poor and uneven and the gender gap remains visible at influential leadership positions in healthcare (Bismark et al., 2015; Fontenot, 2012; Hopkins et al., 2006; Hoss et al., 2011; Lantz, 2008). The benefits from gender balanced health workforce at all levels of leadership have been put forward responding to expectations for health systems' improved performance and, ultimately, for sustainability and social cohesion; yet, resistance to social change is present and the barriers holding back any progress are persistent. At the EU and Member States level, society becomes more diverse and health workforce challenges, being a critical element of health systems' sustainability, become more intense; hence, the importance of gendered barriers in healthcare sector cannot be underestimated. To that end, this thesis seeks to explore the comprehensive manifestation and prevalence of barriers held responsible for such puzzling outcomes within healthcare and, in EU's a broader note, in social reality.

Considering the breadth and the complexity of the gender equality topic, this thesis argues from the perspective of barriers to gender equality at the intersection of gendered barriers in the healthcare sector within country's socio-cultural and economic contexts and gender equality policy objectives at the EU level. 


\subsection{RESEARCH QUESTIONS}

As stated at the very beginning of the thesis, progress has been made in the field of gender equality at the EU and Member States level. However, despite the combined efforts and dedicated resources the outcomes remain poor, uneven and fragmented across Member States and sectors (EC, 2019b; EC, 2019d; Eurostat, 2018); in particular, in the healthcare sector, the slow progress that has been made creates a considerable ripple effect that influences negatively health workforce and health systems'sustainability, as well as society and economy (Downs, 2016; Kuhlman, 2017, OECD, 2018; WHO, 2019b). Hence, it remains to address the question what are the barriers hindering EU and Member States from achieving better outcomes, what can be improved and how; what is the angle to approach a problem that seeks to be addressed effectively in order to produce concrete outcomes and bring tangible social change?

Thereby, in light of the research objectives, the main research question is as follows:

What are the barriers to gender equality in the European Union context? The case of healthcare sector

With the aim to contribute to answering this central research question, each chapter of this thesis addresses corresponding sub-questions in line with the rationale outlined previously. In this study, it is postulated that barriers to women's leadership are similar across sectors but manifest themselves in a chorus and in a varying degree of prevalence depending mainly on national socio-cultural and economic contexts. Rather than put forward a single causal proposal to address effectively the barriers' durability and transferability, the study looks into ways to bridge blind spots in policy and practice at both EU and Member States level to better serve gender equality challenges faced by citizens and the sought after social cohesion.

\subsection{METHODOLOGY}

\subsubsection{Methods}

This study applied a qualitative research methodology built on a profound concern to understand the explored phenomenon, and offer an interpretation for purposes of providing informed and sophisticated knowledge reconstructions (Lincoln \& Guba, 2000). In order to define what "to understand" actually means, how to justify claims on "to understand" and to frame the interpretation of "to understand", the social constructionism paradigm was adopted (Schwandt, 2000, pp 197-201). A considerable part of social phenomena consists of the meaning making activities of groups and individuals around those phenomena and are of fundamental interest to social constructionism because it is the meaning making activities that shape action (Lincoln \& Guba, 2000). In this sense, the construction of knowledge embodies aspects of human experiences and, in some sense, is ideological, political and permeated with values. (Rouse, 1996). Meanings, concepts, frameworks and schemes are invented to make sense of experience; these constructions are tested and adapted on a continuous basis and in the light of new experiences. Moreover, the 
sociocultural and historical dimensions are very much present in the knowledge construction process. In sum, our understanding is not constructed in isolation, but against a backdrop of shared beliefs, understandings, values, practices, etc. (Schwandt, 2000, p. 197).

In line with this stance, theoretical and methodological assumptions were employed. Methodology is unavoidably interwoven with and develops from the nature of various disciplines and theories. On the grounds that there is no "single truth" and all truths are partial and incomplete (Denzin \& Lincoln, 2000, p. 162) and that some methods are more suited than others for conducting research on human construction of social realities (Lincoln \& Guba, 1985), this thesis applied a mixed methods qualitative approach to ensure the quality criteria of trustworthiness and authenticity in congruence of experiential and practical knowing as rooted in the social constructivism paradigm (Lincoln \& Guba, 2000, p. 170). The mixed methods qualitative studies have been criticized for content validity and lack of exhaustiveness involving a tendency to create bias and limitations (Symonds and Gorard, 2010). However, the criticism focuses on a rather binary positioning than on an inclusive approach whereby methods may cover the limitations of one another and enhance methodological diversity (Giddinds, 2006; Giddings and Grant, 2007). To the advantages of mixed methods qualitative approach belongs the argument that through triangulation, mixed methods counterbalance the weaknesses of single research method and provide better quality findings. Although, this is inherently biased supposing that triangulation of numbers with other data and/or large and small samples may compromise generalizability, methodology experts argue that these biases could work the other way around and mixed methods provide "the most informative, complete, balanced and useful research results" (Johnson and Onwuegbuzie, 2007, p. 129) and should be "a paradigm-building exercise" in social and behavioral sciences of $21^{\text {st }}$ century. (Hammersley, 2004, p. 201; Tashakkori and Teddlie, 2013).

Taking into consideration the broad and complex nature of explored phenomenon and to address aptly the sub-questions of this research and formulate a hypothesis in line with the main research question of this thesis, the mixed methods qualitative research was considered appropriate (Guba \& Lincoln, 2000; Collins et al, 2007). The study aligned with the methodological commitments of qualitative research method including obtaining and analyzing textual data, such as comments on a questionnaire and interviews'transcripts and data generated from the interaction between researchers and participants. Reflexivity relied on critical subjectivity; transparency as the study progresses, contextual understanding of particular social processes and application of qualitative research findings to other situations were also included in methodology considerations (Avis, 2005, p. 3; Dingwall, 1997). Qualitative research was supplemented by the fundamental tenet of feminist research on the centrality of women aiming to "put the social construction of gender at the center of one's enquiries" (Lather, 1988, p. 571) and interpret the experiences through immersion in the data (Kralik, 2005).

\subsubsection{Thesis' design}

This research study used the following design applying a mixed methods qualitative approach to collect a variety of enriched data on the barriers to women's leadership, validate the findings and triangulate the results (Guba \& Lincoln 1994; Collins et al, 2007). Following progressive analysis and comparison of collected data, an explanatory theory was formulated on addressing effectively 
the explored phenomenon and will be plausibly applied and tested in other contexts (Holloway, 2005; p. 101). The study was supplemented by qualitative findings on EU gender equality policy and implementation to deduce conclusions on potential policy inconsistencies and ways of improvement. The thesis' stepwise design is presented below in Figure 1.4.2:

Figure 1.4.2 Thesis's design

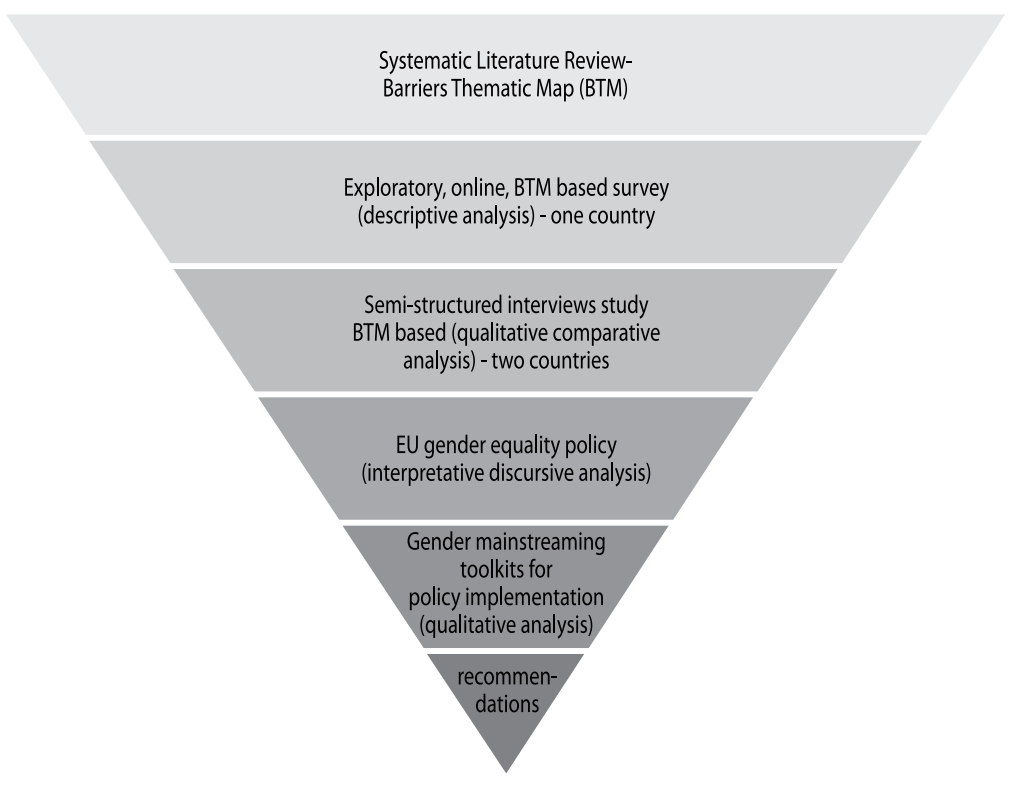

- Problem statement \& hypothesis. A systematic literature review was undertaken aiming a) to uncover gendered barriers across healthcare, academy and business sectors, b) to contrast the differences in gendered barriers across sectors and c) to develop the Barriers Thematic Map (BTM) to women's leadership with quantitative logic and a prevalence chart; attention was drawn on the under-studied prevalence of barriers and the need to be addressed differently within different work environments. The geographical target of the study was Europe with the time range for publications from 2000 to 2015.

- Hypothesis testing: the hypothesis testing on barriers thematic map and barriers' prevalence was focused in healthcare sector within two EU countries' socio-cultural and economic contexts: Greece and Malta. It was deployed in two studies: one exploratory study in one country's healthcare sector and one comparative study in two countries' healthcare sector:

The exploratory study was set out aiming to forage for the most and the least important barriers to women's leadership based on barriers thematic map; the study was drawn upon perceptions of women healthcare leaders in Greece; interest stemmed from country's poor performance on gender equality index and current economic turbulence. 
The comparativestudy was conducted aiming to assess empirically gendered barriers to women's leadership in healthcare through the lens of national socio-cultural and economic contexts. Study focused on Greece and Malta; interest was drawn from countries' poor performance in the gender employment gap and the rapid socio-cultural and economic changes occurring in the European Mediterranean region.

\section{- EU policy and implementation level}

An interpretative discursive analysis was followed to gain deeper understanding of the sustainable development thinking in gender equality policy agenda adopted by EU and in relation to its relevance to interests and challenges faced by Member States' citizens. In particular, the relevance of EU SDG5 themes and indicators and the prioritization of policy objectives to actual social reality across Member States was considered.

A qualitative analysis of change was used to explore the transformative capacity of the developed EU gender mainstreaming toolkits aiming to unpack the complexity among toolkits, organizational context and outcomes; the study aimed also to gain deeper insights on potential room for improved implementation of gender mainstreaming toolkits in order to bring about organizational and social change.

\subsubsection{Data collection}

To ensure the trustworthiness of the findings, qualitative and quantitative data was harvested from primary and secondary sources (Lincoln and Guba, 2000).

\section{Primary data:}

- Primary data on barriers to women's leadership and their prevalence was harvested applying a systematic literature review method. The systematic literature review method was used to "summarize the body of knowledge on a particular topic" (Aveyard, 2014, p. 48) and provide the full picture based on existing evidence. Systematic research was adopted across five electronic databases (Google Scholar, PubMed/Medline, Cochrane Library, Web of Science and Emerald) using various combinations of key words: "women leadership", "barriers", "complexities", "interactions", "healthcare", "academia", and "business". The findings of the search were further analyzed using summative content analysis, to extract and group the findings into thematic content categories. Then, a qualitative meta-summary method was adopted to produce a thematic map with quantitative logic calculating the effects of each barrier on the basis of its frequency (Sandelowski and Baroso, 2003; Sandelowski et al, 2007). In this study, the findings were judged to be "summaries" of qualitative data; hence, the meta-summary method was deemed appropriate. The main aim of this process was to address the effort of developing barriers thematic map (BTM) to women's leadership with quantitative logic and a prevalence chart.

- Primary data of an online questionnaire harvested by 30 purposively invited female healthcare Greek leaders; the best-worst object case survey method was used and designed in Sawtooth Software to explore the most and the least important barriers to women's leadership in provided choice scenarios. A total of 14 choice scenarios were presented including a set of five 
barriers with varying combinations and ordering of barriers per choice scenario. Four versions of 14 selected choice scenarios were developed and each respondent received randomly one of the four versions. Descriptive data analysis was used to understand and interpret the results.

- Primary data was collected from 18 semi-structured interviews with healthcare leaders, including women and men; the aim was to empirically assess the gendered barriers encountered by women in healthcare leadership through the socio-cultural lens in Greek setting. Directed content analysis was used to identify and analyze themes against the coding scheme of the Barriers Thematic Map to women's leadership. Summative content analysis was applied to quantify the usage of themes whilst qualitative meta-summative method was used to interpret and contextualize the findings.

- Primary data was collected from 18 semi-structured interviews with healthcare leaders, including women and men; the aim was to empirically assess the gendered barriers encountered by women in healthcare leadership through the socio-cultural lens in Maltese setting. Directed content analysis was used to identify and analyze themes against the coding scheme of the Barriers Thematic Map to women's leadership. Summative content analysis was applied to quantify the usage of themes whilst qualitative meta-summative method was used to interpret and contextualize the findings. Primary data from Greece and Malta were contrasted to gain deeper insights on similarities and differences of the manifestation and prevalence of barriers in healthcare sector between two countries.

\section{Secondary data:}

- A content analysis of ten websites of key organizations (European Commission - Directorate General for Justice, European Parliament, European Institute for Gender Equality, G7 Germany: The Schloss Elmau Summit, Standing Committee of European Doctors, The World Bank, Just Actions Organization, Commonwealth Secretariat's Report, McKinsley Global Institute, The Netherlands Organization for Scientific Research), (Chapter 2)

- Published scientific articles and EU (European Commission, European Parliament, Council of Europe) evaluation reports and policy documents, communications, minutes of high level meetings on gender equality and women's empowerment. (Chapter 2 - 6)

- A narrative literature search in Google Scholar, PubMed, Web of Science and on dedicated websites that chart the implications of financial crisis on women's empowerment and gender equality and in healthcare sector. (Chapter 2 - 6)

- A narrative literature search on discursive interpretative analysis of European Union gender equality policy and on the adoption and implementation of EU sustainable development goals (SDGs). (Chapter 5)

- A narrative literature review on theory of organizational and social change and on implementation sciences. (Chapter 6)

\section{Ethical approval}

Ethical approval was received from Ethics Committees from Maastricht University (No METC 16-4266, January 19, 2017), National and Kapodistrian University of Athens (Medical School) (February 3, 2017) and from the University of Malta (March 10, 2017). 


\subsection{OUTLINE OF THE BOOK}

This thesis has seven chapters. The introductory chapter (Chapter 1) presented the main conceptual frameworks employed in the research such as gender equality, gendered barriers to women's leadership advancement placed within healthcare context, gender equality policy and implementation at the EU level. Furthermore, the chapter provided the thesis' design, milestones and timeline of the study, research questions, methodology and data sources.

As a starting point, Chapter 2 describes the comprehensive mapping of barriers to women's leadership across three vital sectors, healthcare, academia and business. Twenty-six barriers were identified and populated a Barriers Thematic Map (BTM) with quantitative logic and varying degrees of barriers' prevalence. BTM uncovered several forms of gender inequalities across sectors and draw attention to under-studied barriers' prevalence across sectors. In addition, study's findings pointed to a potential knowledge gap in policies addressing gender equality challenges horizontally across different work settings and to practice related blind spots.

Chapters 3 and 4 present the two studies employed to test research hypothesis on the presence and varying prevalence of barriers to women's leadership in healthcare within countries' boundaries. Chapter 3 offers an exploratory study aiming to forage for the most and the least important barriers to women's leadership in healthcare based on developed barriers' thematic map. Survey focused on women healthcare leaders in Greece interest stemming from country's poor performance on gender equality index and current economic turbulence. Chapter 4 introduces a comparative study aiming to assess empirically gendered barriers to women's leadership in healthcare through the lens of socio-cultural national contexts. Study focused on Greece and Malta attention drawn from countries' poor performance in the gender employment gap and the rapid socio-cultural and economic changes occurring in the European Mediterranean region. Findings were contrasted to barriers thematic map (BTM), whereas the similarities and differences between the researched countries were compared and evidence based conclusions were extrapolated.

In sum, women and men healthcare leaders' perceptions on barriers to women's leadership in the explored sector were assessed. The data generated from the two studies aimed to place the explored phenomenon within social reality, contextualize and interpret findings and gain in depth insights in relation to research hypothesis.

Chapter 5 turns to gender equality policy agenda at the EU level. The chapter evaluates the sustainable development thinking in gender equality policy agenda in EU in relation to its relevance to interests and challenges faced by Member States' citizens. In particular, the chapter explores the relevance of EU SDG5 themes and indicators and the prioritization of policy objectives to actual social reality across Member States. The translation of SDG5 into national achievable targets is assessed on the grounds of persistent and uneven gender inequalities across Member States; 
the added value of required EU's proactive leadership in supporting Member States to develop evidence-informed gendered policies is also discussed.

Chapter 6 discusses the transformative capacity of the developed EU gender mainstreaming toolkits against organizational culture and climate. The study is undertaken through the lens of theory of change placing toolkits in milieu of change processes. In particular the study draws on qualitative analysis of change to gain in depth understanding of the complexity between toolkits, organizational context and outcomes; the potential room for improvement for more effective implementation of gender mainstreaming toolkits in order to bring about organizational and social change is considered.

Finally, the concluding Chapter 7, the General Discussion, provides a synthesis of the main findings from this research and discusses scholarship's and civil society's current viewpoints on gendered barriers and gender equality policy. The chapter turns to EU's gender equality policy agenda identifying inconsistencies and ways of improvement at both policy objectives prioritization and implementation level. Then, the chapter addresses the limitations of this thesis and devises implications for policy and future research.

\section{REFERENCES}

Acker, J. (2006) Inequality regimes: Gender, class, and race in organizations. Gender \& society, 2006;20(4), 441-464.

Acker, J. (2012). Gendered organizations and intersectionality: problems and possibilities. Equality, Diversity and Inclusion: An International Journal, 31(3), 214-224.

Aveyard, H. (2014). Doing a literature review in health and social care: A practical guide. McGraw-Hill Education (UK).

Avis, M (2005) Is there an epistemology for qualitative research? In Holloway, I. (Ed) Qualitative research in health care. McGraw-Hill Education (UK), (pp 3-17)

Bennis W (1984) The competencies of leadership. Train Dev J 1984;38(8):15-9

Bismark, M., Morris, J., Thomas, L., Loh, E., Phelps, G., \& Dickinson, H. (2015) Reasons and remedies for under-representation of women in medical leadership roles: a qualitative study from Australia. BMJ Open. 2015 Nov 16;5(11):e009384. doi: 10.1136/bmjopen-2015-009384.

Booth, C. and Bennett, C. (2002). Gender Mainstreaming in the European Union: Towards a New Conception and Practice of Equal Opportunities? European Journal of Women's Studies (430), pp. 430-446.

Bulgarian Presidency of the Council of the European Union. The Trio Programme (2019). Available at: https://eu2018bg. bg/en/trio-programme (Accessed: March $2^{\text {nd }}$ 2019)

Carli, L.L and Eagly, A. M. (2011). Leadership and gender. In The nature of leadership (pp. 437-476). Sage Publications.

Carnes, M., Morrissey, C., Geller, S. (2008) Women's health and women's leadership in academic medicine: hitting the same glass ceiling? Journal of women's health (2002) 2008 Vol: 17 (9) pp: 1453-1462 doi:10.1089/jwh.2007.0688

Chalmers, D. (2004). European Union Law. Cambridge: Cambridge University Press.

Coe, I. R., Wiley, R., \& Bekker, L. G. (2019). Organizational best practices towards gender equality in science and medicine. The Lancet, 393(10171), 587-593.

Collins, K. M., Onwuegbuzie, A. J., \& Jiao, Q. G. (2007). A mixed methods investigation of mixed methods sampling designs in social and health science research. Journal of mixed methods research, 1(3), 267-294.

Council of Europe. Equality between women and men. (2019) Available at: https://rm.coe.int/CoERMPublicCommonSearchServices/DisplayDCTMContent?documentld=090000168064f51b (Accessed: January $4^{\text {th }}, 2019$ )

Council of Europe. Convention on preventing and combating violence against women and domestic violence. Istanbul, 11.V.2011. Available at: https://www.coe.int/en/web/conventions/full-list/-/conventions/rms/090000168008482e (Accessed: January $4^{\text {th }}, 2019$ ) 
Czabanowska, K., Domagała, A., Kalaitzi, S., Krogulec, A., Burazeri, G., \& Babich, S. (2017). Exploring the Added Value of Women Health Care Managers in Poland. Materia socio-medica, 29(4), 280.

Denzin, N. K. \& Lincoln, Y. S. (Eds.). (200). Handbook of qualitative research. Thousand Oaks, CA: Sage

Diekman, A. B., \& Eagly, A. H. (2000). Stereotypes as dynamic constructs: Women and men of the past, present, and future. Personality and social psychology bulletin, 26(10), 1171-1188.

Dingwall, R. (1997). Accounts, interviews and observations. Context and method in qualitative research, 51-65.

Downs, J. A., Mathad, J. S., Reif, L. K., McNairy, M. L., Celum, C., Boutin-Foster, C., ... \& Konopasek, L.. (2016) The ripple effect: why promoting female leadership in global health matters. Public Health Action. 2016 Dec 21;6(4):210-211. doi: 10.5588/pha.16.0072.

Eagly, A. H., and Chin, J. L.. (2010) Diversity and leadership in a changing world. Am Psychol. 2010 Apr;65(3):216-24. doi: $10.1037 / \mathrm{a} 0018957$.

Eagly H. A. and Carli L. L. (2007) Through the Labyrinth: The Truth About How Women Become Leaders. Boston, Massachusetts: Harvard Business School Publishing

Eagly, A. H., \& Steffen, V. J. (1984). Gender stereotypes stem from the distribution of women and men into social roles. Journal of personality and social psychology, 46(4), 735.

Economou, C., Kaitelidou, D., Kentikelenis, A., Sissouras, A., \& Maresso, A.. (2014) The impact of the financial crisis on the health system and health in Greece. Economic crisis, health systems and health in Europe: country experience. Copenhagen: WHO/European Observatory on Health Systems and Policies.

Ellemers, N. (2014). Women at work: How organizational features impact career development. Policy insights from the behavioral and brain sciences, 1(1), 46-54.

Ely, R. J.; Ibarra, H.; Kolb, D.M. Taking gender into account: Theory and design for women's leadership development programs. (2011) Academy of Management Learning \& Education, 2011, 10.3: 474-493.

European Commission (2019a). Policies, information and services. Gender Equality. Available at: https://ec.europa.eu/ info/policies/justice-and-fundamental-rights/gender-equality_en (Accessed: March $2^{\text {nd }}, 2019$ )

European Commission (2019b). 2019 Report on equality between women and men in the EU. 2019 Brussels. Available at: https://ec.europa.eu/info/sites/info/files/aid_development_cooperation_fundamental_rights/annual_report_ ge_2019_en.pdf

European Commission (2019c). Strategic Engagement for Gender Equality 2016-2018. 2016 Brussels. Available at: https://ec.europa.eu/anti-trafficking/sites/antitrafficking/files/strategic_engagement_for_gender_equality_ en.pdf (Accessed: November 19 $9^{\text {th }}, 2018$ )

European Commission (2019d). She Figures, March 2019. Available at: https://ec.europa.eu/info/publications/she-figures-2018_en (Accessed: April 12 ${ }^{\text {th }}, 2019$ )

European Commission (2019e) Communication from the Commission. A strengthened commitment to equality between women and men. A Women's Charter. Available at: https://eur-lex.europa.eu/legal-content/EN/TXT/?Uri=CELEX:52010DC0078 (Accessed: March 2nd, 2019 )

European Commission. (2018) Report on equality between women and men in the EU. 2018 Brussels. Available at: https://publications.europa.eu/en/publication-detail/-/publication/950dce57-6222-11e8-ab9c-01aa75ed7 1a1

European Commission (2017). Communication from the commission to the European Parliament, the council, the European Economic and Social Committee and the Committee of the Regions. An initiative to support work-life balance for working parents and carers. Available at: https://eur-lex.europa.eu/legal-content/EN/TXT/?uri=COM\%3A2017\%3A252\%3AFIN (Accessed: June 25th 2018 )

European Institute for Gender Equality. Gender Equality Index Report 2017. Available at: https://eige.europa.eu/ publications/gender-equality-index-2017-measuring-gender-equality-european-union-2005-2015-report (Accessed: February $13^{\text {th }}$ 2019)

European Institute for Gender Equality. Gender Equality Glossary and Thesaurus (2019). Available at: https://eige. europa.eu/thesaurus/browse (Accessed: December $4^{\text {th }}, 2018$ )

EUR-lex. Access to European Union Law (2019a) The Treaty of Lisbon. Available at: https:/leur-lex.europa.eu/legal-content/EN/TXT/? uri=celex\%3A12007L\%2FTXT (Accessed: February $12^{\text {th }}, 2019$ )

EUR-lex. Access to European Union Law (2019b) Women's Charter. Available at: https:/leur-lex.europa.eu/legal-content/ EN/ALL/? uri=CELEX:52010DC0078 (Accessed: February $12^{\text {th }}, 2019$ )

EUR-lex. Access to European Union Law. The Treaty of Rome. (2019c) Available at: https://eur-lex.europa.eu/legalcontent/EN/TXT/?uri=CELEX:11957E/TXT (accessed on February 12th, 2019a) 
EUR-lex. Access to European Union Law. The Treaty of Amsterdam. (2019d) Available at: https://eur-lex.europa.eu/ legal-content/EN/TXT/?uri=CELEX:11997D/TXT (accessed on February 12th, 2019b)

Eurostat (2018) Sustainable Development in the European Union. Monitoring Report on Progress towards the SDGs in an EU Context. 2018 edition. Available at: https://ec.europa.eu/eurostat/web/products-statistical-books/-/KS01-18-656

Eurostat (2019b) Which sector is the main employer in the EU Member States? Available at: https://ec.europa.eu/ eurostat/web/products-eurostat-news/-/DDN-20171024-1 (Accessed: December 12 $2^{\text {th }}, 2018$ )

Fjeldsted, K. (2013) Female Leadership in Health Care. Leadership in Health Care Organizations. Standing Committee of European Doctors. Available from: http://www.cpme.eu (Accessed: April $\left.3^{\text {rd }}, 2016\right)$

Fontenot, T. E. R. I. (2012). Leading ladies: women in healthcare leadership. Frontiers of health services management, 28(4), $11-21$.

Giddings, L. S. (2006). "Mixed-methods research, positivism dressed in drag?" Journal of Research in Nursing 11(3): 195-203.

Giddings, L. S., \& Grant, B. M. (2007). A Trojan horse for positivism? A critique of mixed methods research. Advances in nursing science, 30(1), 52-60.

Guba, E.G. \& Lincoln, Y.S. (2000). Competing paradigms in qualitative research. In N.K. Denzin \&Y.S. Lincoln (Eds.). Handbook of qualitative research. (pp 105-117) Thousand Oaks, CA: Sage

Hammersley, M. (2004). "(Review of the) Handbook of Mixed Methods in Social and Behavioral Research by A. Tashakkori ; C. Teddle." British Educational ResearchJournal 30(1): 201-201.

Helman, C. G.. Culture, health and illness. CRC press, 2007

Holloway, l.. Qualitative research in health care. McGraw-Hill Education (UK), 2005

Hopkins, M. M., O'Neil, D. A., \& Bilimoria, D. (2006). Effective leadership and successful career advancement: perspectives from women in health care. Equal opportunities international, 25(4), 251-271.

Hoss, M. A. K., Bobrowski, P., McDonagh, K. J., \& Paris, N. M. (2011). How gender disparities drive imbalances in health care leadership. Journal of Healthcare Leadership, 3(1), 59-68.

Hoyt, L. C. (2010) Women, men and leadership exploring the gender gap at the top. Social and Personality Psychology Compass 4/7 (2010): 484-498, doi: 10.1111/j.1751-9004.2010.00274.x

Human Resources for Health. Global Resource Center. Resource spotlight: gender and health workforce statistics. Available at: http://www.hrhresourcecenter.org/gender_stats (Accessed March 10th, 2017)

Inglehart, R., Norris, P., \& Ronald, I. (2003). Rising tide: Gender equality and cultural change around the world. Cambridge University Press.

International Standard Industrial Classification of All Economic Activities. Revision 4. (2008). United Nations. Available at: https://unstats.un.org/unsd/publication/seriesM/seriesm_4rev4e.pdf (Accessed: January $5^{\text {th }}$, 2017)

Jonson, R. B., A. J. Onwuegbuzie, et al. (2007). Toward a Definition of Mixed Methods Research. Journal of Mixed Methods Research 1: 112-133.

Kabeer, N. (2001) Reflections on the measurement of women's empowerment. Stockholm: Sida Studies No. 3

Kapilashrami, A., and Hankivsky, O. (2018). Intersectionality and why it matters to global health. The Lancet, 391(10140), 2589-2591.

Kodama, C. M. and Dugan, J. P. (2013). Leveraging leadership efficacy for college students: Disaggregating data to examine unique predictors by race. Equity \& Excellence in Education, 46(2), 184-201.

Kralik, D. (2005) Engaging feminist though in qualitative research. A participatory approach. In Holloway, I.. Qualitative research in health care. McGraw-Hill Education (UK), (pp 270-287)

Kuhlmann, E., Ovseiko, P. V., Kurmeyer, C., Gutiérrez-Lobos, K., Steinböck, S., von Knorring, M., ... \& Brommels, M. (2017). Closing the gender leadership gap: a multi-centre cross-country comparison of women in management and leadership in academic health centers in the European Union. Human resources for health, 15(1), 2.

Lantz, P. M. (2008). Gender and leadership in healthcare administration: 21st century progress and challenges. Journal of Healthcare Management, 53(5), 291-301.

Lather, P. (1988). Feminist perspectives on empowering research methodologies. In Women's studies international forum (Vol. 11, No. 6, pp. 569-581). Pergamon.

Lerch-Pieper, N., Brander, S., Valarino, I., Zurbriggen, C., Maurer, E., Herr, W. (2018) Challenging the "leaky pipeline" in faculties of medicine. Available at: https://smw.ch/en/op-eds/post/challenging-the-leaky-pipeline-in-faculties-ofmedicine/ (Accessed June 30th 2018)

Linková, M. (2017). Academic excellence and gender bias in the practices and perceptions of scientists in leadership and decision-making positions. Gender a výzkum, 18(1), 42-66. 
Madsen, S.R. (2010). The experiences of UAE women leaders in developing leadership early in life. Feminist Formations, 22(3), pp.75-95.

McDonagh, K. J., Bobrowski, P., Hoss, M. A. K., Paris, N. M., \& Schulte, M. (2014). The leadership gap: Ensuring effective healthcare leadership requires inclusion of women at the top. Open Journal of Leadership, 2014.

McLaughlin H, Silvester J, Bilimoria D, ....Goeke J. (2017) Women in power, Contributing factors that impact on women in organizations and politics; psychological research and best practice Organ Dyn (2017) doi.org/10.1016/j. orgdyn.2017.09.001

McTavish, D. and Miller, K., (2009). Gender balance in leadership? Reform and modernization in the UK further education sector. Educational Management Administration \& Leadership, 37(3), pp.350-365.

Mediterranean Institute of Gender Studies (MIGS) (2019). Glossary of Gender related terms. Available at: https://www. medinstgenderstudies.org/glossary-on-gender/ (Accessed: $12^{\text {th }}$ February 2019)

Newman, C., Ng, C., Pacqué-Margolis, S., \& Frymus, D.. (2016) Integration of gender-transformative interventions into health professional education reform for the 21st century: implications of an expert review. Hum Resour Health. 2016 Apr 12;14:14. doi: 10.1186/s12960-016-0109-8.

Newman, C., Chama, P. K., Mugisha, M., Matsiko, C. W., \& Oketcho, V.. (2017) Reasons behind current gender imbalances in senior global health roles and the practice and policy changes that can catalyze organizational change. Glob Health_Epidemiol Genom. 2017 Dec 10;2:e19. doi: 10.1017/gheg.2017.11. eCollection 2017.

Mossialos, E., Allin, S., \& Davaki, K.. (2005) Analysing the Greek health system: a tale of fragmentation and inertia. Health Econ. 2005 Sep;14(Suppl 1):S151-68.

OECD. Gender Equality. (2018) Available at: http://www.oecd.org/gender/data/women-make-up-most-of-the-healthsector-workers-but-they-are-under-represented-in-high-skilled-jobs.html (Accessed September 27th, 2018)

Parsons, T. (1964). Evolutionary universals in society. American sociological review, 339-357.

Riska, E.. Medical careers and feminist agendas. American, Scandinavian and Russian Women Physicians, New York: Adline De Gruyter.; 2001

Rouse, J (1996) Feminism and the social construction of scientific knowledge. In L. H. Nelson \& J. Nelson (Eds) Feminism, science, and the philosophy of science (pp 195-215). Dordrecht, Netherlands. Kluwer.

Rubery, J., Grimshaw, D., \& Figueiredo, H. (2005). How to close the gender pay gap in Europe: towards the gender mainstreaming of pay policy. Industrial Relations Journal, 36(3), 184-213.

Sandelowski, M., \& Barroso, J. (2003). Classifying the findings in qualitative studies. Qualitative health research, 13(7), 905-923.

Sandelowski, M., Barroso, J., and Voils, C. I. (2007). Using qualitative metasummary to synthesize qualitative and quantitative descriptive findings. Research in nursing \& health, 30(1), 99-111.

Schuh S, Hernandez Bark A, Van Quaquebeke N, Hossiep R, Frieg P, Van Dick R (2014) Gender Differences in Leadership Role Occupancy: The Mediating Role of Power Motivation Journal of Business Ethics Vol: 120 (3) pp:363-379

Symonds, J. E., and Gorard, S. (2010). Death of mixed methods? Or the rebirth of research as a craft. Evaluation \& Research in Education, 23(2), 121-136.

Schwandt, T. A. (2000). Three epistemological stances for qualitative inquiry: Interpretivism, hermeneutics, and social constructionism. Handbook of qualitative research, 2, 189-213.

Tashakkori, A. and E. Teddlie, Eds. (2003). Handbook of mixed methods in social and behavioral research. Thousand Oaks, CA, Sage

Toh, S. M. and Leonardelli, G. J. (2012). Cultural constraints on the emergence of women as leaders. Journal of World Business, 47(4), 604-611.

Young, P. (2004). Leadership and gender in higher education: A case study. Journal of Further and Higher Education, 28(1), 95-106.

World Health Organization. (2019a) Glossary of terms and tools. Available at: https://www.who.int/gender-equityrights/knowledge/glossary/en/ (Accessed: February $2^{\text {nd }}$ 2019)

World Health Organization. (2019b) Female health workers drive global health. Available at: https://www.who.int/ news-room/commentaries/detail/female-health-workers-drive-global-health (Accessed: March 30 th , 2019)

World Economic Forum. The Global Gender Gap Report 2018. Available at: http://www3.weforum.org/docs/WEF_ GGGR_2018.pdf (Accessed: January 3 $3^{\text {rd } 2019)}$ 



\section{Chapter}

\section{Women leadership barriers in healthcare, academia and business}

\section{Published as:}

Stavroula Kalaitzi, Katarzyna Czabanowska, Sally Fowler-Davis, Helmut Brand, (2017) "Women leadership barriers in healthcare, academia and business", Equality, Diversity and Inclusion: An International Journal, 36(5):457-474. doi:10.1108/EDI-03-2017-0058 [IF (2017): 1,14] 

ABSTRACT

Purpose: The purpose of this study is to map the barriers to women leadership across healthcare, academia and business and identify barriers' prevalence across sectors. A Barriers Thematic Map (BTM) with quantitative logic and a prevalence chart have been developed, with the aim to uncover inequalities and provide orientation to develop inclusion and equal opportunity strategies within different work environments.

Methodology: A systematic literature review method was adopted across five electronic databases. Rigorous inclusion/exclusion criteria were applied to select relevant publications, followed by critical appraisal of the eligible articles. The geographical target was Europe, with a publication time range spanning the period from 2000 to 2015. Certain specialized international studies were also examined. The key themes were identified using summative content analysis and the findings were analyzed using qualitative meta-summary method to formulate hypotheses for subsequent research.

Findings: In total, 26 barriers were identified across the aforementioned sectors. A high degree of barriers commonalities was identified, with some striking differences between the prevalence of barriers across sectors.

Research limitations: The results of this study may need further validation using statistical methodology given the knowledge base gaps regarding the range of barriers and the differences in the prevalence. Bias and interpretation in reporting anchored in different theoretical frameworks ought to be further examined. Additional variables such as ambiguously stated barriers, sector overlap, women's own choices, cultural and educational background and analysis in the context of economic crisis, ensuing austerity and migratory pressure, are also worth exploring.

Practical implications: Women's notable and persisting underrepresentation in top leading positions across sectors reflects a critical drawback towards organizational and societal progress particularly regarding inclusion and balanced decision making. Practice-related blind spots may need to be further examined and addressed through specific policies.

Originality/Value: The comparative nature of barriers to women leadership across three sectors allows the reader to contrast the differences in gender inequalities and to comprehend inclusion challenges in healthcare, academia and business. The authors draw attention to varying degrees of barriers' prevalence that have been under-studied and deserve to be further explored. This gap in knowledge extends to policy, thus, highlighting the need to address the gender equality and inclusion challenges in a context-specific manner across work environments. 



\section{1 INTRODUCTION}

Women's participation in the workforce has grown over the last 20 years reaching $63.5 \%$ across European Union (EU-28) (Eurostat, 2015). However, women are underrepresented in top leadership positions, with less than $16.6 \%$ achieving board level positions (European Commission, 2013). A structural weakness identified by the EU Commission is that employment rates across Member States are still significantly lower than in other parts of the world, with only $63 \%$ of women in work compared to $76 \%$ of men (European Commission, 2010). The European Parliament (2015) stated that gender mainstreaming constitutes an essential factor for the achievement of a sustainable and inclusive society. The European Institute for Gender Equality (EIGE, 2015) argues that twenty first century needs for smart, sustainable and inclusive growth require higher gender equality scores. The United Nations (UN) included gender equality and the empowerment of women in the sustainable development goals (SGDs) (Goal No 5) for the 2030 Agenda, on the grounds that gender inequality adversely impacts upon development outcomes for the society as a whole (World Health Organization (WHO), 2015). The World Economic Forum (2014) quantifies the magnitude of gender-based disparities holding them responsible for undermining the long-term competitiveness of the global economy. Gender equality has also been identified as a precondition for the full enjoyment of human right by women, with unequal treatment and discrimination of women representing a gross and frequent violation of basic human rights (European Parliament, 2015, WHO 2015, World Economic Forum, 2014).

Subsequently, the new framework for gender equality and the empowerment of women (European Commission, 2015a) has been developed with indicators around four pillars including: economic and social empowerment, strengthening voice and participation and shifting institutional culture. Nevertheless, the effort to address the gender equality challenge may fall behind should a comprehensive approach to address gender equality and inclusion barriers not be deployed.

Thus, the Global Gender Gap Report (World Economic Forum, 2014) and EU Progress Report (European Commission, 2012) examine barriers existing in relation to women leadership such as work/life balance, gender bias, stereotypes, lack of confidence and equal access to opportunities. In addition, the G7 Summit Report (2015) described in-depth such career hindering factors including: non-friendly corporate environment, glass ceiling, ${ }^{1}$ lack of mentoring, adequate networking and societal culture. These reports evidence that gender inequalities have not yet been explored in the same depth concerning such sectors as healthcare, academia and business.

Although there is a sound body of literature exploring the barriers encountered by women leaders and aspiring women leaders, there is hardly any evidence related to the comprehensive evaluation

1. "Invisible barriers based on prejudice that limit the advancement of women to higher positions in their career paths". (European Parliament, 2015, p. 13) 
of barriers to gender equality, inclusion and their potential prevalence across these three sectors bearing in mind their impact on global economy.

Therefore, the authors undertook a systematic literature review, summative content analysis and meta-summary methodology on barriers to women leadership in healthcare, academia and business, aiming to conduct a comprehensive barrier mapping resulting in a barrier thematic map (BTM) with quantitative logic and a prevalence chart to showcase the varying degrees of barrier prevalence across three sectors: healthcare, academia and business.

\subsection{BACKGROUND}

Considered separately, each of the sectors in question has its characteristics and intricacies which add to the body of knowledge on the barriers confronting women in their quest for advancement in leadership roles.

\subsubsection{Healthcare}

Women leaders in healthcare remain significantly underrepresented in top leadership positions, even though they represent the vast majority of the specialized healthcare workforce (Bismark et al., 2015; Fontenot, 2012; Hopkins et al., 2006; Hoss et al., 2011; Lantz, 2008). Out of the global healthcare workforce, $75 \%$ are women, but only 38\% hold top positions (Just actions, 2015). In the healthcare provision sector, women leaders represent only $18 \%$ of hospital CEOs and $14 \%$ of healthcare boards of directors (Hauser, 2014), whereas when examining clinical leadership, we find that only $15.9 \%$ have reached top level positions (Newman, 2011). Fjeldsted (2013) argues that although women doctors bring excellent qualities and results into medical services, yet the talent pipeline of women medical and clinical leadership needs to be further enhanced and supported (Hauser, 2014, Newman, 2011). The main barriers held responsible for gender equality in this sector include the triple burden of domestic, clinical and leadership roles, which result in higher burnout rates, poor career management (Sexton et al., 2014), gender-related stereotypes, unequal career opportunities, and gender-related pay gap (Newman, 2011).

\subsubsection{Academia}

Similar factors affect women leaders in top academic positions, with a range of academic office held by women ranging from $11 \%$ to $40 \%$ (European Commission, 2015b) taking into consideration that the proportion of women in top leading positions varies across countries and institutions. Whereas women represent $59 \%$ of the graduate pool within the EU-28, the number of women drops to $18 \%$ when it comes to the pool of academics holding full professorship at universities (European Parliament, 2015). The Netherlands Organization for Scientific Research (2013, p.5) states that less than $15 \%$ of full professors in the country are women and this percentage gets lower when examining the inflow at the level of assistant professors. Existing literature (Madsen, 2010; McTavish and Miller, 2009; Young, 2004), addressing the gender-related imbalance on higher academic echelons, argues that career advancement via the academic pipeline has been marked as slow due to unconscious, gender-related biases resulting in women marginalization and 
devaluation (Carnes et al., 2008). In addition, male friendly organizational practices with gender inequality impact (McTavish and Miller, 2009) along with the lack of development of leadership skills (Acker, 2010; Kodama and Dugan, 2013; Madsen, 2012) have also been identified as key factors contributing to in gender disparities within academic settings.

\subsubsection{Business}

There is ample evidence documenting the gender-related leadership profile in the business arena. The Global Gender Parity Group, a multi-stakeholder community of business leaders within the World Economic Forum, states that gender equality is a business imperative (World Economic Forum, 2014); the G7 Report 2015 (p.58) concurs, echoing conclusions and highlighting the same priority. Even though gender gaps progressively narrow, women still represent a minority on corporate boards. The Gender Equality Index, a composite indicator in the area of power, reaches an average 16\% in the EU-28 for 2012 (The Gender Equality Index Report, 2015, p.57). Despite the fact that women account for approximately $59 \%$ of tertiary education graduates, their proportion in top-level business decision-making is limited, with only an average of $13.7 \%$ of board seats with only 3.4\% of chairs or presidency being held by women among the largest publicly listed companies in the European Union (European Commission, 2012, p. 12). Male predominance in boardrooms is a global reality in United States companies too, with women representation in the boards of the largest companies reaching only 15.7\%, while in Australia this percentage is pushed further down to 10,9\%, and in Canada to 10.3\% (European Commission, 2012, p.12, Figure 5).

The 2012 EU Progress Report acknowledges a positive increasing trend, albeit at a non-satisfactory pace, since European Union's competitiveness requires a more balanced representation of women to contribute to an overall enhanced economic performance, upgraded corporate governance and effectiveness, mirroring the market and leading to better use of the talent pool. Patel (2013) suggested that the development of women leadership has a strong business value in terms of strengthening the economy with an estimated, women-generated income of around $\$ 18$ trillion globally in 2014, an amount double the combined gross domestic product of China and India (as reported by Silverstein and Sayre, 2009 in "The Female Economy", p.48). A report recently published by the McKinsey Global Institute (2015) claims that by 2025 increased gender parity may contribute \$28 trillion to global economic growth. Such a trend and growth would not only improve aspects related to corporate performance, but also substantially contribute to women creating their own wealth.

\subsection{THEORETICAL AND CONCEPTUAL CONSIDERATIONS}

Researchers adopted the Article 3c of the Istanbul Convention (Council of Europe, 2011) stating that "Gender shall mean the socially constructed roles, behaviors, activities and attributes that a given society considers appropriate for women and men"; in contrast to "sex" referring to genetic and biological characteristics defining humans as male or female (UN Training Center, 2016). The researchers recognized the nature of knowledge is non-objective and understanding of the issues of gender through multiple subjective realities formed into working definition (Teddlie and Tashakkori, 2003). The adoption of a definition of gender mainstreaming from the United 
Nations therefore being adequate to support the review"the process of assessing the implications for women and men of any planned action, including legislation, policies or programmes, in all areas and at all levels [Economic and Social Council of the UN (UN ECOSOC), 1997)]. This definition constitutes a basis for making women's as well as men's concerns and experiences an integral dimension of the design, implementation, monitoring and evaluation of policies and programmes in all political, economic and societal spheres so that women and men benefit equally and inequality is not perpetuated since "the ultimate goal is to achieve gender equality" (ECOSOC, 1997).

For the purposes of this study, the authors adopted the operational definitions related to the three investigated sectors from the United Nations'International Standard Industrial Classification (2008). Healthcare is described as "generally consisting of hospital activities, medical and dental practice activities", and "other human health activities" (p. 252); academia as the setting for the "provision of tertiary education" (p. 249) and business is understood as "enterprise determined by the added value generated by its constituent units" (p. 31); the business added value feature is adopted to avoid confusion with potential overlap of healthcare and academia activities.

\subsection{METHODS}

Using multi-methods approach to validate the findings (Guba and Lincoln, 1994), a systematic literature review method was used to "summarize the body of knowledge on a particular topic" (Aveyard, 2014, p. 48) and provide the full picture based on existing evidence. The protocol for the search and extraction was supported by a further multi-method approach to analysis that validated the findings (Guba and Lincoln, 1994) to develop a barriers thematic map across the explored sectors.

Rigorous search criteria were used (see below selection criteria section to retrieve and select, critically appraise and synthesize the relevant articles included. The main aim of this process was to address the effort of developing a barrier thematic map (BTM) with quantitative logic and a prevalence chart. The findings of the search were further analyzed using summative content analysis. Two researchers, SK and KC, conducted the literature review over a period of nine months (October 2015 to June 2016) and in two parts. During the first part, research was focused on women leadership in healthcare, academia and business and during the second part on women leadership and barriers in healthcare, academia and business. In the second part the researchers mapped the prevalence of each barrier across targeted sectors by calculating the times each barrier was reported upon to design and populate a quantitative thematic map.

The first part is a traditional systematic review process utilizing Cochrane protocols ${ }^{2}$ as presented

2. The Cochrane protocol is a plan or set of steps to be followed in a study. A protocol for a systematic review should describe the rationale for the review; the objectives; and the methods that will be used to locate, select and critically appraise studies, and to collect and analyze data from the included studies. http://community.cochrane.org/ organizational-info/resources/faqs\#who-is-cochrane 
in the following PRISMA 3 study flow diagram (Moher et al., 2009) summarizing the search strategy (Figure I). The second part followed the qualitative meta-summary method with quantitative logic calculating the effects of each barrier on the basis of its frequency (Sandelowski et al., 2007). Metasummary is a particular approach that can be used to integrate qualitative findings from several studies. It is often performed when the qualitative findings to be included in the research study are evaluated by the researchers to be in the form of "summaries" of qualitative findings as synthesized data as described by Sandelowski and Baroso (2003). In this study, the findings are judged to be "summaries" of qualitative data; hence, the meta-summary method was deemed appropriate.

Figure I | PRISMA flow diagram indicating articles' selection for systematic review of barriers to women leadership in healthcare, academia and business.

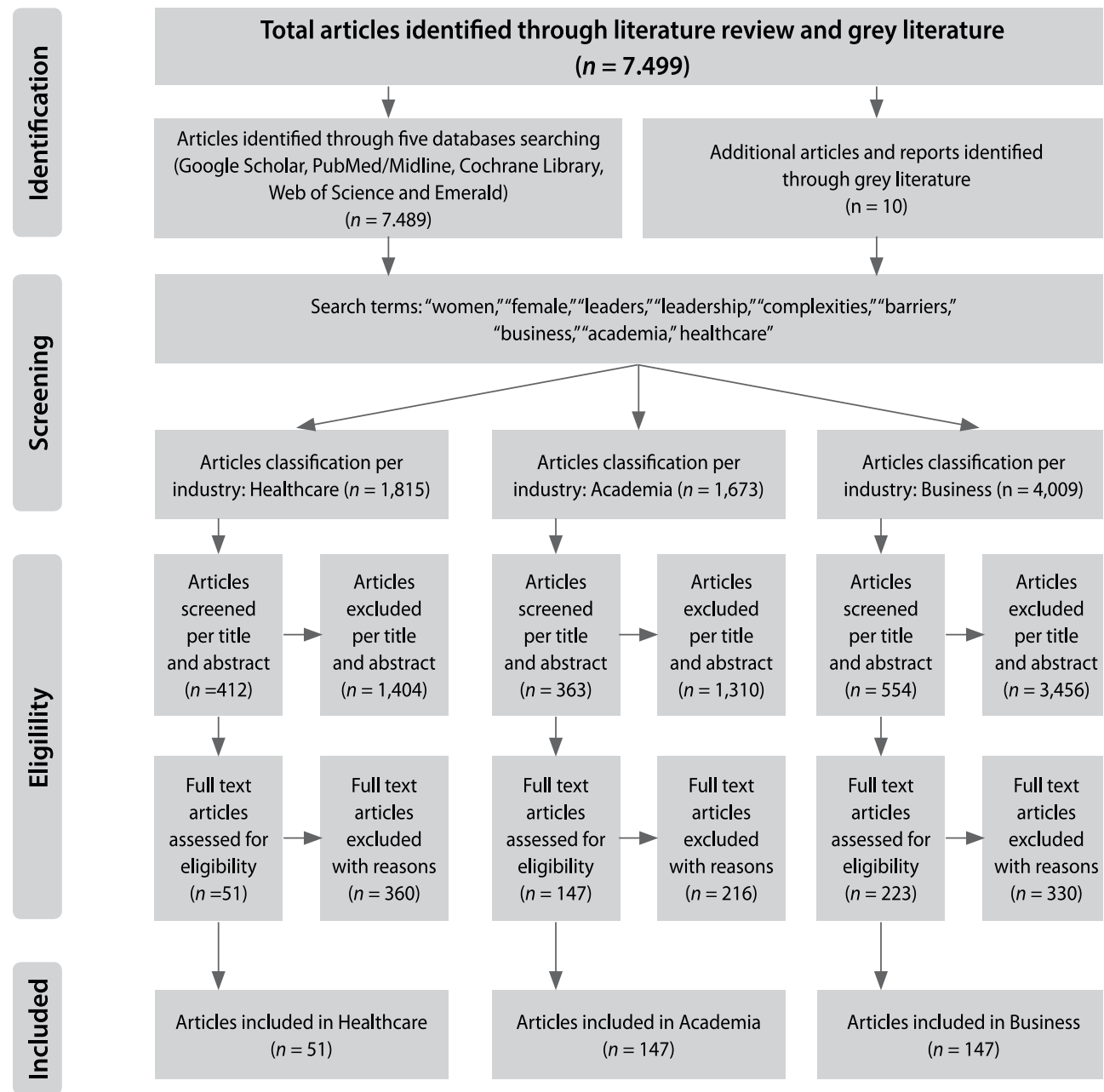

3. Preferred Reporting Items for Systematic Reviews and Meta-Analyses (PRISMA). www.prisma-statement.org 


\subsubsection{Search strategy}

The review question developed was - "What are the barriers to women leadership across healthcare, academia and business?" -used to identify common and different barriers to women leadership. Five electronic databases (Google Scholar, PubMed/Medline, Cochrane Library, Web of Science and Emerald) and ten websites of key organizations (European Commission Directorate General for Justice, European Institute for Gender Equality, European Parliament, G7 Germany: The Schloss Elmau Summit, Standing Committee of European Doctors, The World Bank, Just Actions Organization, Commonwealth Secretariat's Report, McKinsley Global Institute, The Netherlands Organization for Scientific Research) were searched. The database search used various combinations of key words: "women leadership", "barriers", "complexities", "interactions"," "healthcare", "academia", and "business". The term "barriers to women leadership" was often used interchangeably with "complexities" or "interactions". For the purpose of this study, the term "barriers" to women leadership was used with the meaning of a "concrete wall, visible or invisible" (Eagly and Carli, 2007), towards top leading positions. Grey literature ${ }^{4}$ was searched for nine months using snowballing techniques (Streeton et al., 2004) including websites, and reports from agencies and organizations specialized in each domain.

\subsubsection{Selection criteria}

Articles were eligible for inclusion/exclusion based on the following rigorous criteria: (1) published between 2000 and 2015; papers published previously to this period were considered old and of no interest to this study; (2) published in English; (3) a title and an abstract were included; (4) research studies, reviews or reports. All identified articles were initially assessed based on their title and abstract. A second screening was performed for final eligibility by retrieving the full text. The geographical spectrum of the search was Europe-wide along with some specialized international studies.

Exclusion criteria: articles (1) were related to women leadership in politics, military, police and religion; and (2) not representing original research and/or reporting thereof, rather, papers in which authors were reviewing or representing a direct reference to a book or book chapters.

\subsection{DATA ANALYSIS}

A qualitative meta-summary method, including extraction and grouping of findings into thematic content categories, was adopted in order to produce a thematic map with quantitative logic. It is important to note that, in most cases, reporting was done in a manner that necessitated a process of "ungrouping" the data across sectors and themes. Therefore, this approach was deemed the most appropriate given the data were often indiscriminately presented in a large body literature related to researched three different sectors. Additionally, data were scanned in reverse to match

4. The Fourth International Conference on Grey Literature (GL '99) in Washington, DC, in October 1999 defined grey literature as follows: "That which is produced on all levels of government, academics, business and industry in print and electronic formats, but which is not controlled by commercial publishers." http://www.greylit.org/about 
thematic tags across sectors, to ensure themes per sector had not been missed, given this more general character of reporting or the terminological heterogeneity of reporting. The thematic map with quantitative logic was used to calculate the frequency of effect size for each thematic content category findings as a validity indicator and to help determine which topics were most relevant for formulating hypotheses for subsequent research (Sandelowski et al., 2007). Also, differences were found on conclusions regarding key themes, given the complexity of the topic and the different background of researchers examining this topic. For example, some studies argue that the lack of "role model" barrier is a key drawback in women leadership advancement, whereas other studies support the fact that "role model" affects women leadership disproportionately (Fletcher, 2007; Ridgeway, 2001). The researchers selected and synthesized such findings to elicit deeper nuanced understanding regarding the topic of interest.

\subsection{FINDINGS}

Two researchers, SK and KC, conducted the search independently and compared their findings. A total of 7499 articles were retrieved including ten reports were also retrieved through grey literature search. After excluding the non-eligible articles based on their title and abstract, a total of 1329 articles were screened and approved based on their title and abstract. The large volume of articles not classified as eligible referred to barriers in an indirect and/or unclear manner in respect to this study's objectives. Articles were classified per sector. 412 were eligible for a second screening for healthcare sector, 363 articles for academia and 554 articles for business sector. Following further abstract screening, and after duplicate removal, 51 articles were selected as eligible for full text retrieval and screening for healthcare sector, 147 articles for academia and 223 articles for business sector.

The final eligible articles were further grouped and analyzed per sector and 26 barrier themes, as reported/identified and/or listed in the reviewed articles. The same two researchers were coding texts in an extraction frame in Excel spreadsheets searching for prevailing barriers and subsequently registering where every barrier was clearly recorded with information as reported per article, and including author(s), publication date, and journal. When the term "gender" was interchangeably used with the term "sex" (e.g. "sex bias" and "gender bias"), article eligibility was assessed on the basis of the article's approach to gender, i.e., whether it considered gender to be a socially constructed characteristic (UN Women Training Center, 2016). The researchers compared their interpretations on an ongoing basis. Disagreements were resolved by discussing interpretations until reaching consensus (Bowling, 2014). The barriers were assigned to sectors according to the visual representation of Table 1. In total, 26 barrier categories were identified: 22 in the healthcare sector, 21 in the academic sector and 25 in the business sector.

The frequency to which a given barrier was mentioned in the articles was calculated and summarized; a barrier thematic map (BTM) with quantitative logic was produced in order to calculate the effect sizes of each barrier per sector based on its frequency. The prevalence of each barrier was then calculated. The higher the frequency of a particular barrier, the greater its frequency was considered to be (Barnett-Page and Thomas, 2009). 


\subsection{RESULTS}

The name given to each barrier, out of the 26 identified, was generated from the articles reviewed by the researchers; they used the term selected as a "theme" identified for the purpose of the study. The themes identified are mapped below (Table 1). The themes were then grouped per sector, and then checked against the body of literature. In total, 22 barriers were identified in the healthcare sector, 21 barriers in the academic sector and 25 in the business sector (Table I).

Table I | Barriers Thematic Map (BTM) to women leadership in healthcare, academia and business Researchers calculated the frequency of each barrier, namely the number of times a given barrier

\section{BARRIERS}

1. Age $^{5}$

2. Lack of career advancement opportunities ${ }^{6}$

3. Culture

4. Family (espousal) support ${ }^{8}$

5. Gender bias (discrimination) ${ }^{9}$

6. Gender gap ${ }^{10}$

7. Gender pay gap"11

8. Glass ceiling ${ }^{12}$

9. Glass cliff'13

10. Isolation ${ }^{14}$

11. Lack of executive sponsor ${ }^{15}$

12. Lack of flexible working environment ${ }^{16}$

13. Lack of confidence ${ }^{16}$

14. Lack of mentoring ${ }^{17}$

15. Lack of networking ${ }^{19}$

16. Leadership skills ${ }^{20}$

17. Personal health ${ }^{21}$

18. Queen bee syndrome ${ }^{22}$

19. Race discrimination ${ }^{23}$

20. Lack of role model ${ }^{24}$

21. Sexual harassment ${ }^{25}$

22. Lack of social support ${ }^{26}$

23. Stereotypes (male dominated culture, negative organization environment) ${ }^{27}$

24. Limited succession planning ${ }^{28}$

25. Tokenism ${ }^{29}$

26. Work/life balance ${ }^{30}$

\section{HEALTHCARE \\ ACADEMIIA \\ BUSINESS}

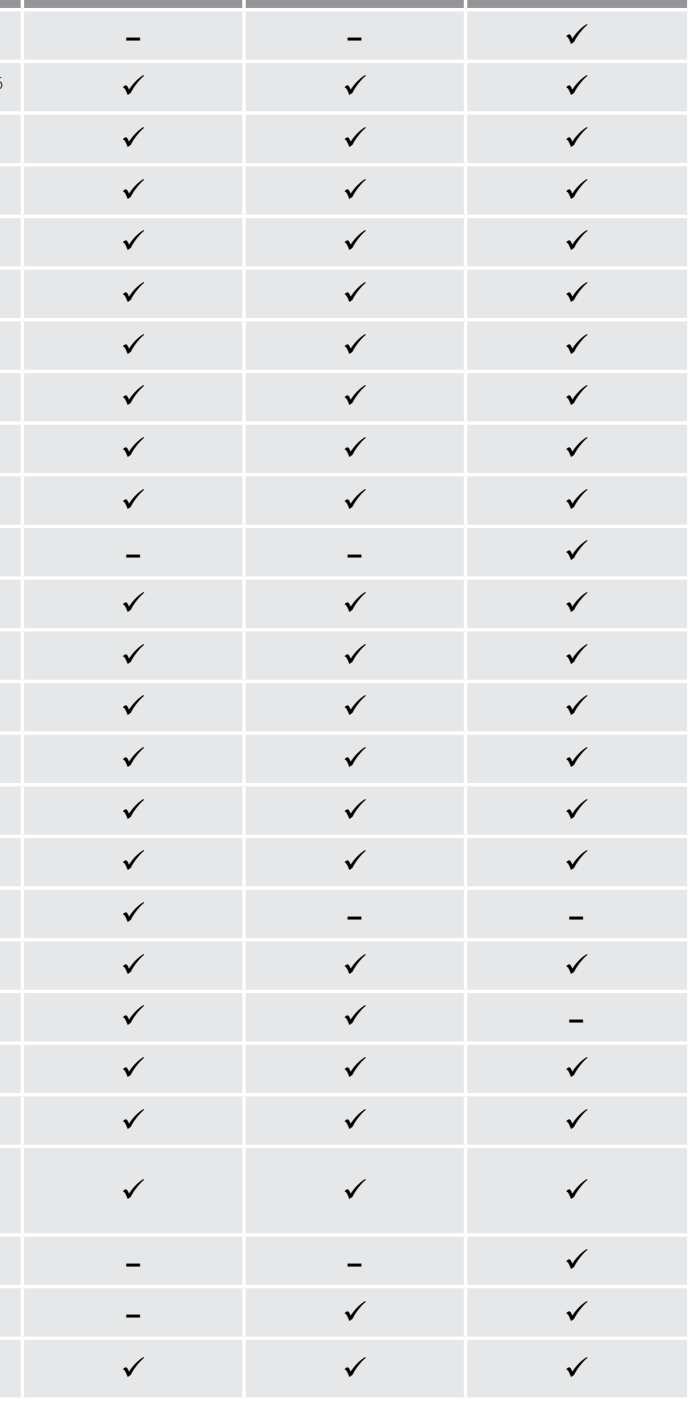


was mentioned in the literature explored, and produced the barriers thematic map (BTM) based on quantitative logic (Table II). Quantitative findings of varying degrees of barrier prevalence are presented both on arithmetical and percentage forms to facilitate interpretation, ensure accuracy and lend validity.

\footnotetext{
5. "Significant gender difference .... and career barrier" Pfister \& Radtke, 2009
}

6. "Unequal access to research positions, funding, publishing and academic awards and are also affected by rigid criteria for promotion and recognition and luck of funding or suitable policies to support them" Report on women's careers in science, universities and glass ceiling encountered. European Parliament, 2015, p. 6

7. Cultural and institutional barriers that generate direct or indirect discrimination against women in scientific careers and decision making" Report on women's careers in science, universities and glass ceiling encountered. European Parliament, 2015, p. 7

8. "Sources of support cited included partners, other family members, and childcare" Bismark et al., 2015, p. 6

9. "Societies often perceive some professions as being made for male and some for female" Report on women's careers in science, universities and glass ceiling encountered. European Parliament, 2015, p. 14

10. Women are under-represented at higher hierarchical levels, even in sectors where they represent a majority" Report on women's careers in science, universities and glass ceiling encountered. European Parliament, 2015, p. 13

11. "Unequal pay for equal work... or work of equal value" Report on women's careers in science, universities and glass ceiling encountered. European Parliament, 2015, p. 15

12. "Invisible barriers based on prejudice that limit the advancement of women to higher positions in their career paths"Report on women's careers in science, universities and glass ceiling encountered. European Parliament, 2015, p. 13

13. "Female leaders .... are more often assigned to risky, precarious positions, with few material and social resources", Ellemers, 2014, p.50

14. "predominance of 'old boys clubs', inflexible corporate cultures and male dominated leadership teams that do not support or enable women to move into comparable leadership roles" O'Neill \& Boyle, 2011, p.3

15. "lack of executive sponsorship to have had diversity training and specific capabilities to effectively mentor women executives" O'Neill \& Boyle, 2011, p.3

16. "Many taken-for-granted organizational features reflect men's lives and situations, making difficult for women to get on and stay" Ely et al, 2011, p.12

17. "Self-doubt, ....., underestimating personal capabilities", Bismark et al, 2015, p.4

18. "Limited access to capable mentors", Elmuti et al, 2009, p.171

19. "informal networks can shape career trajectories by regulating access to jobs; channeling the flow of information and referrals; creating influence and reputation; supplying emotional support, feedback, political advice and protection" Ely et al, 2011, p.13

20. "Leadership programs ... to address the particular challenges women face when transitioning to more senior leadership roles." Ely et al, 2011, p.16

21. "devalue and marginalize women and issues associated with women, such as their health" Carnes et al., 2008

22. "the reluctance of successful females to support other women", Ellemers, 2014, p. 50

23. "Underrepresented groups ..... found themselves at a competitive disadvantage", Lightfoot et al., 2014, p. 3

24. "The historical and contemporary achievements of women in science and technology, entrepreneurship, and decision-making positions" Report on women's careers in science, universities and glass ceiling encountered. European Parliament, 2015, p. 8

25. "an unwelcome behavior of sexual nature ....that if allowed to continue could create a hostile work environment for the recipient". www.un.org/womenwatch/osagi/pdf/whatissh.odf

26. "Resistance in culture of female leadership.... (non) adoption of new cultures and social norms" Elmuti et al, 2009 , p. 5

27. "habitual privileging of stereotyped 'maleness' as the only credible context for leadership, created a heavily-gendered work environment" Bismark et al., 2015, p. 5

28. "actions are lacking such as succession plans that focus on a concrete plan for development of women for these (top echelons) positions" McDonagh et al., 2014, p. 4

29. "one woman or two women (a few tokens) to at least three women (directors) (consistent minority), Torchia et al., 2011, p. 299

30. "The need to successfully reconcile professional and family obligations" Report on women's careers in science, universities and glass ceiling encountered. European Parliament, 2015, p. 9 
Table II | Barriers Thematic Map (BTM) with quantitative logic (arithmetical and percentage prevalence) to women leadership in healthcare, academia and business based on the systematic literature review findings

\begin{tabular}{|c|c|c|c|c|c|c|}
\hline \multirow[b]{2}{*}{ Women's Leadership Barriers } & \multicolumn{3}{|c|}{ ARITHMETICAL FREQUENCY } & \multicolumn{3}{|c|}{ PERCENTAGE PREVALENCE } \\
\hline & Healthcare & Academia & Business & $\begin{array}{c}(\%) \\
\text { Healthcare }\end{array}$ & $\begin{array}{c}(\%) \\
\text { Academia }\end{array}$ & $\begin{array}{c}(\%) \\
\text { Business }\end{array}$ \\
\hline Gender gap & 38 & 97 & 117 & 12 & 12 & 10 \\
\hline $\begin{array}{l}\text { Lack of career advancement } \\
\text { opportunities }\end{array}$ & 40 & 85 & 82 & 12 & 10 & 7 \\
\hline Stereotypes & 33 & 70 & 134 & 10 & 8 & 12 \\
\hline Work/life balance & 28 & 82 & 109 & 9 & 10 & 10 \\
\hline Lack of mentoring & 32 & 87 & 72 & 10 & 11 & 6 \\
\hline $\begin{array}{l}\text { Lack of flexible working } \\
\text { environment }\end{array}$ & 24 & 80 & 71 & 7 & 10 & 6 \\
\hline Gender bias & 18 & 57 & 87 & 5 & 7 & 8 \\
\hline Lack of confidence & 23 & 39 & 35 & 7 & 5 & 3 \\
\hline Leadership skills & 16 & 41 & 39 & 5 & 5 & 3 \\
\hline Lack of networking & 16 & 28 & 29 & 5 & 3 & 3 \\
\hline Glass ceiling & 10 & 17 & 52 & 3 & 2 & 5 \\
\hline Glass cliff & 12 & 14 & 27 & 4 & 2 & 2 \\
\hline Culture & 5 & 25 & 68 & 2 & 3 & 6 \\
\hline Gender pay gap & 4 & 30 & 42 & 1 & 4 & 4 \\
\hline Race discrimination & 3 & 15 & 57 & 1 & 2 & 5 \\
\hline Lack of social support & 7 & 23 & 44 & 2 & 3 & 4 \\
\hline Personal health & 8 & 11 & 13 & 2 & 1 & 1 \\
\hline Family (espouse) support & 4 & 13 & 12 & 1 & 2 & 1 \\
\hline Lack of role models & 2 & 5 & 0 & 1 & 1 & 0 \\
\hline Sexual harassment & 2 & 0 & 1 & 1 & 0 & 0 \\
\hline Queen bee syndrome & 3 & 0 & 0 & 1 & 0 & 0 \\
\hline Tokenism & 0 & 4 & 7 & 0 & 0 & 1 \\
\hline Age & 0 & 0 & 6 & 0 & 0 & 1 \\
\hline Isolation & 0 & 2 & 10 & 0 & 0 & 1 \\
\hline Lack of executive sponsor & 0 & 0 & 2 & 0 & 0 & 0 \\
\hline Limited succession planning & 0 & 0 & 2 & 0 & 0 & 0 \\
\hline Total & 328 & 825 & 1,118 & & & \\
\hline
\end{tabular}

To provide a full overview of the high degree of barriers commonalities and varying prevalence to women leadership across sectors, a chart was developed (Figure II). 
Figure II | Barriers prevalence to women leadership in healthcare, academia and business as resulted from the selected articles

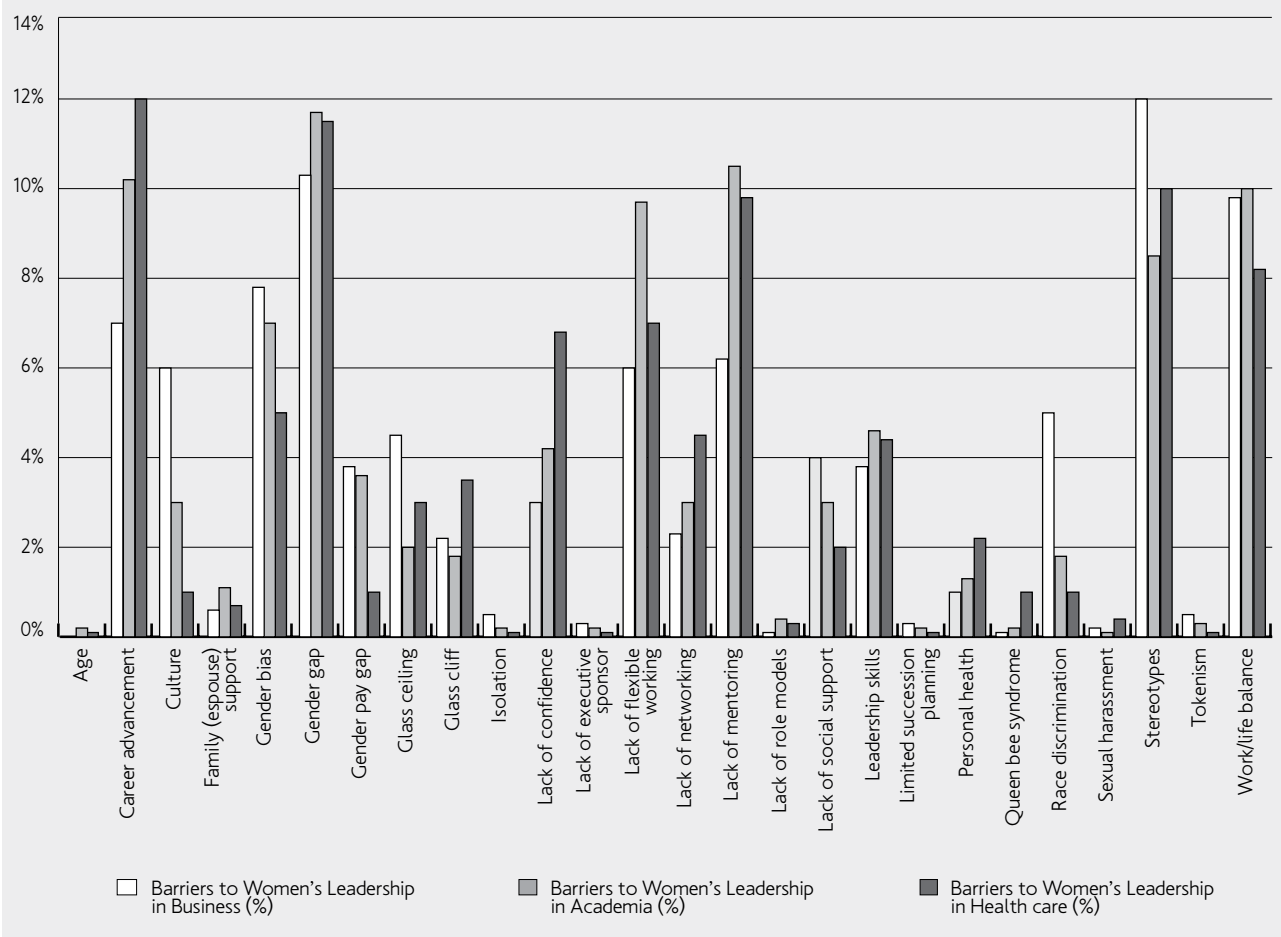

The prevailing barriers identified across the healthcare, academic and business sectors were gender gap (12\%-12\%-11\%); lack of career opportunities advancement (12\% - 10\% - 7\%); stereotypes (10\% - 8\% - 12\%); work/life balance (9\% - 10\% - 10\%), and lack of mentoring (10\% - 11\% - 6\%), lack of flexible working environment (7\% - 10\% - 6\%). Of the 26 identified barriers, four appear in two sectors interchangeably (lack of role models in healthcare / academic sectors, sexual harassment in healthcare / business, tokenism and isolation in academic / business sectors), three barriers are encountered only in the business sector (age, lack of executive sponsor, limited succession planning), whereas the "queen bee syndrome" barrier emerges only in the healthcare sector.

Irregularities are present in prevalence across barriers, since no barrier corresponds to the same prevalence degree across three sectors. The high prevalence a barrier shows in one sector does not reflect to the other two. For example, stereotypes are the most important barrier in the business sector (12\%), whereas gender gap and lack of career advancement are the most important barriers in the healthcare sector (12\%); gender gap has equivalent prevalence in the academia sector (12\%) closely followed by lack of mentoring (11\%). 
The prevalence fluctuations of highly prevailing barriers across the healthcare, academic and business sectors is presented below in more detail (Figure III)

Figure III | Differences in prevalence of highly prevailing barriers* across sectors *those presenting a degree of $10 \%$ prevalence at least in one sector

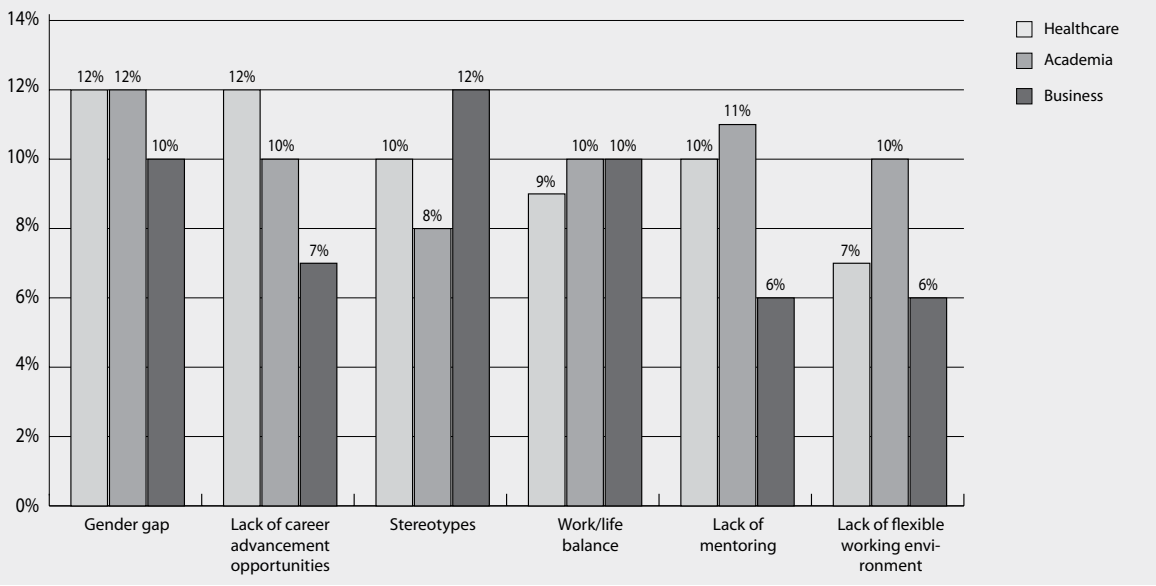

Similar heterogeneity is present for barriers with medium prevalence across the healthcare, academic and business sectors. For example, lack of confidence (7\% - 5\% - 2\%), glass ceiling (3\% $-2 \%-5 \%$ ) and race discrimination (1\%-2\%-5\%) (Figure IV). Heterogeneity is also present for barriers with low prevalence, as, for example, the lack of role models ( $1 \%-1 \%-0 \%)$, lack of family (spousal) support (1\%-2\%-1\%) and personal health (2\%-1\%-1\%) (Figure V).

Figure IV | Differences in prevalence of medium prevailing barriers* across sectors *those presenting a degree of $7 \%-4 \%$ prevalence at least in one sector

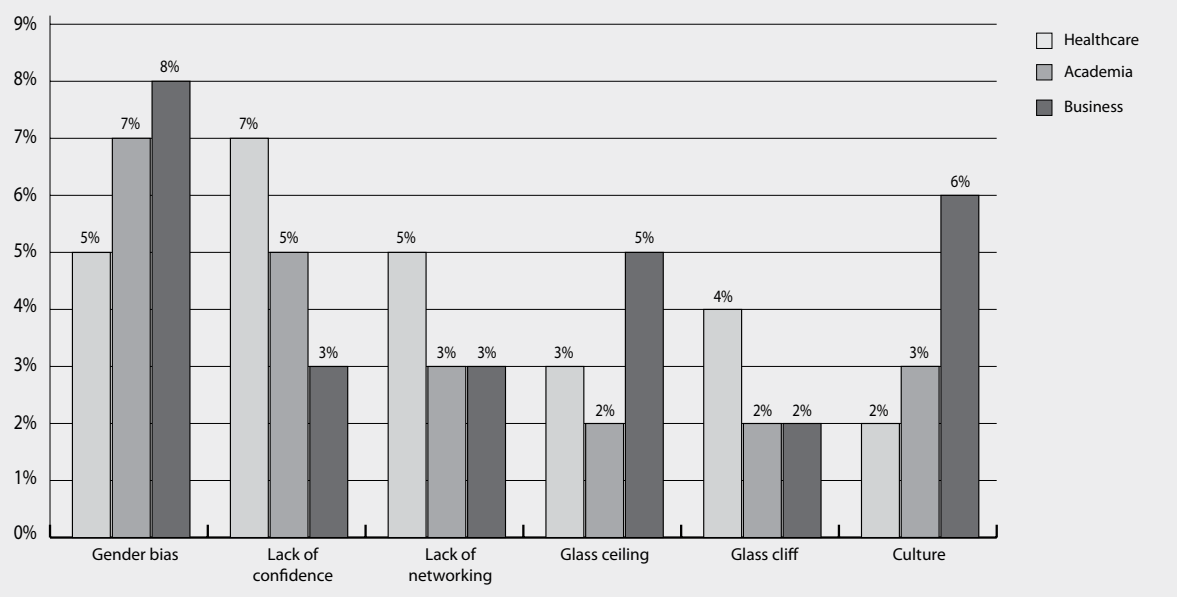


Figure V | Differences in prevalence of low prevailing barriers* across sectors *those presenting a degree of $2 \%-0 \%$ prevalence at least in one sector

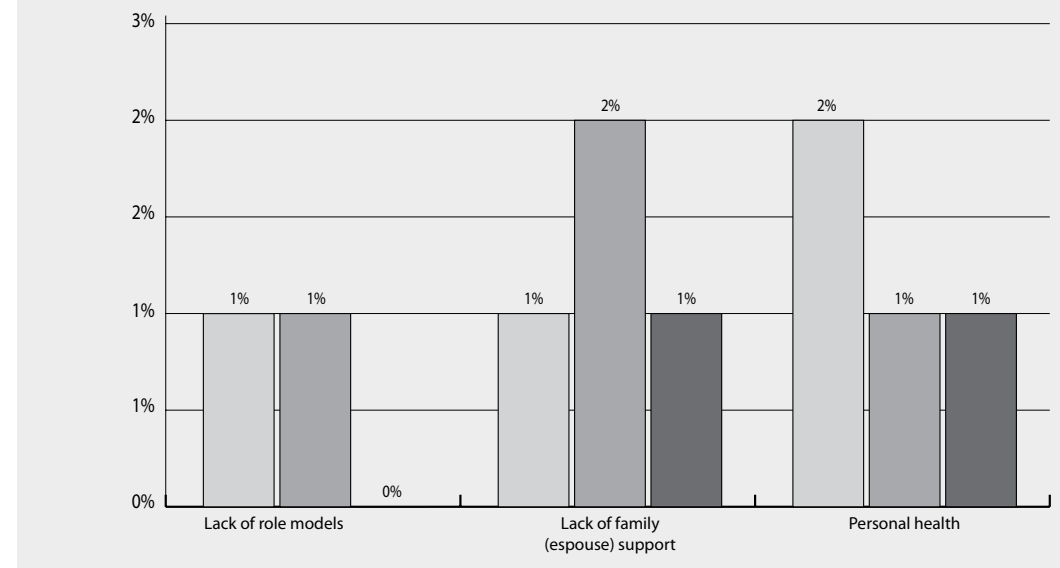

\subsection{DISCUSSION}

A long list of barriers to women leadership was present across all three sectors. The number of barriers in the healthcare sector marginally outnumbered that of barriers in the academic sector with 22 and 21 barriers, respectively, whereas the business sector exceeded the other two sectors with 25 barriers. The researchers consider this difference to be substantial enough to surmise that the business sector presents the greatest challenges of these three in terms of fostering gender equality and inclusion. Literature has dealt extensively with the majority of the barriers hindering gender equality and inclusion, but there are certain that have remained outside the sphere of detailed study and reporting, and, consequently, there is lack of initiatives to address them. In the context of identifying commonalities, and when considering frequency as the number of times a barrier is addressed by literature and examining the varying degree of prevalence, no common barrier across sectors has been identified with the same degree of prevalence across examined sectors. For example, "stereotypes" is a common prevailing barrier across sectors, but with varying prevalence of $10 \%-8 \%-12 \%$ respectively, in the healthcare, academic and business sectors. The identified varying prevalence implies that each sector is governed by its own rules and needs in respect of women leadership. It is, nevertheless, important to note that labor relations and the contractual framework are important for establishing the context under which organizational culture develops. Further result elaboration may benefit from correlating such factors to presence and prevalence of barriers per sector. Therefore, albeit all sectors are characterized by gender disparities, the gender equality challenge has to be addressed on the basis of sector-by-sector cases and may, even, benefit from a closer examination at regional levels, particularly, in relation to primary data collection. 
A concrete example on barrier commonalities with some striking differences is that of the six prevailing barriers identified across explored sectors. Thematically, prevailing barriers are the same (gender gap; lack of career advancement opportunities, stereotypes, work/life balance, lack of mentoring and lack of flexible working environment) but their ranking order varies across sectors implying the contextual nature of barriers' prevalence (Figure III).

Study findings on high prevalence of "culture" in business sector align with Ely et al (2011) assertion that strong resistance to women leadership in top positions is being fed to a certain extent by a culturally driven competition between men and women leaders. The "cultural tightness" expressed in multi-faceted non-egalitarian practices ${ }^{31}$ (Toh and Leonardelli, 2012) along with sociocultural constraints considered as weaknesses to motivate leverage to women leadership (Schuh et al., 2014) may well be considered to be the source resulting in the detected barriers' prevalence. The considerable prevalence of "gender bias", "glass ceiling," "gender pay gap", "lack of networking" and "lack of social support" reaffirming Eagly and Chin's (2010) argument on preconceptions and men stereotyping, which, either operating at unconscious level or not, leave women leaders facing a double standard in the labor market. Surprisingly enough, the lack of self-confidence barrier in healthcare indicates that sound scientific background might not be sufficient to climb the leadership ladder unless combined with development of leadership skills. The gender pay gap holds the same medium prevalence in both business and academia, but is reported as very low in the healthcare sector.

Drawn upon these findings, the researchers argue that literature accurately reports the women's inequality and inequity state across sectors with varying degrees of barrier prevalence; the findings reflect difficult working settings, ill-equipped to fostering women leadership potential. The barriers thematic map (BTM) to women leadership illustrates a comprehensive barrier list and their prevalence across the healthcare, academic and business sectors showing the differences in gender equality and inclusion challenges across those sectors.

\subsection{CONCLUSIONS}

The findings of this systematic literature review produced a Barriers Thematic Map (BTM) to women's leadership in healthcare, academia and business with varying degrees of barriers' prevalence. The BTM uncovered the differences in gender inequalities and inclusion across sectors drawing attention to understudied barriers prevalence. This gap in knowledge extends to policy, thus highlighting the need to address the gender equality and inclusion challenges differently in a context specific manner across work environments. Those practice related blind spots may need to be further researched and supported by specific policies.

31. Egalitarian = believing in or based on the principle that all people are equal and deserve equal rights and opportunities. Available at: https://en.oxforddictionaries.com/definition/egalitarian 


\subsection{LIMITATIONS AND FUTURE RESEARCH}

Our study highlighted the knowledge gap in addressing differently the gender equality and inclusion challenges across different work environments and in a context-specific manner.

The researchers applied the summative content analysis method to their introductory analysis and qualitative meta-summary method to formulate hypotheses for subsequent research; however, the quantitative findings and the varying degree of barriers' prevalence may need further testing through the application of rigorous statistical methodology given the knowledge base gaps regarding the range of barriers and the differences in their prevalence. Bias and interpretation in reporting anchored in different theoretical frameworks ought to be further examined. Additional variables such as ambiguously stated barriers, sector overlap, women's own choices, cultural and educational background, analysis in the context of the economic crisis, ensuing austerity and migratory pressure are also worth exploring.

Barriers to women leadership across sectors have been addressed evenly, however, sectors are not similar and neither is the need for leadership capacity building. The leadership capacity in each sector has been assumed and this is a pre-existing backdrop to the study and potential contextual barriers to women's equal opportunities. For example, the work/life balance barrier in healthcare emerges in a different working context than in academia or in business; in other words, it is the result of different conditions and has different significance although it may have reported upon or examined under one terminological label (e.g., rotated working hours in healthcare vs. unstable working hours in academia vs. long working hours in business).

Reporting comes from different disciplines and for different reasons with heavy reporting bias and interpretation anchored in different theoretical frameworks. Subsequently, further research may be required to examine in detail the overall impediments towards creating environments that foster gender equality and diversity; qualitative research may explore all stakeholder perspectives, including those of human resources personnel, recruiters, policy makers, and, of course, of women themselves. Organizational settings greatly vary across jurisdictions, as do cultural and social norms, e.g. age, social status, marital status, childbirth, working experience, career inflection points; there is no stratification for this and/or bias isolation in the reporting; therefore, a stringent application of statistical methodology and an extraction framework to see where measurements reported are done, what is the legal setting, labor agreements, etc. may be needed.

Implications emerged from economic and migration crisis may also been explored as barriers to gender equality.

Operational definitions of healthcare, academia and business sectors have been adopted aiming to clearly describe each sector's activities; yet, sectors may overlap, e.g. healthcare encompasses business and academia, and academia encompasses healthcare, and business encompasses 
academia. Future research may be needed to address intersections amongst sectors in terms of gender equality and inclusion challenges.

Research may also explore own choices in women's underrepresentation in leadership positions, although they cannot be examined in isolation from broader organizational, societal and cultural context and constraints.

Transgender persons and gender equality challenges they face were not within the scope of this study, even though deemed to be explored.

\subsection{IMPLICATIONS}

Women's notable and persisting underrepresentation in top leading positions may be reflected as a critical drawback towards organizational, societal and cultural progress in terms of inclusion and balanced decision making. Gender stereotypes in leadership equal opportunities, gender-related corporate culture, inflexibility in workplaces structures, and inadequacies in social policies, as well as gender roles in family responsibilities and the social acceptance are deeply rooted constraints which may foster the "ambition gap". In other words, the perceived tendency for women to choose family before work or to step away from a career opportunity (Schwanke, 2013). The more competitive, inflexible and less policy-protected the work setting is, the more the scales tilt women deciding not to take advantage of leadership opportunities or being steered toward choosing to be family/children free. Double standards in domestic roles reinforce also gender inequalities with social and organizational implications. Domestic responsibilities and organizational cultures impact differently upon women and men leaders when it comes to claiming leadership positions (Hoyt, 2010). Women face multiple challenges and may, therefore, not be able to counter such an effect at personal cost, as a man may have the luxury to do. However, not all news is bad, since gender stereotypes are the product of dynamic relationships between individuals, their interactions, constructions and interpretations; they cannot have an absolute character and are subject to change overtime (Montero, 2002).

Women's pronounced inequality in top leading positions constitutes a misdiagnosed problem that people with good intentions have misread, partially at causal, but mostly at corrective and preventive levels. It appears that the problem has been somewhat understood, but remains solved. Despite the fact that a growing number of organizations and institutions attempt to address the problem by establishing policies, strategies and initiatives, reality is far removed from the goal set. The identified 26 barriers and their varying prevalence per sector may uncover dialectics on unexplored practical implications and on developing specific policy-making. 
CHAPTER 2. WOMEN LEADERSHIP BARRIERS IN HEALTHCARE, ACADEMIA AND BUSINESS

\section{Acknowledgements}

The authors are grateful to Elena Petelos of Department of Social Medicine, School of Medicine, and University of Crete and Department of Health Services, Faculty of Health, Medicine and Life Sciences, University of Maastricht for her valuable comments that greatly improved the manuscript.

Declaration of conflicting interest

The authors declared no potential conflicts of interest with respect to the research, authorship, and/or publication of this article. 


\section{REFERENCES}

Acker, S. (2010). Gendered games in academic leadership. International studies in sociology of education, 20(2), pp 129152.

Aveyard, H. (2014). Doing a literature review in health and social care: A practical guide. McGraw-Hill Education (UK).

Barnett-Page, E. and Thomas, J. (2009). Methods for the synthesis of qualitative research: a critical review. BMC medical research methodology, 9(1), 1.

Bismark, M., Morris, J., Thomas, L., Loh, E., Phelps, G., and Dickinson, H. (2015). Reasons and remedies for underrepresentation of women in medical leadership roles: a qualitative study from Australia. BMJ open, 5(11), e009384.

Bowling, A. (2014). Research methods in health: investigating health and health services. McGraw-Hill Education (UK).

Carnes, M., Morrissey, C., Geller, S.. (2008) Women's health and women's leadership in academic medicine: hitting the same glass ceiling? Journal of women's health (2002) 2008 Vol: 17 (9) pp: 1453-1462 doi: 10.1089/jwh.2007.0688

Council of Europe. Council of Europe Convention on preventing and combating violence against women and domestic violence: Istanbul, 11. V. 2011. Council of Europe.

Guba, E.G. and Lincoln, Y.S. (1994). Competing paradigms in qualitative research. In N.K. Denzin and Y.S. Lincoln (Eds.). The landscape of qualitative research: Theories and issues. Thousand Oaks, CA: Sage, 195-220.)

Eagly, H. A., Carli, L. L.. (2007) Through the Labyrinth:TheTruth About How Women Become Leaders. Boston, Massachusetts: Harvard Business School Publishing

Eagly, A., Chin, J-L. (2010) Diversity and leadership in a changing world. American Psychologist, Vol 65(3), Apr 2010, pp. 216-224. Retrieved from: http://dx.doi.org/10.1037/a0018957

ECOSOC, U. (1997). Mainstreaming the gender perspective into all policies and programmes in the United Nations system. New York: UN ECOSOC.

Ellemers, N. (2014). Women at Work How Organizational Features Impact Career Development. Policy Insights from the Behavioral and Brain Sciences, 1(1), 46-54.

Elmuti, D., Jia, H., and Davis, H. H. (2009). Challenges women face in leadership positions and organizational effectiveness: An investigation. Volume 8, Number 2-Fall 2009, 167.

Ely, R. J., Ibarra, H., and Kolb, D. M. (2011). Taking gender into account: Theory and design for women's leadership development programs. Academy of Management Learning \& Education, 10(3), 474-493.

European Commission (2013). Women and men in leadership positions in the EU. DOI:10.2838/50821

European Commission (2010). Europe 2020. A European strategy for smart, sustainable and inclusive growth. Retrieved from: http://ec.europa.eu/eu2020/pdf/COMPLET\%20EN\%20BARROSO\%20\%20\%20007\%20-\%20 Europe\%202020\%20-\%20EN\%20version.pdf

European Commission. (2015a). New framework for Gender Equality and Women's Empowerment: transforming the Lives of Girls and Women through EU External Relations (2016-2020) adopted. Retrieved from: http://europa.eu/ rapid/press-release_IP-15-5690_en.htm

European Commission (2012). Women in Economic decision-making in the EU: Progress Report - A Europe 2020 initiative. DOI: $10.2838 / 65541$

European Commission (2015b) She Figures 2015. Gender in Research and Innovation. Statistics and Indicators. Retrieved from: https://ec.europa.eu/research/swafs/pdf/pub_gender_equality/she_figures_2015-leaflet-web. pdf

European Institute for Gender Equality (2015). Gender Equality Index Report 2015. Measuring gender equality in the European Union 2005-2012. Retrieved from: http://eige.europa.eu/sites/default/files/documents/ mh0415169enn.pdf

European Parliament (2015). Report on Women's careers in science and universities, and glass ceiling encountered Retrieved from: http://www.europarl.europa.eu/sides/getDoc.do?pubRef=-//EP//NONSGML+REPORT+A8-2015$0235+0+D O C+P D F+V 0 / / E N$

Eurostat Statistics Explained (August 2015). Employment Statistics. Retrieved from: http://ec.europa.eu/eurostat/ statistics-explained/index.php/Employment_statistics\#Employment_rates_by_sex.2C_age_and_educational_ attainment

Fjeldsted, K. (2013) Female Leadership in Health Care. Leadership in Health Care Organizations. Standing Committee of European Doctors. Retrieved from http://www.cpme.eu

Fletcher, C. (2007). Passing the buck: gender and management of research production in UK Higher Education: Management perspectives from a case study. Equal Opportunities International, 26(4), 269-286 
Fontenot, T. E. R. I. (2012). Leading ladies: women in healthcare leadership. Frontiers of health services management, 28(4), 11-21.

G7 Germany: The Schloss Elmau Summit (2015)

Hauser, M. C. (2014). Leveraging Women's Leadership Talent in Healthcare. Journal of Healthcare Management, 59(5), 318.

Hopkins, M. M., O'Neil, D. A., and Bilimoria, D. (2006). Effective leadership and successful career advancement: perspectives from women in health care. Equal opportunities international, 25(4), 251-271.

Hoss, M. A. K., Bobrowski, P., McDonagh, K. J., and Paris, N. M. (2011). How gender disparities drive imbalances in health care leadership. Journal of Healthcare Leadership, 3(1), 59-68.

Hoyt, L. C. (2010) Women, men and leadership exploring the gender gap at the top. Social and Personality Psychology Compass 4/7 (2010): 484-498, 10.1111/j.1751-9004.2010.00274.x

International Standard Industrial Classification of All Economic Activities. Revision 4. (2008). United Nations. Retrieved from: https://unstats.un.org/unsd/publication/seriesM/seriesm_4rev4e.pdf

JustActions (n.d.) Retrieved May 30, 2016 from JustAction Workgood http://justactions.org/action/female-leadership/

Kodama, C. M. and Dugan, J. P. (2013). Leveraging leadership efficacy for college students: Disaggregating data to examine unique predictors by race. Equity \& Excellence in Education, 46(2), 184-201.

Lantz, P. M. (2008). Gender and leadership in healthcare administration: 21st century progress and challenges. Journal of Healthcare Management, 53(5), 291-301.

Lightfoot, E. and Slayter, E. (2014). Disentangling over-representation of parents with disabilities in the child welfare system: Exploring child maltreatment risk factors of parents with disabilities. Children and Youth Services Review, 47, 283-290.

Madsen, S.R. (2010). The experiences of UAE women leaders in developing leadership early in life. Feminist Formations, 22(3), pp.75-95.

Montero, M. (2002). On the Construction of Reality and Truth. Towards an Epistemology of Community Social Psychology. American Journal of Community Psychology, 30: 571-584. DOl:10.1023/A:1015864103005

McDonagh, K. J., Bobrowski, P., Hoss, M. A. K., Paris, N. M. and Schulte, M. (2014). The leadership gap: Ensuring effective healthcare leadership requires inclusion of women at the top. Open Journal of Leadership, 2014.

McKinsey Global Institute. (September 2015). The power of parity: how advancing women's equality can add $\$ 12$ trillion to global growth. Retrieved from: http://www.mckinsey.com/global-themes/employment-and-growth/howadvancing-womens-equality-can-add-12-trillion-to-global-growth

McTavish, D. and Miller, K., (2009). Gender balance in leadership? Reform and modernization in the UK further education sector. Educational Management Administration \& Leadership, 37(3), pp.350-365.

Moher, D., Liberati, A., Tetzlaff, J., Altman, D. G., and The PRISMA Group. (2009). Preferred Reporting Items for Systematic Reviews and Meta-Analyses: The PRISMA Statement. PLoS Medicine, 6(7), e1000097. Retrieved from: http://doi. org/10.1371/journal.pmed.1000097

Netherlands Organization for Scientific Research. Researchers' Report 2013. Country Profile: Netherlands. Retrieved from: http://ec.europa.eu/euraxess/pdf/research_policies/country_files/Netherlands_Country_Profile_RR2013_ FINAL.pdf

Newman, P. (2011). Releasing potential: women doctors and clinical leadership. London: National Health Service.

O'Neill, C. O. L. L. E. E. N., and Boyle, S. T. A. C. E. Y. (2011). Leadership challenges for women at work. Chief Learning Officer, 10(6), 76-78.

Patel, G. (2013) Gender Differences in Leadership Styles and the Impact within Corporate Boards. The Commonwealth Secretariat, Social Transformation Division

Pfister, G. and Radtke, S. (2009). Sport, women, and leadership: Results of a project on executives in German sports organizations. European Journal of Sport Science, 9(4), 229-243.

Ridgeway, C. L. (2001). Gender, status, and leadership. Journal of Social Issues, 57(4), 637-655.

Sandelowski, M. and Barroso, J. (2003). Classifying the findings in qualitative studies. Qualitative health research, 13(7), 905-923.

Sandelowski, M., Barroso, J., and Voils, C. I. (2007). Using qualitative metasummary to synthesize qualitative and quantitative descriptive findings. Research in nursing \& health, 30(1), 99-111.

Sexton, J. B., Sharek, P. J., Thomas, E. J., Gould, J. B., Nisbet, C. C., Amspoker, A. B., ... and Profit, J. (2014). Exposure to Leadership WalkRounds in neonatal intensive care units is associated with a better patient safety culture and less caregiver burnout. BMJ quality \& safety, bmjqs-2013.

Schuh S, Hernandez Bark A, Van Quaquebeke N, Hossiep R, Frieg P, Van Dick R (2014) Gender Differences in Leadership Role Occupancy: The Mediating Role of Power Motivation Journal of Business Ethics Vol: 120 (3) pp:363-379 
Schwanke, D.A., (2013). Barriers for women to positions of power: How societal and corporate structures, perceptions of leadership and discrimination restrict women's advancement to authority. Earth Common Journal, 3(2).

Silverstein, M., Sayre, K. (September 2009) The Female Economy. Harvard Business Review, 87 (9), 46-53. Retrieved from: https://hbr.org/2009/09/the-female-economy

Streeton, R., Cooke, M. and Campbell, J. (2004) Researching the researchers: using a snowball technique. Nurse Researcher. 12(1), pp. 35-46. 1351-5578.

Teddlie, C. and Tashakkori, A. (2003). Major issues and controveries inthe use of mixed methods in the social and behvioral sciences. Handbook of mixed methods in social \& behavioral research, 3-50

Toh, S. M., and Leonardelli, G. J. (2012). Cultural constraints on the emergence of women as leaders. Journal of World Business, 47(4), 604-611.

UN Women Training Centre. Gender Equality Glossary. Retrieved October 315t, 2016 https://trainingcentre.unwomen. org $/ \mathrm{mod} / \mathrm{glossary} /$ view.php?id=36\&mode=letter\&hook=G\&sortkey=\&sortorder=

World Economic Forum (2014). The Global Gender Gap Report 2014. Retrieved from: http://reports.weforum.org/ global-gender-gap-report-2014/

World Health Organization (2015). Health in 2015 from SDGs to MDGs. Retrieved from: http://apps.who.int/iris/bitstre am/10665/200009/1/9789241565110_eng.pdf

Young, P. (2004). Leadership and gender in higher education: A case study. Journal of Further and Higher Education, 28(1), 95-106. 




\section{Chapter}

\section{Exploring women healthcare leaders' perceptions on barriers to leadership in Greek context}

\section{Published as:}

Kalaitzi S, Cheung KL, Hiligsmann M, Babich S and Czabanowska K (2019)

Exploring Women Healthcare Leaders'Perceptions on Barriers to Leadership in Greek Context. Front. Public Health 7:68. doi: 10.3389/fpubh.2019.00068 [IF (2018): 2,031] 

ABSTRACT

Background: Gender inequalities have been identified as important derailment factors for health workforce and health system sustainability. Literature holds responsible a list of gendered barriers faced by female health workforce. However, there is a gap in the evidence based research on women leaders' own perceptions of barriers to leading positions advancement. This study aims to explore leadership barriers perceived by women healthcare leaders within country's context; research focused on Greece due to country's poor performance on gender equality index and current economic turbulence. Study supplements survey data and provides orientation for further gender sensitive research in health workforce development through country's specificity lens to better inform education and policy makers.

Methods: The best-worst object case survey method was used, applying an online questionnaire designed in Qualtrics. The online questionnaire was sent to 30 purposively invited participants. Respondents were asked to tick the most and the least important barriers to women's leadership in provided choice scenarios. Descriptive data analysis was used to understand and interpret the results.

Results: Women leaders perceived stereotypes, work/life balance, lack of equal career advancement, lack of confidence, gender gap and gender bias to be the barriers with the greatest relative importance in constraining opportunities for pursuing leading positions in Greek healthcare setting. Twenty more barriers were identified and ranked lower in relative importance. The results are considered exploratory and not to obtain population based outcomes.

Conclusion: This exploratory study reports the perceived barriers of women leaders in pursuing leading positions within Greek healthcare context. The findings point mainly to organizational and socio-cultural related barriers potentially aggravated by country's unfortunate current economic turbulence. Further extensive research is required to establish grounded conclusions and better inform education and policy makers in developing gender sensitive strategies to sustainable health workforce development. 



\subsection{INTRODUCTION}

Gender inequalities in the global healthcare workforce have been identified as important derailment factors for health workforce and health systems' sustainability. The healthcare sector is a steadily increasing source of employment in most OECD countries with women representing the vast majority of the specialized health workforce (1). Hence, it would be reasonable to expect a powerful influential women presence in health and healthcare decision making circles and especially across the spectrum of clinical practice, education, planning, advocacy, and policy. However, in spite of the fact that $75 \%$ of the global healthcare workforce is comprised of women in some countries, only about $25 \%$ of those women hold leadership positions (2). In the healthcare provision sector, women leaders represent only $18 \%$ of hospital CEOs and $14 \%$ of healthcare boards of directors (3); in clinical leadership, only15.9\% of women have reached top level positions (4); in academic medicine, Grade A has been achieved only by $14 \%$ of women pursuing a highlevel career in the field (5).

The added value of women's leadership in health and healthcare has been addressed extensively by literature $(3,4,6-11)$; the excellent qualities and results to health systems outcomes both at universal health coverage and at national and community level have been evidenced extensively; the importance of gender equality and diversity of health workforce have also been acknowledged by scholarship and global agencies, such as WHO (12), OECD (1), as a governance priority to strengthen health services, professional education and employment systems and make health systems responsive to life events and societal challenges.

Global health organizations, such as WHO, argue that the health sector is a good place to start unlocking the full potential of women at work and achieving progress toward meeting the United Nations Sustainable Development Goals (SDGs) (12). The relationship between gender (SDG5 and in particular to SDG5.5 "Ensure women's full and effective participation and equal opportunities for leadership at all levels of decision-making") and health (SDG3) and their intersection across multiple SDGs, such as SDG 8 (gender and the health workforce, formal and informal, decent work, fair employment), SDG4 (education), SDG10 \& 17 (accessible services), SDG16 \& 17 (governance) and SDG1 \& 8 \& 9 (macroeconomic policies), accentuate the catalyzing role of gender equality and diversity toward achieving progress at all levels, interpersonal, institutional, societal, national, and global (13). In line with this rationale, European Union through its constitutional bodies, such as European Commission and its agencies and European Parliament, address health as a core issue interconnecting well-being of individuals and societies, social inclusion, economic growth, and environmental protection (14). It was also explicitly acknowledged that health and healthcare systems are tightly linked to social and employment policies where gender inequalities, such as work life balance, employment contracts, are integral part of well-functioning societies and economies and should be counted in the equation for achieving inclusive growth in the twentyfirst century societies (15).

On the other hand, gender asymmetries are considered a universal fact of human societies 
reflecting the distinction between power and culturally legitimized authority, the ability to gain compliance and recognition "taking male authority for granted and accepting somehow the exercise of power by women as not that important or secondary to their expected social role" $(16,17)$. The hierarchical gender stratification of careers may be considered that are supported by hierarchical relations of women and men in society (18); example given in healthcare sector where in spite of increased feminization of health workforce, women remain severely underrepresented in leading positions.

Multiple studies have explored the journey of women leadership in healthcare dissecting, among others, working patterns, styles, roles, institutional processes, sector insufficiencies, governance flaws. However, little attention has been drawn on women leaders' perceptions on barriers constraining their increased presence in healthcare leading roles which is not mirrored accordingly in respective leading roles. Leadership requires several qualities and healthcare leadership is no exception, given the complex, unprecedented challenges healthcare systems and societies are currently facing $(19,20)$. The leadership prism reveals itself differently in each context and culture (21); it is largely shaped by context, gender and culture, reflecting dynamic relationships among its components (22). Cultural and socioeconomic contexts, oftentimes intensified by unfortunate economic or social turbulences, influence the socially accepted perceptions on legitimized gendered authority and leadership both at societal and professional level $(16,23)$; the deeply rooted process of durability and transferability of these perceptions may intercept the course of change needed in modern societies.

The aim of this paper is to provide the findings of a small exploratory study sought to discover the perceptions of women leaders on perceived barriers to women leadership advancement within country's healthcare context; research focused on Greece due to country's poor performance on gender equality index and current economic turbulence. Study supplements survey data which provides orientation for further gender sensitive research in health workforce development through country's specificity lens to better inform education and policy makers.

\subsection{METHODS}

\subsubsection{Country}

Greece was of interest as the survey target because it was recently announced in European Institute of Gender Equality progress report (24) that descended to the lowest rank in the Gender Equality Index (50.0), being the only EU country with a deteriorating score over a 10-year period in the domain of economic and social power of women. Greece was also ranked low in women's representation in the medical workforce among OECD countries; out of 65,499 doctors, 27,549 were women, namely $41.20 \%(25,26)$, whereas it is estimated that only $11 \%$ assume academic professorship (27). In addition, the Greek healthcare system was profoundly affected by the recent financial and debt crisis of 2009 suffering, amongst others, from several inefficiencies, health workforce included (28); dramatic salary cuts, non-renewal of employment contracts resulting in 
under-staffing; unofficial expectations for long, unpaid work hours, long unemployment periods, or employment on part-time basis deteriorated significantly key indicators on employment and population health (29). The crisis affected predominantly women and single-parent families (30, 31). Austerity intensified discrimination against women, especially in employment forms and under-payment (32) and supported re-establishment of stereotypes mainly in health services sector, social care, education, and public administration. Any progress gained in the field of gender equality and equal work opportunities during 1980s was compromised generating a backlash in employment practices and choices $(30,31)$.

\subsubsection{Participants}

The stratified sampling technique across academic, clinical, and medical settings was applied to identify the important common patterns or variations cutting across healthcare settings and to gain an understanding of perceptions of gendered barriers to women's leadership across Greek healthcare settings (33). Researchers aimed to recruit 20-30 women leaders as participants representing an appropriate cross sectors variation sample in a typical case sampling for exploring perceptions $(20,34)$; the identified sample size and sampling method was deemed by the authors as the most applicable for the study's purposes $(33,35)$.

Participants were identified through publicly announced women leaders' email addresses found via a systematic web search of Greek healthcare organizations. Snowball sampling technique was also applied as better combined with sampling strategy for examination of commonalities and differences (33). First, medical, nursing, and public health schools were identified in the web site of Ministry of Education and then separately explored. Next, all hospitals presented in the web site of the Ministry of Health were identified and separately searched. Finally, medical and health organizations and associations were also identified through the web site of the Ministry of Health and separately searched.

The following inclusion criteria were used to retrieve, select and accept women leaders' email addresses across healthcare settings: (a) Academic setting (medical/nursing schools, public health school): full/assistant professor; (b) Clinical setting (public/private hospital): CEO, vice president, board member, clinical director, assistant clinic director; (c) Medical setting (medical/ health body, health ministry): president, vice president, board member, director, assistant director. Contact information of invited participants was collected between April 2017-August 2017. Men healthcare leaders were excluded as not being within the scope of this small exploratory study; researchers acknowledge the researched women's perspectives to be initial and exploratory and further gender balanced research is required to yield grounded conclusions.

Participants were assured anonymity throughout the survey procedure since online questionnaires were anonymously replied and registered in Qualtrics (36). Invited participants were informed about the study's purpose, procedure, anonymity, and their rights via the invited introductory email message. Data are stored to university's server and are protected via password owned by involved researchers only. 


\subsubsection{Online Questionnaire Instrument}

The Best Worst Scaling (BWS) method was used to identify the most and least important barriers across the identified three healthcare settings. Best-Worst Scaling was deemed appropriate for this exploratory study since it has been increasingly used to investigate preferences over a number of topics in the healthcare field (37). It was also considered the best choice for this study, as ranking tasks are simplified and it facilitates the evaluation of varying degrees of different barriers involved in composite decisions (38). It also normalizes all relative-importance weights to the $(0,1)$ interval and, thus, eliminates scale artifacts and reduces social desirability bias, since respondents evaluate trade- offs between attributes (39).

The online questionnaire was designed using the Sawtooth Software (40). Four different versions of a self-administered questionnaire and an explanatory introduction were developed. One open-ended question was included, providing participants the possibility to mention additional barriers or to fill in freehand comments. Demographic and professional features (gender, age, professional role) were considered at the beginning. Each participant was asked to describe their professional role, selecting one out of three different options: academic, clinical and medical, as defined for this study.

A total of 14 choice scenarios were presented including a set of five barriers with varying combinations and ordering of barriers. Four versions of 14 selected choice scenarios were developed and each respondent received randomly one of the four versions. A snapshot from the choice scenarios addressed to participants is presented in Figure I.

Figure I | Snapshot from the BWS choice scenarios addressed to participants

Please identity the Most Important barrier, and the Least Important barrier to Woman Leadership in Healthcare.

\begin{tabular}{c|c|c} 
Most Important & & Least Important \\
\hline & Gender gap & 0 \\
0 & Sexual harassment & 0 \\
$\bigcirc$ & Lack of career advancement opportunities & 0 \\
$\bigcirc$ & Race descrimination & 0 \\
& Queen bee syndrome & 0 \\
\hline
\end{tabular}

Please identity the Most Important barrier, and the Least Important barrier to Woman Leadership in Healthcare.

\begin{tabular}{c|c|c} 
Most Important & & Least Important \\
\hline 0 & Lack of confidence & 0 \\
0 & Family (espouse) support & 0 \\
0 & Lack of executive sponsor & 0 \\
0 & Stereotypes & 0 \\
& Isolation & 0
\end{tabular}


At the end of the questionnaire, participants were asked to rate the difficulty of completing the choice scenarios based on a Likert scale ( 1 = very easy, to 7 = very difficult) (41). The BWS survey was sent to participants via Qualtrics on January 16, 2018 and closed on February 6, 2018. It was active for an initial period of 2 weeks, and a reminder was sent out on January 30, 2018.

\subsubsection{Identification of Barriers}

Participants were asked to identify the most and least preferred barriers from the choice scenario list of five barriers based on the Barriers Thematic Map (BTM) (42). The BTM was deemed appropriate for this exploratory study since it reports a comprehensive list of 26 barriers to women leadership with varying degrees of prevalence (Table I) compiled using a multi- method approach and validated from several experts and focus groups during dedicated workshops $(42,43)$.

Table I | Barriers Thematic Map (BTM) to women's leadership.

\section{BARRIERS THEMATIC MAP (BTM) TO WOMEN LEADERSHIP}

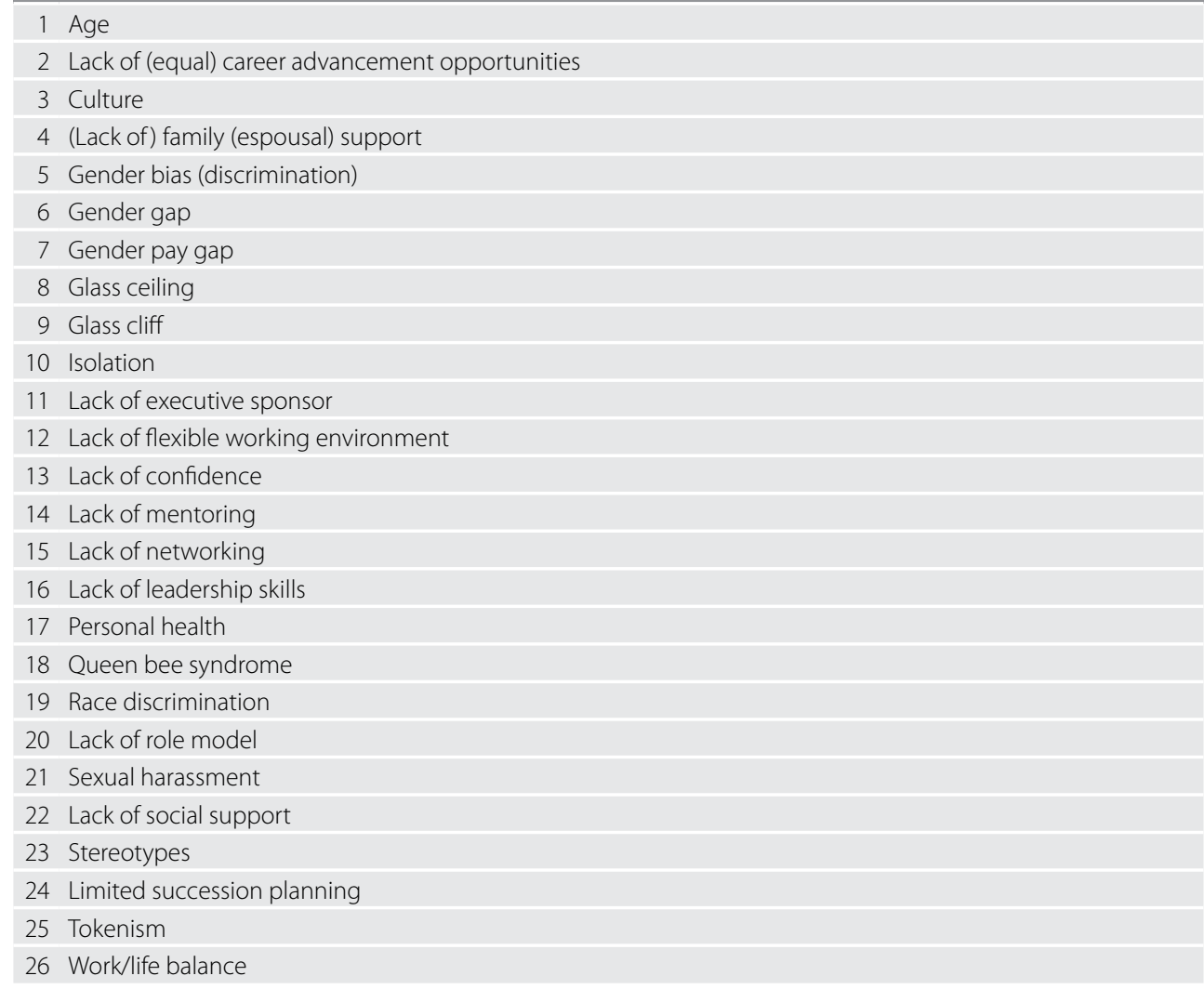
Source: Kalaitzi et al., 2017

\subsubsection{Approach to Analysis}

All fully answered online questionnaires were deemed completed and included in the data analysis. The calculation of the mean relative importance score (RIS) with its $95 \%$ confidence 
interval, generated by the Hierarchical Bayes (HB) estimation using Sawtooth platform, allowed for ranking the barriers from the most to least important $(44,45)$.

\subsection{RESULTS}

\subsubsection{Participant Characteristics}

A total of thirty online questionnaires were sent out; twenty- four participants completed the online questionnaire and were included in the analysis; their basic demographics are summarized in Table II. The responsive rate of $80 \%$ (24/30) calculated by dividing the number of usable responses returned by the invited participants' number (24/30) and was deemed appropriate and supported this exploratory study's findings $(35,46-48)$.

Table II | Demographics of participants.

\begin{tabular}{|l|c|}
\hline \multicolumn{1}{|c|}{ PARTICIPANT CHARACTERISTICS } & PERCENTAGE $(\boldsymbol{n = 2 4 )}$ \\
\hline Professional role & $12(50 \%)$ \\
\hline Academic & $11(46 \%)$ \\
\hline Clinical & $1(4 \%)$ \\
\hline Medical & \\
\hline Age & $11(46 \%)$ \\
\hline $39-50$ & $10(42 \%)$ \\
\hline $51-60$ & $3(13 \%)$ \\
\hline $61-65$ & $12(50 \%)$ \\
\hline Difficulty to reply (7-point Likert scale) & $10(42 \%)$ \\
\hline $1-3$ (less difficult) & $2(8 \%)$ \\
\hline $4-5$ (medium difficult) & \\
\hline $6-7$ (very difficult) & \\
\hline
\end{tabular}

All participants were women; respondents assumed mostly academic and clinical leading roles (50 and $46 \%$, respectively). The age of the respondents ranged from 39 to 50 years $(46 \%, n=11$ ), $51-60$ years $(42 \%, n=10), 61-65$ years $(13 \%, n=3)$ representing mainly mid-career stage, namely the entryway to senior leading positions. All respondents had an overall fit statistic higher than 0.25 and were thus all included in the analysis (40). Respondents rated BWS survey as less to medially difficult on a 7-point Likert scale rates ranging from 2 to 6 (mean:3.45) (41). Five comments were provided in the open-ended question field related to barriers focusing mostly on lack of organizational support and socially and culturally related barriers.

Relative Importance of Barriers to Women's Leadership in Healthcare in Greece The RIS (Relative Importance Score) of the barriers is illustrated in Table III. 
Table III | Barriers to women's leadership in Greek healthcare and their Relative Importance Scores (RIS) based on Hierarchical Bayes (HB) estimation.

\section{BARRIERS TO WOMEN LEADERSHIP IN GREEK HEALTHCARE}

AND THEIR RELATIVE IMPORTANCE SCORES (RIS)

\begin{tabular}{|c|c|}
\hline Stereotypes & $8.80(7.06$ to 10.55$)$ \\
\hline Work/life balance & 6.22 (4.24 to 8.20$)$ \\
\hline Lack of equal career advancement opportunities & 5.72 (4.26 to 7.18$)$ \\
\hline Lack of confidence & 5.25 (3.32 to 7.18$)$ \\
\hline Gender gap & 5.25 (3.25 to 7.25$)$ \\
\hline Gender bias & 5.18 (3.55 to 6.81$)$ \\
\hline Glass ceiling & 4.72 (2.87 to 6.57$)$ \\
\hline Lack of family (espouse) support & 4.71 (3.69 to 5.73) \\
\hline Lack of role models & 4.70 (3.31 to 6.09) \\
\hline Lack of social support & 4.46 (3.44 to 5.48$)$ \\
\hline Lack of flexible working environment & 4.36 (2.64 to 6.07$)$ \\
\hline Lack of leadership skills & 4.21 (2.82 to 5.59$)$ \\
\hline Lack of networking & 4.01 (2.83 to 5.19$)$ \\
\hline Lack of mentoring & 3.79 (2.40 to 5.18$)$ \\
\hline Isolation & 3.22 (1.61 to 4.82$)$ \\
\hline Culture & 3.21 (2.08 to 4.34$)$ \\
\hline Limited succession planning & 3.09 (2.49 to 3.69) \\
\hline Glass cliff & 2.64 (1.66 to 3.62) \\
\hline Personal health & 2.48 (1.18 to 3.78$)$ \\
\hline Gender pay gap & 2.34 (1.63 to 3.05$)$ \\
\hline Queen bee syndrome & 2.07 (1.13 to 3.02) \\
\hline Tokenism & 1.97 (0.98 to 2.97) \\
\hline Lack of executive sponsor & 1.97 (0.94 to 2.99) \\
\hline Race discrimination & 1.93 (1.30 to 2.55$)$ \\
\hline Sexual harassment & 1.89 (1.45 to 2.33$)$ \\
\hline Age & 1.68 (0.88 to 2.48$)$ \\
\hline
\end{tabular}

Figure II shows ranking of barriers to women's leadership in Greek healthcare context; the visual cut-off point (RIS $=5.19$ ) may be considered as a threshold to differentiate the most important barriers from the remaining ones in this study. 
Figure II | Ranked barriers to women's leadership in healthcare in Greece $(\boldsymbol{n}=24)$. The RIS in box indicates the most important barriers' threshold (RIS>5.19).

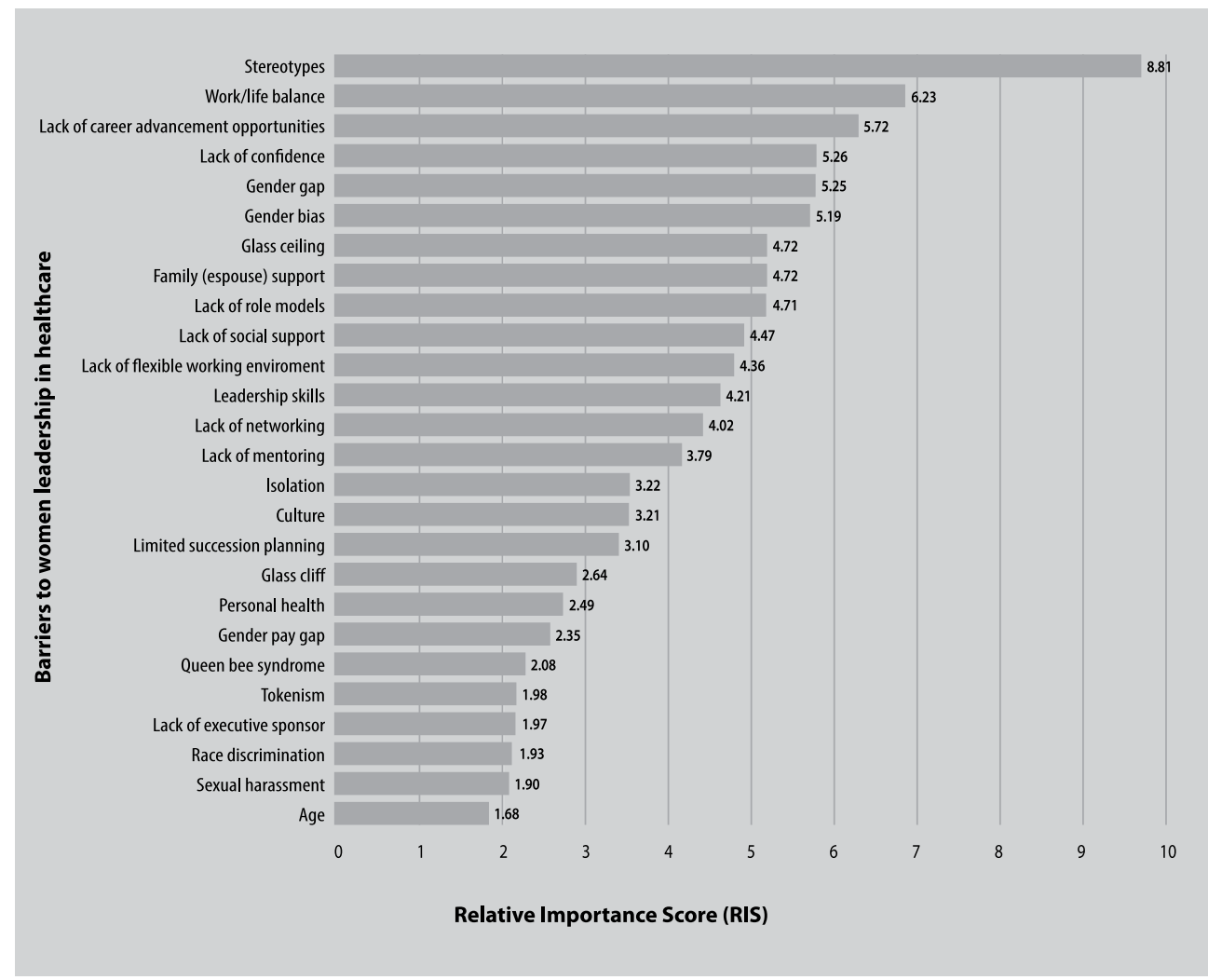

Out of twenty-six, the six most important barriers (RIS> 5.00) to women's leadership in Greek healthcare settings $(n=24)$ included stereotypes (RIS:8.80), work/life balance (RIS:6.22), lack of equal career advancement opportunities (RIS:5.72), lack of confidence (RIS:5.25), gender gap (RIS:5.25), and gender bias (RIS:5.19). Stereotypes tops the barriers relative importance list (RIS:8.80) with considerable distance from the second item, "work/life balance" (RIS:6.22), whereas "lack of equal career opportunities," "lack of confidence," "gender gap," and "gender bias" share ranking in the vicinity of RIS:5.72- 5.19. The two most targeted barriers, namely stereotypes and work/life balance, may indicate some relatedness or even complementarity between them in fostering and maintaining socially deeply rooted gendered roles within country's specific context. Organizational and socio-cultural bounded barriers were the main concerns of respondents; four out of the five responses to open ended question of the online questionnaire corroborate the findings on lack of organizational support and cultural constraints to be the harshest constraints to be dealt with.

Medium relative importance barriers include fifteen barriers ranging from RIS:4.72-2.07 describing 
challenges both at personal and at organizational level, such as lack of family (espousal) support, lack of mentoring, lack of leadership skills and glass ceiling, glass cliff, lack of flexible working environment. However, nonetheless their abundance and variety the medium relative importance ranking may be indicate that are not perceived too rigid or unsurmountable.

Five out of the 26 barriers have been reported in the lowest relative importance ranks raging from RIS 1.97-1.68 and include "tokenism," "lack of executive sponsor," "race discrimination," "sexual harassment," and "age." However, underlying dynamic relations among organizations' structure, society, and country's economic turbulence may have influenced the attention drawn to these constraints of which the research importance should not be underestimated.

\subsection{DISCUSSION}

The importance of organizational and socio-cultural contexts in developing and fostering barriers to women's leadership in Greek healthcare setting was emerged from respondents' replies. Participants perceived stereotypes, work/life balance, lack of equal career advancement, lack of confidence, gender gap, and gender bias to be the barriers with the greatest relative importance. These barriers may have direct effects in discouraging women to pursuit leading roles in medical practice, education, and medical organizations. Skills and talent may be wasted; gender diversity and inclusion efforts within healthcare organizations may be compromised initiating cascading effects on organizational culture and performance.

In line with literature, this small exploratory study's findings point to a mix of perceived barriers which may elucidate women's poor promotion and retention from leadership positions in healthcare. Downs et al. (8) argue that elevating women neutralizes gender equality threat and create a ripple effect benefiting families, communities, organizations, and countries. Newman (4) asserts gender discrimination and inequalities impede the development of robust workforces resulting in critical systems inefficiencies; hence, gender balanced health workforce should be a leadership and governance priority both in education and employment systems. Price and Clearihan (20) align with the argument on pressing needs for increased presence of female voice in health leadership context. They discuss women's perceptions of restricting capacity to engage leadership roles focusing on work/life balance in the sense of assuming large amount of domestic work, and on inflexible work environment, such as the inconvenient time and location of professional meetings. The organizationally and socially rooted women's leadership deficit in healthcare was also explored through the lens of perceptions on women's capabilities, credibility and capacity in functioning properly in formal professional roles. Bismark et al. (9) argue that these perceived deficits derive from internalized beliefs about traits and qualities of women who aspire to be leaders. The lack of mentoring, the (un)conscious biases, the male dominated working environment and the conservative social norms in terms of uptake of leading career pathways while running a household have also been hold responsible for the sturdiness of perceptions on women's leadership deficit (49). 
Within Greek healthcare context, the described organizational barriers, such as reinforced stereotypes, inflexible work environment, may be considered to reflect dynamic, overlapping, and cross cutting relationships amongst organizations, individuals and socially constructed perceptions about women and leadership. Those approaches were also supported by the comments made by two respondents who emphasized deep-rooted stereotypes and lack of organizational support, confirming Claus' argument that the durability and transferability of gendered perceptions amongst cultures and groups of individuals are difficult to eradicate (2013). Gendered asymmetries in healthcare may contribute to perpetuation of stereotypes hinting the pathway to cultural reproduction of male dominance in professional settings (34). Nonetheless the high social regard of health professions, organizational and cultural mechanisms may explain the underlying interactions between gender and the choices and barriers related to gendered professional careers in health $(50,51)$. On top of that, the dramatic suffrage of healthcare sector (28) resulted in employment contracts' derailment (29) affecting predominately women and single parent families in health, care and education sectors (31). The imposed social, economic, and organizational constraints may have burden women's perceptions on barriers to their career advancement; thereby, complex relationships between the labor market, gender norms, and economic instability may have interplayed to limit women's choices and possibilities both within professional and social settings (52).

Gendered barriers to equal opportunities in career advancement within working environments may be considered to be the product of dynamic relationships between individuals, organizations, and society. They cannot and should not have an absolute character and need to be subjected to assessment overtime and within professional and socio-cultural contexts. Diversity and inclusion are essential to promote cultural awareness and change, challenge conventional ideas, and improve performance across organizations (53). Perceived leadership abilities and positions correlate closely with gender representation within healthcare sector; the health profession is still highly perceived socially (51) and may assume the role of change agent in ongoing transformation toward sustainability of healthcare sector and societies as well. Therefore, the talent pipeline for women healthcare leadership needs to be supported and enhanced (54-56).

Identifying perceptions on barriers that may hinder the development of women potential may be an essential first step for further evidence base research on the reasons and potential solutions to address gendered challenges in health workforce. Acknowledging the complexity of the phenomenon, the challenge is to explore further these barriers and acquire in depth understanding of involved actors and context; barriers through contextual lens may be framed as an opportunity to develop evidence informed strategies and policies in education and employment and promote inclusiveness and sustainability in healthcare organizations and modern societies. Besides, our task is to seek out and grow leaders, women and men, able to pave the way toward an inclusive and sustainable transformation of healthcare sector and society as well (57). 


\subsection{LIMITATIONS}

This study explored the perceptions of the relative importance of barriers to women's leadership in healthcare in Greece. The researchers recognize the limited number of participants in online survey even though the sample size was deemed appropriate for the study's exploratory purposes.

The researchers acknowledge the women leaders' perceptions to be initial and exploratory; they are not considered to contribute in obtaining population based outcomes. However, comprehensiveness of the barriers coding scheme and sampling from all facets of healthcare achieved to provide adequate initial descriptions of women leaders' perceptions on barriers. Hence, the exploratory findings of organizational and cultural contexts as two major barriers to women leadership may provide orientation for an in-depth country specific research.

In depth qualitative and quantitative research in countries with similar and/or different socioeconomic status could yield valuable data to triangulate the findings and provide grounded conclusions on this researched topic.

Due to practical issues, fourteen choice sets were incorporated, while Sawtooth survey was initially designed to include sixteen.

\subsection{CONCLUSION}

This exploratory study reports on the perceptions of women leaders of barriers in pursuing leading positions within Greek healthcare context. The findings point mainly to organizational and socio-cultural related barriers potentially aggravated by country's unfortunate current economic turbulence. Further extensive research on perceptions of women and men is required to establish grounded conclusions and better inform education and policy makers in developing gender sensitive strategies to sustainable health workforce development.

\section{Ethics statement}

Research conducted according to ethical principles. Ethical approval was received from Ethics Committees from Maastricht University (No METC 16-4-266, January 19, 2017) and National and Kapodistrian University of Athens (Medical School) (February 3, 2017)

\section{Author contributions}

SK and KC were involved in the conception of the study. SK KC, MH and KLC were involved in the design of the study. $\mathrm{MH}$ conducted the data analysis. Data interpretation was carried out by SK and KC with input from MH and KLC. SK and KC drafted the manuscript with input from MH, KLC and SB. All authors approve the final version of this manuscript and all authors agree to be accountable for all aspects of the work. 


\section{REFERENCES}

OECD. Health Workforce Policies in OECD Countries. (2018). Available online at: http://www.oecd.org/health/healthsystems/health-workforce-policies- in-oecd-countries-9789264239517-en.htm (accessed March 24, 2018).

HRH Global Resource Center. Resource Spotlight: Gender and Health Workforce Statistics. (2017). Available online at: http://www. hrhresourcecenter.org/gender_stats (accessed March 10, 2017).

Hauser MC. Leveraging women's leadership talent in healthcare. J Healthc Manag. (2014) 59:318-22.

Newman C. Time to address gender discrimination and inequality in health workforce. Hum Resour Health. (2014) 12:25. doi: 10.1186/1478-4491-12-25

JustActions. Female Leadership. (2016). Available online at: http://justactions.org/action/female-leadership/ (accessed May 30, 2016).

Czabanowska K, Domagała A, Kalaitzi S, Krogulec A, Burazeri G, Babich S. Exploring the added value of women health care managers in poland. Materia Soc Med. (2017) 29:280. doi: 10.5455/ msm.2017.29.280-285

Fjeldsted K. Female Leadership in Healthcare. (2016). Available online at: http://www.cpme.eu (accessed April 14, 2016).

Downs JA, Mathad JS, Reif LK, McNairy ML, Celum C, Boutin-Foster C, et al. The ripple effect: why promoting female leadership in global health matters. Public Health Action. (2016) 6:210-1. doi: 10.5588/pha. 16.0072

Bismark M, Morris J, Thomas L, Loh E, Phelps G, Dickinson H. Reasons and remedies for under-representation of women in medical leadership roles: a qualitative study from Australia. BMJ Open. (2015) 5:e009384.doi: 10.1136/ bmjopen-2015-009384

Fontenot T. Leading ladies: women in healthcare leadership. Front Health Serv Manage. (2012) 28:11-21. doi: 10.1097/01974520-201204000-00003

Hoss MAK, Bobrowski P, Mc Donagh KJ, Paris NM. How gender disparities drive imbalances in health care leadership. J Healthc Leadersh. (2011) 3:59-68. doi: 10.2147/JHL.S16315

World Health Organization. World Health Organization. (2018). Available online at: http://www.euro.who.int/en/ media-centre/sections/statements/ 2017/statement-by-dr-zsuzsanna-jakab,-who-regional-director-for-europe,for-international-womens-day

Manandhar M, Hawkes S, Buse K, Nosrati E, MagarV. Gender, health and the 2030 agenda for sustainable development. Bull World Health Organ. (2018) 96:644. doi: 10.2471/BLT.18.211607

Franklin P. Sustainable Development Goal on Health (SDG3): The Opportunity to Make EU Health a Priority. EPC Discussion Paper (2017).

European Commission. Communication from the Commission on Effective, Accessible and Resilient Health Systems. Brussels (2014).

Rosaldo MZ. Woman, culture, and society: a theoretical overview. Woman Cult Soc. (1974) p.21.

Parsons T. Evolutionary universals in society. Am Sociol Rev. (1964) 339-57. doi: 10.2307/2091479

Fox MF, Whittington K, Linkova M. Gender, (In) equity, and the Scientific Workforce Handbook of Science and Technology Studies. Cambridge: Mass MIT Press (2017).

Czabanowska K, Rethmeier K, Lueddeke G, Smith T, Malho A, Otok R, et al. Public health in the 21st century: working differently means leading and learning differently. Eur J Public Health. (2014) 24:1047-52. doi: 10.1093/eurpub/ cku043

Price K, Clearihan L. Exploring female GPs' perceptions about medical leadership. Aust Fam Phys. (2015) 44:399-402. Available online at: https://www.racgp.org.au/afp/2015/june/exploring-female-gps\%E2\%80\%99-perceptionsabout-medical-leadership/

Eagly AH, Chin JL. Diversity and leadership in a changing world. Am Psychol. (2010) 65:216. doi: 10.1037/a0018957

Klenke K. Women and Leadership: A Contextual Perspective. New York, NY: Springer Publishing Company (2004).

Helman CG. Culture, Health and IIIness. New York, NY: CRC press (2007).

European Institute for Gender Equality. Gender Equality Index 2017. (2017). Available online at: http://eige.europa.eu/ gender-equality-index/ 2015/EL (accessed March 14, 2018).

Hellenic Statistical Authority. Survey on Physicians and Dentists. (2018). Available online at: http://www.statistics.gr/ documents/20181/14132567/ Survey+on+physicians+and+dentists+\%28+2017+\%29/be775cf4-330c-47e0- 83c947b52e18a371?version=1.0 (accessed January 23, 2018).

OECD Health Statistics. Women Make up Most of the Health Sector Workers But They are Under-Represented in High Skilled Jobs. (2017). Available online at: http://www.oecd.org/gender/data/women-make-up-most-of-thehealth-sector-workers-but-they-are-under-represented-in-high-skilled-jobs.htm (accessed December 11, 2017). 
Kaldoudi E. Women in Science and Engineering. The Greek reality. (2010). Available at: http://2016.ifmbe.org/wpcontent/uploads/2012/12/ MEDICON_WinS_Kaldoudi.pdf (accessed January 23, 2019).

Mossialos E, Allin S, Davaki K. Analysing the Greek health system: a tale of fragmentation and inertia. Health Econ. (2005) 14:S151-68. doi: 10.1002/hec.1033

Economou C, Kaitelidou D, Kentikelenis A, Sissouras A, Maresso A. The Impact of the Financial Crisis on the Health System and Health in Greece. Economic crisis, health systems and health in Europe: country experience. Copenhagen: WHO/European Observatory on Health Systems and Policies (2014).

European Parliament. The Policy in Gender Equality in Greece. (2013). Available online at: http://www.europarl.europa. eu/RegData/etudes/note/ join/2013/493028/IPOL-FEMM_NT(2013)493028_EN.pdf (accessed March 3, 2018).

Karamessini M. Labour market impact of four recessions on women and men in Greece: Comparative analysis in a long-term perspective. Social Cohes Dev. (2016) 7:93-104. doi: 10.12681/ scad.8978

Cholezas I, Tsakloglou P. Gender Earnings Differentials in the Greek Labour Market. Athens: Economic Policy Studies (2006).

Palinkas LA, Horwitz SM, Green CA, Wisdom JP, Duan N, Hoagwood K. Purposeful sampling for qualitative data collection and analysis in mixed method implementation research. Adm Policy Ment Health. (2015) 42:533-44. doi: 10.1007/s10488-013-0528-y

Pattani R, Marquez C, Dinvarian C, Sharma M, Bain J, Moore JE, et al. The perceived organization impact of the gender gap across a Canadian department of medicine and proposed strategies to combat it: a qualitative study. BMC Med. (2018) 16:48. doi: 10.1186/s12916-01 8-1032-8

Robson C, McCartan K. Real World Research. West Sussex, UK: John Wiley and Sons (2016).

Qualtrics. The Leading Research and Experience Software. (2017). Available online at: https://www.qualtrics.com/ (accessed February 5,2017).

Cheung KL, Wijnen BF, Hollin IL, Janssen EM, Bridges JF, Evers S, et al. Using best-worst scaling to investigate preferences in health care. Pharmacoeconomics. (2016) 34:1195-209. doi: 10.1007/s40273-01 6-0429-5

Flynn TN, Louviere JJ, Peters TJ, Coast J. Best-worst scaling: what it can do for health care research and how to do it. J Health Econ. (2007) 26:171-89. doi: 10.1016/j.jhealeco.2006.04.002

Mühlbacher AC, Kaczynski A, Zweifel P, Johnson FR. Experimental measurement of preferences in health and healthcare using best-worst scaling: an overview. Health Econ Rev. (2016) 6:2. doi: 10.1186/s13561-0 15-0079-x

Sawtooth Software. Counting Analysis. (2017). Available online at: https:// www.sawtoothsoftware.com/ (accessed April 5, 2017).

Allen IE, Seaman AC. Likert Scales and Data Analyses. (2017). Available online at: http://asq.org/quality-progress/2007/07/ statistics/likert-scales-and-data- analyses.html (accessed September 5, 2017).

Kalaitzi S, Czabanowska K, Fowler-Davis S, Brand H. Women leadership barriers in healthcare, academia and business. Equal Divers Incl Int J. (2017) 36:457-74. doi: 10.1108/EDI-03-2017-0058

World Health Organization. Strengthening Women's Leadership in Public Health in Ukraine. Available online at: http:// www.euro.who.int/en/countries/ukraine/news/news/2017/05/strengthening-womens-leadership-in-publichealth-in-ukraine (accessed June 15, 2017).

Johnson RM. Understanding HB: An Intuitive Approach. (2007). Available online at: http://www.sawtoothsoftware. com/download/techpap/maxdifftech. pdf (accessed April 5, 2017).

Edwards MJ, Adams RA, Brown H, Parees I, Friston KJ. A Bayesian account of "hysteria". Brain. (2012) 135:3495-512. doi: 10.1093/brain/ aws129

Draugalis JR, Coons SJ, Plaza MC. Best practices for survey research reports: a synopsis for authors and reviewers. Am J Pharm Educ. (2008) 72:11. doi: 10.5688/aj720111

Hsieh H-F, Shannon S. E. Three approaches to qualitative content analysis. Qual Health Res. (2005) 15:1277-88. doi: $10.1177 / 1049732305276687$

Guba EG, Lincoln YS. Naturalistic Inquiry. Beverly Hills, CA: Sage (1985).

Mrcela AK, Igniatovic M. Women, work and health. Zdr Varst. (2017) 56:220-6. doi: 10.2478/sjph-2013-0015

Claus AV, Sandlin RJ, Callahan J. Culture and leadership: Women in non-profit and for-profit leadership positions within European Union. Hum Resource Dev Int. (2013) 16:330-45. doi: 10.1080/13678868.2013. 792489

Riska E. Medical Careers and Feminist Agendas. American, Scandinavian and Russian Women Physicians, New York: Adline De Gruyter (2001).

Theobald S, Morgan R, Hawkins K, Ssali S, George A, Molyneux S. The importance of gender analysis in research for health systems strengthening. Health Policy Plan. (2017) 32(Suppl. 5):v1-v3. doi: 10.1093/heapol/ czx163

McLeod PL, Lobel SA, Cox TH Jr. Ethnic diversity and creativity in small groups. Small Group Res.(1996) 27:248-64. doi: $10.1177 / 1046496496272003$ 



\section{Chapter}

\section{Women, healthcare leadership and societal culture: A qualitative study}

\section{Published as:}

Women, healthcare leadership and societal culture: a qualitative study.

Kalaitzi S, Czabanowska K, Azzopardi-Muscat N, Cuschieri L, Petelos E, Papadakaki M, Babich S. Journal of Healthcare Leadership. doi.org/10.2147/JHL.5194733 [IF (2017): 1,12] 

ABSTRACT

Purpose: Women leaders encounter societal and cultural challenges that define and diminish their career potential. This occurs across several professions including healthcare. Scant attention has been drawn to the discursive dynamics among gender, healthcare leadership and societal culture. The aim of this study is to assess empirically gendered barriers to women's leadership in healthcare through the lens of sociocultural characteristics. The comparative study was conducted in Greece and Malta. The interest in these countries stems from their poor performance in the gender employment gap and the rapid sociocultural and economic changes occurring in the European-Mediterranean region.

Subjects and methods: Thirty-six individual in-depth interviews were conducted with healthcare leaders, including both women and men (18 women and 18 men). Directed content analysis was used to identify and analyze themes against the coding scheme of the Barriers Thematic Map to women's leadership. Summative content analysis was applied to quantify the usage of themes, while qualitative meta-summative method was used to interpret and contextualize the findings. Results: Twenty and twenty-one barriers to women's leadership were identified within the Greek and Maltese healthcare settings, respectively. Prevailing barriers included work/life balance, lack of family (spousal) support, culture, stereotypes, gender bias and lack of social support. Inter-country similarities and differences in prevalence of the identified barriers were observed.

Conclusion: The study appraised empirically the gendered barriers that women encounter in healthcare leadership through the lens of national sociocultural specificities. Findings unveiled underlying interactions among gender, leadership and countries' sociocultural contexts, which may elucidate the varying degrees of strength of norms and barriers embedded in a society's egalitarian practices. Cultural tightness has been found to be experienced by societal dividends as an alibi or barrier against sociocultural transformation. Findings informed a conceptual framework proposed to advance research in the area of women's leadership. 



\section{1 INTRODUCTION}

Cultures are never static. They are in a constant process of flux and negotiations, adapting and changing over time and space. Helman 'stated that culture must always be seen in its particular context made up of, among others, socioeconomic factors. Leach ${ }^{2}$ held that the cultural lens which societal divisions, such as profession and gender, develop are imbued with different values, rules and perspectives on life. These often coexist uncomfortably within the same social context. Intersecting identities, namely, "the mutually constitutive relations among social identities" (Shields, 2008, p. 301), reflect the individual's social location, beliefs, perceptions and power relations embedded within. Along that perspective, Maurice ${ }^{5}$ underlined the importance of interplay between societal and professional settings within countries' cultural boundaries. These were articulated by Foucault " as "regimes of truth", namely, discourses in time and context bearing an "invisible power" under their cultural capacity. 'Likewise, the leadership prism exhibits itself differently in each context and culture. This is also true in relation to women leaders and culturally legitimized social power and authority. ${ }^{7-9}$ Literature has dealt with asymmetries in cultural evaluations of gender within geographic boundaries. Unveiling women's voice is one the most important missing voices in the majority of western accounts of culture."

\subsubsection{Delimiting countries' sociocultural contexts}

This study focuses on two countries in the European Union (EU)-Mediterranean (Med) region. Greece has been heavily affected by the global financial crisis and the ensuing burden generated various economic, political, social and cultural impacts. Malta, while not having been seriously negatively affected by the financial crisis, has experienced a rapid sociocultural transition in recent years. ${ }^{12,13}$ These economic and social changes are both relevant to gender and power dimensions. ${ }^{14}$ The authors focused on Greece and Malta, two EU-Med countries, which have been ranked low-to-middle in the Gender Equality Index ${ }^{15}$ and are among the worst performers in terms of gender employment gap. ${ }^{16-18}$ The objective lies in understanding similarities and differences in sociocultural and economic contexts with reference to the explored phenomenon by highlighting the "structures and systems that support or inhibit women on the path toward leadership in health".

\section{Greece}

Greece has been profoundly affected by the devastating economic crisis which generated harsh social and economic implications; it is considered as an "omens of a Greek tragedy", referring among others to the deepening lack of proper healthcare delivery. ${ }^{18}$ The healthcare system suffered dramatically ${ }^{20}$ and had been previously reported as "a major factor" contributing to the country's economic hardship. As such, it came under intense scrutiny. Dramatic reductions in health sector salaries and changes to working conditions, such as employment under fixed-term contracts, resulted in hasty retirements to ensure better pensions, even substantially reduced, and in understaffing and poor quality of healthcare delivery. ${ }^{21}$ Health indicators deteriorated, including child and elderly health, due to decline in public spending and house- hold income. 22,23 The crisis affected predominantly women and single-parent families, especially in the health, education 
and social care sectors; ${ }^{24,25}$ women who were tertiary education graduates were concentrated in less-rewarding, but economically safer disciplines. ${ }^{26}$ The ensuing social and economic constraints forced women to make the culturally expected and accepted choice to prioritize family support and care, formal or informal, over pursuit of career advancement according to the power structure of Greek society. ${ }^{27}$ Being a collectivist culture, Greek society values the family unit, which remains male dominated. The social pattern touches upon patriarchy, expecting women to assume less authority and power than spouses within social and family boundaries and to continue to be responsible for household duties despite a high level of education and contribution to the household income. ${ }^{28}$ In a nutshell, cultural, economic and political process embedded in an institutional and societal context had an important effect on labor choices and women's senses of worth within the Greek society.29 The devastating financial crisis in Greece since 2009 has jeopardized any progress gained in gender equality and equal work opportunities, triggering a backlash in employment practices and choices. ${ }^{24}$

\section{Malta}

Malta has been traditionally a patriarchal, deeply religious society, which was further influenced by the impact of British colonialism and the country's relative geographic isolation. ${ }^{30}$ Historically, Maltese women became professionally active in caring positions in the domestic, education or health sectors. ${ }^{31}$ Emancipation was given a push forward because of conscription during the Second World War which, over a period of time, eventually resulted in their taking on various roles including the directorship of hospitals and full professorship in academy. ${ }^{31,32}$ However, the long-standing, socially constructed, gendered norms and expectations dictated prioritization of household and child-rearing tasks over a career. Thus, women were prevented from achieving their full potential in terms of empowerment and leadership. ${ }^{33}$ In 2004, women represented only 32.6\% of the Maltese labor market, with many opting for part-time work to reconcile work with family demands, resulting in ongoing situations of economic hardship and dependence. ${ }^{16}$ Additionally, sectorial and occupational segregation still abounds with many opting for family-friendly employment, such as education, service workers and assistant professionals. ${ }^{16}$ Although the policy agenda has changed and structural measures, including availability of free child care, have been adopted, enabling great strides forward to be accomplished over a few years, sociocultural resistance remains strong. Discrimination and rigid stereotypes in relation to family roles keep limiting women's participation in the labor market, and in corporate and political roles, despite high educational levels and professional experience. ${ }^{34}$ Advances among younger couples have not yet superseded the social norm which expects women to shape their life choices to fit in their husbands' interests since "God forbid if a husband would have to adapt his life to suit his wife's lifestyle" (p. 23). ${ }^{24}$ In essence, the country is still performing poorly in women's leadership and gender equality; the Global Gender Gap Report 2016 states that Malta is one of the three lowest performing countries in Western Europe regarding gender equality. ${ }^{17}$

\subsubsection{Health care sector and women's leadership}

Studying the healthcare sector ${ }^{5}$ may identify and explain the distinctiveness of barriers specifically 
experienced by women leaders in this setting by exploring the interplay between sector and societal settings within countries' cultural boundaries. The value of analyzing the relationship between the country-specific sectoral framework and dominant sociocultural and economic factors shaping social reality derives from the position that actors cannot be separated from structures and vice versa. Actors intrinsically participate in a way or another in building the social reality in which they are active. $^{35}$ Comparison and extrapolation of the phenomenon through the lens of social and cultural diversity between countries may establish a basis to better understand the relationship of dominant sociocultural factors and barriers hindering women's leadership advancement. Previous research confirms that women fall severely behind men in assuming leading roles in healthcare as they are hindered by numerous barriers. ${ }^{36-39}$ Even though their added value in the healthcare sector is acknowledged, ${ }^{40,41}$ women leaders encounter societal and cultural challenges that define and diminish their career potential. This study considers the dynamic dialogue among societal culture, professional leadership and gender as a socially constructed concept ${ }^{40}$ pervading the society in a constant flux and negotiation. These interactions shape mechanisms over time, such that dominant perceptions are enabled and constantly reinforced through country's social, cultural and economic influences.

This paper draws upon qualitative data which are used to understand the social phenomenon of women leaders' underrepresentation in healthcare sector by unveiling the underlying dynamics among women, healthcare leadership and country's specific societal culture. Taking into account that the healthcare sector constitutes one of the biggest employers worldwide and is populated mainly by women, ${ }^{36}$ researchers sought to explore the dominant factors, such as culturally imbued norms, affecting women in this setting; roles and values assumed by healthcare leaders reflecting external influences such as education, family, community and peers are also considered. ${ }^{43}$ The aim of this study is to assess empirically the gendered barriers encountered by women leaders in healthcare through country's sociocultural specificity.

\subsection{SUBJECTS AND METHODS}

The researchers undertook a small exploratory, qualitative study using semi-structured interviews ${ }^{44}$ to "put people in the context of their lives and the lives of those around them". ${ }^{45}$ The research question addressed was "What are the barriers and their importance in shaping women's leadership in Greek and Maltese healthcare settings?" Authors set out to critically evaluate and contextualize the empirical findings to gain in-depth understanding of the relationship between the barriers identified as hindering the advancement of women leaders in healthcare within the country-specific sociocultural and economic contexts. ${ }^{46}$

\section{Ethical approval}

Ethical approval was obtained from the ethics committees of the Maastricht University (No. METC 16-4-266; January 19, 2017), the National and Kapodistrian University of Athens (Medical School) (February 3, 2017) and the University of Malta (March 10, 2017). 


\subsubsection{Study design}

The study used a non-experimental, descriptive design. Thirty-six semi-structured interviews were conducted with the healthcare leaders in Greece and Malta. Gender balance was achieved in the purposive sampling of interviewees from the academic, clinical and medical groups to ensure the best possible inclusive insights with regards to the research question posed (Figure I).

Figure I | study design - interviewees.

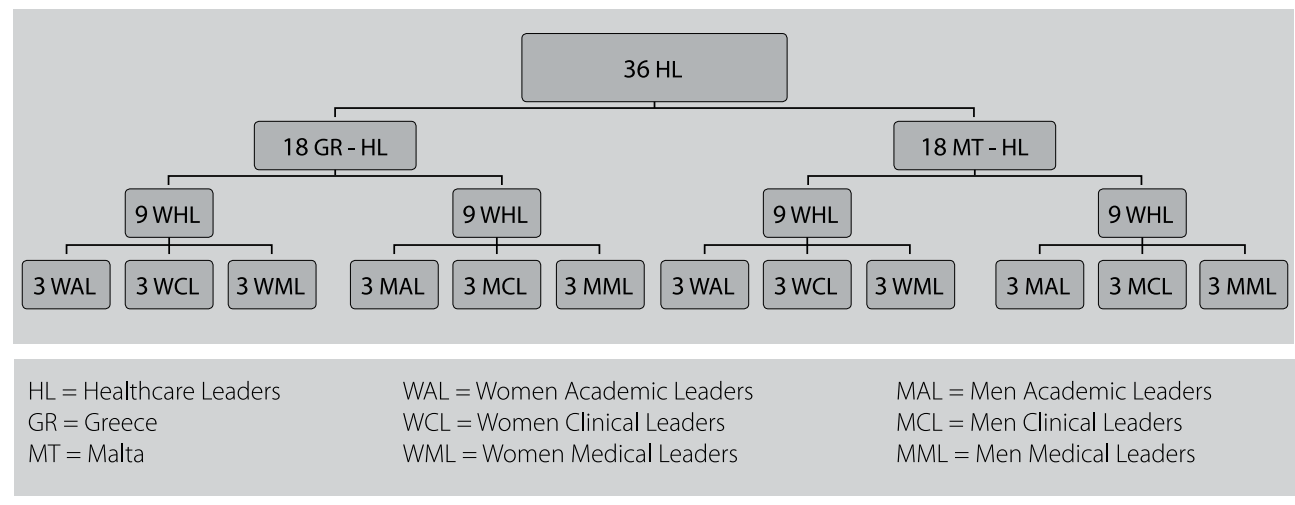

Abbreviations: $G R$, Greece; $H L$, healthcare leaders; MAL, men academic leaders; $M C L$, men clinical leaders; $M M L$, men medical leaders; MT, Malta; WAL, women academic leaders; WCL, women clinical leaders; WML, women medical leaders.

\subsubsection{Participant recruitment}

Geographically defined urban areas were conveniently selected in Greece for the needs of sample selection: Athens, Thessaloniki, Patra and Heraklion for Greece. National sampling was performed in Malta. A number of eligible organizations/ agencies operating in the district were identified, representing the academic, clinical and medical facets (eg, medical schools, hospitals, medical associations) in the healthcare sector. Academic leaders included trained medical practitioners at the level of full professor. Clinical leaders included trained medical practitioners holding the position of chief executive officer or board member or a clinical directorship in a public or private hospital. Medical leaders included trained medical practitioners presiding over a professional organization and/ or holding top leading positions in health ministry, health or medical organizations..$^{45}$ Purposeful and snowball sampling were used to identify participants in the research team members' networks in each country, rippling outward to wider networks of linked colleagues and agencies. Three men and three women were selected per facet and per country, namely, 18 participants per country and 36 participants in total (Figure 1). The purposeful sampling of 18 participants per country provided variation in the facets and participants in this study. The number was sufficient to reach thematic saturation. ${ }^{45,47}$ 


\subsubsection{Research procedures}

Potential interviewees were approached by phone or email; all participants agreed to participate and were interviewed with no subsequent dropouts. Greek leaders were interviewed between March 2017 and October 2017; Maltese leaders were inter- viewed between June 2017 and August 2017. Interviewees were free to choose between a face-to-face interview, with their office as the interview setting, and a telephone interview. In both cases, both interviewee and researcher confirmed that nobody else was present during interviewing. Interviews were recorded with the interviewee's consent, except for two Greek interviewees who asked researcher SK to take field notes by hand. Interviewees were asked if they wished to confirm transcription output, but they declined due to time constraints. Transcription output was reviewed by two members of the research team (MP and SB). Interviews were conducted in Greek for Greek native interviewees and translated into English by a third party, and in English for Maltese interviewees since English is an official language in Malta. Researchers SK, EP and MP checked the translated Greek texts separately to increase the reliability of the data. ${ }^{48}$

Prior to the interview, participants were informed orally and in writing about the study objectives, methods and data protection, and granted their consent including signing an informed consent form. Two experienced members of the research team (SK and LC) carried out the semi-structured interviews; inter- views lasted from 20 to 50 minutes. The interview questionnaire focused on the nature of encountered barriers, on reasoning and potential ways to overcome them (Figure II) and was informed by the output of a previously conducted systematic literature review pertaining to gendered barriers to women's leadership in healthcare ${ }^{49}$ and by dedicated workshops and focus groups. $^{50,51}$

Figure II | The interview questionnaire

Interview questionnaire for the study:
"Exploring barriers to women's leadership in Greek and Maltese healthcare setting"
1. How did you become a professor in medical school / hospital CEO / president of the health body?
2. What is your education level?
3. Please tell us about your experiences in professorship / top level administration / presidency in terms of gender diver-
sity (e.g. easier/tougher as a woman/man, relationship with male/female colleagues, administrators, students, etc.)
4. What barriers/difficulties related to your gender if any have you faced during your carrier advancement?
5. Would you please elaborate further on the nature of the barriers you faced? (probe question)
6. What according to you might have been the reasons of the barriers you faced?
7. How did you feel when confronted with the barriers? How did you deal with them? Have you been offered opportu-
nities during your carrier advancement related to your gender? Why? Why not?
8. Have you had any support while advancing in your career? If so from whom?
9. What are your thoughts about gender diversity in your field?
10. What does gender equality mean to you?
11. What is your advice to younger female professionals who want to make career in the health care field?
12. What is your advice to younger male professionals who want to make career in the health care field?




\subsection{ANALYSES}

Following each interview, interviewers noted initial thoughts and ideas. Field notes and transcribed interviews were read several times by four researchers to gain close immersion in the data. More specifically, a case description was initially drafted for each of the 36 interviews using all data. Then, the process included data coding into meaningful groups using the coding scheme of the Barriers Thematic Map (BTM). ${ }^{49}$ Researchers adopted the BTM coding scheme to contrast the study's findings on the grounds of comprehensiveness and pro- vided prevalence (Figure 3). BTM illustrates a comprehensive list of 26 barriers to women's leadership with varying degrees of prevalence resulting from a systematic literature review with European coverage ranging from 2000 to 2015; the list has also been validated by several experts and focus groups during dedicated workshops. ${ }^{50,51}$ Thereby, the BTM was deemed to offer an educated, context-free (both at country and sector levels), theoretical basis on barriers to women's leadership in healthcare. The prevalence component was considered useful in terms of a comprehensive approach of barriers; it served the objectives of this empirical study by means of providing a comparative tool to explore similarities and differences between researched countries and extrapolate evidence-based conclusions.

Figure III | Characteristics of BTM study vs current study.
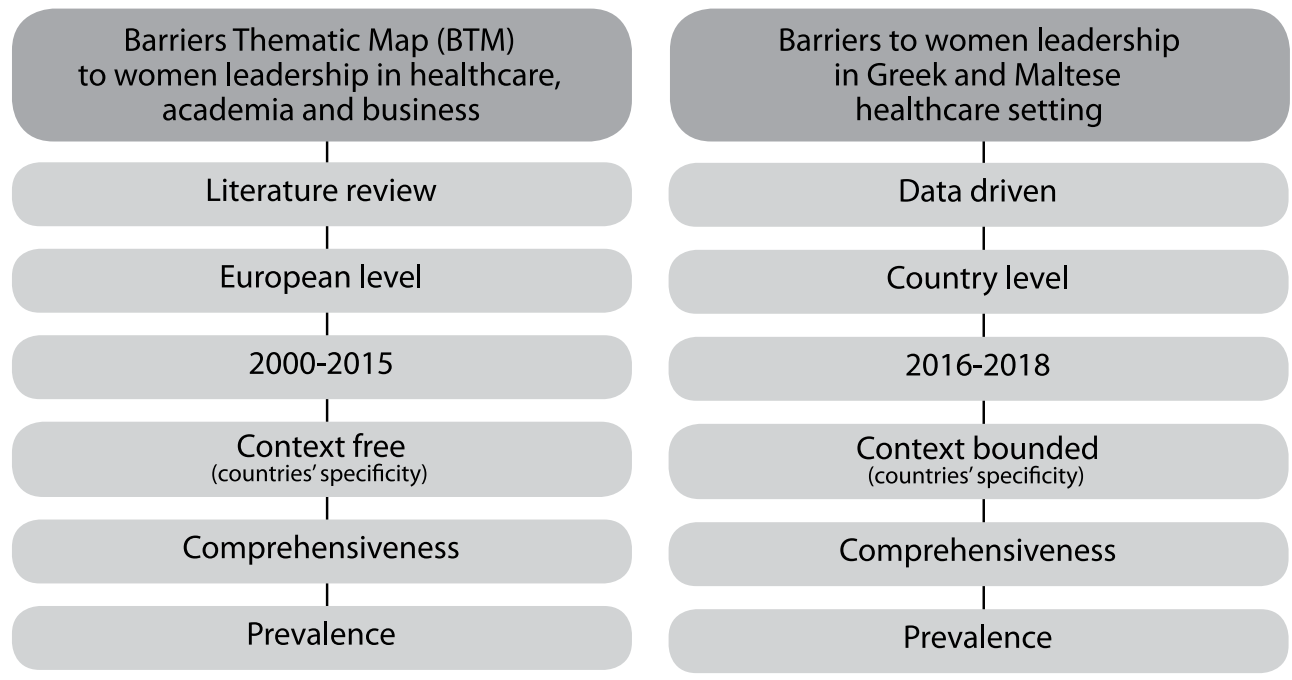

Abbreviation: BTM, Barriers Thematic Map.

Two randomly selected interviews per participant country were piloted for decoding and matching with BTM for the purposes of performing a validity check. The list of different BTM codes was then sorted into potential themes by gendered barriers encountered by healthcare leaders, based on patterns of meaning. ${ }^{52}$ Two experienced qualitative researchers per participant country coded interviews' data independently from the raw data and applied pattern matching technique with BTM (Greece: EP, MP; Malta: NA, LC). 
Data were examined using directed content analysis to identify and analyze themes. ${ }^{53}$ These were further examined to explore the relationship among factors of interest and barriers hindering women leaders' advancement, as well as to gain informed insights on the country-specific interplay and process in shaping social reality. Thus, contextualization was addressed as an important component of theory on barriers constraining women leaders' representation in healthcare. ${ }^{54}$ Summative content analysis was then used to quantify the usage of themes (barriers) ${ }^{55}$ and allow deeper understanding of the contextual use of themes. The qualitative meta-summative method was lastly applied to interpret the content and discover underlying meanings. ${ }^{56,57}$ The analysis strategy applied, strengthened by the different backgrounds of the research team (academics, medical and non-medical, public health specialists), contributed to the study's ecological triangulation58 and supported reliability and validity. ${ }^{48}$ The COnsolidated criteria for REporting Qualitative research checklist was considered regarding study's qualitative research criteria and completed to ensure sound approach in data accuracy and analysis (Table S1).

\subsection{RESULTS}

Twenty and twenty-one barriers to women's leadership were identified from the interview data within Greek and Maltese healthcare settings, respectively (Table I; Figure IV). The barriers were classified into percentage order of the two explored countries to better serve the objectives of data interpretation and elaborate on the research question on countries' specificity in relation to women's underrepresentation in healthcare leadership.

Table I | Barriers to women's leadership in Greek and Maltese healthcare setting (arithmetic presentation)

\begin{tabular}{|l|c|c|}
\hline \multicolumn{1}{|c|}{$\begin{array}{c}\text { Barriers to women's leadership } \\
\text { in healthcare }\end{array}$} & Greece (\%) & Malta (\%) \\
\hline Work/life balance & 17 & 13 \\
\hline Lack of family (spousal) support & 12 & 11 \\
\hline Culture & 4 & 12 \\
\hline Gender gap & 10 & 5 \\
\hline Stereotypes & 5 & 9 \\
\hline Gender bias & 8 & 6 \\
\hline Lack of social support & 6 & 6 \\
\hline Lack of equal career advancement opportunities & 5 & 4 \\
\hline Isolation & 3 & 5 \\
\hline Lack of flexible working environment & 3 & 5 \\
\hline Lack of executive sponsor & 4 & 4 \\
\hline Lack of mentoring & 1 & 4 \\
\hline Lack of networking & 3 & 3 \\
\hline Lack of leadership skills & 3 & 2 \\
\hline
\end{tabular}




\begin{tabular}{|l|c|c|}
\hline \multicolumn{1}{|c|}{$\begin{array}{c}\text { Barriers to women's leadership } \\
\text { in healthcare }\end{array}$} & Greece (\%) & Malta (\%) \\
\hline Gender pay gap & 3 & 1 \\
\hline Sexual harassment & 3 & 0 \\
\hline Lack of confidence & 2 & 3 \\
\hline Lack of role models & 0 & 3 \\
\hline Queen bee syndrome & 2 & 1 \\
\hline Age & 2 & 0 \\
\hline Glass ceiling & 0 & 2 \\
\hline Race discrimination & 0 & 1 \\
\hline Tokenism & 1 & 0 \\
\hline Glass cliff & 0 & 1 \\
\hline Personal health & 0 & 0 \\
\hline Limited succession planning & 0 & 0 \\
\hline
\end{tabular}

Figure IV | Barriers to women's leadership in Greek and Maltese healthcare setting (illustrative presentation).

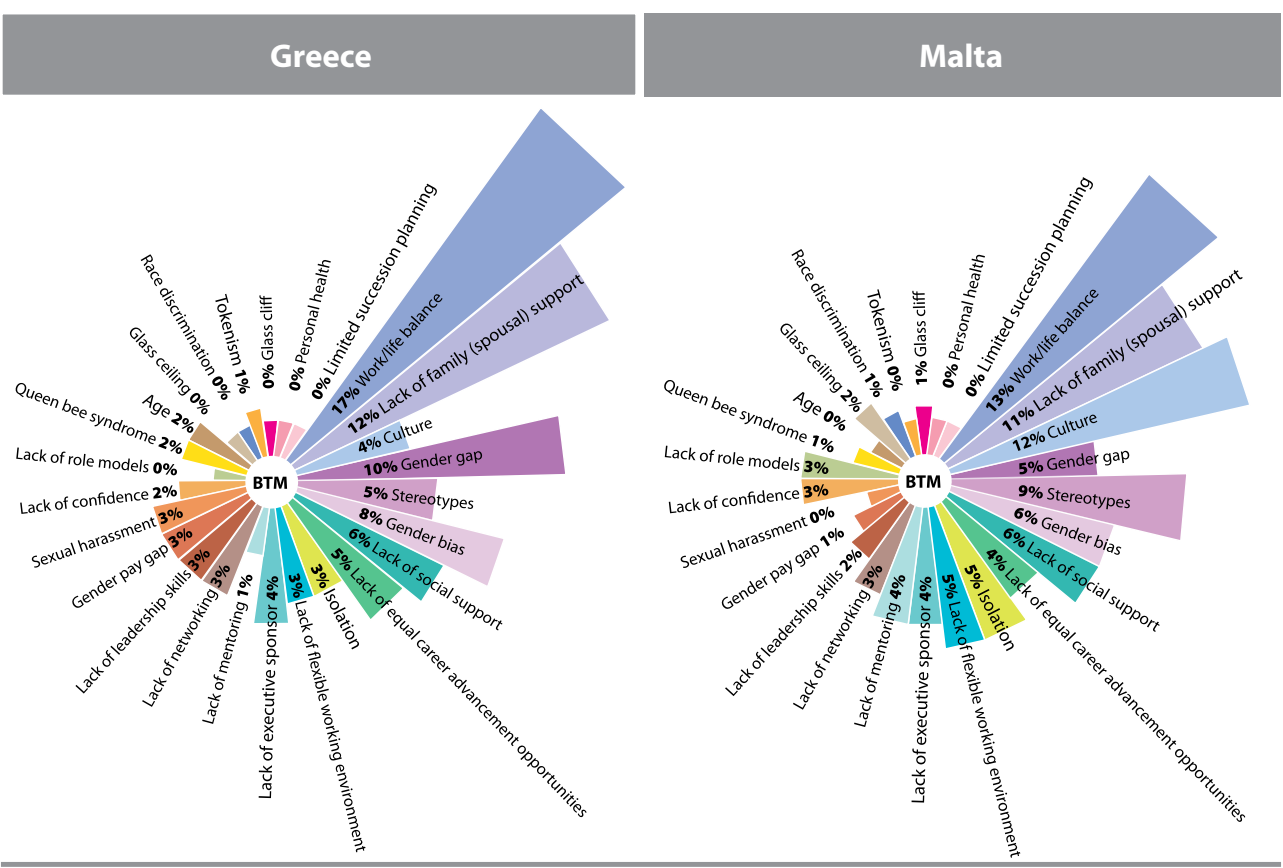

Abbreviation: BTM, Barriers Thematic Map.

The unfolding processes of cultural reality in relation to the social phenomenon being explored presented both commonalities and variations in the prevalence of the barriers identified in the 
Greek and Maltese healthcare settings. To avoid an excessive focus on culturalism, the authors applied the "bounded variability" concept ${ }^{59}$ on the grounds that differences between countries have limits and, therefore, explored contexts were delimited by discussed barriers. The social construction of the concept of barriers was deemed conceptually, contextually and functionally equivalent among male and female Greek and Maltese interviewees, providing a suitable grouping of experiences and perceptions.

Striking similarities and differences in identified barriers and their respective prevalence illustrate the complexity of the web of barriers within each country's sociocultural and economic substance and indicate each country's uniqueness in relation to the phenomenon being explored. Work/life balance (17\%), lack of family (spousal, namely, husband, wife, partner, mate, significant other) support (12\%), gender gap (10\%), gender bias (8\%) and lack of social support (6\%) featured in Greek interviewees' experiences and perceptions across healthcare settings. The top-ranking barriers presented in Malta included work/life balance (13\%), culture (12\%), lack of family (spousal) support (11\%), stereotypes (9\%), gender bias and lack of social support both ranked at $6 \%$. The barriers that were perceived less frequently in both countries were the lack of leadership skills, lack of mentoring and networking, lack of confidence, lack of flexible working environment, the gender pay gap, the queen bee syndrome ("the reluctance of successful females to support other women", p. 50)60 and the lack of equal career opportunities.

\section{Work/life balance}

The difficulties in achieving work/life balance and the costs or sacrifices expected from women pursuing a top-level career in the field were explicitly described using negative overtones by Greek and Maltese healthcare leaders:

Work/life balance is very difficult, almost impossible to be achieved. [WA15] and

Sometimes it does involve making sacrifices and letting go of the work/family balance. [WC8]

or

prioritize my job; ... I chose not to raise a family. [WC7]

or

stepping out of career leading aspirations due to unforeseen family care tasks

I had to re-assess my work/life balance, my priorities, when my mother got sick. [WA1]

However, male counterparts contended:

It depends on the sacrifices a woman is willing to do. [MM24]

or at the best,

... they [women] need to get that delicate compromise. [MM17]

assuming that getting the work/life balance challenge right is an issue firmly related to women, indicating that this is not a burden to be placed on their shoulders.

\section{Lack of family (spousal) support}

Similar gender asymmetries were noticed in addressing the lack of family (spousal) support, such as:

I told my daughter that she was good enough to become a doctor, but her life was going to suffer moving to a country where no family support was available. [MA5] 
or

If you do not have spousal support, you can forget it. [WA3]

and to challenges of power balance between spouses:

My ex-husband was very competitive with me on both a professional and social level; I believe my professional success cost me opportunities in my personal life. [WC19]

or

They [women] are good at their science and on the other hand they have to run their household by themselves. I have seen it in my female colleagues and the young female professors. They face significant difficulties. [MA9]

\section{Culture}

Culture was considered mainly by Maltese interviewees as a structured, well-established, not easy to bend system of shared concepts, beliefs, values and roles59 granting legitimate authority to its actors and defining acceptable boundaries of power and freedom to act. Culturally, authority is not equally attributed to women:

In our Mediterranean culture, men have more of a lust for power, they are after power for the sake of power; women are more consensus seekers, cooperative and very logical, unless you make them your enemy. [MM16]

or

Mediterranean culture is more chauvinistic and has more difficulties with having women in leading positions. [MA6]

unless related to the traditional, socially constructed role of family caregiver:

Women have a more important say at home; there is still this mentality; it is a cultural influence and it is more natural for women to keep with this kind of mentality. [MC12]

Socially legitimized expectations regarding roles, respon- sibilities and claims for women, except for the cases of approving husband, were also highlighted:

My husband helped me a lot; he was not envious of my career. [WM2]

or

A woman has to consider whether she wants to raise a family; for a man does not make a big difference. [MM24] Whereas Greek leaders perceived the systemic influence of culture more flexibly:

In Greece men do not participate significantly in family issues; they participate more than previous years, but still this is not enough. [MA9]

or

It was easier for him (the General Director) to tell off a woman. [WA15]

\section{Stereotypes, gender bias, isolation, gender gap}

In both the Greek and Maltese contexts, a high prevalence (5\% and 9\%, respectively) of stereotypes coupled with gender bias ( $8 \%$ and 6\%), isolation (3\% and 5\%) and gender gap (10\% and 5\%) depict a rather women-unfriendly working environment that denies equal authority on the grounds of deeply rooted power roles:

At the higher echelons of the medical profession there are few women, even though they are very good, of very high standard. The few women I know in leadership positions in medicine are high performers and must be better than their male counterparts. [MM16] 
or

Women have to prove themselves constantly, which is different from men who, once they reach a certain level, are more accepted by fellow men. [WC7]

or

Here it is a male dominated situation in terms of power, [...] even though women are treated as equal to equal in terms of scientific competence. [WA27]

or

Our organization is male dominated; the rules of the game are quite male friendly and women unfriendly. [MM16]

Social and professional exclusion due to stereotypes and bias was articulated explicitly as being one of the major barriers to career advancement:

I avoided joining some lobbies depriving myself of some career opportunities; they were male dominated lobbies, sort of Big Boys' Club; I could not and did not want to cope with their terms. [WC19]

or

Women are in a disadvantaged position. To be honest, we have not yet reached a satisfactory level of women representation. [WM35]

\section{Lack of social support}

The strong positioning of traditional cultural values in the Maltese social reality appears to demarcate the boundaries of expected roles, responsibilities and claims for women and induces social consequences when trespassing these boundaries:

Our culture, our society, enforces a lot of guilt on women coming not only from men, but from women as well. [WA2]

or

So being a woman, a doctor and occupying a top position, is strange, you know; there is so much unjustified jealousy and criticism. [WM15]

On the contrary, Greek society seems to be more concerned about gaining power and social status; the achieved and ascribed status is desirable and sought after:

A woman in Greece coming from a middle or lower social class faces often tough criticism from her social environment should she choose to prioritize her career over her family. [MA1]

or

I may work harder than men just to receive the same recognition. [WM11]

Furthermore, a dysfunctional gap between gained professional recognition and the respective culturally legitimized authority was reported:

Medicine is a science, there is no hierarchy, but this is not always given within social system. [WM23]

Age was proposed by interviewees as a biological barrier holding back women during career stages of critical importance due to its coinciding with pregnancy and child- birth. In fact, both women and men reported that pregnant women or women of reproductive age are considered, even though it should not be allowed, as it is a liability to their organization's performance since:

Pregnancy is not a disease and should not be addressed as such. [WM35]

Furthermore, sexual harassment as a means of power exertion to offer or to pursue career ad- 
vancement (top down to bottom up and vice versa) was reported as a well-known, often unvoiced occurrence limiting opportunities on non- meritocratic grounds.

(Un)conscious biases and stereotypes applied by gate- keepers to prevent women from entering the higher echelons were described as "male-dominated environment" and "Big Boys' Club" (WA2). These were deemed instrumental in retaining highly qualified women leaders in middle management ranks. On the other hand, complying with social expectations and in the absence of supporting structures and flexible working policies, women often opted for more family-friendly specialties. For example, specialties with programmed working hours (e.g., public health, radiology, dermatology) were more likely to be sought by women com- pared to more time-demanding, unprogrammed and stressful specialties (eg, surgery, oncology). This has the effect of limiting career choice. Interviewees widely held that it was the women's choice to pursue a top career over raising a family. Compromising aspirations for career endeavors have also been approached as a culturally driven type of competition between spouses, affecting both genders in terms of social status. ${ }^{62}$ The paradox of the deficit in women leaders in healthcare despite their added value was acknowledged from all interviewees. "Hard workers" (MM22), "problem solvers" (MC18) and "inclusive leaders" (WC31) were the terms used to describe the competences through which women are believed to contribute significantly to organizational performance in contrast to the typical male aggressive leadership style. However, it was commonly accepted that, even though talented women have typically equal access to career advancement opportunities, career-family dilemmas, deeply socially rooted biases and organizational culture and practices reduce their odds for attaining success.

Research findings reflect interviewees' perceptions on the tripartite interactions between gender, healthcare leadership and sociocultural contexts, shedding light on the relationships between the barriers to women's leadership in the Greek and Maltese healthcare context (Table 2). All three groups of interviewees (academic, clinical and medical) presented commonalities with respect to barriers to women's leadership and the role of societal and professional culture. However, deeper exploration of the interviews may uncover critical nuances related to each group's professional context. For example, time constraints in clinical leading roles may manifest differently than in academic roles (urgency vs long hours). Similarly, it may be argued that the power interplay in professional hierarchy roles may also be considered an aggravating factor in generating barriers to women's leadership. Barriers to women's leadership related specifically to healthcare groups or to professional power interplay are of critical importance to better understand the context of gendered challenges in healthcare and merit further exploration. 
Table II | interview excerpts on prevailing barriers to women's leadership in Greek and Maltese healthcare setting

\begin{tabular}{|c|c|c|}
\hline BARRIERS & $\begin{array}{l}\text { INTERVIEW EXCERPTS FROM GREEK } \\
\text { HEALTHCARE LEADERS }\end{array}$ & $\begin{array}{l}\text { INTERVIEW EXCERPTS FROM } \\
\text { MALTESE HEALTHCARELEADERS }\end{array}$ \\
\hline $\begin{array}{l}\text { Work/life } \\
\text { balance }\end{array}$ & $\begin{array}{l}\text { "It depends on the sacrifices a woman is willing to do; what she } \\
\text { wants to prioritize (family or career) and what to leave behind" } \\
\text { (MM24) } \\
\text { "I prioritize my job; being at the hospital almost 24/7; I chose not } \\
\text { to raise a family" (WC7) }\end{array}$ & $\begin{array}{l}\text { "If you want to balance your career aspirations as } \\
\text { a family person, it's tough; especially for women; they } \\
\text { need to get that delicate compromise" (MM17) } \\
\text { "Sometimes it does involve making sacrifices and } \\
\text { letting go of the work-family balance" (WC8) } \\
\text { "I had to re-assess my work-life balance, my priorities } \\
\text { when my mother got sick" (WA1) }\end{array}$ \\
\hline $\begin{array}{l}\text { Lack of family } \\
\text { (espousal) } \\
\text { support }\end{array}$ & $\begin{array}{l}\text { "My ex-husband was very competitive with me on both } \\
\text { a professional and social level; I believe my professional success } \\
\text { cost me opportunities in my personal life" (WC19) } \\
\text { "They [women] are good at their science and on the other hand } \\
\text { they have to run their household by themselves. I have seen } \\
\text { it in my female colleagues and the young female professors. } \\
\text { They face significant difficulties" (MA9) }\end{array}$ & $\begin{array}{l}\text { "My husband helped me a lot; he was not envious } \\
\text { of my career" (WM2) } \\
\text { "I told my daughter that she was good enough } \\
\text { to become a doctor, but her life was going to suffer } \\
\text { moving to a country where no family support was } \\
\text { available" (MA5) } \\
\text { "If you do not have spousal support, you can forget } \\
\text { it" (WA3) }\end{array}$ \\
\hline Gender gap & $\begin{array}{l}\text { "Women are in a disadvantaged position. To be honest, we have } \\
\text { not yet reached a satisfactory level of women representation" } \\
\text { (WM35) }\end{array}$ & $\begin{array}{l}\text { "At the higher echelons of the medical profession } \\
\text { there are few women, even though they are very } \\
\text { good, of very high standard. The few women I know } \\
\text { in leadership positions in medicine are high perform- } \\
\text { ers and must be better than their male counterparts" } \\
\text { (MM16) }\end{array}$ \\
\hline Gender bias & $\begin{array}{l}\text { "I may work harder than men just to receive the same } \\
\text { recognition" (WM11) }\end{array}$ & $\begin{array}{l}\text { "Women have to prove themselves constantly, which } \\
\text { is different from men who, once they reach a certain } \\
\text { level, are more accepted by fellow men" (WC7) }\end{array}$ \\
\hline $\begin{array}{l}\text { Lack of social } \\
\text { support }\end{array}$ & $\begin{array}{l}\text { "A woman in Greece coming from a middle or lower social class } \\
\text { faces often tough criticism from her social environment should } \\
\text { she chooses to prioritize her career over her family" (MA1) } \\
\text { "Medicine is a science, there is no hierarchy, but this is not } \\
\text { always given within social system" (WM23) }\end{array}$ & $\begin{array}{l}\text { "Our culture, our society, enforces a lot of guilt } \\
\text { on women coming not only from men, but from } \\
\text { women as well" (WA2) } \\
\text { "So being a woman, a doctor and occupying } \\
\text { a top position, is strange, you know; there is so much } \\
\text { unjustified jealousy and criticism" (WM15) }\end{array}$ \\
\hline Stereotypes & $\begin{array}{l}\text { "Here it is a male dominated situation in terms of power, ..... } \\
\text { even though women are treated as equal to equal in terms } \\
\text { of scientific competence" (WA27) } \\
\text { "I avoided joining some lobbies depriving myself of some } \\
\text { career opportunities; they were male dominated lobbies, sort } \\
\text { of Big Boys' Club; I could not and did not want to cope with } \\
\text { their terms" (WC19) }\end{array}$ & $\begin{array}{l}\text { "Our organization is male dominated; the rules of the } \\
\text { game are quite male friendly and women unfriendly" } \\
\text { (MM16) } \\
\text { "Our faculty is still a male dominated environment, } \\
\text { a Big Boys' Club; if you look at the committees, they } \\
\text { do not have a woman member" (WA2) }\end{array}$ \\
\hline Culture & $\begin{array}{l}\text { "A woman has to consider whether she want to raise a family; } \\
\text { for a man does not make a big difference" (MM24) }\end{array}$ & $\begin{array}{l}\text { "Women have a more important say at home; there } \\
\text { is still this mentality; it is a cultural influence and } \\
\text { it is more natural for women to keep with this kind } \\
\text { of mentality" (MC12) } \\
\text { "In our Mediterranean culture, men have more of } \\
\text { a lust for power, they are after power for the sake of } \\
\text { power; women are more consensus seekers, cooper- } \\
\text { ative and very logical, unless you make them your } \\
\text { enemy" (MM16) }\end{array}$ \\
\hline & $\begin{array}{l}\text { "In Greece men do not participate significantly in family issues; } \\
\text { they participate more than previous years, but still this is not } \\
\text { enough" (MA9) }\end{array}$ & $\begin{array}{l}\text { "Mediterranean culture is more chauvinistic and has } \\
\text { more difficulties with having women in leading } \\
\text { positions" (MA6) }\end{array}$ \\
\hline
\end{tabular}




\section{DISCUSSION}

This study empirically appraised the "regimes of truth"6 with regards to gendered barriers and culturally legitimate societal power and authority in the Greek and Maltese healthcare sector. The similarities and differences explored through a country's sociocultural lens highlighted the need to address a common challenge comprehensively within a contextually bound frame. This would contribute to evidence-based research, facilitating the development of evidence-informed policy in this field.

Previously published research on barriers to women's leadership in healthcare was mainly approached at the sec- tor or practice level. For example, Newman et al ${ }^{39,63}$ discuss several gendered constraints in pre-service and in-service education and employment systems hindering gender equality and diversity in health workforce research, leadership and governance. Similarly, Kuhlmann et al ${ }^{64,65}$ consider challenges in terms of leadership at all levels of management and organizational performance. Bismark et $\mathrm{l}^{47}$ identified and interpreted a range of barriers across medical leadership roles through the perceptions of capability, capacity and credibility. Schuh et al66 reported sociocultural constraints lowering power motivation to aspiring women leaders and, thus, mediating the link between gender and leadership role imbalances. Toh and Leonardelli67 related cultural constraints to women leaders'advancement with the degree of cultural tightness, namely, the strength of norms and social sanctions embedded in society's egalitarian practices.

Building upon the available literature on women's leadership in healthcare and on cultural pressures on women leaders, this study discusses the relationship between the pervasiveness of gendered barriers, leadership in healthcare and country's sociocultural specificities. The plethora of barriers (20 for Greece and 21 for Malta) with striking differences in the reported frequency corroborates essential sociocultural features of EU-Med countries. Taking into account that the conceptualization and operationalization of barriers were consistent across interviewees and that leadership is largely shaped by dynamic relationships between context, gender and culture,68 it may be deduced that gender asymmetries in terms of power and authority are socially and culturally defined within a country's context.

Cultural expressions include the ability to gain compliance and recognition, the distinction between power and culturally legitimate authority, ${ }^{9}$ as indicated by the:

I may work harder than men just to receive the same recognition. [WM1 1]

comment. Yet, generalization may be dangerous and lead to misunderstandings and prejudices1 unless subculture context, such as the healthcare profession, is taken into consideration. Paraphrasing Parsons, ${ }^{69}$ it may be argued that anything so general as gender asymmetries may be the result of a canvas of different factors deeply involved in the foundations of society, the qualities of which are sociocultural dependent.

In alignment, the Maltese approach that:

"Men have more of a lust for power, they are after power for the sake of power; women are more consensus seekers, cooperative and very logical". [MM16]

contrasting with the Greek: 
"It was easier for him (the General Director) to tell off a woman". [WA15] manifests the gradation of cultural effects' strength on gender, power and authority relationship within countries' healthcare sociocultural contexts; the cultural stiffness Maltese society experiences to overcome deeply rooted perceptions is well evidenced also by the yielded prevalence on "culture" (Malta: 12\%, Greece: 4\%).

Following Durkheim, ${ }^{11}$ that the structure and quality of social relationships in terms of private life influence modes of thinking and cultural interaction, it may be suggested that gender-ascribed roles and responsibilities have been institutionalized and culturally legitimized in both countries. Work/life balance and lack of family (spousal) support scored high in Greek (17\%, 12\%) and Maltese $(13 \%, 11 \%)$ settings underpinned with particular socioeconomic features; for example, Greek women were observed to opt for lower and less-rewarding but economically safer positions to secure support for their families due to the economic crisis in Greece; in contrast, the Maltese women were found to opt for part-time or lower level jobs aligning with the ascribed sociocultural obligation to prioritize family tasks over career. However, even in Sweden, widely considered to be a socially progressive country which may lend itself to work/life studies standing out in its statutory requirements in the field, culture and cultural differences are considered more important factors than legal measures toward achieving balance between personal and professional life. ${ }^{70}$ Hence, it may be argued that culture's tightness expressed in norms and legitimizations may strengthen deeply established practices, resulting in less power and authority for women, thus leading to women's leadership deficit. ${ }^{67}$ Hence, persisting underrepresentation of women leaders may be approached by addressing the tight control societal culture exerts over its subdivisions and their constituents. In line with this, Fox et $\mathrm{al}^{71}$ noted that the hierarchical gender stratification of careers is being seconded by informal gender classifications in the society. This was also reported by an interviewee:

"Medicine is a science, there is no hierarchy, but this is not always given within social system". [WM23] Nonetheless, health professions are still held in high regard socially. ${ }^{72}$ However, even though culture should be considered a mix of constant influences, the boundaries among societies are vague.1 It may be claimed that in explored sector, societal culture is experienced by some as a resisting barrier to professional advancement and subsequent social change and by others as an alibi for not leaving a personal comfort zone. For example, women's leadership is perceived positively by Maltese male leaders, but still they settle with the family-related constraints imposed to women by local culture. Similarly, Greek male leaders recognize the systemic influence of culture in family-related issues and the small steps made toward change; yet, they acknowledge the long way to go to achieve an acceptable balance in family/work responsibilities. It may be argued that the analogy applies for the men's perceptions of women's leadership; all male interviewees acknowledged the leadership potential of their female counterparts, both at scientific and output levels; they also accepted that the barriers encountered by women in acquiring leading positions are many and complicated and, oftentimes, societal and professional cultures do not provide the required authorization to society members to function differently. The paradox of women's leadership challenges lies on the observation that women perceive the barriers hindering their career advancement the same way as men do. Despite potential underlying professional power struggles, which may happen in any professional interaction and among all genders, all 
interviewees' perceptions recognized the impact of societal culture on women's leadership. The observed cultural tightness seems to moderate the degree to which egalitarian practices may be receptive by social dividends to accept, implement and sustain such changes. However, healthcare professions being in high social regard, their potential to serve as a catalyst to social and cultural transformation, to challenge established norms and values and offer role models to social settings should not be underestimated. Considering the multiple social identities, a person bears and the societal impact that they may generate, it may be argued that healthcare leaders should be reckoned as a critical component in an agenda for positive social change.

The present study illuminated the discursive dynamics among gender, professional leadership and societal culture shaping mechanisms that influence social behavior and women's professional choices. Gendered barriers to health- care leadership within country's sociocultural contexts may be better addressed by taking into consideration the evidence of the barriers within country's specificity that adversely impact women's leadership opportunities. Further research on the impact of these tripartite interactions across cultures is very much needed.

\subsection{IMPLICATIONS}

People grow and change within the realm of their relation- ships. ${ }^{73}$ Acker ${ }^{74}$ described the dynamics produced from interactions of gender, hierarchy and sociocultural setting as "inequality regimes", embodying perceptions on authority, power, leadership and more. Bringing change requires challenging traditional, culturally rooted views and values which are influenced in an untraceable, constant and time- less way. Rather than put forward a single causal proposal to empower change, authors propose a tripartite conceptual framework which links a country's sociocultural contexts with comprehensive data on gendered barriers harvested from the healthcare sector (Figure V).

Figure V | Conceptual framework to address gendered barriers to healthcare leadership within country's sociocultural contexts.

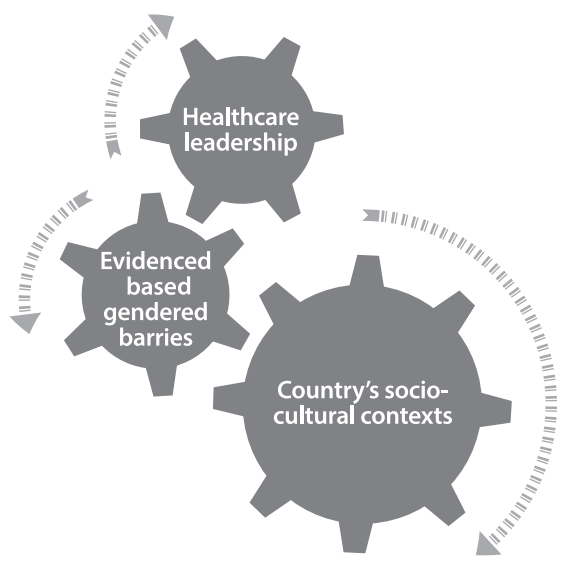


Addressing the durability and transferability of gendered barriers within sector and country contexts, a reality check may be provided via barriers' detailed mapping and prevalence through country-specific lenses, such as socioeconomic and cultural contexts. Policies to equalize career opportunities may suffer from blind spots; for example, policy measures may address a lack of flexible working environments that give flexible work schedules to young parents, leaving though untouched sexual harassment challenges or the needs for leadership, mentoring and inclusion training programs. Thereby, mapping and evaluating the barriers and their prevalence may provide a "snapshot" to gendered challenges in organizations and support meaningful, progressive practices eschewing resources' waste in fragmentary, fashionable interventions. For example, application of an easy-to-use online toolkit providing anonymously data on barriers to women's leadership advancement in healthcare organizations may offer a reliable basis to assess existing gendered policies and practices. Nonetheless, further research is recommended to assess required gendered organizational policy changes and expected benefits for both healthcare organizations and society.

Prior research asserts culture has been the "wooden leg" of policies, ${ }^{75}$ overriding statutory efforts at change. Policymakers may be better informed by a comprehensive, evidenced-based approach responsive to country's socio- cultural specificity and may develop policies and practices resonating to actual gendered needs and gaps. In that line, society and its subdivisions may experience a more effective and smooth transition toward desirable social balance and equality within work and social contexts.

\subsection{LIMITATIONS}

The authors acknowledge the study's limitations resulting from the constraints posed by the finite time and resources for this research. Convenience and snowballing sampling may be considered a limitation as the lack of random selection does not ensure representativeness. For example, the lack of interviewees residing in rural areas may have missed an important and different perspective. However, the interviewees' diverse origins and accumulated experiences provided a rich source of data on which to base meaningful analysis. The directed content approach to the analysis also has some inherent limitations in terms of researchers sticking to existing theory and not recognizing potential contextual aspects of the researched phenomena that may limit the applicability of such theory. ${ }^{53}$ To address these limitations and achieve neutrality or confirmability of trustworthiness, research team members, except SK and KC, examined those theme definitions before the team undertook the study.

The "coding down" approach to theme development intro- duces a limitation in terms of potential narrowing perceived notions from interview content. However, published literature offered the researchers the possibility to make inferences from new data.

Regarding language limitations on the translation of the interviews' content, translators' expertise 
in the subject area may not have been adequate to translate subtle nuances expressed by the interviewees.

The interviewees might have been susceptible toward study's topic since their participation has been related to their work area. The Hawthorne effect and reporting bias76 may have occurred in interviewees'responses due to their leading position. Still the study is considered to have made an empirical contribution to the literature on discursive dynamics on barriers to women's professional advancement through the country-specific cultural lens.

Nuances on potential similarities and differences on perceptions about barriers among explored healthcare groups (academic, clinical and medical) have not been discussed in detail as they are not within the scope of this study. Similarly, gendered professional hierarchies and the underlying power interplay, such as doctor-nurse and/or midwife, have not been deeply elaborated. The authors acknowledge the contribution of such findings in the field of women's leadership in healthcare; to this end, the research team proposes to further explore the professional power interplay through the lens of gender in healthcare.

The transferability of the study findings across regional and international contexts may be limited. Expansion of the study to include neighboring countries in the region would add to the trustworthiness of the findings. The study would also benefit from further exploration of additional factors such as employment contract variations in public/private sectors, subsectors' particularities and implications from migratory pressure.

\subsection{CONCLUSION}

The study explored the gendered barriers to women's leadership in healthcare through a country-specific approach. Findings unveiled underlying interactions among gender, leadership and country's sociocultural contexts, which may elucidate the varying degrees of strength of norms and barriers embedded in society's egalitarian practices. Cultural tightness can act as an alibi or barrier against sociocultural transformation. A conceptual framework is proposed to address evidence-based research in the field and inform policymakers in developing sector- and country-specific policies for advancing women's leadership in healthcare.

\section{Author contributions}

SK and KC were involved in the conception and design of the study. SK and LC conducted the interviews. SK and EP checked the translated Greek texts. KC, SB, EP and MP were involved in the extraction of themes and the pattern matching technique. All authors contributed to data analysis, drafting and revising the article, gave final approval of the version to be published, and agree to be accountable for all aspects of the work. 


\section{Disclosure}

The authors report no conflicts of interest in this work.

\section{REFERENCES}

1. Helman CG. Culture, Health and IIIness. London: CRC Press; 2007.

2. Leach ER. Social Anthropology. New York, USA: Oxford University Press; 1982.

3. Shields SA. Gender: an intersectionality perspective. Sex Roles. 2008;59(5-6):301-311.

4. Collins PH. Black Feminist Thought: Knowledge, Consciousness, and the Politics of Empowerment. 2nd ed. New York, NY: Routledge; 2000.

5. Maurice M. Méthode comparative et analyse sociétale: les implications théoriques des comparaisons internationales [Comparative method and societal analysis. The theoretical implications of international comparisons]. Sociol Trav. 1989;31(2):175-191.

6. Foucault M. The Foucault Effect: Studies in Governmentality. Chicago, USA University of Chicago Press; 1991.

7. Hayward CR. D-facing power. Polity. 1998;31(1):1-22.

8. Eagly AH, Chin JL. Diversity and leadership in a changing world. Am Psychol. 2010;65(3):216-224.

9. Rosaldo MZ. Woman, culture, and society: a theoretical overview. In: Woman Culture, and Society. Stanford, CA, USA: Stanford University Press: 1974;21.

10. Durkheim E. Über soziale Arbeitsteilung. Studie über die Organisation höherer Gesellschaften ["Social Division of Labor, Study on the Organization of Higher Societies"] Frankfurt: Suhrkamp. 1988;2.

11. Mestrovic S. Durkheim and Postmodern Culture. New York, USA: Routledge; 2017.

12. Azzopardi-Muscat N, Buttigieg S, Calleja N, Merkur S. Malta: health system review. Health Syst Transit. 2017;19(1):1137.

13. Economou C, Kaitelidou D, Karanikolos M, Maresso A. Greece: health system review. Health Syst Transit. 2017;19(5):1192.

14. United Nations Interregional Crime and Justice Research Institute. The impact of the crisis on gender equality and women's wellbeing in the European Union Mediterranean countries. Available from: http://www. unicri.it/infocus/ on/vawreport. Accessed: June 3,2018.

15. European Institute for Gender Equality (EIGE). Gender Equality Index; 2017. Available from: https://eige.europa.eu/ gender-equality- index/2015/. Accessed: March 14,2018.

16. European Commission. Labor Market and Entrepreneurship. Overcoming Gender Stereotypes. Country Report for Malta. Available from: http:// www.afaemme.org/projects/closed/labour-market-and-entrepreneurship- overcominggender-stereotypes. Accessed: February 2, 2018.

17. World Economic Forum. The Global Gender Gap Report; 2017. Avail- able from: https://www.weforum.org/reports/ the-global-gender-gap- report-2017. Accessed: May 13, 2018.

18. Mckee M, Stuckler D. Health effects of the financial crisis: lessons from Greece. Lancet Public Health. 2016;1 (2):e40e41.

19. Moustakas C. Phenomenological Research Methods. New York, NY: Sage Publications; 1994.

20. Mossialos E, Allin S, Davaki K. Analysing the Greek health system: a tale of fragmentation and inertia. Health Econ. 2005;14(Suppl 1):S151-S168.

21. Economou C, Kaitelidou D, Kentikelenis A, Sissouras A, Maresso A. The impact of the financial crisis on the health system and health in Greece. In: Economic Crisis, Health Systems and Health in Europe: Country Experience. Copenhagen,Denmark:WHO/European Observatory on Health Systems and Policies; 2014.

22. Vlachadis N, Kornarou E. Increase in stillbirths in Greece is linked to the economic crisis. BMJ. 2013;346:f1061.

23. Stuckler D, Basu S, Suhrcke M, Coutts A, Mckee M. The public health effect of economic crises and alternative policy responses in Europe: an empirical analysis. Lancet. 2009;374(9686):315-323.

24. European Parliament. The policy in gender equality in Greece. Available from: http://www.europarl.europa.eu/ RegData/etudes/note/join/2013/493028/IPOL-FEMM_NT(2013)493028_EN.pdf. Accessed: March 3, 2018. 
25. Karamessini M. Labour market impact of four recessions on women and men in Greece: comparative analysis in a long-term perspective. Soc Cohes Dev. 2010;7(2):93-104.

26. Cholezas I, Tsakloglou P. Gender earnings differentials in the Greek labour market. Economic Policy Studies. 2006. Greek.

27. Friedl E. The position of women: appearance and reality. Anthropol Q. 1967;40(3):97-108.

28. Georgas J. Changing family values in Greece: from collectivist to individualist. J Cross Cult Psychol. 1989;20(1):80-91.

29. Karamessini M, loakimoglou E. Wage determination and the gender pay gap: a feminist political economy analysis and decomposition. Fem Econ. 2007;13(1):31-66.

30. Kalikadien M. Pathways \& Policies to Tackle the Under-representation of Women in Academic Leadership in Malta. A Case Study on the Perspectives of Female Academic Leaders in Malta's Health Sector [dissertation on MSc Public Policy and Human Development]. Maastricht: Maastricht University; 2014.

31. Scicluna A. Maltese Women: Health, Care and Work 1850s-1900s [master's thesis]. Msida: University of Malta; 2013.

32. Cusens S. The Role of Women in World War Il: the Case of Malta [master's thesis]. Msida: University of Malta; 2014.

33. Abela A, Frosh S, Dowling E. Uncovering beliefs embedded in the culture and its implications for practice: the case of Maltese married couples. J Fam Ther. 2005;27(1):3-23.

34. Camilleri P.The Rise and Rise of the Female Graduate: Some milestones in tertiary education for women in Malta. University ofMalta Annual Report. 2006. Available from: https://www.um.edu.mt/data/assets/pdf_file/0003/88941/ theriseandrise.pdf. Accessed: October 12,2018.

35. Hantrais L, Mangen S. editors. Cross-National Research Methodology and Practice. London: Routledge; 2013.

36. OECD. Gender equality. Available from: http://www.oecd.org/gender/ data/women-make-up-most-of-the-healthsector-workers-but-they-are- under-represented-in-high-skilled-jobs.htm. Accessed: September 27, 2018.

37. Human Resources for Health. Global Resource Center. Resource spotlight: gender and health workforce statistics. Available from: http://www.hrhresourcecenter.org/gender_stats. Accessed March 10, 2017.

38. Lerch-Pieper N, Brander S, Valarino I, Zurbriggen C, Maurer E, Herr W. Challenging the "leaky pipeline" in faculties of medicine. Available from: https://smw.ch/en/op-eds/post/challenging-the-leaky-pipeline-in- faculties-ofmedicine/. Accessed: June 30, 2018.

39. Newman C, Chama PK, Mugisha M, Matsiko CW, Oketcho V. Reasons behind current gender imbalances in senior global health roles and the practice and policy changes that can catalyze organizational change. Glob Health Epidemiol Genom. 2017;2:e19.

40. Czabanowska K, Domagała A, Kalaitzi S, et al. Exploring the added value of women health care managers in Poland. Mater Sociomed. 2017;29(4):280-285.

41. Downs JA, Mathad JS, Reif LK, et al. The ripple effect: why promoting female leadership in global health matters. Public Health Action. 2016;6(4):210-211.

42. World Health Organization. Gender, Equity and Human Rights. Geneva: World Health Organization. Available from: http://www.who.int/gender-equity-rights/understanding/gender-definition/en/.Accessed on November 2, 2018.

43. Lammers CJ, Hickson DJ. Are organizations culture-bound? In: Organizations Alike and Unlike. London: Routledge and Kegan Paul; 1979:402-403.

44. Guba EG, Lincoln YS. Competing paradigms in qualitative research. In: Handbook of Qualitative Research. Thousand Oaks, CA, US: Sage Publications, Inc.; 1994;2(163-194):105.

45. Seidman I. Interviewing as Qualitative Research: a Guide for Researchers in Education and the Social Sciences. New York, USA: Teachers College Press; 2013.

46. Ravitch SM, Carl NM. Qualitative Research:Bridging the Conceptual, Theoretical, and Methodological. Thousand Oaks, CA, US: Sage Publications, Inc.; 2015.

47. Bismark M, Morris J, Thomas L, Loh E, Phelps G, Dickinson H. Reasons and remedies for under-representation of women in medical leadership roles: a qualitative study from Australia. BMJ Open. 2015;5(11):e009384.

48. Lincoln YS, Guba EG. Naturalistic Inquiry. Thousand Oaks, CA, US: Sage Publications, Inc.; 1985;75.

49. Kalaitzi S, Czabanowska K, Fowler-Davis S, Brand H. Women leader- ship barriers in healthcare, academia and business. Equality, Diversity and Inclusion: An International Journal. 2017;36(5):457-474.

50. World Health Organization. Strengthening Women's Leadership in Public Health in Ukraine. Geneva: World Health Organization. Available from: http://www.euro.who.int/en/countries/ukraine/news/news/2017/05/strengtheningwomens-leadership-in-public-health-in-ukraine. Accessed March 15, 2018.

51. Kalaitzi S, Czabanowska K. Women's leadership in healthcare - the three-faceted quest. Eur J Public Health. 2016;26(Suppl 1): ckw166-018.

52. Patton MQ. Qualitative Evaluation and Research Methods. Thousand Oaks, CA, US: Sage Publications, Inc.; 1990. 
53. Hsieh HF, Shannon SE. Three approaches to qualitative content analysis. Qual Health Res. 2005;15(9):1277-1288.

54. Mayring P. Qualitative content analysis: theoretical background and procedures. In: Approaches to Qualitative Research in Mathematics Education. Dordrecht: Springer; 2015:365-380.

55. PotterWJ, Levine-Donnerstein D. Rethinking validity and reliability in content analysis. J App/ Commun Res. 1999.

56. Morgan DL. Qualitative content analysis: a guide to paths not taken. Qual Health Res. 1993;3(1):112-121.

57. Sandelowski M, Barroso J, Voils Cl. Using qualitative metasummary to synthesize qualitative and quantitative descriptive findings. Res Nurs Health. 2007;30(1):99-111.

58. Barnett-Page E, Thomas J. Methods for the synthesis of qualitative research: a critical review. BMCMed Res Methodol. 2009;9(1):59.

59. Rose R, Mackenzie WJM. Comparing forms of comparative analysis. Polit Stud (Oxf). 1991;39(3):446-462.

60. Ellemers N. Women at work how organizational features impact career development. Policy Insights Behav Brain Sci. 2014;1(1):46-54.

61. Keesing RM, Strathern A. Fieldwork. Cultural Anthropology: a Con- temporary Perspective. Fort Worth: Harcourt Brace College Publishers; 1998.

62. Ely RJ, Ibarra H, Kolb DM. Taking gender into account: theory and design for women's leadership development programs. Acad Manag Learn Educ. 2011;10(3):474-493.

63. Newman C, Pacqué-Margolis S, Frymus D. Integration of gender-transformative interventions into health professional education reform for the 21 st century: implications of an expert review. Hum Resour Health. 2016:14:14.

64. Kuhlmann E, Batenburg R, Dussault G. Health workforce governance in Europe: where are we going? Health Policy. 2015;119(12): 1515-1516.

65. Kuhlmann E, Ovseiko PV, Kurmeyer C, et al. Closing the gender leadership gap: a multi-centre cross-country comparison of women in management and leadership in academic health centres in the European Union. Hum Resour Health. 2017;15(1):2.

66. Schuh SC, Hernandez Bark AS, van Quaquebeke N, et al. Gender differences in leadership role occupancy: the mediating role of power motivation. J Bus Ethics. 2014;120(3):363-379.

67. Toh SM, Leonardelli GJ. Cultural constraints on the emergence of women as leaders. J World Bus. 2012;47(4):604611.

68. Klenke K. Women and Leadership:A Contextual Perspective. NewYork, NY, USA: Springer Publishing Company; 2004.

69. Parsons T. Evolutionary universals in society. Am Soc Rev. 1964;29(3):339-357.

70. Lane C. Work - life in Sweden. Executive briefing series. Center for Work \& Family. Boston College. Available from: https:// www.bc.edu/content/dam/files/centers/cwf/research/publications3/executivebrief-ingseries-2/ExecutiveBriefing_ Work-LifeinSweden.pdf. Accessed: September 17, 2018.

71. Fox MF, Whittington K, Linkova M. Gender, (in) equity, and the scientific workforce. In: Handbook of Science and Technology Studies. Cambridge: Mass MIT Press; 2017.

72. Riska E. Medical Careers and Feminist Agendas. American, Scandinavian and Russian Women Physicians, New York: Adline De Gruyter; 2001.

73. Holloway I. Qualitative Research in Health Care. Berkshire, England: McGraw-Hill Education; 2005.

74. Acker J. Inequality regimes: gender, class, and race in organizations. Gend Soc. 2006;20(4):441-464.

75. Allard K, Haas L, Hwang CP.Family-supportive organizational culture and fathers'experiences of work-family conflict in Sweden. GendWork Organ. 2011;18(2):141-157.

76. Bowling A. Research Methods in Health: Investigating Health and Health Services. Berkshire, England: McGraw-Hill Education; 2014. 


\section{Supplementary material}

Table S1 | COREQ checklist" for Kalaitzi et al (2019) "Women, healthcare leadership and societal culture - a qualitative study"

\begin{tabular}{|c|c|c|c|}
\hline TOPIC & $\begin{array}{l}\text { ITEM } \\
\text { NO. }\end{array}$ & GUIDE QUESTIONS/ DESCRIPTION & REPORTED ON PAGE NO. \\
\hline \multicolumn{4}{|c|}{ Domain 1: Research team and reflexivity } \\
\hline \multicolumn{4}{|l|}{ Personal characteristics } \\
\hline interviewer/facilitator & 1 & $\begin{array}{l}\text { Which author/s conducted the interview } \\
\text { or focus group? }\end{array}$ & SK/KC (p. 11) \\
\hline credentials & 2 & $\begin{array}{l}\text { What were the researcher's credentials? } \\
\text { For example, PhD, MD }\end{array}$ & $\mathrm{PhDc} / \mathrm{PhD}$ \\
\hline Occupation & 3 & $\begin{array}{l}\text { What was their occupation at the time of } \\
\text { the study? }\end{array}$ & Doctoral student/researcher \\
\hline gender & 4 & Was the researcher male or female? & Female(s) \\
\hline experience and training & 5 & $\begin{array}{l}\text { What experience or training did the } \\
\text { researcher have? }\end{array}$ & Official/field training \\
\hline \multicolumn{4}{|l|}{ Relationship with participants } \\
\hline relationship established & 6 & $\begin{array}{l}\text { Was a relationship established prior to } \\
\text { study commencement? }\end{array}$ & No \\
\hline $\begin{array}{l}\text { Participant knowledge of } \\
\text { the interviewer }\end{array}$ & 7 & $\begin{array}{l}\text { What did the participants know about the } \\
\text { researcher? For example, personal goals, } \\
\text { reasons for doing the research }\end{array}$ & $\begin{array}{l}\text { Participants were informed about } \\
\text { the reasons of this research ( } p .11)\end{array}$ \\
\hline interviewer characteristics & 8 & $\begin{array}{l}\text { What characteristics were reported about } \\
\text { the interviewer/ facilitator? For example, } \\
\text { bias, assumptions, reasons and interests in } \\
\text { the research topic }\end{array}$ & $\begin{array}{l}\text { interests (research, paper } \\
\text { publication) (p. 11) }\end{array}$ \\
\hline \multicolumn{4}{|l|}{ Domain 2: Study design } \\
\hline \multicolumn{4}{|l|}{ Theoretical framework } \\
\hline $\begin{array}{l}\text { Methodological orienta- } \\
\text { tion and theory }\end{array}$ & 9 & $\begin{array}{l}\text { What methodological orientation was } \\
\text { stated to underpin the study? } \\
\text { For example, grounded theory, discourse } \\
\text { analysis, ethnography, phenomenology, } \\
\text { content analysis }\end{array}$ & Directed content analysis (p. 13) \\
\hline \multicolumn{4}{|l|}{ Participant selection } \\
\hline sampling & 10 & $\begin{array}{l}\text { How were participants selected? } \\
\text { For example, purposive, convenience, } \\
\text { consecutive, snowball }\end{array}$ & Purposeful and snowball (p. 10) \\
\hline Method of approach & 11 & $\begin{array}{l}\text { How were participants approached? } \\
\text { For example, face-to-face, telephone, } \\
\text { mail, email }\end{array}$ & email, telephone (p. 10) \\
\hline sample size & 12 & How many participants were in the study? & $36(p .10)$ \\
\hline non-participation & 13 & $\begin{array}{l}\text { How many people refused to participate } \\
\text { or dropped out? reasons? }\end{array}$ & Two due to time constraints \\
\hline \multicolumn{4}{|l|}{ Setting } \\
\hline setting of data collection & 14 & $\begin{array}{l}\text { Where was the data collected? For exam- } \\
\text { ple, home, clinic, workplace }\end{array}$ & Workplace (p. 11) \\
\hline
\end{tabular}




\begin{tabular}{|c|c|c|c|}
\hline $\begin{array}{l}\text { Presence of non-partic- } \\
\text { ipants }\end{array}$ & 15 & $\begin{array}{l}\text { Was anyone else present besides the } \\
\text { participants and researchers? }\end{array}$ & No (p. 11) \\
\hline Description of sample & 16 & $\begin{array}{l}\text { What are the important characteristics of } \\
\text { the sample? For example, demographic } \\
\text { data, date }\end{array}$ & $\begin{array}{l}\text { Highly educated, healthcare } \\
\text { professionals (p. 10) }\end{array}$ \\
\hline \multicolumn{4}{|l|}{ Data collection } \\
\hline interview guide & 17 & $\begin{array}{l}\text { Were questions, prompts, guides provided } \\
\text { by the authors? } \\
\text { Was it pilot tested? }\end{array}$ & $\begin{array}{l}\text { Questions, prompts; tested with } \\
\text { focus groups }(p .11,13)\end{array}$ \\
\hline $\begin{array}{l}\text { repeat interviews audio/ } \\
\text { visual recording }\end{array}$ & $\begin{array}{l}18 \\
19\end{array}$ & $\begin{array}{l}\text { Were repeat interviews carried out? } \\
\text { if yes, how many? } \\
\text { Did the research use audio or visual } \\
\text { recording to collect the data? }\end{array}$ & $\begin{array}{l}\text { No } \\
\text { Audio (p. 11) }\end{array}$ \\
\hline Field notes & 20 & $\begin{array}{l}\text { Were field notes made during and/or after } \\
\text { the interview or focus group? }\end{array}$ & Yes (p. 11) \\
\hline Duration & 21 & $\begin{array}{l}\text { What was the duration of the interviews } \\
\text { or focus group? }\end{array}$ & 20-50 minutes (p. 11) \\
\hline Data saturation & 22 & Was data saturation discussed? & Yes (p. 10, 13) \\
\hline Transcripts returned & 23 & $\begin{array}{l}\text { Were transcripts returned to participants } \\
\text { for comment and/or correction? }\end{array}$ & $\begin{array}{l}\text { Yes, but declined due to time } \\
\text { constraints (p. 11) }\end{array}$ \\
\hline \multicolumn{4}{|c|}{ Domain 3: analysis and findings } \\
\hline \multicolumn{4}{|l|}{ Data analysis } \\
\hline number of data coders & 24 & How many data coders coded the data? & 4 (р. 13) \\
\hline $\begin{array}{l}\text { Description of the coding } \\
\text { tree }\end{array}$ & 25 & $\begin{array}{l}\text { Did authors provide a description of the } \\
\text { coding tree? }\end{array}$ & Yes (p. 12) \\
\hline Derivation of themes & 26 & $\begin{array}{l}\text { Were themes identified in advance or } \\
\text { derived from the data? }\end{array}$ & in advance (p. 12) \\
\hline software & 27 & $\begin{array}{l}\text { What software, if applicable, was used to } \\
\text { manage the data? }\end{array}$ & N/A \\
\hline Participant checking & 28 & $\begin{array}{l}\text { Did participants provide feedback on the } \\
\text { findings? }\end{array}$ & No \\
\hline \multicolumn{4}{|l|}{ Reporting } \\
\hline Quotations presented & 29 & $\begin{array}{l}\text { Were participant quotations presented to } \\
\text { illustrate the themes/findings? } \\
\text { Was each quotation identified? For exam- } \\
\text { ple, participant number }\end{array}$ & Yes (pp. 16-22, 25-27) \\
\hline $\begin{array}{l}\text { Data and findings } \\
\text { consistent }\end{array}$ & 30 & $\begin{array}{l}\text { Was there consistency between the data } \\
\text { presented and the findings? }\end{array}$ & Yes (pp. 14-15) \\
\hline clarity of major themes & 31 & $\begin{array}{l}\text { Were major themes clearly presented in } \\
\text { the findings? }\end{array}$ & Yes (pp. 15-21) \\
\hline clarity of minor themes & 32 & $\begin{array}{l}\text { is there a description of diverse cases or } \\
\text { discussion of minor themes? }\end{array}$ & Yes (pp. 21-22) \\
\hline
\end{tabular}




\section{Table S1 | (Continued)}

\begin{tabular}{|l|l|l|l|}
\hline \multicolumn{1}{|l|}{ TOPIC } & $\begin{array}{l}\text { ITEM } \\
\text { NO. }\end{array}$ & GUIDE QUESTIONS/ DESCRIPTION & REPORTED ON PAGE NO. \\
\hline Derivation of themes & 26 & $\begin{array}{l}\text { Were themes identified in advance or } \\
\text { derived from the data? }\end{array}$ & in advance (p. 12) \\
\hline software & 27 & $\begin{array}{l}\text { What software, if applicable, was used to } \\
\text { manage the data? }\end{array}$ & N/A \\
\hline Participant checking & 28 & $\begin{array}{l}\text { Did participants provide feedback on the } \\
\text { findings? }\end{array}$ & No \\
\hline Reporting & 29 & $\begin{array}{l}\text { Were participant quotations presented to } \\
\text { illustrate the themes/findings? } \\
\text { Was each quotation identified? For }\end{array}$ & Yes (pp. 16-22, 25-27) \\
\hline Quotations presented & example, participant number & \\
\hline $\begin{array}{l}\text { Data and findings } \\
\text { consistent }\end{array}$ & 30 & $\begin{array}{l}\text { Was there consistency between the data } \\
\text { presented and the findings? }\end{array}$ & Yes (pp. 14-15) \\
\hline clarity of major themes & 31 & $\begin{array}{l}\text { Were major themes clearly presented in } \\
\text { the findings? }\end{array}$ & Yes (pp. 15-21) \\
\hline clarity of minor themes & 32 & $\begin{array}{l}\text { is there a description of diverse cases or } \\
\text { discussion of minor themes? }\end{array}$ & Yes (pp. 21-22) \\
\hline
\end{tabular}

Note: Developed from: by permission of Oxford University Press. ${ }^{1}$

Abbreviation: COREQ, COnsolidated criteria for REporting Qualitative research.

\section{REFERENCE}

1. Tong A, Sainsbury P,Craig J. Consolidated criteria for reporting qualitative research (COREQ): a 32-item checklist for interviews and focus groups. Int J Qual Health Care. 2007;19(6):349-357. 




\section{Chapter}

\section{The sustainable development thinking in gender equality policy in EU: misplaced priorities and unmet challenges}

\section{Based on:}

The sustainable development thinking in gender equality policy in EU: misplaced priorities and unmet challenges

Kalaitzi S, Czabanowska K, Petelos E, Brand H. 



\section{ABSTRACT}

The European Union Sustainable Development Goals (EU SDGs) Indicator set monitoring progress towards SDGs was recently published, including specific indicators for SDG5 on gender equality and empowerment of all women and girls. Gender inequalities are reported persistent and uneven across Member States; hence, the translation of SDG5 into national achievable targets seems to remain at a preliminary stage. This paper seeks to better understand the prioritization of social policy objectives to actual social reality across Member States through the EU SDG 5 perspective. It also seeks to identify potential gaps for improving informed social policy decisions. The study argues that the policy efforts towards meeting EU SDG5 indicators may have misplaced priorities by overlooking persisting and contextualized gendered challenges holding back essential progress on social policies across EU. The authors advocate EU's proactive leadership to optimize support to Member States in developing gender sensitive, evidence-informed social policies. The study is undertaken within the theoretical framework of interpretative discursive analysis of gender equality policy in EU placing the EU SDG5 themes and indicators in the EU gender equality policy continuum. The undertaken qualitative analysis of a wealth of empirical data in this paper, constitutes a concrete contribution to the discussion for effective translation of EU-SDG5 into Member States' gender policies; it also adds to the dialogue for a more than ever needed social cohesion and justice across the European Union. 



\subsection{INTRODUCTION}

The European Union (EU) has a strong track record of commitment to sustainable development in the European Treaties, expressed by policies on economic development, social cohesion and democratic societies (European Commission, 2018). The Treaty of Lisbon stipulates that the EU "shall combat social exclusion and discrimination and shall promote social justice and protection, equality between women and men" (Art 2, para 2), "shall work for the sustainable development of Europe" (Art 2, para 3) and will respect "the principles of the United Nations Charter" (Art 2, para 5) (EUR-lex, 2019a). Therefore, it is no surprise that the EU assumed an early champion role in designing the United Nations (UN) 2030 Agenda for Sustainable Development Goals (SDGs) and embraced the SDGs as the roadmap for its sustainable future (United Nations, 2015).

In line with the approach of Frans Timmermans, the first Vice-President of European Commission, "you cannot manage what you don't measure" (Kloke-Lesch, 2018, p. 147) Eurostat developed the EU SDGs Indicator set to monitor progress towards SDGs across all EU policies and initiatives; preference was given to indicators measuring impacts and outcomes of EU policy towards implementation of UN SDGs - 2030 Agenda (Eurostat, 2017). The evidence based monitoring of the progress aimed to guide, amongst others, the course of action and social priorities towards achieving the sustainable development for the citizens of Member States.

Turning to SDG5 (Achieve gender equality and empower all women and girls), the recently announced moderate and uneven progress indicates that translating EU-SDG5 into national achievable targets across Member States seems to have a considerable distance to cover (Eurostat, 2017). For example, although women's representation in national parliaments and in senior management positions has increased, it remains significantly low in the labour market; similarly, the gender gap has been widening in tertiary educational attainment and in the employment rate of recent graduates, caring activities have increased resulting to inactivity and the gender pay gap remained almost unchanged. The evidence based findings of the monitoring report on SDGs progress across EU point to the need for adoption of sound policies and strategies to eliminate gender discrimination and foster women's empowerment in all societal spheres.

Scholars and gender equality experts have voiced criticism on the effectiveness of the adopted EU gender mainstreaming strategy to meet the pursued policy objectives. Jacquot (2010) contends that the gender mainstreaming strategy is inadequate to address a broader spectrum of discrimination, whereas Cullen (2014) decries the developed weak conjunctions of the implemented strategy with anti-discriminatory policies and the lost direct connection with social policy. In that spirit, Krizsan and Lombardo (2013) question the quality of the policies developed within the framework of gender mainstreaming strategy in terms of the missing element of contextuality; more specifically, the absence of the context-sensitive empirical findings on implemented policies, which are considered key quality criteria to analyze policy decisions, define 
success indicators and provide meaningful orientation, was held responsible for the weak relevance to targeted gendered challenges across Member States and for the subsequent ineffective policies. Similarly, Verloo (2007) argued that the shift of power relations between different actors in gender equality arena across Member States resulted in setting diversified priorities in gender equality policy agenda. For example, in Spain, austerity politics promoted a neoliberal agenda of public budget cuts and changes in welfare policies; these coupled with deregulation of the labour market and the privatization of public services affected mainly family policies (Celis et al, 2013). In Poland, austerity measures led to the privatization of care and, therefore, shifted the burden to families, namely to women assuming the caregiver tasks; Finland experienced similar recoils in social policies (Elomaki \& Kantola, 2017). In Greece, women's progress towards gender equality in paid work bounced back through "better" integration in employment under financial crisis, whereas the public cuts affected significantly the welfare state and mainly women at all ages and professional ranks (Karamessini, 2014). Thereby, the neoliberal shifts on governance across EU had disproportionate gender consequences across Members States ranging from varied deregulation of the labour market to fostering exclusionary processes (Walby, 2004; Scharff, 2016). Hence, the recently identified theoretical and empirical gaps on contextualized and diverse gender inequalities unveiled the need to update gender-related knowledge, which would relate better to the need for change within the social reality across Member States (Gutsche, 2018; Verloo \& Paternotte, 2018).

This paper seeks to explore the knowledge gap on the relevance of the themes and indicators of EU SDG5 Indicator set to gendered challenges faced by the citizens of Member States. Taking into consideration the suboptimal progress towards achieving gender equality objectives, this study aims to better understand, interpret and evaluate the relevance of EU SDG5 themes and indicators and the prioritization of policy objectives to actual social reality across Member States. It also seeks to identify potential gaps for improving informed policy decisions. The study argues that the creditable policy efforts towards meeting EU-SDG5 indicators may have misplaced priorities by overlooking persisting and contextualized gendered challenges which may hold back social change and progress towards inclusive sustainable development across Member States. The authors advocate EU's proactive leadership underpinned by academia and civil society contributions to optimize support to Member States in developing gender sensitive, evidence-informed policies. The study is undertaken within the theoretical framework of interpretative discursive analysis of gender equality policy in EU placing the EU SDG5 themes and indicators in the EU gender equality policy continuum; by providing a qualitative analysis of a wealth of empirical data, the paper makes a contribution to the discussion for effective translation of EU-SDG5 into Member States' gender policies.

\subsection{METHODS}

The authors undertook a qualitative study applying a multi methods approach (Guba and 
Lincoln, 1994). The aim was to provide a comprehensive overview of existing evidence, critically evaluate the findings and gain deeper understanding of the explored research questions "What is the relevance of the themes and indicators of EU SDG5 Indicator set to gendered challenges faced by Member States' citizens? Do the adopted themes and indicators reflect the prioritization of gendered challenges faced by the citizens of Member States? Do the adopted themes and indicators reflect potential emerging gendered challenges faced by the citizens of Member States? What are the policy frameworks to achieve EU SDG5 objectives? What are the potential gaps in policy agenda to better address gendered challenges at Member States level?"

In the first place the study applied a protocol for the data search and mapping supported by the systematic mapping (SM) method. The SM is a methodology providing a structure of the type of research terms and results by categorizing them and shaping a coarse-grained summary, a map (Petersen et al, 2008). The SM has been used in social sciences to reliably index evidence on the researched topic, provide descriptive information and identify potential knowledge gaps useful for research and policy makers (McKinnon et al, 2015). In this paper, the SM of EU SDG5 was undertaken to provide a structured map of the embedded themes, indicators and policy frameworks in order to address aptly and critically the above-mentioned research questions. The systematic mapping of EU SDG5 Indicator set 2017 (Eurostat, 2017) was applied as follows:

Figure I | The systematic mapping process steps

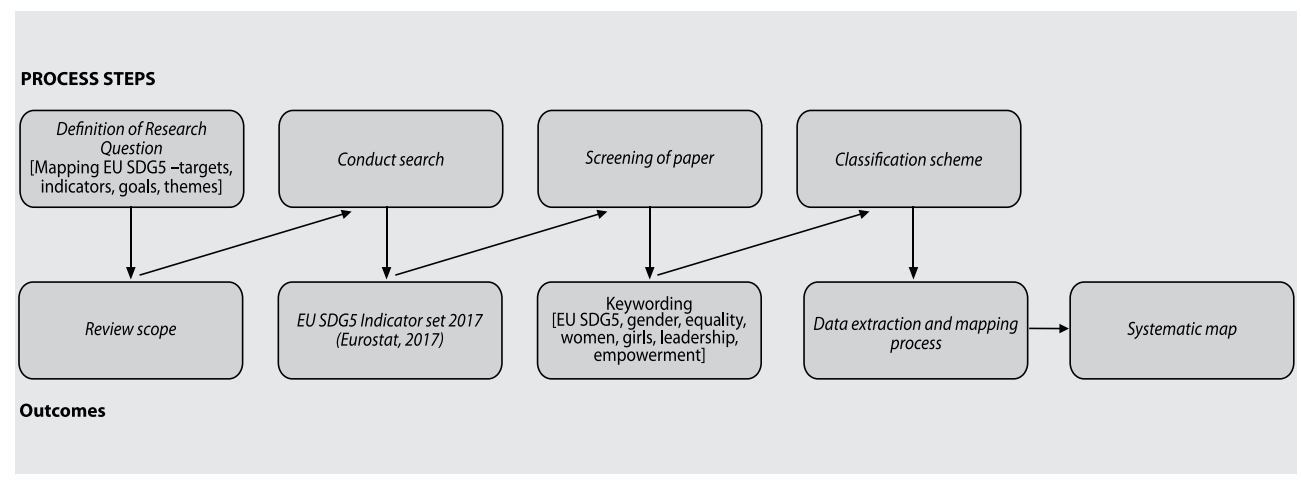

Adapted by Petersen et al (2007)

Secondly, a qualitative analysis was followed using the interpretative discursive approach offering a theoretical understanding of the researched subject as a starting point and then reflect on the data through this lens (Willig et al, 2017). Locating the qualitative methodology to discursive interpretation approach provides also a clear path as to what is of more interest to the analysis and what may be the specific research questions to drive the analysis forward; it also contributes 
in disclosing the discursive nature of contemporary social change by analyzing, understanding and explaining the relationship between complex past processes, current hegemonic narratives and interpretative discursive approaches (Chouliaraki and Fairclough, 1999; Wodak \& Mayer, 2009).

In that vein, the authors embarked on an interpretative discursive analysis of the research findings to gain understanding of the relevance of the EU SDG5 themes, indicators and policy frameworks to actual social reality in Member States and critically reflect on potential gaps in priorities setting of the respective policy objectives. This approach offers also the theoretical framework to comprehend the adopted policy prism at the time, to sharpen the way of looking at gender equality policy objectives and to detect potential asymmetries between policy discourse and prioritization of the gendered challenges (Mahoney, 2012; Lombardo \& Meier, 2016). However, the authors acknowledge that interpretative discursive perspectives on EU gender policies and their evaluation is an emerging field in scholarship (Bacchi, 2005).

Arguably, the gradual and transformative change in EU gender equality policy is depicted in changes of objectives, priorities, ways of operating and thinking, although the mechanisms of these changes are based on continuity (Streeck and Thelen, 2005). Setting off with the Treaty of Rome, the EU enshrined the equal treatment principle with the main policy objective being to enhance women's participation to the labour market [(Art. 141, 1957) Art. 157 TFEU) EUR-lex, 2019b]. With the entry into force of the Treaty of Amsterdam (1997), the EU assumed competence to fight gender discrimination aiming to equalize opportunities for women and men [19(1) TFEU) EUR-lex, 2019c]. In 2009 the Treaty of Lisbon [Art 3(3) TEU] consolidated the obligation of ensuring gender equality for both the Union and the Member States; the policy agenda assumed the obligation to gender mainstreaming which was built around multiple pillars, such as combining law, funding for positive action programs and integrating equality in all policy areas within EU and Member States (Jacquot, 2015). Thus, the previously developed triangle of social, economic and employment gender policy was merged into one gender strategy embedding all gender equality policy objectives to better serve a growing competitive, knowledge driven economy (Cavaghan, 2017). In 2015 the EU committed to fully integrate SDG5 in EU policy elabourating thus a global affirmation of core European values and stating its capacity as a global player, bending though the EU gender equality policy objectives to fit under the concept of EU's future sustainability (EC, 2018).

\subsection{RESULTS}

Gender equality themes and indicators in EU SDG5 have been systematically mapped with data extracted from the EU SDG Indicator set (Eurostat, 2017). The EU elaboration on SDG5 towards achieving gender equality and empowerment of all women and girls is presented mapped against the themes and indicators in Table I. 
Table I | Themes and indicators of the EU elaboration on SDG5 to achieve gender equality and empower all women and girls

\begin{tabular}{|c|c|}
\hline THEMES & INDICATORS \\
\hline \multirow[t]{2}{*}{ Leadership positions } & Positions held by women in senior management \\
\hline & Seats held by women in national parliaments and governments \\
\hline $\begin{array}{l}\text { Gender-based } \\
\text { violence }\end{array}$ & $\begin{array}{l}\text { Physical and sexual violence to women experienced within } 12 \\
\text { months prior to the interview }\end{array}$ \\
\hline Employment & $\begin{array}{l}\text { Gender employment gap } \\
\text { Gender pay gap in unadjusted form } \\
\text { Inactive population due to caring responsibilities }\end{array}$ \\
\hline Education & $\begin{array}{l}\text { The gender gap for tertiary education attainment } \\
\text { The gender gap for early leavers from education } \\
\text { The gender gap for employed recent graduates }\end{array}$ \\
\hline
\end{tabular}

Multi-purpose indicators, namely indicators used to monitor more than one SDG, such as "early leavers from education and training" (SDG4), "employment rate of recent graduates" (SDG4) are reported in the EU SDG indicator set. Although acknowledging that gender emerges as a crosscutting theme and permeates several goals, such as SDG2 (food security and nutrition), SDG3 (health services and care), SDG4 (education), SDG8 (economic growth and development), SDG14 (community conservation and preservation of bio-diversity), SDG13 (climate change) and SDG16 (peacebuilding), it is beyond the scope of this study to explore the gender intersection of SDGs and therefore they are not included in the present mapping (Eurostat, 2017).

The EU current policy frameworks linked to reported SDG5 themes, "leadership positions", "genderbased violence", "employment", "education" and related indicators are also depicted in EU SDG Indicator Set (Eurostat, 2017) and mapped as follows in Table II:

Table II | EU SDG5 (Gender equality and empower all women and girls) - Themes and indicators against policy frameworks

\begin{tabular}{|l|l|}
\hline THEMES & POLICY FRAMEWORK \\
\hline Leadership positions & social policy under employment policy \\
\hline Gender-based violence & social policy under employment policy \\
\hline Employment & legislative framework \\
\hline Education & employment policy \\
\hline
\end{tabular}


The adopted policy frameworks aiming to support implementation of EU SDG5 relate mainly to employment policy fitting under the bigger EU social policy umbrella. The legislative framework resonates only to "physical and sexual violence to women" touching upon only the violation of human rights and criminalization of relevant actions (Eurostat, 2017, p. 16). It has to be underlined though that SDGs are not legally binding instruments hence, the presented policy frameworks have only informative capacity and can function only as guiding instruments, with the responsibility to assume action for implementation placed mainly on national stakeholders and policy actors (Eurostat, 2017).

\subsection{DISCUSSION}

The sustainable development thinking in European gender equality policy seems to fall short both in terms of the translation of EU SDG5 into national achievable targets and in terms of accurately reflecting gendered challenges and priorities at Member State level. Build upon evidence harvested from Member States' bodies, the progress is reported moderate and uneven (Eurostat, 2017). The laudable but limited endeavor to adopt SDG5 in the EU setting may have not taken into account the diverse socio-economic context across Member States neither the component of varying gendered challenges faced by the citizens of Member States.

In the absence of SDG5 targets and indicators set for and by Member States, the progress of EU gender equality agenda as depicted by EU SDG Indicators set manifests big differences. For example, the gender employment gap ranged by a considerable 25,8 percentage points across Member States with three countries, Malta, Italy and Greece reporting widening of the gender employment gap in the past five years, whereas Lithuania, Finland, Sweden and France maintained quite low percentages (data yielded as of 2016) (Eurostat, 2017; pp. 113). On the contrary, the percentages of physical or sexual violence to women are scaled high for Sweden, France, Netherlands, and Finland, but medium for Greece, Italy and Lithuania, and low for Malta, Spain and Slovenia (data yielded as of 2012) (Eurostat, 2017; pp. 115). Furthermore, the anti-discrimination approach to gender inequalities across EU received emphasis on equal pay in Nordic countries but on policies against gender violence in Central and Eastern European countries (Kantola \& Nousiainen, 2012; Krizsan \& Lombardo, 2013). Similarly, Romania and Bulgaria, both countries transiting from communism to pluralism, interpreted EU gender equality policy framework differently within their national contexts; Romania suffered from compliance, awareness and confidence gap in gender policy making (Massino \& Popa, 2015), whereas Bulgaria experienced inconsistent direction in developing gender sensitive policies, although backed up considerably by women activists (Stoilova, 2015). Thereby, although the EU SDG indicator set aimed to monitor progress and steer a process of convergence between Member States to achieve quantifiable progress, the reported themes and policy frameworks appear to touch delicately upon difficulties encountered at Member State level (Eurostat, 2017). The high degree of heterogeneity of the challenges, and the magnitude and scope thereof, including the means of implementation, reveal the long remaining distance to bridge for Member States, the discrepancy in translating the SDG5 into national goals and, of course, 
the unmet expectations of European citizens (EP, 2019). The impact of gendered challenges faced by each Member State alone may have been overlooked or drawn suboptimal political attention towards achieving SDG5.

\section{Misplaced priorities}

Policy reasoning and arguments is a process of creating, changing and defending boundaries (Stone, 1997). Authors acknowledge the broadened perimeter of EU gender equality policy and the efforts to align with SDG5 and additional related goals, such as SDG3 (health services and care), SDG4 (education), SDG8 (economic growth and development), SDG13 (climate change), SDG14 (community conservation and preservation of bio-diversity) and SDG16 (peacebuilding), under the sustainable development perspective (Eurostat, 2017). However, the broadened and cross-cutting boundaries of the deployed gender equality policy agenda may be appraised as an inherent weakness bearing the inevitable calculated risks of diluted policy objectives and potential misplaced priorities. Although accredited any progress made, the relevance and prioritization of elaborated EU gender equality policy objectives are profoundly questioned. The long-standing burden of gender inequalities and the emergence of new challenges, which manifest themselves differently and affect diversely Member States, may raise a red flag pointing to the need for an updated discourse on policy objectives setting. The recent EU economic and budgetary crisis offers a typical example of progressive marginalization and deconstruction of gender equality policy objectives which manifested at various levels and depth within the national austerity contexts (Karamessini and Rubery, 2014; Cavaghan, 2017). For example, in some countries the impact of the consolidation measures was mild; in others, there was a considerable backlash in employment, social transfers, and services broadening backwards the gender disparities and affecting previous effective gender equality structures (Lyberaki et al, 2013). Furthermore, the majority of the countries had not implemented gender-sensitive policy planning and implementation over the crisis neither had assessed the consolidation measures from a gender perspective. It is estimated that only onetenth of the policy initiatives took into account gender aspects at all policy process stages (Lyberaki et al, 2013). As such, 102 policy initiatives have been announced or implemented in response to the crisis in EU28, but only 9,8\% of them embedded a gender aspect at all policy process stages (Lyberaki et al, 2013; Table 7.1, p. 205). In sum, gender equality policy objectives in the EU have not been framed as part of mitigating efforts against the economic crisis that swept over Europe; instead, they were rather consumed and became part of the problem (Klatzer and Schlager, 2014). Furthermore, the significant spillover effects produced by poor performance of one or several Member States, potentially undermined the efforts of other Member States to achieve gender equality; these implications may have also not been discussed in an effective and responsive way in gender equality policy agenda setting at EU level (Crepaidi et al, 2015).

The depth and breadth of EU gender equality policy objectives bent to fit into the SDG5 agenda may not embrace fully all aspects of internal challenges faced by each Member State alone, such as the uneven impact of structural weaknesses of the EU - Member States economy and the emerging opposition to gender equality policymaking. For instance, several events such as demonstrations against the Istanbul Convention (Council of Europe, 2019), the restricted sexual 
and bodily autonomy, the growing gender-based violence (European Parliament, 2019) or the intensified political polarizations enhanced by electoral victories of antifeminist political parties and the subsequent reduction of political room for civil society may lead to a negative impact on setting the policy agenda. Furthermore, the increasing oppositional trends may open up further avenues for opposition and compromise any implementation effort of gender equality initiatives (Patternotte \& Kuhar, 2018; Cavaghan, 2017). In this context, the opposition to gender equality policies has become more visible at national level involving several governmental and civic society actors and mechanisms [Verloo (ed), 2018]. The pressure exerted by those forces against gender equality policies may compromise fundamental gender equality principles which link systematically gender at all political domains and at all policies and, thus, trigger a backslash to gender equality policy continuum in EU (Jacquot, 2015; Beveridge et al, 2000). As current political attention has been mainly focused on other issues, such as austerity and migration crisis management at EU level, there is a widening policy gap in covering the distance between the enshrined gender equality principle and the reality experienced differently at national context across Member States.

\section{Unmet challenges}

The significant divergence in scope and ambition between Member States in translating SDG5 agenda into national goals and objectives, including prioritization and implementation, is of critical essence provided that responsibility for the implementation of sustainable development agenda basically lies with Member States. However, TFEU Art 19 (EUR-lex, 2019d), TEU Art 2, 3(1), 3(3) and Art 9 (EUR-lex, 2019e) stipulate clearly the competence and responsibility of the EU to work towards prevailing equality between women and men, respect of non-discrimination and observation of the equality principle in EU citizens. Thereby, the EU assumed the leading role to supplement rigorously Member States' efforts to develop and adapt accordingly national strategies and policies towards eliminating inequalities, and matching sustainable development thinking at both Member States and EU level. Potential lack of gender expertise, cognitive competencies in daily processes of knowledge construction within EU and national policy actors may be key barriers in bridging gender rhetoric with practice and therefore to promote effectively and bring about transformative change (Cavaghan, 2017). The provided EU toolkits towards achieving gender equality objectives, such as GEAR (Gender Equality in Academic and Research Institutions), GIA (Gender Impact Assessment) (EIGE, 2018), support the promotion and implementation of the EU's gender mainstreaming strategy; however, the absence of clear mandates, motivational instruments, tangible customized targets, and accountability elements may invite a blurred approach and foster inertia. Available policy instruments, such as budgetary, funding, educational and legal means, may be better channeled on a needs assessment basis to Member States and counterbalance the EU leadership deficit at a policy making and implementation level.

The new roadmap of EU gendered policies aims to tackle the social construction of gender inequalities and the multiplicity of discriminations. However, any difficulties to integrate guidelines and operationalize gender equality principle may be addressed more effectively taking a customized orientation in addressing challenges at Member State level. Concrete policy objectives and guiding principles around priority areas and actions, continuous monitoring and evaluation mechanisms 
of progress made at national level may enhance the policy relevance and provide clear orientation to setting priorities in addressing challenges faced by Member States' citizens. Clearly, the sound metrics and data to track progress and ensure accountability may underpin good governance to achieve targeted goals (Sachs et al, 2016). Furthermore, benchmarking progress against that of peers may also help to extend understanding of reasons for differential performance, to fine-tune policies, strategies and practices and produce genuine impact. This would, of course, allow for a more accurate reflection of the needs, priorities and wishes of citizens and improved alignment with SDG5, but it would also facilitate any implementation action. Thereby, it may be better that robust mapping of such local, regional and national priorities will be developed in a bottom-up approach to ensure a comprehensive capture of challenges and priorities at these levels, to help inform policy making at both EU and Member States level. However, the ability to report evidence based progress also has to be taken into consideration, as capacity limitation, both in terms of resourcing and in terms of expertise.

Looking at the current anchoring of gender equality policymaking through Kingdon's policy streams approach (2014), it may be argued that the three policy streams are developed: the problem stream referring essentially to gender equality policy problems in society that require attention, the policy stream pertaining to several potential policy solutions that originate from EU and national policymakers, experts and lobby groups and the politics stream involving factors such as legislative framework and civil society. In such context, it seems that the streams tend to adjoin opening a policy window for the EU to be consistent to its commitment for social cohesion, sustainable growth and equality between women and men facilitate policy change (EC, 2018; EURlex, 2019d), yet, they may fail to adjoin should the sustainable development thinking of the EU does not develop a more context sensitive antenna.

Arguably, the European gender equality policy bears significant political and social impact on a society organized to live together and aligned with an egalitarian social order rather than a hierarchical one. These values need to be reflected in the EU policy commitment and leadership to translate SDG5 into national targets and respond to concrete gender challenges faced by the citizens of Member States. To avoid widening the gap between principle and reality, to shorten the distance between European moral universalistic principles and their implementation, the EU leadership may need to take the extra mile. Moving away from modern political gaze attraction, EU policymakers could call upon national governments, civil society and institutions at all levels to step up on setting country related priorities, monitor, assess progress regularly and accelerate efforts to eliminate gender disparities.

Developing instruments such as indices with considerable statistical capacity may be a useful informative tool but does not necessarily result in actual implementation across the European ground. Future iterations may indicate how EU policymakers and involved EU and national bodies are held responsible to promote and implement gender equality across Member States applying a more proactive leadership and ensuring the policy cycle is evidence informed and developed by and for Member States. Expertise from academia and contributions from civil society are critical 
elements in developing context-specific, evidence-informed gender equality policies to bring about substantial change and to address effectively the barriers and gridlocks to promote and implement a customized version of SDG5 targets. Such an approach is necessary to develop a narrative for EU's ambition towards a sustainable future for Member States to which its citizens can relate soundly; this relationship would, ultimately, contribute to a more than ever needed social cohesion across the European Union.

\subsection{LIMITATIONS}

The study outlined the milestones of gender equality policy trajectory anchored in EU Treaties aiming to provide a background knowledge useful for the analysis of the findings. It is beyond the scope of this study to offer a detailed trajectory of the policy and legal milestones on gender equality policy in EU. Further research presenting in detail the course of policy making, potential turns and gridlocks at EU and Member State level would add considerably to deeper understanding on prioritization of policy objectives and on impact to achieved progress.

The study would also benefit significantly by studying the intersection of the reported EU SDG5 themes and indicators with the domains and indicators developed by the European Institute for Gender Equality aiming to monitor the progress made across Member States. Although approached from different angles, studying common grounds and differences would contribute significantly in shaping the full landscape of monitoring and assessing the progress towards gender equality at EU and Member State level.

From the qualitative research perspective, the interpretation of the findings is the product of the researchers' unique interaction with the data and the process of meaning making. Although the authors elaborated extensively on interpretation of the findings, a further pluralistic discussion would add considerably to study's social validity.

\subsection{CONCLUSIONS}

The sustainable development thinking in European gender equality policy seems to fall short in terms of the translation of EU SDG5 objectives into national achievable targets. The themes and indicators of EU SDG5 set to monitor progress towards achieving gender equality objectives appear to have weak relevance to gendered challenges faced by citizens at national contexts. Although creditable policy efforts have been assumed to achieve EU SDG5 objectives, the high degree of heterogeneity of the gendered challenges and their impact in any progress made may have been overlooked or drawn suboptimal political attention. In the absence of EU SDG5 targets and indicators set for and by Member States, the policy gap between the enshrined gender equality principle and the social reality experienced at national contexts may be addressed by EU's proactive leadership; academia and civil society contributions may underpin significantly EU 
policy at all levels in optimizing support to Member States to develop context sensitive, evidenceinformed policies and, thus, join the EU's narrative for a shared sustainable future.

\section{Declaration of conflicting interests}

The author(s) declared no potential conflicts of interest with respect to the research, authorship, and/or publication of this article.

\section{Funding}

The author(s) received no financial support for the research, authorship, and/or publication of this article.

\section{REFERENCES}

Bacchi C. (2005). Discourse, discourse everywhere: Subject"agency"in feminist discourse methodology. Nordic Journal of Women's Studies, 13(03), 198-209. Available at: https://doi.org/10.1080/08038740600600407

Beveridge, F., Nott, S., \& Stephen, K. (2000). Mainstreaming and the engendering of policy-making: a means to an end? Journal of European Public Policy, 7(3), 385-405. doi:10.1080/13501760050086099

Cavaghan, R. (2017) The gender politics of EU economic policy: Policy shifts and contestations before and after the crisis. In: Kantola J \& Lombardo E (Eds) Gender and the economic crisis in Europe: Politics, institutions and intersectionality. Palgrave Macmillan, New York, pp 49-71.

Celis, K., Kantola, J., Waylen, G., \& Weldon, S. L. (2013). Introduction: Gender and politics: A gendered world, a gendered discipline. In: Waylen, G., Celis K., Kantola J. \& Weldon S.L. (Eds). The Oxford Handbook of Gender and Politics. Oxford University Press. New York, pp 1-25

Chouliaraki, L., \& Fairclough, N. (1999). Discourse in Late Modernity: Rethinking Critical Discourse Analysis (Critical Discourse Analysis EUP). Edinburg, UK: Edinburg University Press.

Council of Europe (2019) Istanbul Convention. Action against violence against women and domestic violence. Available at: https://www.coe.int/en/web/istanbul-convention/text-of-the-convention (Accessed: February 12th, 2019)

Crepaidi C., Loi D., Pesce F. \& Samek M. (2015). Evaluation of the strengths and weaknesses of the strategy for equality between women and men 2010-2015. Available at: https://publications.europa.eu/en/publication-detail/-I publication/dad702b0-fc82-11e5-b713-01aa75ed71al (Accessed: December 12 th, 2018 )

Cullen, P. (2015). Feminist NGOs and the European Union: contracting opportunities and strategic response. Social Movement Studies, 14(4), 410-426. doi: 10.1080/14742837.2014.965674

Elomäki A. \& Kantola J. (2017) Austerity Politics and Feminist Resistance in Finland: From Established Women's Organizations to New Feminist Initiatives. In: Kantola J. \& Lombardo E. (Eds) Gender and the Economic Crisis in Europe. Gender and Politics. Palgrave Macmillan, New York, pp 231-255.

EUR-lex. Access to European Union Law (2019a) The Treaty of Lisbon. Available at: https://eur-lex.europa.eu/legalcontent/EN/TXT/?uri=celex\%3A12007L\%2FTXT (Accessed: February 12 ${ }^{\text {th }}, 2019$ )

EUR-lex. Access to European Union Law (2019b) The Treaty of Rome. Available at: https://eur-lex.europa.eu/legalcontent/EN/TXT/?Uri=CELEX:11957E/TXT (Accessed: February 12 $2^{\text {th }}, 2019$ )

EUR-lex. Access to European Union Law (2019c) The Treaty of Amsterdam. Available at: https://eur-lex.europa.eu/legalcontent/EN/TXT/? Uri=CELEX:11997D/TXT (Accessed: February 12 ${ }^{\text {th }}, 2019$ )

EUR-lex. Access to European Union Law (2019d) Consolidated version of the Treaty on the Functioning of the European Union. Available at: https://eur-lex.europa.eu/legal-content/EN/TXT/PDF/?uri=CELEX:12012E/TXT (Accessed: March $2^{\text {nd }}, 2019$ )

EUR-lex. Access to European Union Law (2019e) Consolidated version of the Treaty of European Union. Available at: https://eur-lex.europa.eu/LexUriServ/LexUriServ.do?uri=OJ:C:2008:115:0013:0045:en:PDF (Accessed: March 2nd, 2019)

European Commission (2018). 2018 Report on equality between women and men in the EU. Available at: https:// publications.europa.eu/en/publication-detail/-/publication/950dce57-6222-11e8-ab9c-01aa75ed71a1 (Accessed: October 25 $5^{\text {th }}, 2018$ ) 
European Institute for Gender Equality (2018) Gender Mainstreaming. Toolkits. Available at: https://eige.europa.eu/ gender-mainstreaming/toolkits (Accessed: December 12 $2^{\text {th }}, 2018$ )

European Parliament (2019) Gender mainstreaming in the EU: State of Play. Available at: http://www.europarl.europa.eu/ RegData/etudes/ATAG/2019/630359/EPRS_ATA(2019)630359_EN.pdf (Accessed: January 1 1 th , 2019)

Eurostat (2017) Sustainable Development in the European Union. Monitoring Report on Progress towards the SDGs in an EU Context. 2018 edition. Available at: https:/ec.europa.eu/eurostat/web/products-statistical-books/-/KS01-18-656 (Accessed: October 2nd, 2018)

Guba, E. G., \& Lincoln, Y. S. (1994). Competing paradigms in qualitative research. Handbook of qualitative research, 2(163194), 105.

Jacquot S. (2010). The paradox of gender mainstreaming: Unanticipated effects of new modes of governance in the gender equality domain. West European Politics, 33(1), 118-135. doi: 10.1080/01402380903354163

Jacquot S. (2015). Analyzing Change in European Gender Equality Policy. In: Transformations in EU gender equality: From emergence to dismantling. Parlgrave Macmillan, New York, pp 1-17.

Kantola J. \& Nousiainen K. (2012) The European Union: Initiator of a New European Anti-Discrimination Regime? In: Krizsan A., Skjeie H., Squires J. (eds) Institutionalizing Intersectionality. Gender and Politics series. Palgrave Macmillan, London, pp. 33-58.

Karamessini M. (2014) Structural crisis and adjustment in Greece: social regression and the challenge to gender equality. In: Karamessini M \& Rubery J (Eds), In: Women and austerity: The economic crisis and the future for gender equality. Routledge, New York, pp 165-185.

Karamessini M. \& Rubery J. (2014) Economic crisis and austerity: challenges to gender equality. In: Women and austerity: The economic crisis and the future for gender equality. Routledge, New York, pp 314-350.

Kingdon, J. W. (2014). The policy window and joining the streams. In: Agendas, Alternatives and Public Policies, 2nd ed. Pearson, Essex, UK, pp 165-195.

Klatzer E. \& Schlager C. (2014). Gender and Macroeconomics: Economic Governance in the European Unionreconfiguration of gendered power structures and erosion of gender equality. In: The SAGE Handbook of Feminist Theory SAGE Publications Ltd, pp 483-499. doi: 10.4135/9781473909502

Kloke-Lesch, A. (2018). Why is the EU failing to champion the SDGs? Journal of International Relations and Sustainable Development. Issue 12, June 2018. Available at: https://www.cirsd.org/en/horizons/horizons-summer-2018-issueno-12/why-is-the-eu-failing-to-champion-the-sdgs (Accessed: November 13th, 2018)

Krizsan, A., \& Lombardo, E. (2013). The quality of gender equality policies: A discursive approach. European Journal of Women's Studies, 20(1), 77-92. doi: 10.1177/1350506812456462

Lyberaki A., Samek Lodovici M., Bettio F., D'Ippoliti C., Corsi M., Verashchagina A. (2012) The impact of the economic crisis on the situation of women and men and on gender equality policies. Synthesis report. Brussels: Publication Office of the European Union. Available at: https://publications.europa.eu/en/publication-detail/-/ publication/4a10e8f6-d6d6-417e-aef5-4b873d1a4d66/language-en\# (Accessed: October 15th, 2018)

McKinnon, M. C., Cheng, S. H., Garside, R., Masuda, Y. J., \& Miller, D. C. (2015). Sustainability: Map the evidence. Nature News, 528(7581), 185. Available at: https://www.nature.com/news/sustainability-map-the-evidence-1.18962 (Accessed: October 14th, 2018)

Mahoney, J. (2012). The logic of process tracing tests in the social sciences. Sociological Methods \& Research, 41 (4), 570597. doi: $10.1177 / 0049124112437709$

Massino J. \& Popa R.M. (2015). The Good, the Bad, and the Ambiguous: Women and the Transition from Communism to Pluralism in Romania. In: Gender (In) equality and Gender Politics in Southeastern Europe. Palgrave Macmillan, London, pp 171-191

Paternotte D. \& Kuhar R. (2018). Disentangling and locating the "global right": Anti-gender campaigns in Europe. Politics and Governance, 6(3), 6-19. doi:10.17645/pag.v6i3.1557

Petersen K., Feldt R., Mujtaba S., \& Mattsson M. (2008). Systematic Mapping Studies in Software Engineering. In: EASE (Vol. 8, pp. 68-77). Available at: https://www.researchgate.net/profile/Michael_Mattsson/publication/228350426_ Systematic_Mapping_Studies_in_Software_Engineering/links/54d0a8e90cf20323c218713d/SystematicMapping-Studies-in-Software-Engineering.pdf (Accessed: September 3rd, 2018)

Sachs J., Schmidt-Traub G., Kroll C., Durand-Delacre D. \& Teksoz, K. (2016): SDG Index and Dashboards - Global Report. New York: Bertelsmann Stiftung and Sustainable Development Solutions Network (SDSN). Available at: http:// sdgindex.org/reports/2016/ (Accessed: October 14 $4^{\text {th }}$ 2018)

Scharff, C. (2016). The psychic life of neoliberalism: Mapping the contours of entrepreneurial subjectivity. Theory, Culture \& Society, 33(6), 107-122. Available at: https://doi.org/10.1177/0263276415590164 (Accessed: January $\left.13^{\text {th }}, 2019\right)$ 
Stoilova, M. (2015). Mind the Gap: The Changing Face of Gender (In) equality in Bulgaria after 1989. In: Gender (In) equality and Gender Politics in Southeastern Europe. Palgrave Macmillan, London, pp 192-212

Stone D. A. (1997). Policy Analysis and Political Argument. In: Policy paradox: The art of political decision making, $3^{\text {rd }}$ ed. WW Norton \& Company, New York, pp 379-385

StreeckW. \& Thelen K.A. (2005) Institutional change in advanced political economies. In: StreeckW. \& Thelen K.A. (Eds) Beyond continuity: Institutional change in advanced political economies. Oxford University Press. New York, pp 1 - 38

United Nations (2015). Transforming our world: The 2030 agenda for sustainable development. Resolution adopted by the General Assembly. Available at: https://sustainabledevelopment.un.org/post2015/transformingourworld (Accessed: September 12 ${ }^{\text {th }}, 2018$ )

Verloo, M. (2007). European Union Gender Policy since Beijing:Shifting Concepts and Agendas. In: Verloo M (Ed) Multiple Meanings of Gender Equality: A critical frame analysis of gender policies in Europe. Budapest: Central European University Press. Retrieved March 19 ${ }^{\text {th }}, 2019$, from Project MUSE database.

Verloo M (Ed.) (2018) Varieties of opposition to gender equality in Europe. Routledge

Verloo M. \& Paternotte D. (2018). The Feminist Project under Threat in Europe. Politics and Governance, 6(3), 1-5. doi:10.17645/pag.v6i3.1736

Walby, S. (2004). The European Union and gender equality: Emergent varieties of gender regime. Social Politics: International Studies in Gender, State \& Society, 11(1), 4-29. Available at: https://doi.org/10.1093/sp/jxh024 (Accessed: November 10 $0^{\text {th }}, 2018$ )

Willig, C., \& Rogers, W. S. (Eds.). (2017). The SAGE handbook of qualitative research in psychology. Sage.

Wodak, R., \& Meyer, M. (2009). Critical discourse analysis: History, agenda, theory and methodology. Methods of critical discourse analysis, 2, 1-33. Available at: https://us.corwin.com/sites/default/files/upm-binaries/24615_01_ Wodak_Ch_01.pdf (Accessed: December $8^{\text {th }}$, 2018) 



\section{Chapter}

\section{Gender mainstreaming toolkits towards achieving organizational change: a qualitative analysis}

\section{Based on:}

Gender mainstreaming toolkits towards achieving organizational change: a qualitative analysis Kalaitzi S, Czabanowska K, Brand H. 

ABSTRACT

Purpose: The gender mainstreaming strategy, including the relevant toolkits, is criticized for poor institutionalization and outcomes across European Union. The paper assesses critically the transformative capacity of gender mainstreaming toolkits against organizational culture and climate. The study is undertaken through the lens of theory of change placing toolkits in milieu of organizational change processes. The study aims to explore potential room for improved implementation of toolkits towards achieving organizational change and provide orientation to policy actors and decision makers for further action.

Methods: A mixed methods approach was used to provide validated insights to research question. The systematic mapping method was applied to extract data and develop a geography of researched items around variables related to processes of change. The qualitative analysis was followed to critically assess the identified data, provide deeper understanding of contextual influences and build theory for improvement.

Findings: Findings unveiled that the duality of gender mainstreaming strategy may have inherited an internal contradiction to relevant toolkits resulting to poor implementation. Improved qualitative elements of the toolkits, the lack of organizational learning capabilities and informed, transformational leadership have also been identified as the potential missing key drivers for extensive implementation.

Practical implications: Organizational change may score better should interventions have organization friendly qualities and are directly linked with organizational culture and climate.

Social implications: Organizational change is a journey, not a destination, underpinned by shared driving principles, such as equality and inclusion.

Originality/value: Improved qualitative elements of the gender mainstreaming toolkits may facilitate their extensive use and effective implementation within organizational context. 



\section{1 INTRODUCTION}

The European Union endorsed gender mainstreaming as its official policy approach to accelerate progress towards achieving gender equality (EP, 2019a; EC, 2019; Verloo, 2005). The European Institute for Gender Equality (EIGE), the autonomous agency of the European Union to strengthen gender mainstreaming in all EU policies and the resulting national policies, developed a range of gender mainstreaming toolkits to support EU bodies and Member States to design and implement gendered policies focusing mainly on organizational culture, practices and procedures (EIGE, 2019). However, the gender mainstreaming strategy, including the relevant toolkits, although well-structured and endowed with a variety of methods, tools and explanatory guides, were criticized for poor institutionalization and outcomes (EP, 2019b; EC, 2018b).

Gender mainstreaming1 was presented as the guiding principle of gender equality policy, as a polysemous instrument designed to produce cultural and social change in society and organizations across EU and develop a gender equality approach reflecting its core values (Jacquot, 2010). Yet, skepticism remains for more than two decades not on gender mainstreaming's structural aspect alone, but on its effective implementation and contribution to concrete achievements as well. Data from the European Institute for Gender Equality (2018) show that progress is moving forward at a snail pace at its best; actually, in 12 out of the 28 Member States the gender equality index moved backwards and in some cases, such as in Greece, touched the worst score ever (EIGE report, 2017). The fluctuations in the values across the domains mapped in gender equality index are also striking. In that line, the She Figures report (EC, 2018a) announced that only one third of the EU's researchers in science and engineering are women, whereas in business sector women represent only $20,2 \%$. In academic sector, women represented $48 \%$ of doctoral students but only $24 \%$ of grade A academic positions, falling down to 15\% in STEM (Science, Technology, Engineering and Mathematics). Furthermore, women make up only $27 \%$ of boards of research organizations and just $20 \%$ on board leaders. In terms of gender pay gap, there is still an average $17 \%$ less than male counterparts across sectors. Research holds responsible for the alarming developments, amongst others, the inconsistencies in gender equality policy at EU and Member States level, as well as the presence of numerous and persisting gendered barriers across organizations aggravated by a substantial impact of national, socio-cultural norms (Lombardo, 2005; Kantola et al, 2017; Jacquot, 2017; Kalaitzi et al, 2019).

Organizations are dynamic entities with a certain momentum running according to embedded

1. Gender mainstreaming refers to "the systematic integration of the respective situations, priorities and needs of women and men in all policies and with a view to promoting equality between women and men and mobilizing all general policies and measures specifically for the purpose of achieving equality by actively and openly taking into account, at the planning stage, their effects on the respective situation of women and men in implementation, monitoring and evaluation (Commission of the European Communities 1996:2. Available at: http://www.europarl.europa. eu/RegData/etudes/ATAG/2019/630359/EPRS_ATA(2019)630359_EN.pdf) 
organizational culture and climate (Denison, 1996). Organizational culture and climate are critical in attracting, recruiting and retaining talented women and aspiring women leaders at all levels of leadership in organizations across sectors and countries. The organizational culture is a socially constructed phenomenon referring to "a pattern of shared basic assumptions learned by a group as it solves its problems of external adaptation and internal integration, which has worked well enough to be considered valid and, therefore, to be taught to new members as the correct way to perceive, think, and feel in relation to those problems" (Schein, 2010, p. 18). The concept of "shared" is central to organizational culture concept and includes values espoused by leadership, management and the organization at large (Ostroff et al, 2013). On the other note, the organizational climate is described as the formal and informal organizational strategy, policies, practices and procedures. Although potentially overlapping, organizational culture and climate are fundamental building blocks for understanding the social processes associated with individual and group behaviors (Schneider et al, 2011). They are also dominant in understanding how practices and assumptions construct gender within organizations and, therefore, are viewed as key drivers to organizational change efforts (Ostroff et al, 2013).

However, organizational culture and climate are tempered by multiple gendered constraints, such as bias, stereotypes, glass ceiling, gender pay gap, work/life balance, culture, lack of social support and lack of role models, which are mainly held responsible to equality and inclusion challenges across organizations (Kalaitzi et al, 2017; Toh and Leonardelli, 2012; Acker, 2006). Literature delineates extensively an unfriendly and unsupportive organizational culture, with deeply rooted gender stereotypes and bias embedded firmly in policies, practices and procedures resulting in a significant cost of talent and intellectual capital for both organizations and society (Bismark, 2015; Fox et al, 2017; Ellemers, 2014; Schuh et al, 2014; Coe et al, 2019). Arguably, the change agents, namely the leaders and decision makers, have an impact both on organizational policies and on the patterns of behaviors shaping thus a shared, goal-oriented climate in organizational context; yet, they may be poorly informed about the nature and the impact of embedded gendered barriers in organizational culture and climate as well as about the strategies and toolkits to address these challenges (Denison, 1996; Coe et al, 2019; Schneider et al, 2011; Dragoni, 2005). This knowledge gap results in failing to fully tap into the available talent pool, to limit the potential for improved organizational performance and to bring about substantial change in organizational context.

Within this paper, authors aim to draw on the implementation of EU gender mainstreaming toolkits within organizational context. The aim is to critically assess the transformative capacity of gender equality toolkits and explore potential room for improved implementation towards achieving organizational change. The study is undertaken through the lens of theory of change placing toolkits in milieu of change processes. In particular, the qualitative analysis of change is applied to gain in depth understanding of the complexity between toolkits, context and outcomes and gain deeper insights of the explored phenomena. 


\subsection{METHODS}

Researchers undertook an exploratory, qualitative study using a multi methods approach to provide a validated and comprehensive overview of existing evidence (Guba and Lincoln, 1994). The research questions addressed were "What are the toolkits developed to support EU bodies and Member States to implement gender mainstreaming towards achieving gender equality objectives? What is the transformative capacity of gender mainstreaming toolkits? What are the strengths and weaknesses of the proposed toolkits? What aspects need to be further elaborated to improve toolkits' effective implementation?" The authors set out to harvest data and critically evaluate the findings to gain deeper understanding of the developed toolkits within the framework of gender mainstreaming strategy in EU. Qualitative data analysis was followed through the theory of change perspective placing toolkits and targeted changes within milieu, to understand the complexity and the linkages among toolkits, context and outcomes and potentially identify room for improved effectiveness (Weiss, 1995; Connell and Kubisch, 1998).

The protocol for the search, data extraction and mapping were supported by the systematic mapping methodology in order to offer a structured map of the researched items (Petersen et al, 2007; Bailey et al, 2007). The systematic maps (SMs) were developed and extensively used in social and decision sciences to assess what research was undertaken, what methods were followed and within which study settings (McKinnon et al, 2015; Bates et al, 2007). Systematic mapping was used to reliably index evidence on a specific subject; further on, SMs produce detailed descriptive information and provide a geographical information system pinpointing knowledge gaps useful for research, policy and decision makers (Haddaway et al, 2016; McKinnon et al, 2015).

The systematic mapping of gender mainstreaming toolkits aimed to develop a structured map of researched items (Petersen et al, 2007). Taking into consideration that gender mainstreaming is a variable entity encompassing both the gender equality and the mainstreaming aspects, systematic mapping of toolkits was developed around the following variables deemed important to better understand the processes of targeted change: area, objectives, priorities and implementation (Walby, 2005; Mackay and Bilton, 2003; Behning and Pascual, 2001).

The theory of change (ToC) approach was undertaken to explore the organizational change phenomena placing toolkits in milieu. The ToC is widely followed to understand the way an intervention brings about its effects linking inputs and activities to a chain of intended, observable outcomes (Scriven, 1991; Rogers, 2008). Weiss (1995) described it as a theory of how and why an initiative works or not, how a given intervention, or set of interventions, is 
expected to lead to a specific development change drawing on a causal analysis based on available evidence. Connell and Kubisch (1998) highlighted the systematic and cumulative aspect of the theory linking activities, outcomes and contexts of initiative through the lens of comparative advantages, effectiveness, feasibility, accountability and uncertainties that are part of any change process. Dhillon and Vaca (2018) also applauded the analytical processes applied by the ToC in order to address effectively the complexity of the context, timing, interests and resources of the involved organization; they also claimed the superiority of the method over the often used interchangeably logic models on the grounds that ToC processes are deeper and more participatory and provide details on achieved outcomes and their causal strands over time.

The qualitative analysis of organizational change was applied to understand and rigorously assess organizational change phenomena, to find connections between variables and provide deeper and more nuanced understanding of contextual influences and, following, to build theory for improvement (Garcia and Gluesing, 2013; Patton, 1999).

\section{Search strategy}

The website of European Institute for Gender Equality, European Commission, European Parliament and Council of Europe, the EU bodies involved in gender mainstreaming strategy, were thoroughly searched within a period of three months (September 2018 - November 2018) to identify comprehensive evidence on gender mainstreaming toolkits. Additional desk research was realized using snowballing techniques including websites such as Google, Google Scholar, PubMed aiming to check for potential misplaced items (Streeton et al, 2004). The online search used various combinations of keywords: "gender mainstreaming" AND "gender equality" AND "gender" OR "women" AND "toolkits". Researchers (KS, CK) conducted the search independently and compared their findings along with their interpretations on an ongoing basis (Sandelowski et al, 2007). Disagreements were addressed by discussing interpretations until reaching consensus (Barnett-Page and Thomas, 2009; Bowling, 2014).

\subsection{RESULTS}

Five toolkits were found to be developed by European Institute for Gender Equality, aiming to support EU bodies and Member States to design and implement gendered strategies and policies across organizations (EIGE, 2019). The identified toolkits include the Gender Equality in Academy and Research (GEAR); the Gender Equality Training; the Gender Impact Assessment (GIA); the Institutional Transformation toolkit and the Gender Sensitive Parliaments toolkit (Table I). 
Table I | Gender mainstreaming toolkits developed by the European Institute of Gender Equality

\begin{tabular}{|c|c|c|c|c|}
\hline TOOLKIT & AREA & OBJECTIVES & PRIORITIES & IMPLEMENTATION \\
\hline $\begin{array}{l}\text { GEAR (Gender } \\
\text { Equality in } \\
\text { Academy and } \\
\text { Research) }\end{array}$ & $\begin{array}{l}\text { Research and higher } \\
\text { education institutions; } \\
\text { funding organizations }\end{array}$ & $\begin{array}{l}\text { To develop gender } \\
\text { mainstreaming strategies } \\
\text { and develop GEPs; to } \\
\text { mobilize adequate } \\
\text { resources and to achieve } \\
\text { cultural } \\
\text { and institutional change }\end{array}$ & $\begin{array}{l}\text { To foster equality in } \\
\text { scientific careers; } \\
\text { to ensure gender balance } \\
\text { in decision making } \\
\text { processes and bodies } \\
\text { and to integrate the } \\
\text { gender dimension in } \\
\text { research and innovation } \\
\text { content }\end{array}$ & $\begin{array}{l}\text { Gender Equality Plans } \\
\text { (GEPs) }\end{array}$ \\
\hline $\begin{array}{l}\text { Gender } \\
\text { Equality } \\
\text { Training }\end{array}$ & $\begin{array}{l}\text { Commissioning authorities } \\
\text { ("A commissioning } \\
\text { authority is a person or } \\
\text { body responsible for the } \\
\text { planning, delivery and } \\
\text { funding of the gender } \\
\text { equality competence } \\
\text { development activity. EIGE, } \\
\text { Gender Equality Training, } \\
\text { Gender mainstreaming } \\
\text { toolkit, p. 5) }\end{array}$ & $\begin{array}{l}\text { To stimulate investment } \\
\text { in the gender equality skills } \\
\text { of policymakers and public } \\
\text { administration employees; } \\
\text { to facilitate the process } \\
\text { of designing effective } \\
\text { gender equality training } \\
\text { and to overcome gender } \\
\text { gaps at individual, } \\
\text { institutional and social level }\end{array}$ & $\begin{array}{l}\text { To identify gender } \\
\text { inequalities and gender } \\
\text { gaps in field of activity; } \\
\text { to define gender } \\
\text { equality objectives; o } \\
\text { take account of gender } \\
\text { when planning and } \\
\text { implementing policies; to } \\
\text { monitor progress and to } \\
\text { evaluate programs from a } \\
\text { gender perspective }\end{array}$ & $\begin{array}{l}\text { Gender equality } \\
\text { competence } \\
\text { development (e.g., } \\
\text { training, networking). } \\
\text { A three phases } \\
\text { guide (preparation, } \\
\text { implementation, } \\
\text { evaluation and follow- } \\
\text { up) supported by a "find } \\
\text { a trainer" database }\end{array}$ \\
\hline $\begin{array}{l}\text { GIA (Gender } \\
\text { Impact } \\
\text { Assessment) }\end{array}$ & $\begin{array}{l}\text { Governmental, regional or } \\
\text { local offices, departments } \\
\text { or ministries initiating a } \\
\text { new regulation or policy } \\
\text { should be involved in the } \\
\text { process of gender impact } \\
\text { assessment. }\end{array}$ & $\begin{array}{l}\text { To improve the design and } \\
\text { the planning of the policy } \\
\text { under consideration, in } \\
\text { order to prevent a negative } \\
\text { impact on gender equality } \\
\text { and to strengthen gender } \\
\text { equality through better } \\
\text { designed, transformative } \\
\text { legislation and policies }\end{array}$ & $\begin{array}{l}\text { To adapt the policy } \\
\text { to make sure that any } \\
\text { discriminatory effects } \\
\text { are either removed or } \\
\text { mitigated; to define } \\
\text { gender equality } \\
\text { objectives and formulate } \\
\text { the policy so as to } \\
\text { proactively promote } \\
\text { gender equality. }\end{array}$ & $\begin{array}{l}\text { A five steps guide } \\
\text { (definition of the policy } \\
\text { purpose, checking } \\
\text { gender relevance, } \\
\text { gender sensitive } \\
\text { analysis, weighting } \\
\text { gender impact, } \\
\text { findings and proposals } \\
\text { for improvements) } \\
\text { depending on the } \\
\text { institutional settings and } \\
\text { different actors involved }\end{array}$ \\
\hline $\begin{array}{l}\text { Institutional } \\
\text { transformation }\end{array}$ & $\begin{array}{l}\text { Public institutions within } \\
\text { the EU as bodies that are } \\
\text { accountable for gender } \\
\text { equality; the public sector, } \\
\text { tackling institutions with } \\
\text { governing executive power } \\
\text { such as a ministry or similar } \\
\text { administrative body }\end{array}$ & $\begin{array}{l}\text { To addresses issues } \\
\text { of organizational culture } \\
\text { as a cross-cutting matter } \\
\text { ("organization" is used } \\
\text { to signify the concrete } \\
\text { mechanisms } \\
\text { of implementing gender } \\
\text { mainstreaming as } \\
\text { a strategy of organizational } \\
\text { development" ElGE, } \\
\text { Institutional Transformation, } \\
\text { p.6). }\end{array}$ & $\begin{array}{l}\text { To integrate gender } \\
\text { equality into the regular } \\
\text { rules, procedures and } \\
\text { practices of an institution; } \\
\text { to achieve gender } \\
\text { equality both internally } \\
\text { and especially in regard } \\
\text { to working results and } \\
\text { outcomes }\end{array}$ & $\begin{array}{l}\text { A three phases action } \\
\text { plan (introduction, } \\
\text { implementation, } \\
\text { consolidation) } \\
\text { supported by best } \\
\text { practices }\end{array}$ \\
\hline $\begin{array}{l}\text { Gender } \\
\text { Sensitive } \\
\text { Parliaments }\end{array}$ & Parliamentary institutions & $\begin{array}{l}\text { To support parliaments in } \\
\text { assessing and monitoring } \\
\text { gender-sensitivity in terms } \\
\text { of their organization and } \\
\text { working procedures }\end{array}$ & $\begin{array}{l}\text { To foster and strengthen } \\
\text { gender sensitivity } \\
\text { of national parliaments } \\
\text { and European Parliament } \\
\text { on five main areas: } \\
\text { 1) equal opportunities } \\
\text { to enter the parliament } \\
\text { and 2) to influence the } \\
\text { working procedures, } \\
\text { 3) to have adequate space } \\
\text { on parliamentary agenda, } \\
\text { 4) to produce gender } \\
\text { sensitive legislation and } \\
\text { 5) to comply with its } \\
\text { symbolic function. }\end{array}$ & $\begin{array}{l}\text { An online, self- } \\
\text { assessment, scoring } \\
\text { and interpretation tool } \\
\text { on gender sensitive } \\
\text { parliaments }\end{array}$ \\
\hline
\end{tabular}


The five toolkits are organized around four variables: areas, objectives, priorities and implementation (Figure I) to better serve the data interpretation and elaborate on the research questions "What are the toolkits developed to support EU bodies and Member States to implement gender mainstreaming towards achieving gender equality objectives? What is the transformative capacity of gender mainstreaming toolkits? What are the strengths and weaknesses of the proposed toolkits? What aspects need to be further elaborated to improve toolkits' effectiveness?"

Figure I | Geography of the gender mainstreaming toolkits

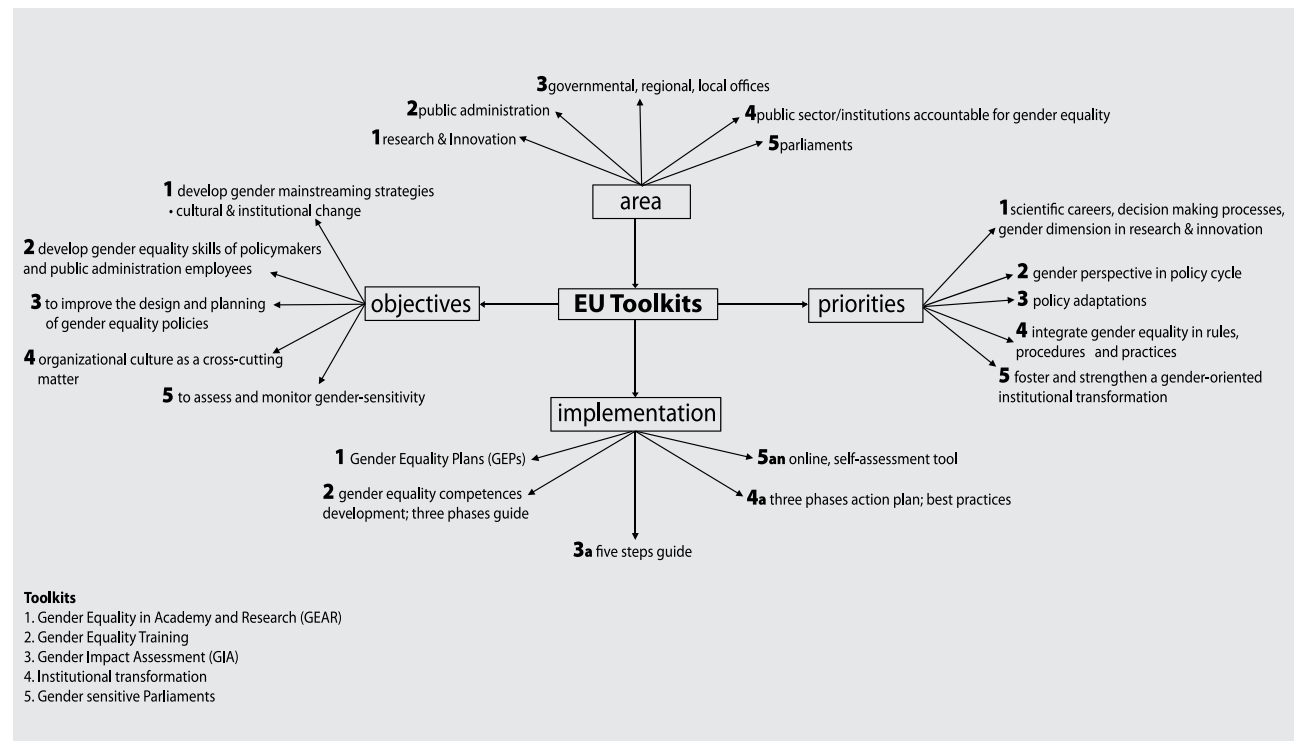

Each toolkit targets an area and is supplemented by various components such as an implementation guide, best practices (EIGE, 2019a). For example, the GEAR toolkit targets on the needs for institutional change in research and higher education organizations; it focuses on a thematic area or on a combination of thematic areas, such as gender awareness raising and competence development / recruitment, selection and career progression support and it provides a detailed guide on phases on organizational change, supportive literature and examples of best practices by phase. The Gender Equality Training Toolkit aims on positive change of policymakers and public administration employees'attitude; it provides a set of standards to address the needs of authorities at different stages of the gender competence development (EIGE, 2019b, p. 3). Similarly, the GIA offers a set of methods and tools, such as gender budgeting, gender analysis and indicators, aiming to achieve impact at all stages of policy cycle, that is at policy design, planning, implementation, evaluation to ensure desired equality outcomes (Dunn, 2015). The Institutional transformation toolkit pursues a systematic and planned process for organizational learning targeting to integrate gender equality into regular rules, regulations and practices of 
an organization (EIGE, 2019c, p. 7). Considering the different types of administrative regimes of organizations across Member States, the varied levels of prior knowledge, responsibilities and competencies of involved actors regarding the change processes, the toolkit provides a stepwise guide to initiate and develop the processes for organizational change supported by examples and good practices, which could potentially be used or adapted accordingly. The fifth toolkit, the Gender Sensitive Parliaments, aims to support national parliaments and the European Parliament to assess and monitor gender sensitivity in working procedures, to respond to the needs and interests of genders in its composition, structures, operations and work and offer a positive example to society at large (EIGE, 2019a). An online self-assessment tool has been developed focusing around five areas: equal opportunities to enter the parliament, to exert influence on parliament's working procedures, to space out women's issues on parliamentary agenda, to produce gender sensitive legislation and to adequately embed its symbolic functioning as a gender sensitive organization.

Toolkits are meant to be involved in a change process where stages of gender equality progress (if any) may not be clearly identifiable or well delineated; organizations may be more or less committed or ready for change, with discerning priorities in different areas, with varying time needs, whereas the start point and the end point may be different for each case (Torraco, 1997). Toolkits may be interlinked, not mutually exclusive, and be applied according to the targeted audience, objectives, priorities, and the starting point for change (EIGE, 2019a). They may also be integrated into specific change methods and procedures already established by the organization or they may be introduced to start a new change process (Dhillon \& Vaca, 2018; Connell \& Kubisch, 1998).

\subsection{DISCUSSION}

The five identified toolkits developed to support EU bodies and Member States to achieve gender equality objectives seem to fall short in serving the transformative element of gender mainstreaming strategy. The main goal of gender mainstreaming across EU has not been about promoting gender equality alone, but mainly about being capable of achieving it; hence, the gender mainstreaming policy is especially grounded in a strategy of change which may not be adequately supported by of the available toolkits (Verloo, 2005; Jacquot, 2010; Lombardo and Mergaert, 2013; Cavaghan, 2017).

Literature addressed the duality of gender mainstreaming pointing out two frames of reference, one stemming from a gender equality aspect and the other from a mainstreaming aspect, each pursuing objectives which may be considered mutually inconsistent (Walby, 2005). That is, the former to promote the gender equality as a feminist goal and the latter is typically linked to a strategy to improve governance. This "fuzzy core" (Daly, 2005, p. 445) was also articulated by Woodward (2001) as internal contradiction drawing at the same time elements from feministic 
theory and from instrumentation and, thus, leading to the question of whether such a gender mainstreaming approach can challenge the inherent, structural power relations between gender and hierarchy in a complementary way and bring about change within organizational context.

In that note, gender equality evaluation reports state that gender mainstreaming toolkits have not been adequately received by policy actors and decision makers; consequently, they may have been poorly institutionalized resulting in suboptimal outcomes (EP, 2019b; EC, 2018b). Although the toolkits offer a coherent reference framework on priority policy areas and objectives to be implemented for gender equality strategies, little attention was received by respective national bodies and organizations. The embedded contextuality, the weak legal and/or administrative mandates to apply gender mainstreaming in organizations across Member States and the missing gender expertise to commission that change are held responsible for the suboptimal outcomes of the endeavor (EP, 2019c). Their character and robustness have been questioned in terms of translating change in governance into social and cultural change (Cavaghan, 2017; HafnerBurton and Pollack, 2009). As such, it was considered insufficient the transformative tackling of the symptoms rather than the structural causes of inequalities, such as the under-paid work for women, the intersecting forms of discrimination, or the unequal access to funding resources (EP, 2019c). To ensure the substantial room for improvement in adopting gender mainstreaming toolkits in practice, a range of methods was developed, such as gender analysis, impact assessment, gender budgeting and evaluation and gender indicators (EP, 2019b; EIGE, 2018); still, the gender inequalities remained entrenched in the organizational culture and climate as echoed by the statistics produced by Member States and EU bodies (Eurostat, 2017; EIGE, 2019a; Stamarski and Son Hing, 2015). Thereby, achieving gender equality within the framework of organizational change requires improved qualitative elements of the toolkits; specific, easy, simple, affordable, measurable and effective (SESAME) may be some qualities attractive enough to organization leaders and decisions makers to turn a positive eye to gender sensitive organizational change processes. A transformative intervention with embedded SESAME qualities counterbalances significantly putting operations and budget at risk; whereas it may be a leverage for progress and improvement of organizational culture and climate. Toolkits ensuring smooth, inclusive and effective change may be the tipping point at which organizational change may be broadly accepted and implemented.

On the other hand, policy actors and decision makers make the rhetoric that they follow a gender mainstreaming approach and apply available toolkits; yet, gender inequalities may have been alleviated only but not eradicated within organizational context. Bringing about organizational change towards achieving a gender sensitive work setting requires addressing together organizational culture and climate; a gender sensitive climate may not generate the targeted outcomes should organizational policies and practices are not developed around the shared goals, beliefs of an organization's human capital and, vice versa, efforts to bring change in culture may be unsuccessful should assumptions conflict with the (in)formal policies and practices of an organization (Huffman, 2002). 
To that end, attention should be drawn on the learning capabilities of an organization, such as the ability to gain insights and understanding through observation and analysis, to create the motive, means and opportunities for change and the willingness to examine successes and failures (Serrat, 2017). Learning and change is inherently a social process that cannot be separated from the context in which takes place (Wenger, 2010). Thereby, enhanced learning capabilities able to manage gender equality would allow to develop a gender sensitive approach in organizational culture and climate looking deeper to the nature and the reasons of gendered challenges (Sen, 1980). As such, internal organizational capabilities, such as minimizing internal resistance or gender related criticism may be linked to an update of organizational culture (Dass and Parker, 1999).

In addition to the need for enhanced learning capabilities, change in organizational culture requires for dedicated and informed change agents, namely leaders and decision makers (Sharma, 2016). These change agents play a very important role in the shaping and consensus of perceptions on organizational culture and climate. Their clear vision, knowledge and abilities to implement, their behavior patterns, the consistency in behavior and the ways of communication may serve as interpretative filters of organizational procedures, processes and practices and contribute to the development of common perceptions, values and beliefs (Zohar and Luria, 2004; Dragoni, 2005). The changing capacity lies on the leaders' transformational skills which create opportunities to share and clarify perceptions, foster closer relationships with subordinates and creates cultural and climate consensus (Ostroff et al, 2013; Naumann and Bennett, 2000).

The dialectics of organizational change may be enriched considering that the attainment of durable and sustainable change is a journey, not a destination, which is guided by shared driving principles, such as equality and inclusion, and any progress made must be measured at predetermined milestones and evaluated against priorities and targets (Coe et al, 2019). The knowledge gap on organize and implement effectively organizational change towards gender equality may be addressed by deeper understanding of the factors by which organizational culture and climate may change, such as enhancement of learning capabilities and informed leadership. This knowledge must become a core organizational competency applied at all levels of leadership and management acknowledging in practice that the full potential of an organization's human capital is an essential driver of both organizational and social change. Besides, "It is not the strongest of the species who survive, nor the most intelligent; rather it is those most responsive to change" (Charles Darwin). The same stands for organizations.

\subsection{LIMITATIONS}

This study highlighted the knowledge gap in implementing effectively the gender mainstreaming toolkits within organizational context. Nonetheless, the results of the study may need further research to achieve generalizability and validate the impact of the variables in toolkits' selection and implementation. 
Further research on additional factors which may influence the organizational change processes is needed to ensure deeper and more rich understanding on the research question.

EU gender mainstreaming toolkits have been searched extensively in response to research question; however, identified toolkits may be limited. Research on more toolkits developed by international organizations may be needed to enrich understanding on organizational behavior to gender equality toolkits and to explore intersections among sectors, toolkits and pursued change.

The applied Theory of Change may also have some limitations. The potential weaknesses of the ToC may be identified in areas not being timely and properly recognized as being part in the process of change or in assumptions that change is happening because of intervention whereas the actual causes may be different or complementary (Dhillon and Vaca, 2018). To address these limitations research team aims to explore the study's findings through the theory of social change.

\subsection{CONCLUSIONS}

The study explored the transformative capacity of EU gender mainstreaming toolkits towards achieving organizational change. The complexity between toolkits, organizational context and outcomes was assessed critically. Findings unveiled that the duality of gender mainstreaming strategy, namely the gender equality and mainstreaming elements, may have inherited an internal contradiction to relevant toolkits resulting to poor adoption and implementation. The paper claims that improved qualitative elements of the toolkits may facilitate their extensive use and effective implementation within organizational context. Furthermore, the lack of organizational learning capabilities and informed, transformational leadership have also been identified as the potential missing key drivers for organizational change. The paper argues that addressing this knowledge gap should become a core organizational competency applied at all levels of organizational leadership.

\section{Conflicts of interest}

The authors declare no potential conflicts of interest with respect to the research, authorship, and/ or publication of this article.

\section{Funding}

No external funding was received for this work. 


\section{REFERENCES}

Acker, J. (2006) Inequality regimes: Gender, class, and race in organizations. Gender \& society, 2006;20(4), 441-464.

Bailey, J., Budgen, D., Turner, M., Kitchenham, B., Brereton, P., \& Linkman, S. (2007, September). Evidence relating to Object-Oriented software design: A survey. In null (pp. 482-484). IEEE.

Barnett-Page, E., Thomas, J.. Methods for the synthesis of qualitative research: a critical review. BMC Med Res Methodol. 2009 Aug 11;9:59. doi: 10.1186/1471-2288-9-59.

Bates, S., J. Clapton, and E. Coren. 2007. Systematic maps to support the evidence base in social care. Evidence and Policy 3:539-551.

Beauregard, A. T. (2008). Managing diversity in organizations. Equal Opportunities International, 27, 392-395. Available at: http://dx.doi.org/10.1108/02610150810874331

Behning, U., Pascual, A. S. (Eds.). (2001). Gender mainstreaming in the European employment strategy. Brussels: European Trade Union Institute.

Bismark, M., Morris, J., Thomas, L., Loh, E., Phelps, G., and Dickinson, H. (2015). Reasons and remedies for underrepresentation of women in medical leadership roles: a qualitative study from Australia. BMJ open, 5(11), e009384. doi: 10.1136/bmjopen-2015-009384

Bowling, A. (2014). Research methods in health: investigating health and health services. McGraw-Hill Education (UK).

Cavaghan, R. (2017). Making gender equality happen: Knowledge, change and resistance in EU gender mainstreaming. Routledge.

Coe, I. R., Wiley, R., Bekker, L. G. (2019). Organisational best practices towards gender equality in science and medicine. The Lancet, 393(10171), 587-593.

Connell, J. P., Kubisch, A. C. (1998). Applying a theory of change approach to the evaluation of comprehensive community initiatives: progress, prospects, and problems. New approaches to evaluating community initiatives, 2(15-44), 1-16.

Daly, M. (2005) Gender Mainstreaming in Theory and Practice, Social Politics: International Studies in Gender, State and Society, vol.12, Issue 3, pp.433-450.

Dass, P. and Parker, B. (1999). Strategies for managing human resource diversity: From resistance to learning. Academy of Management Executive, 13(2), 68-80.

Denison, D. R. (1996). What is the difference between organizational culture and organizational climate? A native's point of view on a decade of paradigm wars. Academy of management review, 21(3), 619-654.

Dhillon L. and Vaca, S. (2018). Refining theories of change. Evaluation, 14(30).

Dragoni, L. (2005). Understanding the emergence of state goal orientation in organizational work groups: the role of leadership and multilevel climate perceptions. Journal of Applied Psychology, 90(6), 1084.

Dunn, W. N. (2015). Public policy analysis. Routledge.

Eagly, H. A., Carli, L. L.. (2007) Through the Labyrinth: The Truth About How Women Become Leaders.

Boston, Massachusetts: Harvard Business School Publishing

Ellemers, N. (2014). Women at work: How organizational features impact career development. Policy insights from the behavioral and brain sciences, 1(1), 46-54.

European Commission (2019) Report on equality between women and men in the EU. Available at: https://ec.europa. eu/info/sites/info/files/aid_development_cooperation_fundamental_rights/annual_report_ge_2019_en_1.pdf

European Commission. (2018a) Directorate General for Research and Innovation. She Figures 2018. Available at: https://ec.europa.eu/info/publications/she-figures-2018_en

European Commission (2018b) Report on equality between women and men in the EU 2018. Available at: https:// publications.europa.eu/en/publication-detail/-/publication/950dce57-6222-11e8-ab9c-01aa75ed71a1

European Commission. (2017) Special Eurobarometer 465 Report "Gender Equality 2017" Brussels 2017. Available at: http://ec.europa.eu/commfrontoffice/publicopinion/index.cfm

European Institute for Gender Equality (2017). Gender Equality Index 2017: Measuring gender equality in the European Union 2005 - 2015 report. Available at: https://eige.europa.eu/publications/gender-equality-index2017-measuring-gender-equality-european-union-2005-2015-report

European Institute for Gender Equality. Gender mainstreaming. Toolkits (2019a). Available at: https://eige.europa.eu/ gender-mainstreaming/toolkits 
European Institute for Gender Equality (2019b). Gender Equality Training. Gender mainstreaming toolkit. 2016 Vilnius, Lithuania. Available at: https://eige.europa.eu/publications/gender-equality-training-gender-mainstreamingtoolkit

European Institute for Gender Equality (2019c). Institutional Transformation. Gender mainstreaming toolkit. 2016 Vilnius, Lithuania. Available at: https://eige.europa.eu/gender-mainstreaming/toolkits/gender-institutionaltransformation

European Parliament (2019a) Directorate General for External Policies of the Union. Europe's approach to implementing the Sustainable Development Goals: good practices and the way forward. February 2019. Available at: http:// www.europarl.europa.eu/thinktank/en/document.html?reference=EXPO_STU\%282019\%29603473

European Parliament (2019b) Gender mainstreaming in the EU: State of play. Available at: http://www.europarl. europa.eu/RegData/etudes/ATAG/2019/630359/EPRS_ATA(2019)630359_EN.pdf

European Parliament (2019c) Gender responsive EU Budgeting. Update of the study:" The EU Budget for Gender Equality" and review of its conclusions and recommendations. Available at: http://www.europarl.europa.eu/ thinktank/en/document.html?reference=IPOL_STU(2019)621801

Eurostat (2017) Sustainable Development in the European Union. Monitoring Report on Progress towards the SDGs in an EU Context. 2018 edition. Available at: https://ec.europa.eu/eurostat/web/products-statistical-books/-/KS01-18-656

Fox, M. F., Whittington, K., \& Linkova, M.. Gender, (In) equity, and the Scientific Workforce. Handbook of Science and Technology Studies, Mass MIT Press, Cambridge, 2017

Garcia D, Gluesing J. (2013) "Qualitative research methods in international organizational change research", Journal of Organizational Change Management, Vol. 26 Issue: 2, pp.423-444, https://doi.org/10.1108/09534811311328416

Guba, E. G., Lincoln, Y. S. (1994) Competing paradigms in qualitative research. Handbook of qualitative research, 1994; 2(163-194), 105.

Haddaway, N. R., Bernes, C., Jonsson, B. G., Hedlund, K. (2016). The benefits of systematic mapping to evidence-based environmental management. Ambio, 45(5), 613-620. doi: 10.1007/s13280-016-0773-x

Hafner-Burton, E. M., Pollack, M. A. (2009). Mainstreaming gender in the European Union: Getting the incentives right. Comparative European Politics, 7(1), 114-138.

Huffman, M. L. (2002). Gender, Power, and Organizations: An Introduction. Contemporary Sociology, 31 (1), 35.

Jacquot S. (2010). The paradox of gender mainstreaming: Unanticipated effects of new modes of governance in the gender equality domain. West European Politics, 33(1), 118-135. doi: 10.1080/01402380903354163

Jacquot, S. (2017). A Policy in Crisis. The Dismantling of the EU Gender Equality Policy. In: Gender and the Economic Crisis in Europe (pp. 27-48). Palgrave Macmillan, New York

Kalaitzi, S., Czabanowska, K., Fowler-Davis, S., \& Brand, H. (2017). Women leadership barriers in healthcare, academia and business. Equality, Diversity and Inclusion: An International Journal, 36(5), 457-474.

Kalaitzi, S., Czabanowska, K., Azzopardi-Muscat, N., Cuschieri, L., Petelos, E., Papadakaki, M., \& Babich, S. (2019). Women, healthcare leadership and societal culture: a qualitative study. Journal of healthcare leadership, 11, 43.

Kantola, J et al. (2017) Gender and the Politics of the Economic Crisis in Europe. In: Kantola J \& Lombardo E (Eds) Gender and the economic crisis in Europe: Politics, institutions and intersectionality. Palgrave Macmillan, New York, pp 1-25.

Krishnan, N and Szczepura, A. (2018) The glass cliff effect for women in STEM. The Lancet. 2018 Jun 9;391(10137):23202321. doi: 10.1016/S0140-6736(18)30861-4.

Lombardo, E. (2005). Integrating or Setting the Agenda? Gender Mainstreaming in the European Constitution-Making Process, Social Politics: International Studies in Gender, State \& Society, 12(3), 412-432. doi:10.1093/sp/jxi022

Lombardo, E. and Mergaert, L. (2013). Gender Mainstreaming and Resistance to Gender Training: A Framework for Studying Implementation. NORA - Nordic Journal of Feminist and Gender Research, 21 (4), pp.296-311.

Mackay, F., Bilton, K. (2003). Learning from Experience: Lessons in Mainstreaming Equal Opportunities. University of Edinburgh, Governance of Scotland Forum.

McKinnon, M.C., S.H. Cheng, R. Garside, Y.J. Masuda, and D.C. Miller. 2015. Sustainability: Map the evidence. Nature 528:185-187.

Morgenroth, T., Ryan, M. K. (2018). Addressing gender inequality: Stumbling blocks and roads ahead. Group Processes \& Intergroup Relations, Vol. 21(5) 671-677. doi: 10.1177/1368430218786079

Naumann, S. E. and Bennett, N. (2000). A case for procedural justice climate: Development and test of a multi-level model. Academy of Management Journal, 43, 881-889. 
Newman, C., Chama, P. K., Mugisha, M., Matsiko, C. W., \& Oketcho, V. Reasons behind current gender imbalances in senior global health roles and the practice and policy changes that can catalyze organizational change. Glob Health Epidemiol Genom. 2017;2:e19. doi: 10.1017/gheg.2017.11. eCollection 2017.

Ostroff, C., Kinicki, A. J., Muhammad, R. S. (2012). Organizational culture and climate. Handbook of Psychology, Second Edition, 12.

Patton, M. Q. (1999). Enhancing the quality and credibility of qualitative analysis. Health services research, 34(5 Pt 2), 1189.

Petersen, K., Feldt, R., Mujtaba, S., Mattsson, M. (2008). Systematic Mapping Studies in Software Engineering. In EASE (Vol. 8, pp. 68-77).

Rogers, P.J. (2008). Using programme theory to evaluate complicated aspects of interventions. Evaluation, 14 (1), 29-48.

Sandelowski, M., Barroso, J., Voils, C. I.. (2007) Using qualitative meta - summary to synthesize qualitative and quantitative descriptive findings. Research in nursing \& health, 2007; 30(1), 99-111.

Schein, E. H. (2010). Organizational culture and leadership. San Francisco

Schneider, B., Ehrhart, M. G., and Macey, W. A. (2011). Perspectives on organizational climate and culture. In S. Zedeck (Ed.), Handbook of industrial and organizational psychology (pp. 373-414). Washington, DC

Schuh, C. et al. Gender differences in leadership role occupancy: The mediating role of power motivation. Journal of Business Ethics, 2014, 120.3: 363-379.

Scriven, M. (1991). Evaluation thesaurus (4th ed.). Thousand Oaks, CA: Sage Publications.

Sen, A. (1980). Equality of what? Cambridge: Cambridge University Press.

Serrat, O. (2017). Knowledge solutions. Springer Singapore.

Sharma, A. (2016). Managing diversity and equality in the workplace. Cogent Business \& Management, 3(1), 1212682.

Stamarski, C. S., Son Hing, L. S. (2015). Gender inequalities in the workplace: the effects of organizational structures, processes, practices, and decision makers' sexism. Frontiers in psychology, 6, 1400.

Streeton, R., Cooke, M., Campbell, J. (2004). Researching the researchers: using a snowballing technique. Nurse researcher, 12(1), 35-47.

Toh, S.M., Leonardelli, G.J. (2012) Cultural constraints on the emergence of women as leaders. Journal of World business, 2012, 47.4: 604-611.

Torraco, R. J. (1997). Theory-building research methods. Human resource development handbook: Linking research and practice, 114-137.

Trice, H. M., Beyer, J. M. (1993). The cultures of work organizations. Prentice-Hall, Inc.

Verloo, M. (2005). Displacement and empowerment: Reflections on the concept and practice of the Council of Europe approach to gender mainstreaming and gender equality. Social Politics: International Studies in Gender, State \& Society, 12(3), 344-365.

Webb I, Temple N. (2015) Social media and gender issues. In: Guzzetti B and Lesley M (Eds) Handbook of Research on the Societal Impact of Social Media. IGI Global, $1^{\text {st }}$ ed, Hersey PA, USA. pp 638-669

Weiss, S (1995) Nothing as practical as good theory: Exploring theory-based evaluation for Comprehensive community initiatives for children and families. In Connell, J, Kubisch, A, Schorr, L, \& Weiss, C. (Eds.). New approaches to evaluating community initiatives (65-92). Washington, DC: Aspen Institute.

Wenger, E. (2010). Communities of practice and social learning systems: the career of a concept. In Social learning systems and communities of practice (pp. 179-198). Springer, London.

Woodward, A. (2001). "Gender Mainstreaming in European Policy: Innovation or Deception." Discussion Paper. Berlin:WZB.

Zohar, D., Luria, G. (2005). A multilevel model of safety climate: Cross-level relationships between organization and group-level climates. Journal of Applied Psychology, 90 (4), 616-628. 



\section{Chapter}

Ceneral discussion 



\subsection{GENERAL SUMMARY OF THE THESIS}

European Union's high level legal and political commitment towards achieving gender equality objectives has produced suboptimal outcomes. Any progress made has been slow, uneven and fragmented. The priorities misplaced by policy makers and the inconsistent commitment across EU bodies and agencies fostered the persistence of barriers to gender equality to women's leadership and equal representation in economy and society, undermining thus the social cohesion and sustainable future for the EU citizens and the generations to come.

The aim of this thesis has been twofold: firstly, to identify comprehensively the barriers and their prevalence to women's leadership and gender equality and, secondly, to gain deeper insights on how a persisting and central policy problem at the EU and Member States level remained poorly addressed for over two decades and has been receiving sub-optimal attention (EC, 2019a; Jacquot, 2017; EP 2019). Applying insights from social constructionism (Schwandt, 2000), the study uses empirical evidence to examine, in the first place, the barriers to women's leadership and gender equality and their varying prevalence and then turns to EU's gender equality policy and implementation sphere to identify potential gaps and solutions to explored phenomenon.

In particular, moving from a comprehensive to a granular approach, the research focused on the barriers to women's leadership in healthcare sector manifested within countries' socio-cultural and economic contexts. Healthcare sector has been selected as the sector of interest to study the research phenomenon on the grounds of the critical importance healthcare bears for health systems, society, economy and policy at both the EU and Member States level (Wismar et al, 2019). Secondly, the research focus was further intrigued by women's striking under-representation in leading positions across healthcare sector although being women populated and of high social regard (Kapilashrami and Hankivsky, 2018; Kuhlmann et al, 2017; Newman et al, 2017; Downs et al, 2016; Bismark et al, 2015; Fjeldsted, 2013). Thirdly, healthcare sector is considered one of the major employers, encompassing several facets, such as academic, clinical and medical, and job categories, which offer ample ground to gain deep insights on the research question (Eurostat 2019a; OECD 2018; HRH, 2017). The research analysis has been evolved in three phases respecting to the quality and trustworthiness criteria of qualitative analysis, such as validity, reliability and triangulation of data, to achieve methodological rigor, resonance, meaningful coherence and ethics (Patton, 1999; Tracy, 2010)

- Problem statement \& hypothesis aiming to develop a barriers map to women's leadership and gender equality and formulate the hypothesis on barriers' comprehensive manifestation and varying prevalence across sectors (Chapter 2).

- Hypothesis testing looking at the barriers' comprehensive manifestation and varying prevalence in the healthcare sector. The developed theory was tested across the healthcare sector in two EU countries (Greece and Malta); the findings were studied and contrasted in order to provide deeper insights on the explored phenomenon (Chapter 3 and 4). 
- Policy and implementation seeking to explore EU policy objectives on gender equality and women's leadership; priorities and challenges of current policy agenda were assessed and implementation of gender mainstreaming toolkits were considered (Chapter 5 and Chapter 6)

The thesis at hand is, at author's best knowledge, the first endeavor to address the knowledge gap in gender equality barriers analysis through a systematic comprehensive and prevalence approach; namely, to explore the barriers' comprehensive manifestation and their varying degree of' prevalence across sectors, with a special focus on the healthcare sector and country's sociocultural and economic contexts. The thesis' milestones and timeline are summarized in Figure 7.1:

Figure 7.1 | Thesis's milestones and timeline

Problem statement \& hypothesis -Systematic literature review (BTM), EU level

(2015-2016)

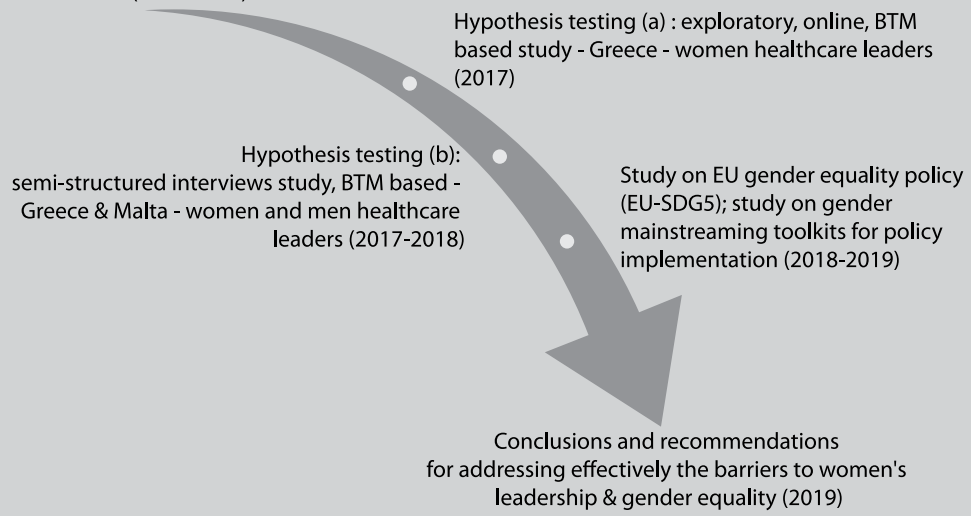

In the following section, the main findings per chapter and per research question are summarized (Section 7.2) followed by broader reflections on scholarship's recent stance on the research topic, supplemented by a discussion assessing the EU gender equality policy and implementation (Section 7.3). In a subsequent step, the way forward is discussed (Section 7.4) debating on the lessons learnt from studying gendered barriers, and delineating the perspectives for future research and policy. The limitations of this thesis are deliberated thoroughly in the last section (Section 7.5).

\subsection{THE MAIN FINDINGS OF THE THESIS}

This thesis consists of three main parts (I. Problem statement and hypothesis - Chapter 2; II. Hypothesis testing - Chapter 3 and 4, and III. Policy and implementation - Chapter 5 and 6) each addressing a specific structural block of the undertaken qualitative research study.

Chapter 2 dealt with the problem statement and hypothesis, namely what are the barriers 
to women's leadership in EU context and how they can be addressed more effectively. A comprehensive map of barriers to women's leadership across three vital sectors for EU economy and society, healthcare, academia and business, was developed. The Barriers Thematic Map (BTM) included twenty-six barriers with quantitative logic and varying degree of prevalence. The BTM uncovered gendered inequalities across sectors and draw attention to under-studied barriers' prevalence across sectors. Furthermore, a potential knowledge gap in gendered policies was identified pointing out the need to address gender equality challenges differently across different work settings and to shed light on practice related blind spots.

Chapter 3 and Chapter 4 focused on hypothesis testing by exploring the phenomenon within social reality, contextualizing and interpreting the findings and gaining in depth insights in relation to research hypothesis. To that end, research was narrowed down to one out of the three sectors, to healthcare sector, within the context of two, comparable countries, Greece and Malta.

Firstly, empirical findings (online survey) on perceptions of Greek women healthcare leaders on barriers to career advancement identified the twenty-six barriers included in BTM. Six barriers (stereotypes, work/life balance, lack of equal career advancement, lack of confidence, gender gap, and gender bias) prevailed in women leaders' perceptions in constraining opportunities for pursuing leading positions in Greek healthcare setting, whereas all twenty-six barriers presented varying degree of prevalence.

Secondly, qualitative research findings (semi-structured interviews undertaken from both women and men healthcare leaders) identified twenty and twenty-one barriers to women's leadership within the Greek and Maltese healthcare settings, respectively. In both research settings prevailing barriers included work/life balance, lack of family (spousal) support, culture, stereotypes, gender bias and lack of social support, yet inter-country similarities and differences in prevalence of the identified barriers were observed. Notably, cultural tightness was found to be experienced at the same time as an alibi or barrier against socio-cultural transformation in Maltese context, avowing prior research claim of culture as the wooden leg of policies. Thus, research findings unveiled underlying interactions among gender, leadership and countries' socio-cultural contexts elucidating the varying degree of strength of norms and barriers embedded in a society's egalitarian practices. Furthermore, findings informed a tripartite conceptual framework which links country's socio-cultural contexts with comprehensive data on gendered barriers harvested from healthcare sector. Applying the framework may offer a reality check detailing barriers' mapping and prevalence through country's specific lenses providing thus a tool to policy to understand better the durability and transferability of gendered barriers and to address potential blind spots in equalizing career advancement.

Chapter 5 turns to gender equality policy agenda at the EU level. The chapter evaluates the sustainable development thinking in gender equality policy objectives in EU pertaining to its relevance to interests and challenges faced by Member States' citizens. In particular, the chapter explores the relevance of EU SDG5 themes and indicators and the prioritization of policy objectives 
to actual social reality across Member States. The translation of SDG5 into national achievable targets is assessed on the grounds of persistent and uneven gender inequalities across Member States; the added value of required EU's proactive leadership in supporting Member States to develop evidence-informed gender policies is also discussed. Findings identified inconsistencies in application of gender equality related articles binding for both EU and Member States (Treaty of Lisbon, Art 2, Art 3.3, Art 6.1, and Art 9), posing thus questions about the prioritization of gendered challenges from EU and national policy actors and stakeholders. The study argues for EU's proactive leadership, underpinned by academia and civil society contributions to optimize support to the Member States to revisit their national policies and develop evidence-informed policies; thus, the sustainable development efforts may be strengthened to align with the gendered priorities and challenges faced by Member States' citizens.

Moving to the policy implementation capacities, Chapter $\mathbf{6}$ discusses the transformative capacity of the developed EU gender mainstreaming toolkits against organizational culture and climate. The study is undertaken through the lens of theory of change placing toolkits in milieu of change processes. In particular the study draws on qualitative analysis of change to gain in depth understanding of the complexity between toolkits, organizational context and outcomes; the potential room for improvement for more effective implementation of gender mainstreaming toolkits in order to bring about organizational and social change is discussed.

Overall, this thesis demonstrated that barriers to women's leadership and in a broader note, to gender equality are numerous, manifest themselves in chorus with varying degree of prevalence across and within sectors and are greatly influenced by country's socio-cultural and economic contexts. Hence, in contrast to published literature, the findings support that barriers to gender equality need to be addressed comprehensively, not on a one to one basis, aiming to capture the wholeness of the problem and, hence, design, implement and evaluate policies, strategies and practices resonating closely to and bearing the dynamics and potential to address the actual priorities and challenges across sectors and countries. In addition, this study showed that policy may find fertile avenues for efficient implementation of gender sensitive policies turning to evidence informed agenda, which will make it possible to map accurately a country's gendered challenges, monitor and evaluate reliably any progress made.

Based on the summary of the main findings the discussion moves now to broader reflections on barriers to women's leadership and gender equality and EU gender policy. Firstly, the developments on scholarship and civil society's approach about the gendered challenges in healthcare are considered; then, the EU gender equality policy is debated in regard of potential weaknesses and ways for improvement.

\subsection{REVISITING THE BARRIERS TO GENDER EQUALITY IN EU CONTEXT}

This thesis identified 26 barriers to women's leadership and gender equality with varying 
degree of prevalence across sectors and within country's socio-cultural and economic contexts. Although there is a growing interest from scholars and EU policy actors to balance out gendered representation across work settings in healthcare and in broader work and social spectrum, any progress made is poor, uneven and fragmented. In the following sub-sections, the recent developments on scholarship and civil society's stance on the gendered barriers in top leading positions in healthcare are discussed; then, the EU gender equality policy is considered in terms of its priorities and challenges faced by Member States' citizens and ways of improvement for the benefit of EU's social cohesion and sustainable development.

\subsubsection{Barriers to gender equality: The case of healthcare sector}

This thesis looked closely at the barriers to women's leadership in healthcare and, at a broader note, to gender equality, on the grounds of the importance healthcare bears for EU citizen's' health and for the European and Member States society and economy in general. The compelling argument on the urgency and the timeliness of the research topic is built on the pressing need for sustainable transformation of the healthcare sector and the need for inclusive leadership at all ranks and facets to lead this endeavor. Health workforce is the beating heart of healthcare and health systems which are mainly populated by women. Hence, the interest of scholars, civil society, European and international agencies on the persisting underrepresentation of women in leading positions and the implications to health systems, economy and society has been growing rapidly during the latest years.

Mapping the published literature following the literature review of this thesis up to date is beyond the scope of this chapter; however, scholarship's recent keen interest on the topic may be indicated by the launch of "The Lancet - Advancing women in science, medicine, and global health" journal in 2018, published under the umbrella of the prestigious collection of journals "The Lancet" (2019). The nascent journal is dedicated to address women's underrepresentation across medical and health leadership scope covering all possible corners, such as barriers and facilitators, gaps in policy, education, organizational culture, and potential interventions. The responsiveness to the calls for paper submission has been ten times fold than the demand indicating clearly that women's underrepresentation in medicine and healthcare has turned to a burning issue seeking out for solution (The \#LancetWomen Newsletter January 2019).

Furthermore, scholarship reviewed critically the explored phenomenon from several disciplinary standpoints; medical, health and public health scientists focused on the structural barriers hindering women's career advancement, such as gender bias, gender pay gap, lack of mentoring (Linkova, 2017; McLaughlin et al, 2017; Newman et al, 2017; Lerch-Pieper et al, 2018; Carli and Eagly, 2011; Bismark et al, 2015; Arulampalam et al, 2004; Ellemers, 2014); the sociologists and psychologists argued for women's leadership special traits, such as transformational trait and inclusiveness, and challenged the social and cultural resistance in equalizing women leaders' roles (Toh and Leonardelli, 2012; Eagly and Chin, 2010; Ingelhart et al, 2003; Acker 2006). Organizational and management researchers considered gender equality by defending the added value the gender balanced leading teams bring into organizations' performance (EC 2019a; Erhardt et al, 2003; 
Benschop and Verloo, 2010; UN Women, 2014); further on this line, health economists, finance and management scientists and experts argued passionately for the contribution of gender equality not in the economic growth alone, but also on social cohesion and society's sustainable future (EC, 2019a; EP, 2019b; OECD, 2019; WHO, 2019). On a different perspective, gender experts criticized rigorously the EU policy and neoliberalism pressures resulting in fading away the genuine meaning of gender equality principle, the neglect of rising opposition to gender policies across Europe and the progressive dismantling of gender equality as a distinct policy objective in the EU policy project (Jacquot, 2017; Paternotte and Kumar, 2018; Kantola and Nousiainen, 2012; Lombardo and Forest, 2015; Verloo et al, 2009).

Arguably, the considerable, multi-disciplinary effort to unpack the complexity of barriers to gender equality demonstrates scholarship's unanimous voice on achieving gender equality objectives and, thereby, on addressing the gendered barriers in a feasible and effective way. The $23,920^{*}$ downloads and reads of the research articles included in the present thesis within two years' time (June 2017- July 2019) is only a small indication of the increasing need to address the knowledge gap in the field (EDI, 2019; Frontiers in Public Health Policy, 2019; J Health Leadersh, 2019).

Similarly, a growing interest on gender inequalities in health and healthcare from civil society actors has been observed in recent years. Non-Governmental Organizations (NGOs) (e.g., Leaders in Healthcare, Women Leaders in Global Health and Women in Global Health Research Initiative) and associations (e.g. European Public Health Association, International Network for Health Workforce Education, European Health Management Association, European Health Economics Association, RINGS - The International Research Association of Institutions of Advanced Gender Studies) advocate gender equality in health workforce from several perspectives, such as equal opportunities to career advancement, and equal pay, underscoring thus the need for further research, awareness and capacity building activities. In the same line, European and international agencies with a close eye to EU region dealt intensively in recent years with women's underrepresentation in healthcare. In particular, Dr Tedros, Director General of WHO, re-stated the necessity for gender transformative action in health (WHO, 2019a), whereas the WHO Global Health Workforce Equity Hub in 2017 was launched (WHO, 2019b). The Organization for Economic Co-Operation and Development (OECD) established the OECD Gender Initiative aiming to examine existing barriers to gender equality in employment and education focusing, amongst others, in health sector (OECD, 2018). It is also noteworthy that top level representatives from countries around the globe co-signed the recent Alma-Ata Declaration on primary healthcare towards achieving sustainable development goals confirming thus explicitly their commitment to gender sensitive healthcare under the perspective of the sustainable governance of health systems (WHO, 2019c).

However, although all involved actors detailed the importance and urgency of gendered challenges in healthcare and established the relevance of gender equality in health workforce to sustainable

\footnotetext{
${ }^{*}$ metrics yielded by journals' site as of September $8^{\text {th }}, 2019$
} 
governance of health systems, the results remain poor. Any progress made has been uneven and at a snail pace indicating that the policy stakeholders may have not acted on a collective and committed basis and as such, the policy intentions and policy implementation have not been bridged yet (EP, 2019b; EC, 2019a). Gender policy scholars argue that improving transferring of the academic knowledge to policy practice servants may have significant impact in consistent commitment to gender equality policy objectives (Cavaghan, 2017). Furthermore, the lack of disaggregated data, monitoring and accountability mechanisms at organization, country and EU level may be of equal importance for holding back policy prioritization and effective, measurable implementation (OECD, 2017; EP, 2019b; EC, 2019a; EIGE, 2017).

\subsubsection{Gender equality policy: the "side dish" of EU policy}

The European Union has a strong track record of commitment to gender equality and women's empowerment anchored in the European Treaties and expressed by policies on economic development, social cohesion and democratic societies (European Commission, 2017). More specifically, EU and Member States have a clear mandate on working towards observing and achieving gender equality between women and men which is explicitly stated in the binding articles of the Treaty of European Union (Treaty of Lisbon, 2007) (EUR-lex, 2019a):

"The Union is founded on the values of respect for human dignity, freedom, democracy, equality, the rule of law and respect for human rights, including the rights of persons belonging to minorities. These values are common to the Member States in a society in which pluralism, non-discrimination, tolerance, justice, solidarity and equality between women and men prevail". (Article 2)

"... to combat social exclusion and discrimination' and to 'promote social justice and protection, equality between men and women, solidarity between generations and protection of the rights of the child'. (Article 3.3)

'The Union recognizes the rights, freedoms and principles set out in the Charter of Fundamental Rights of the European Union of 7 December 2000, as adapted at Strasbourg, on 12 December 2007, which shall have the same legal value as the Treaties". (Article 6.1) ${ }^{1}$ and

"In all its activities, the Union shall observe the principle of the equality of its citizens, who shall receive equal attention from its institutions, bodies, offices and agencies". (Article 9).

However, although gender equality has been enshrined as a fundamental principle in EU treaties

1. Charter of Fundamental Rights of the European Union. Article 21 - Non-Discrimination: "Any discrimination based on any ground such as sex, race, color, ethnic or social origin, genetic features, language, religion or belief, political or any other opinion, membership of a national minority, property, birth, disability, age or sexual orientation shall be prohibited" and Article 23 - Equality between men and women: "Equality between men and women must be ensured in all areas, including employment, work and pay. The principle of equality shall not prevent the maintenance or adoption of measures providing for specific advantages in favor of the under-represented sex." Source: https://eurlex.europa.eu/legal-content/EN/TXT/PDF/?uri=OJ:C:2000:364:FULL\&from=EN 
and as an overarching policy objective in EU policy agenda, it has constructed and contested in multiple ways in EU gender equality policy.

\section{Inconsistent commitment and lack of collective action}

The European Parliament, European Commission and European Council, the institutions producing the policies and laws that apply throughout EU, have adopted different framing to gender inequalities across a wide range of policy areas, such as social affairs, and employment (European Union, 2019).

The European Parliament, supported greatly by the Committee on Women's Rights and Gender Equality (FEMM, 2019) has been "a strong supporter of gender justice" (Van der Vleuten 2012, p. 49) espousing a clear human rights perspective to women's rights (Ahrens and van der Vleuten, 2017). However, internal controversies have been mirrored in several cases blurring the clarity of this approach; for example, the Estrela report on sexual and reproductive health and rights was brought into discussion in a parliamentary session (FEMM 2013; Kantola and Lombardo, 2017); the conservative views, coming mainly from countries banning the abortion, prevailed framing the Estrela report as outside of EU's sphere of influence. As a result, the Parliament adopted a minor statement degrading the policy debate at Member State responsibility level (Kantola and Rolandsen-Agustin, 2016). Similarly, the financial crisis was initially framed as aggravating women's position in the labor market, leading to fostering gender discrimination and gender violence and, ultimately, resulting in dismantling of gender equality policies (Jacquot, 2017; Bauer and Knill, 2012). Yet, in later debates the framing about crisis and gender equality was rejected (Kantola and Rolandsen-Agustin, 2016).

The European Commission framed gender equality policies through gender mainstreaming in all policies (Ahrens and van der Vleuten, 2017; Cavaghan, 2017) undertaken by actors normally involved in policy making (Kantola and Lombardo, 2017); yet it ended up to bureaucrats with a rather technical than political conceptualization of gender equality principle shaping accordingly the policy agenda (Meier and Celis, 2011, p. 4; Kantola 2010, p. 128). Similar to the Parliament, the Directorates-General (DGs) of the European Commission framed differently the gender equality objectives. For example, the DG Trade (TRADE) held against to embed the gender perspective in their policymaking (Woodward and van der Vleuten, 2014) and reinforced the stereotypes on traditional gender roles in family farming (DG AGRI) (Prügl, 2010). Likewise, the DG RTD (Research and Innovation) put forward resistance against gender mainstreaming implementation (Cavaghan, 2017). The European Councils appear also to care for gender equality agendas, although it is hard to debate on their policy framing since they work behind closed doors and the relevant published literature is limited (van der Vleuten, 2012).

The developed EU gender equality policy has been influenced also by additional networks in policy framing and promotion. Such networks include gender experts in the European Commission and Parliament (e.g., FEMM, EIGE, etc), civil society actors, and gender scholars and consultants (Ahrens and van der Vleuten, 2017, Jacquot, 2010). Gender scholars argue that EU gender policies are the battleground for EU institutions underpinned by shifts in power relations (Kantola and Lombardo, 2017). For example, gender equality policy strategies have been framed from equal treatment to 
gender mainstreaming, from economic priorities to social and political contexts and to the recently commitment to Sustainable Development Goal No 5 (Achieve gender equality and empower all women and girls) (UN, 2015), and cross cutting goals (Eurostat, 2018). This indicates the dynamics in power relations, the interplay between the policy objectives of different actors in relation to different policy issues. Therefore, the way gender (in)equality is framed, engages differently the different actors across the EU policy making arena which results in fading away the centrality of the policy problem; hence, the gender equality policy objective is placed as the "side dish" of the actual EU policy making goals (Verloo and van der Vleuten, 2009).

Thereby, the absence of overall and consistent commitment to gender equality in the EU policy is reflected by the lack of collective political commitment and legislative action of the European Parliament, the European Union and the European Council, which, in the opposite case, could have anchored gender equality strongly to all EU policies. Although gender equality is recognized as an overarching policy objective, the broad nature of gender and the varied framing of the problem conceptualization, even within EU bodies, result in different EU gender policies, practices and mechanisms, such as funding and budgeting (EP, 2019b; Kantola and Lombardo, 2017; Bacchi, 2009; Verloo and Lombardo, 2007), which, in turn, conflicts directly with the EU's full legal and political commitment (Art 2, Art 3.3, Art 6.1, Art 9; Treaty of Lisbon, 2007) (EUR-lex, 2019a). This inconsistent commitment may result to limited positive impact on gender equality issues, such as gendered unemployment which, in turn, has complex societal dimensions and as such falls under the scope of various policies, which could be addressed through collective and persistent action. Thus, although gender equality was consistently recognized as an overarching policy objective in all policy areas, issues with a significant impact on gender equality may not be addressed on a committed and collective basis.

A typical example is that the principle of gender equality does not appear to draw a prime attention in gender budgeting, which is an essential tool to ensure that governmental spending observes the principle of gender equality. The EU annual budget has been criticized for suffering from inconsistencies as to whether and to what extent the principle of gender equality is met (EP, 2019b; EIGE, 2019). From the gender budgeting analysis perspective, there were notable inconsistencies among the policy areas in terms of recognizing gender equality as a policy objective per se and with regard to the extent is embedded in policy implementation and spending. The absence of gender equality principle in EU funding has been echoed in the Resolution of European Parliament in 2017 [2016/2144(INI)], as similarly has been omitted in the forthcoming Multiannual Financial Framework 2021-2027 (EC, 2019b; EP, 2019c; EIGE, 2019). Furthermore, the allocation of resources to different policy objectives has not been sufficiently transparent. For instance, programs and actions with different policy objectives were oftentimes grouped under umbrella policies making it difficult to observe budget allocation among different policy objectives (EP, 2019c). Therefore, EU budget implementation could have been strategically prioritized at the discretion of EC and other authorities to certain objectives over others raising thus the risk of gender equality objectives being shadowed by other policy objectives. The Daphne III program offers an additional typical example: the program included mixed policy objectives such as fighting against gender-based violence, 
protection of personal data, the protection of the rights of the child and the empowerment of consumers (EP, 2019b; EP, 2019d). The policy objective "fight against gender-based violence" had to compete against other policy objectives of the same basket to attract the best possible funding and avoid suffering in case the other policy objectives were prioritized. Thereby, the program's coherence with the Istanbul Convention has been questioned (EP, 2019d; Montoya, 2010)

\section{Lack of knowledge transfer}

Bringing the gap between academic knowledge and policy making and implementation turns out to be a rather appealing but composite endeavor to put into practice (EC, 2019d; EIGE, 2017). Gender equality is a socially cross-cutting, multi-faceted issue with noticeably different framings in different contexts and cross policy purposes. The complex and broad nature of the topic may explain the distance between rhetoric and practice in EC policy making and implementation. Cavaghan (2017) states that in daily working practices of civil servants on processes of knowledge construction within the Commission, gender is consider as not relevant or too difficult to address, which results in indifference and non-awareness of gendered policy problems.

Academic knowledge has huge strength which could trade-off the policy complexities. Academic knowledge transfer into gender equality policy agenda and practice, may need to be better embedded in the dynamic interaction of gendered challenges and policy and thus improve the way academic research and policy are connected. Robust, academic generated evidence may have not been entrenched efficiently enough in the knowledge brokering cycle, being loosely tied to policy relevance and prioritization and shared in a not well interpretable and applicable way. Thereby, the present knowledge brokering cycle may have not yet reached the level required to turn the evidence into evidence-informed policy.

In EU gender equality arena, the three parts of the knowledge brokering cycle may have got tangled (Figure 7.3.2). For example, identifying the real policy question (Part 1) requires the involved stakeholders to understand the situation that stimulates the question, to agree on the meaning of the formulated question and on the type and qualities of the evidence to be generated in order to address the policy question. It appears that the stakeholders involved in the knowledge brokering cycle, namely EU, Member States and academics, perceive gender equality objectives differently; for example, recently, EU committed to implement UN SDG5 in EU gender equality policy focusing on four central themes (leadership positions, gender-based violence, employment, education), the Member States have been developing varied gendered policies with uneven level of progress, and academics argue that the gender equality principle has been depowered in policy dialogue, the gender equality policy is dismantling and they set the alarm on the emerging opposition to both gender equality principle and EU gender policy. In that line, the right evidence to address the primary policy question vary across involved actors (Part II); for instance, several EU agencies generate various, non-comparable gendered data; for example, Eurostat developed the EU SDGs Indicator Set generating data around the progress made in the four above mentioned themes (Eurostat, 2017); the European Institute for Gender Equality developed the Gender Equality Index drawn upon seven domains (work, money, knowledge, time, power, health, violence) (EIGE, 2017) and the data genereted by the national bodies of Member States responsible for gender equality varies greatly 
depending on internal policies and capacities. On the other hand, academic research across EU offers aggregated gender data within the possibilities derived from the limited, research funding (Jacquot, 2017; Massino and Popa, 2015; Verloo et al, 2009; Locher, 2012; Kantola and Nousiainen, 2012; Forest and Lombardo, 2012). Therefore, the generated evidence lacks in homogeneity of methodology, comparability and, maybe, transparency. Arguably, communicating the evidence in a timely, understandable, applicable and policy relevant way (Part III) to engage policy makers and practitioners and ensure they feel ownership and consistent commitment is far from reality.

Figure 7.3.2 | The knowledge brokering cycle. Turning evidence into evidence-informed policies [adapted from Lessof et al (2018) Twenty years of evidence into practice: Reflections on the Observatory in 10 (key) lessons. Eurohealth, 24(2): pp 4-7]

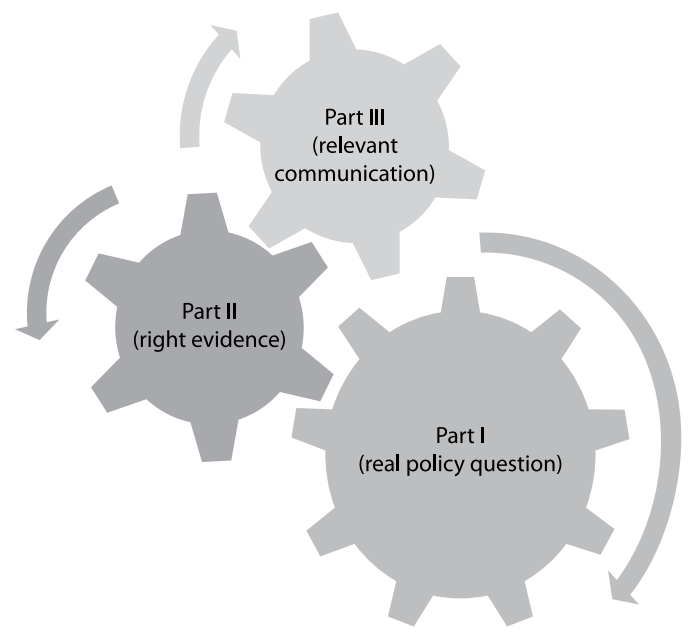

It is common knowledge though that there is rarely one single "best" policy when it comes to complex policy areas, such as gender equality. Thereby, methodologically robust, comparable evidence may uncover the best, or worst, ways in developing sound, evidence informed policies in gender equality field, which are more than ever needed and relevant.

\section{Lack of gender-disaggregated data}

Along with commitment inconsistencies, almost none of the EU gender related policies incorporate a systematic and consistent monitoring mechanism, such as data collection, to evaluate whether the policy has achieved its objectives and what should be improved (EP, 2019b; ElGE, 2017). The lack of collection of gender disaggregated data generated mostly from EU gender programs increased the level of difficulty in evaluating the impact of gender equality policies, in particular at Member States implementation level (EP, 2019b). For example, the European Social Fund, a program involving a complex, multi-level implementation regime, presented varying degrees of commitment to gender equality across Member States (EC, 2019c). Data collection regarding the implementation of such programs became very important to prevent inconsistencies, to fine tune evidence informed policies and revisit misplaced priorities and unmet challenges (EP, 2019b; OECD, 2018; Eurostat, 2017, Wismar et al, 2019). 
Arguably, the development of evidence informed policies may be of added value for EU gender equality policy making enhancing consistent delivery on the legal and policy commitments for equality, well-being and social cohesion across EU which aligns with the clear EU mandate for pursuing gender equality between women and men. Robust evidence generated by academic knowledge may fill in the gaps in the policy cycle and contribute in developing evidence informed gendered policies, relevant and effective to address the gendered barriers faced within country's specific socio-cultural and economic contexts. For example, the gender pay gap varies significantly across EU countries by 22 percentage points, ranging from $3.5 \%$ in Romania to $25.6 \%$ in Estonia (Eurostat, 2019)

As the social dimension is becoming ever more critical for the EU, the need to address any policy gaps and the inconsistent commitment of gender equality policies implementation at both EU and Member States level is increased. Putting evidence into practice is complicated and context dependent; yet, it remains a dynamic process with a continuous interaction between research and policy makers which may identify priorities and evaluate the level of responsiveness to key audiences.

\subsection{IMPLICATIONS FOR RESEARCH AND POLICY}

\subsubsection{The "pathei-mathos" in gender equality}

Gender asymmetries are considered a universal fact of human societies reflecting the distinction between power and culturally legitimized authority (Rosaldo, 2007; Parsons, 1964). Power is multilayered and dynamic, thereby situational and fractured (Holloway, p 266). Leadership is about power and transition; women's leadership is a shifting terrain of gender and power where women have to learn how to transform their relationship with power and men have to learn how to get along with this transformation. Gender equality is mainly about challenging the social norms about gendered authority and the expected social roles. it is also about balancing wisely the power of self-determination, responsibilities and obligations which come with equality; and these are lessons to be learnt by both women and men.

The barriers to gender equality may be the "pathei mathos" towards achieving gender equality. The Aeschylian term, ${ }^{2}$ liberally adapted for the purposes of this thesis, indicates basically a practical

2. The phrase "pathei mathos" has been introduced by Aeschylus, in Agamemnon 176-8, referring to Zeus who laid down the law pathei mathos ("learning through suffering") (Sommerstein, A. The Tangled Ways of Zeus: And Other Studies In and Around Greek Tragedy. Oxford Scholarship Online. 2010. doi: 10.1093/acprof:oso/9780199568314.001.0001). Modern scholars argue that the phrase imply a dialectic of contradictory opposites and thus, for human beings, a separation of otherness which, in turn, may be a cause of suffering for both ourselves and for the other being (Myatt, D. The philosophy of pathei mathos. Available at: https://perceiverations.wordpress.com/ ). Thereby, the "pathei mathos" refers to "the knowing of the good which arises from the human faculty of empathy and which emphatic knowing is different from that knowing which may be acquired by means of Aristotelian essentials of conventional philosophy and experimental science. .... Empathy, thus inclines a person toward certain values, toward a particular type of personal character and disinclines them toward doing what is bad, what is unfair, what is harsh and unfeeling; what intentionally causes or contributes to suffering. ... For empathy involves a numinous sympathy with another living being, a becoming of other that being so that we know, can feel, can understand the suffering or the joy of that living being. (Myatt, D. The Numinous Way of Pathei-Mathos. CreateSpace Independent Publishing Platform, 2013; Part I, Section 1. Morality, Virtues and Way of Life) 
way to acquire a personal insight, a self-knowing and hence a sense of profound truth, of wisdom through enduring with dignity unfortunate experiences.

The bounded social reality is socially constructed, and thus depend on shared beliefs, knowledge, institutional context and personal values to transcend the boundaries and bring change at a broader social level. Capitalizing on experiential learning gained through facing gender challenges and studying on the best possible ways to address them effectively, it may be a lesson learnt from both individuals and our ever-evolving society. The path towards achieving gender equality may be actually about own's inner power to bend the reality and bring small, incremental change on daily living; to transition from one standpoint to the next accumulating small things that by themselves are harmless and useless, but when repeated over and over and again, then become common belief, values, skills, discipline, common wisdom and bring social change. Policy and scholarship may be the great allies in supporting the achievement of gender equality objectives and truthful champions in setting the frameworks and strategies to foster this transition for the benefit of society's and its constituent parts' sustainable future. After all, the whole (society) is more than the sum of its parts (women and men).

\subsubsection{Future perspectives for research}

This thesis provides evidence that the barriers to women's leadership and in a broader perspective to gender equality are multiple, manifest in chorus and with varying degree of prevalence within and across sectors and country's socio-cultural and economic contexts. However, considering the complex and cross-disciplinary nature of the research topic, several implications can be identified for future research.

Healthcare professional roles, namely academic, clinical and medical, oftentimes overlap in practice. For example, an associate professor may also occupy an assistant clinical director position. Thereby, further research should be undertaken seeking to explore deeper the barriers' manifestation and prevalence across healthcare facets. Extrapolation of research findings across healthcare facets may provide in depth understanding on the durability of barriers and their influence to professional and organizational culture and potential facilitators in women's career advancement.

Health professions are of high social regard (Riska 2001; Acker, 2006). Research on the social impact of women healthcare leaders under the role models' capacity would add considerably in the narratives for achieving work/life balance. Moreover, the paradigm of a gendered balanced health workforce at all levels of leadership should be explored in terms of implications at both society and other sectors of economy. For example, the business case of gender equality in health sector has been addressed at global level (UNDP, 2018; WHO, 2019a; OECD, 2018), but not quite at country's level. Exploring the improved performance and related economic benefits linked to increased women's representation at all leadership levels in national health sector, may be an important leverage to prioritize and incentivize gendered policies, especially in low and middle-income countries. 
Although this thesis observed the critical role of culture in relation to the durability and transferability of gendered barriers, the findings cannot be generalized across cultures within which the gendered roles and socio-economic structures differ. Further research agenda on countries' domestic cultural front analyzing the perceptions of both women and men in relation to gendered roles at work and at home will extend the knowledge base on cross-cultural perspective. The research findings may offer deeper insights on country specific interventions to lessen the burden of cultural footprint in gender equality objectives. Additionally, although this thesis included empirical data generated from men's perceptions on women's leadership, it would be extremely useful to extend research exploring men's expectations and contribution in addressing gender equality challenges.

Furthermore, although prior research has dealt extensively with vulnerable groups, such as disabled, minorities, immigrants and older persons, further research on gendered barriers hindering social inclusion and well-being of vulnerable people is very much needed; exploring the nature and prevalence of the constraints may shed light on potential facilitators to counterbalance the negative effects. Especially in case of highly qualified women immigrants, the "knowledge travelers" and oftentimes breadwinners for their families, the implications in knowledge transfer, knowledge economy promotion and cultural integration need to be explored and assessed. In that line, the gendered barriers research should broaden its scope to include LGBTI (Lesbian, Gay, Bisexual, Transgender and Intersex) community focusing especially on micro-manifestations within social and cultural settings which may undermine the cultural and societal openness in gender fluidity.

Last but not least, next generations'values and perceptions on gender equality have to be explored extensively since they will be soon called upon to take the lead. The Generation Y (1980s - mid 1990s) and Generation X (late1990s - mid 2010s) have experienced socio-economic changes transforming, amongst others, cultural attitudes towards gender equality (Ingelhart and Norris, 2001). Research on Gen Y and Gen X's perceptions on barriers and facilitators towards achieving gender equality and social cohesion will provide orientation for effective communication and knowledge transfer among present and future leaders.

\subsubsection{Future perspectives for policy}

Gender equality has been an overarching policy objective in EU policy. Although some progress has been observed in equalizing women's representation, gender transformative policies are needed to address inequities and remove barriers to full professional development and leadership roles.

Scholars and gender experts in gender policies have long argued that sustainable progress may be achieved through prioritization and incentivization of gendered policies, embedding gender equality as a distinct policy objective across all policy areas and at all levels (Jacquot, 2017; Kantola and Rolandsen-Agustin, 2016; Lombardo and Forest, 2015; Verloo and Lombardo, 2007). This requires collective political commitment and legislative action of the EP, EC and the European Council. Particularly in cross-cutting issues that fall within several remits, it is essential the gender equality objective to be consistently pursued and fulfilled. 
Furthermore, although the economic and organizational benefits of gender equality have been acknowledged by policy actors, the inclusion of gender equality objectives within the economic policy agenda has not been ensured nor is the linkage with meso- and macroeconomic implications for EU and Member States economies. The adoption of a gender perspective into the instruments of economic policies and the introduction of gender budgeting tools will arm EU and Member States' bodies with solid instruments for the sought after social change.

Gender specific indicators should be adopted and applied in the design, implementation, monitoring and evaluation phases of all gender equality plans' (GEPs) or further initiatives. In order to ensure accountability and transparency, the data should be of real-time and made available to all involved actors. Yet, although indicators with considerable statistical capacity may be a very useful informative and assessment tool, they may not be enough to implement gender transformative policies. To improve the responsiveness of gendered policies, it is also important that all Member States develop a local gender literate group, consisted of an adequate number of highly skilled and motivated gender experts that can resonate well with the local culture and mindset, address educational gaps and emerging challenges, advocate for gender equality, engage civil society and academia, and build intersectoral partnerships to tackle cross cutting gender inequalities. Enhanced use of data collection systems and dedicated funding will support considerably to monitor and evaluate progress.

Meeting future gender challenges can only be achieved by adopting a whole-of-society and a whole-of-policy approach. The engagement and action of individuals, civil society, researchers, gender experts, and national and EU policy makers are fundamental to ensure the successful development, implementation of effective policies, responsive to gendered challenges faced by EU citizens. As stated in the TFEU, it is important that these actors are actively and fully committed to engage with achieving gender equality objectives and social cohesion (EUR-lex, 2019b).

\subsection{LIMITATIONS}

This thesis entails certain content-related as well as methodological limitations. The limitations of each study that make up this thesis are discussed extensively within each chapter. Hence, the present section will address broader limitations regarding the scope of this research.

In regard of the content-related limitations, the broadness and the cross-disciplinary nature of the topic are the main inherent limitations of this thesis. When the research started, not so many studies addressing comprehensively the gendered barriers were available. In view of this, the approach taken in this research reflects a particular framing of the researched issue and solutions, which is influenced by the expertise and training of the author and the applied conceptual frameworks. Although in line with the qualitative research approach requiring the researcher to be reflective about the stance taken (Hsieh and Shannon, 2005) and construct interpretations against a backdrop of shared understandings and in the light of new experience and knowledge (Schwandt, 2000), the 
analysis of the research findings stemmed from author's individual perspective which inherently limits the scope of the assessment and the proposed solutions.

Furthermore, the research question could have been addressed through the lens of several academic disciplines, such as sociology, psychology, political science, management and organizational behavior science, gender science, feminism. Each of these disciplines could raise the claim for taking a deeper perspective, different understanding within their respective scope. Arguably, scientists from each discipline may have explored the topic differently and come up with different conclusions. Hence, there is ample room for further research, which would be extremely beneficial and informative and would maximize the comprehensiveness and reliability of the findings at hand.

Similar limitations stand for further, deeper study of the twenty-six identified barriers through a multi-disciplinary lens. Although the meaning of each barrier has been assessed and validated within the framework of current research, cross-disciplinary research on the meaning and the manifestation of barriers within different work and social settings is necessary to fully cover the gendered barriers analysis. Furthermore, the contextuality of barriers in terms of their durability and transferability may have also been recognized and assessed differently resulting to different results.

It was not possible with the time and resource constraints of a PhD thesis to test further the Barriers Thematic Map (BTM) or the proposed policy frameworks. To that end, the selection of healthcare sector as study sample was made on the grounds mentioned in the Introduction, but also through the perspective of social constructionism paradigm. Knowledge is affective to and embodies human experience and in a way, is political and pervaded with values (Schwandt, 2000, p. 198); hence, should conditions be well defined, a careful inference to other similar subjects is possible (Rohlfing, 2012). In that line, a careful application of the findings would be possible to other sectors as well. However, further complementary research on a sectorial and/or domestic front would mitigate the limitations of findings' applicability and generalizability.

In addition, this thesis is entrenched on qualitative research methods in order to address the research question on "barriers to women's leadership and gender equality in EU context". However, addressing the research question with qualitative empirical data entails some limitations such as the lack of generalizability, few available participants, social bias, etc (see Chapter 3 and 4, Limitations). In both cases, to mitigate the risk of biases and limited generalizability of the findings inherent to purposive sampling (Polit \& Beck, 2004), an heterogenous participants' sample was opted. The data analysis was performed independently by different researchers and triangulated at a subsequent step with findings from BTM and from further literature search to ensure internal consistency and trustworthiness (Hsieh \& Shannon, 2005; Mayring, 2014).

In general, the breadth and cross-disciplinary dimension of the research topic posed difficulties. This thesis did not provide an all-in-one solution; yet, introduced a comprehensive, evidence informed 
approach for addressing gendered barriers from a policy and implementation perspective. How this approach may be put forward in practice extends beyond the scope of this study and has to be further researched.

\subsection{CONCLUSIONS}

This thesis has stated that the barriers to women's leadership and to gender equality, have to be addressed comprehensively and taking into consideration their varying degree of prevalence. In particular, the varying degree of barriers' manifestation across sectors and within countries' socio-cultural and economic specificity underscored the high degree of contextuality in barriers' manifestation and, thereby, the need for evidence-informed, country specific gendered policies. The research findings on Greece and Malta indicated each country's uniqueness in relation to explored phenomenon. The striking similarities and differences in identified gendered barriers and their prevalence unveiled the underlying interactions among gender, leadership and countries' socio-cultural and economic contexts; this may elucidate the varying degree of strength of norms and barriers embedded in a society's egalitarian practices with cultural tightness acting at the same time as an alibi and/or barrier against socio-cultural transformation.

In addition, although gender equality has been an overarching policy objective in EU policy, an inconsistent commitment on gender equality objectives across EU bodies and agencies was found in contrast to the EU's high level legal and political commitment to gender equality principle and observance; hence, the under placement of gender equality as a distinctive policy objective at EU and, extensively, at Member States level has undermined any progress made and fostered the persistence of gendered barriers. Considering that EU society has been organized for coexistence and in alignment with achieving egalitarian social order, gender equality is a fundamental structural block for social cohesion and sustainable future for the EU citizens and the generations to come. Thereby, both EU and Member States are held responsible to comply with legal and policy commitments they made to observe and achieve gender equality for the benefit of all EU citizens.

\section{REFERENCES}

Acker, J. (2006) Inequality regimes: Gender, class, and race in organizations. Gender \& society, 2006;20(4), 441-464.

Ahrens, P. and van der Vleuten, A. (2017). EU Gender Equality Policies and Politics-New Modes of Governance. Gender and Diversity Studies in European Perspectives.

Arulampalam, W., Booth, A. L., \& Bryan, M. L. (2007). Is there a glass ceiling over Europe? Exploring the gender pay gap across the wage distribution. ILR Review, 60(2), 163-186.

Bacchi, C. (2009). Challenging the displacement of affirmative action by gender mainstreaming. Asian journal of women's studies, 15(4), 7-29.

Bauer, M. W., \& Knill, C. (2012). Understanding policy dismantling: an analytical framework. Dismantling public policies: Preferences, strategies, and effects, 30-51.

Benschop, Y., \& Verloo, M. (2011). Gender change, organizational change, and gender equality strategies. In Jeanes E, Knights D, Yancey Martin, P (Eds) Handbook of gender, work and organization, Wiley-Blackwell, West Sussex, UK, 2011 (pp 277-290). 
Bismark, M., Morris, J., Thomas, L., Loh, E., Phelps, G., \& Dickinson, H. (2015) Reasons and remedies for underrepresenta-tion of women in medical leadership roles: a qualitative study from Australia. BMJ Open. 2015 Nov 16;5(11):e009384. doi: 10.1136/bmjopen-2015-009384.

Carli, L.L and Eagly, A. M. (2011). Leadership and gender. In The nature of leadership (pp. 437-476). Sage Publications.

Cavaghan, R. (2017). Making gender equality happen: Knowledge, change and resistance in EU gender mainstreaming. Routledge.

Downs, J. A., Mathad, J. S., Reif, L. K., McNairy, M. L., Celum, C., Boutin-Foster, C., ... \& Konopasek, L.. (2016) The ripple effect: why promoting female leadership in global health matters. Public Health Action. 2016 Dec 21;6(4):210211. doi: 10.5588/pha.16.0072.

Eagly, A. H., and Chin, J. L.. (2010) Diversity and leadership in a changing world. Am Psychol. 2010 Apr;65(3):216-24. doi: $10.1037 / a 0018957$.

Ellemers, N. (2014). Women at work: How organizational features impact career development. Policy insights from the behavioral and brain sciences, 1(1), 46-54.

Erhardt, N. L., Werbel, J. D., \& and Shrader, C. B. (2003). Board of director diversity and firm financial performance. Corporate governance: An international review, 11(2), 102-111.

European Commission (2019a). 2019 Report on equality between women and men in the EU. 2019 Brussels. Available at:https://ec.europa.eu/info/sites/info/files/aid_development_cooperation_fundamental_rights/annual_ report_ge_2019_en.pdf

European Commission (2019b) EU budget for the future. Available at: https://ec.europa.eu/commission/sites/betapolitical/files/communication-modern-budget-may_2018_en.pdf (Accessed: March

European Commission (2019c) European Social Fund. Gender - An issue of equality. Available at: https://ec.europa. eu/esf/transnationality/content/gender-issue-equality (Accessed: Februry $9^{\text {th }}$, 2019) $^{2}$

European Institute for Gender Equality. Gender Equality Index Report 2017. Available at: https://eige.europa.eu/ publications/gender-equality-index-2017-measuring-gender-equality-european-union-2005-2015-report (Accessed: February 13th 2019)

European Institute for Gender Equality (2019) Gender budgeting. Mainstreaming gender into the EU budget and macroeconomic policy framework. Brussels 2018. Available at: https://eige.europa.eu/publications/genderbudgeting-mainstreaming-gender-eu-budget-and-macroeconomic-policy-framework (Accessed: April 14th, 2019)

EUR-lex. (2019a) Access to European Union Law. The Treaty of Lisbon. Available at: https://eur-lex.europa.eu/legalcontent/EN/TXT/? uri=celex\%3A12007L\%2FTXT (accessed on February 12th, 2019)

EUR-lex. (2019b) Access to European Union Law. Consolidated version of the Treaty on the Functioning of the European Union. Available at: https://eur-lex.europa.eu/legal-content/EN/TXT/PDF/?uri=CELEX:12012E/TXT (accessed on March 2nd, 2019e)

European Parliament. (2019a) Gender mainstreaming in the EU: State of Play. January 2019. Available at: http://www. europarl.europa.eu/RegData/etudes/ATAG/2019/630359/EPRS_ATA(2019)630359_EN.pdf (Accessed: February $8^{\text {th }}$ 2019)

European Parliament (2019b) Gender responsive EU Budgeting. Update of the study 'The EU Budget for Gender Equality' and review of its conclusions and recommendations. March 2019. Available at: http://www.europarl. europa.eu/thinktank/en/document.html?reference=IPOL_STU(2019)621801 (Accessed: March 15th 2019)

European Parliament (2019c) 2021-2027 multiannual financial framework and new own resources. Analysis of the Commission's proposal. Available at: http://www.europarl.europa.eu/RegData/etudes/IDAN/2018/625148/EPRS_ IDA(2018)625148_EN.pdf (Accessed: February 9th, 2019)

European Commission (2019d). She Figures, March 2019. Available at: https://ec.europa.eu/info/publications/shefigures-2018_en (Accessed: April 12th, 2019)

European Parliament (2019d) Women's Rights and Gender Equality. Implementation of the Daphne

programme and other funds aimed at fighting violence against women and girls. January 2019. Available at: http:// www.europarl.europa.eu/RegData/etudes/STUD/2019/608857/IPOL_STU(2019)608857_EN.pdf (Accessed: March $\left.2^{\text {nd }}, 2019\right)$

European Union. (2019) Institutions and bodies. Available from: https://europa.eu/european-union/about-eu/ institutions-bodies_en (Accessed: $19^{\text {th }}$ March 2019)

Eurostat (2018) Sustainable Development in the European Union. Monitoring Report on Progress towards the SDGs in an EU Context. 2018 edition. Available at: https://ec.europa.eu/eurostat/web/products-statistical-books/-/KS01-18-656 
Eurostat. (2019a) Statistics Explained. Gender pay gap statistics. Available from: https://ec.europa.eu/eurostat/ statistics-explained/index.php/Gender_pay_gap_statistics\#Gender_pay_gap_levels_vary_significantly_across_ EU (Accessed: 20th March 2019)

Eurostat (2019b) Which sector is the main employer in the EU Member States? Available at: https://ec.europa.eu/ eurostat/web/products-eurostat-news/-/DDN-20171024-1 (Accessed: December 12th, 2018)

FEMM Women's Rights and Gender Equality (2019) European Parliament Committees. Available at: https://www. europarl.europa.eu/committees/en/femm/members.html (Accessed: December $9^{\text {th }} 2017$ )

FEMM (2013), Report on Sexual and Reproductive Health and Rights - 2013 (2013/2040(INI)), 26 September 2013, rapporteur Edite Estrela (S\&D).

Fjeldsted, K. (2013) Female Leadership in Health Care. Leadership in Health Care Organizations. Standing Committee of European Doctors. Available from: http://www.cpme.eu (Accessed: April 3rd, 2016)

Forest, M., \& Lombardo, E. (2012). The Europeanization of gender equality policies: a discursive-sociological approach. In The Europeanization of Gender Equality Policies (pp. 1-27). Palgrave Macmillan, London.

Holloway, I.. Qualitative research in health care. McGraw-Hill Education (UK), 2005

Hsieh, H. F. and Shannon, S. E. (2005) Three approaches to qualitative content analysis. Qual Health Res. 2005 Nov;15(9):1277-88.

Human Resources for Health. Global Resource Center. Resource spotlight: gender and health workforce statistics. Available at: http://www.hrhresourcecenter.org/gender_stats (Accessed March 10th, 2017)

Inglehart, R., Norris, P., \& Ronald, I. (2003). Rising tide: Gender equality and cultural change around the world. Cambridge University Press.

Jacquot, S. (2010). The paradox of gender mainstreaming: Unanticipated effects of new modes of governance in the gender equality domain. West European Politics, 33(1), 118-135.

Jacquot, S. (2017). A Policy in Crisis. The Dismantling of the EU Gender Equality Policy. In Gender and the Economic Crisis in Europe (pp. 27-48). Palgrave Macmillan, Cham.

Kantola, J. (2010). Gender and the European Union. Macmillan International Higher Education.

Kantola, J and Lombardo, E. (2017). EU gender equality policies. In: Kantola, J. and Lombardo, E. (Eds.). (2017). Gender and the economic crisis in Europe: Politics, institutions and intersectionality. Springer.(pp 331-349)

Kantola, J. and Nousiainen, K. (2012). The European Union: initiator of a new European anti-discrimination regime? In Institutionalizing Intersectionality (pp. 33-58). Palgrave Macmillan, London

Kantola, J., and Rolandsen-Agustin, L. (2016). Gendering transnational party politics: The case of European Union. Party Politics, 22(5), 641-651.

Kapilashrami, A., and Hankivsky, O. (2018). Intersectionality and why it matters to global health. The Lancet, 391(10140), 2589-2591

Kuhlmann, E., Ovseiko, P. V., Kurmeyer, C., Gutiérrez-Lobos, K., Steinböck, S., von Knorring, M., ... \& Brommels, M. (2017). Closing the gender leadership gap: a multi-centre cross-country comparison of women in management and leadership in academic health centers in the European Union. Human resources for health, 15(1), 2.

Lerch-Pieper, N., Brander, S., Valarino, I., Zurbriggen, C., Maurer, E., Herr, W. (2018) Challenging the "leaky pipeline" in faculties of medicine. Available at: https://smw.ch/en/op-eds/post/challenging-the-leaky-pipeline-in-facultiesof-medicine/ (Accessed June 30th 2018)

Linková, M. (2017). Academic excellence and gender bias in the practices and perceptions of scientists in leadership and decision-making positions. Gender a výzkum, 18(1), 42-66.

Locher, B. (2012). Gendering the EU policy process and constructing the gender acquis. In Gendering the European Union (pp. 63-84). Palgrave Macmillan, London.

Lombardo, E. and Forest, M. (2015). The Europeanization of gender equality policies: A discursive-sociological approach. Comparative European Politics, 13(2), 222-239.

Massino, J. and Popa, R. M. (2015). The Good, the Bad, and the Ambiguous: Women and the Transition from Communism to Pluralism in Romania. In Gender (In) equality and Gender Politics in Southeastern Europe (pp. 171-191). Palgrave Macmillan, London.

Mayring, P. (2014). Qualitative content analysis: theoretical foundation, basic procedures and software solution. Available at: https://www.ssoar.info/ssoar/bitstream/handle/document/39517/ssoar-2014-mayring-Qualitative_ content_analysis_theoretical_foundation.pdf (Accessed: March $8^{\text {th }}$ 2017)

McLaughlin $\bar{H}$, Silvester J, Bilimoria D, ....Goeke J. (2017) Women in power, Contributing factors that impact on women in organizations and politics; psychological research and best practice Organ Dyn (2017) doi.org/10.1016/j. orgdyn.2017.09.001 
Meier, P., and Celis, K. (2011). Sowing the seeds of its own failure: Implementing the concept of gender mainstreaming. Social Politics, 18(4), 469-489.

Montoya, C. (2010). The European Union, Transnational Advocacy and Violence against Women in Postcommunist States. In Fabian K (Eds) Domestic Violence in Postcommunist States, Local activism, national policies and global forces. (pp 293-307).

Newman, C., Chama, P. K., Mugisha, M., Matsiko, C. W., \& Oketcho, V.. (2017) Reasons behind current gender imbalances in senior global health roles and the practice and policy changes that can catalyze organizational change. Glob Health Epidemiol Genom. 2017 Dec 10;2:e19. doi: 10.1017/gheg.2017.11. eCollection 2017.

Norris, P., \& Inglehart, R. (2001). Cultural obstacles to equal representation. Journal of democracy, 12(3), 126-140.

OECD. (2017) Development matters. Closing the gender gap requires closing the data gap. Available at: https://oecddevelopment-matters.org/2017/10/20/closing-the-gender-gap-requires-closing-the-data-gap/ (Accessed: January $3^{\text {rd }}$ 2019)

OECD. (2018) Gender Equality. Available at: http://www.oecd.org/gender/data/women-make-up-most-of-thehealth-sector-workers-but-they-are-under-represented-in-high-skilled-jobs.html (Accessed September 27th, 2018)

OECD. (2019) Development finance for gender equality and women's empowerment: A snapshot. Available at: http:// www.oecd.org/development/gender-development/Dev-finance-for-gender-equality-and-womens-economicempowerment-2019.pdf (Accessed: March 4th, 2019)

Paternotte, D. and Kuhar, R. (2018). Disentangling and locating the "global right": Anti-gender campaigns in Europe. Politics and Governance, 6(3), 6-19.

Parsons, T. (1964). Evolutionary universals in society. American sociological review, 339-357.

Patton, M. Q. (1999). Enhancing the quality and credibility of qualitative analysis. Health services research, 34(5 Pt 2), 1189.

Polit, D. F., \& Beck, C. T. (2004). Nursing research: Principles and methods. Lippincott Williams \& Wilkins. (pp 289-312)

Prügl, E. (2010). Feminism and the postmodern state: Gender mainstreaming in European rural development. Signs: Journal of Women in Culture and Society, 35(2), 447-475.

Rohlfing, I. (2012). Case studies and causal inference: An integrative framework. Palgrave Macmillan, New York (pp 125-150)

Rosaldo, M. Z. Woman, culture, and society: A theoretical overview. Woman, culture, and society, 1974;21.

Schwandt, T. (2000) Three epistemological stances for qualitative inquiry. In Denzin, N and Lincoln, Y (eds) Handbook of qualitative research, 2nd ed. Sage Publications, California, USA. Pp 197-200.

The Lancet. Advancing women in science, medicine and global health. Vol 393 :10171: p493-610, e6-e28. Available at: https://www.thelancet.com/journals/lancet/issue/vol393no10171/PIIS0140-6736(19)X0006-9\#

Toh, S. M. and Leonardelli, G. J. (2012). Cultural constraints on the emergence of women as leaders. Journal of World Business, 47(4), 604-611.

Tracy, S. J. (2010). Qualitative quality: Eight"big-tent" criteria for excellent qualitative research. Qualitative inquiry, 16(10), 837-851

United Nations (2015). Sustainable Development Goals. Available at: https://sustainabledevelopment.un.org/sdgs (Accessed: January $6^{\text {th }}, 2017$ )

United Nations Women. Optimizing Performance: Gender Equality in business. Available at: https://unwomen.org.au/ wp-content/uploads/2016/01/2014_WEPS_Summit_Outcomes_FINAL.pdf (Accessed: February $8^{\text {th }}$, 2019)

United Nations Development Programme (2018) Making the business case for gender equality. Available at: https:// www.undp.org/content/undp/en/home/blog/2018/una-justificacion-economica-para-la-igualdad-de-genero. html (Accessed: January 23rd, 2019)

van der Vleuten, A. (2012). Gendering the Institutions and Actors of the EU. In Gendering the European Union (pp. 41-62). Palgrave Macmillan, London.

Verloo, M. M. T. and Lombardo, E. (2007). Contested gender equality and policy variety in Europe: Introducing a critical frame analysis approach. Available at: https://repository.ubn.ru.nl/bitstream/handle/2066/55242/55242. pdf (Accessed: April 12 ${ }^{\text {th }}, 2018$ )

Verloo, M., Meier, P., and Lombardo, E. (2009). Stretching and bending gender equality: A discursive politics approach. In The discursive politics of gender equality (pp. 21-38). Routledge

Verloo, M. and Van der Vleuten, A. (2009). The discursive logic of ranking and benchmarking: Understanding gender equality measures in the European Union. In The Discursive Politics of Gender Equality (pp. 189-205). Routledge. 
World Health Organization (2019a) Female health workers drive global health. Available at: https://www.who.int/ news-room/commentaries/detail/female-health-workers-drive-global-health (Accessed: March 30th, 2019)

WHO. (2019b) Gender Equity Hub. Available at: https://www.who.int/hrh/network/GEH2018-overview.pdf?ua=1 (Accessed: March 6th, 2019)

WHO (2019c) Declaration of Astana 2018. Available at: https:/www.who.int/docs/default-source/primary-health/ declaration/gcphc-declaration.pdf (Accessed: January 29th, 2019)

Wismar M, Meier C, Sagan A and Glinos I. (2019) Developments in Europe's health workforce. Addressing the conundrums. Eurohealth Systems and Policies; Eurohealth, 2018;24(2):38-42

Woodward, A. E., \& van der Vleuten, A. (2014). EU and the export of gender equality norms: Myth and facts. In Gender Equality Norms in Regional Governance (pp. 67-92). Palgrave Macmillan, London. 



\section{Valorisation Addendum}

\section{VALORIZATION ADDENDUM}

It is widely accepted that knowledge valorization adds a surplus value to society and economy and also accelerates scientific progress (Hladchenko, 2015). Valorization can be defined as "the process of value creation from knowledge, by making it applicable and available for economic or societal utilization, and by translating it in the form of new business, products, services, or processes" (Maastricht University, 2019). This section will address an overview of the research findings regarding the relevance for society, policy makers and researchers. The activities undertaken so far and planned to disseminate the research findings are also detailed. Furthermore, the innovative aspect of the study is highlighted as well.

\section{Relevance for society}

Applying insights from social constructivism, this thesis explored the gendered barriers within the framework of bounded social reality, which is shaped from shared beliefs, knowledge, institutional context and personal values.

Building upon previous research on barriers to women's leadership and gender equality, the present dissertation showcased the strong, underlying interactions among gender, leadership and social context shedding light to the varying degree of strengths of norms, power relations and gendered barriers embedded in a society's egalitarian practices (Collins, 2000). The social construction of gendered barriers was established conceptually, contextually and functionally within study's deployment. The proven similarities and differences in the socio-cultural and economic contexts the gendered barriers manifest themselves, draw attention to social patterns which, depending the degree of cultural tightness, have an important effect on employment choices and work/ life balance. Hence, the research findings recognized a direct link between manifestation and prevalence of gendered barriers to country's specificity.

The added value of analyzing the relationship between country's socio-cultural contexts and the socially rooted gendered barriers derives from the epistemological position that actors participate in a way or another in building social reality in which they are active (Hantrais and Mangen, 2013). Thereby, this research may also inform social actors on the important role they play in the dynamic dialogue among societal culture, leadership and gender; these interactions may shape the necessary mechanisms to enable social and cultural change.

Furthermore, the study appraised empirically the "regimes of truth" (Foucault, 1991) pertaining to gendered barriers and culturally legitimate societal power and authority as unfolded in the 
processes of cultural and social reality. In that line, as the social dimension is becoming ever more critical for the EU towards addressing inequalities and achieving social cohesion, the findings of this research may serve as case to raise awareness on the gender asymmetries in terms of power and authority influenced differently within a country's social and cultural context. Putting evidence into practice is complicated and context dependent; yet, it remains a dynamic process with a continuous interaction between research, policy and social actors which may "feel" and evaluate the level of responsiveness to social audiences.

\section{Relevance for policy makers}

Although gender equality principle was anchored in the EU Treaties (e.g. Treaty of Rome, Treaty of Amsterdam, Treaty of Lisbon) and positioned as an overarching policy objective for over two decades, the slow, fragmented and uneven progress indicated that EU policies and strategies have not been translated yet into achievable targets both at EU and Member States level. Scholars, gender experts and policy reports have voiced criticism for the poor outcomes listing a number of reasons and solutions to improve effectiveness.

This thesis invites policy actors and decision makers to follow the "think globally - act locally" strategy in gender equality policies in order to avoid widening the gap between policy and reality. The European gender equality policy has significant political and social impact on a society organized for co-existence and in alignment to achieving egalitarian social order. The studies included in this dissertation provide evidence-informed insights to highlight the importance of contextuality in addressing gendered challenges across Member States. In particular, the research findings established that the features of comprehensiveness and evidence-based prevalence of gendered barriers may be the tipping factor to improve policy relevance to practice and effectiveness.

Achieving gender equality is a journey, not a destination and gender inequalities are deeply rooted in each Member State's specific social reality. Taking that into consideration, policy actors may work hand in hand with decision makers to shape context-specific, evidence-informed policies, strategies and practices to effect substantial change and address effectively the barriers and controversies within country's specific context.

\section{Relevance for researchers}

This thesis applied a qualitative research methodology using mixed methods to better explore the explored phenomena and offer an informed and sophisticated knowledge reconstruction (Lincoln and Guba, 2000). Drawn on social constructivism paradigm, a mixed methods qualitative approach was employed to ensure quality criteria of trustworthiness and authenticity. Although mixed methods qualitative studies have been criticized for tendency to bias and content validity, the studies of this dissertation focused on the triangulation of data as the main advantage of the applied mixed methodology. On the grounds that there is no "single truth" and that all truths are partial and incomplete (Denzin and Lincoln, 2000, p. 162), this thesis opted for a "most informative, 
complete, balance and useful research results" (Johnson and Onwuegbuzie, 2007, p. 129) to better understand and interpret the explored phenomenon and reconstruct knowledge.

In this thesis, the systematic review of the scientific literature was supplemented by policy reports on the progress towards achieving the gender equality objectives, evaluation reports on gender equality policy in EU and Member States and studies conducted by gender experts. Although these sources have not been scientific papers, in the sense that they were not necessarily peer reviewed, it was considered to add value in the knowledge base of this thesis offering expertise, comprehensiveness and timeliness and, thus, shaping a balanced picture of available evidence (Paez, 2017).

\section{Dissemination of findings}

The findings of this research have been distributed via various channels to researchers, policy makers, stakeholders, public health organizations and students. Three out of five studies included in this thesis have been published, two manuscripts are currently under review in international peer-reviewed journals (e.g. Equality, Diversity and Inclusion: An International Journal, Frontiers in Public Health, Journal Healthcare Leadership, Journal of European Social Policy and Journal of Organizational Change Management). The study findings have also been presented and discussed via oral and poster presentations and workshops at relevant international conferences (e.g. EUPHA, European Conference of Health Workforce Education \& Research, Women in Global Health Research Initiative, International Symposium on Human Rights in Patient Care, Global Health Forum). As such publications and conference presentations mainly reach researchers and international experts, other methods have been used to disseminate the findings, such as dedicated workshops and policy briefs. Two policy briefs are currently written to translate the relevant knowledge to the policy makers language in order to optimize the knowledge utilization. However, dissemination of these findings may still not reach decision makers as they may use other information sources and lobbying cycles. Research findings need to be actively communicated and tailored to enhance perceptibility of the decision-makers; to enhance research findings dissemination and enhance applicability, they need to be translated into an easy, affordable and measurable solution (Choi et al, 2003). The translation may be achieved through an increased engagement of scientists within debates dedicated to sustainable development in organizations and society.

The findings of the research undertaken as part of this dissertation have also been integrated in different educational programs. Lectures on the research have been given to the Master Program Governance and Leadership in European Public Health and in the Bachelor program European Public Health, Maastricht University. In addition, lectures are scheduled in the next academic year at the Department of Health Policy and Management, Indianapolis University. A Summer School at Hellenic Mediterranean University, Greece will take place in next academic year offering training on equality, diversity and inclusion to professionals and decision makers from health-related organizations (Public Health Schools, hospitals, research centers, etc) in South Eastern Europe and 
the broader Mediterranean Region. In addition, two free accessed workshops are scheduled to take place in Athens, Greece under the auspices of 50plus Hellas, (the national organization concerned with the rights of people over the age of 50 in Greece and with their quality of life) in order to raise awareness on gendered barriers.

It is within author's intentions to continue knowledge dissemination in the future expanding the channels described above.

\section{Innovation}

Although there is a growing body of literature exploring the barriers to women's leadership and gender equality, there are hardly any studies addressing systematically the barriers' comprehensive manifestation within organizations, not alone the barriers' prevalence in relation to organizational and socio-cultural contexts. At the author's best knowledge, the studies in this dissertation were one of the first to develop a Barriers Thematic Map (BTM) with a prevalence feature.

The BTM may be developed to a digital tool and used by human resources department and/or equality, diversity and inclusion experts in organizations. The tool may produce an overview of the gendered barriers' manifestation and prevalence within organization. The tool includes a data anonymization method which may offer the room to unveil both apparent and implicit barriers experienced by all genders bypassing, thus, potential power relations within organizations. This evidence based snapshot may disclose policy gaps and be linked to organization specific practice related strategies. The yielded evidence-based information will also contribute to effective use of resources, which may be channeled to fulfil targeted needs and, therefore, improve organization's change capabilities and performance. Furthering, the organization's barriers' snapshot may provide orientation for developing specific training programs responding to the identified needs; for example, training focusing on sexual harassment, or on women's empowerment to overcome the glass ceiling effect or training the decision makers on the benefits an organization may reap from gendered balanced teams. Thereby, the research findings may be translated in an innovative, applicable way and incorporated in efforts to bring about organizational and social change towards achieving gender equality objectives.

\section{REFERENCES}

Choi B, McQueen D, Rootman I. Bridging the gap between scientists and decision makers. J Epidemiol Community Health 2003;57(12):918.

Collins, P. H. (2000). Black feminist thought: Knowledge, consciousness, and the politics of empowerment (2nd ed.). NY: Routledge.

The Treaty of Amsterdam. EUR-lex. Access to European Union Law. Available at: https://eur-lex.europa.eu/legalcontent/EN/TXT/?uri=CELEX:11997D/TXT (accessed on February 12th, 2019)

The Treaty of Lisbon. EUR-lex. Access to European Union Law. Available at: https://eur-lex.europa.eu/legal-content/ EN/TXT/? uri=celex\%3A12007L\%2FTXT (accessed on February 12th, 2019) 
The Treaty of Rome. EUR-lex. Access to European Union Law. Available at: https://eur-lex.europa.eu/legal-content/EN/ TXT/? uri=CELEX:11957E/TXT (accessed on February 12th, 2019)

Foucault, M.. The Foucault effect: Studies in governmentality. University of Chicago Press; 1991

Hantrais, L., \& Mangen, S. (Eds.). Cross-national research methodology and practice. Routledge; 2013

Hladchenko, M. (2016). Knowledge valorisation: A route of knowledge that ends in surplus value (an example of the Netherlands). International Journal of Educational Management, 30(5), 668-678.

Maastricht University. Valorisation. Available at: https://www.maastrichtuniversity.nl/meta/329367/valorisation (Accessed: May 20th, 2019)

Paez, A. (2017). Gray literature: An important resource in systematic reviews. Journal of Evidence-Based Medicine, 10(3), 233-240. 



\section{Summary, Пepíinun (En \& Gr)}

\section{SUMMARY}

European Union's high level legal and political commitment towards achieving gender equality objectives has produced suboptimal outcomes for over twenty years. Any progress made has been slow, fragmented and uneven. The inconsistent commitment across EU bodies and agencies and the misplaced priorities by policy makers fostered the persistence of gendered barriers to women's leadership and equal representation in economy and society.

The aim of this thesis has been twofold: firstly, to identify the barriers and their prevalence to women's leadership and to gender equality; secondly, to gain deeper insights on potential gaps and solutions for a persisting and central policy problem at the EU and Member States level, which has been poorly addressed for over two decades.

Considering the breadth and the complexity of the gender equality topic, this dissertation argues from the perspective of barriers to women's leadership at the intersection of gendered barriers in the healthcare sector within country's socio-cultural and economic contexts and the gender equality policy at the EU level. Healthcare sector has been selected as the sector of interest to study the research phenomenon for three reasons: firstly, the healthcare is of critical importance to health systems, society and economy at both the EU and Member States level; secondly, women are significantly underrepresented in leading positions across healthcare sector although being women populated, and, thirdly, healthcare sector is currently considered one of the major employers, encompassing several domains, such as academic, clinical and medical, and job categories. These features are considered to offer ample ground to gain deep insights on the research question.

The studies in this dissertation are grouped in three parts to address aptly the explored phenomenon, formulate hypothesis and comply with the quality criteria of qualitative research: I) Problem statement and hypothesis, II) Hypothesis testing and III) Policy and implementation.

In Part I the problem statement and hypothesis were addressed, namely what are the barriers to women's leadership in the EU context and how they can be addressed effectively at policy and implementation level. To that end, a systematic literature review was undertaken aiming to develop a map of barriers to women's leadership and formulate the hypothesis on barriers' comprehensive manifestation and varying prevalence across three vital for the economy and society sectors: healthcare, academy and business. The Barriers Thematic Map (BTM) included 26 barriers with quantitative logic and varying degree of prevalence across sectors. The BTM 
uncovered gendered inequalities across sectors and draw attention to the under-studied barriers prevalence across and within sectors. The identified knowledge gap pointed out the need to address gender equality challenges differently across different work settings and to shed light on practice related blind spots. (Chapter 2)

In Part II the developed hypothesis on Barriers Thematic Map and barriers' prevalence was placed within social reality and tested. Research was narrowed down to one out of the three sectors, the healthcare sector, within the context of two, comparable countries, Greece and Malta; attention drawn from countries' poor performance in the gender employment gap and the socio-cultural and economic changes occurring in the European Mediterranean region.

The hypothesis testing was deployed in two studies: one exploratory study in Greek healthcare sector and one comparative study in Greek and Maltese healthcare sector. The exploratory study (online survey) aimed to forage the perceptions of women healthcare leaders in Greece about the most and the least important barriers to women's leadership based on Barriers Thematic Map (Chapter 3). The comparative study (semi-structured interviews) aimed to assess empirically gendered barriers to women's leadership in healthcare through the lens of country's socio-cultural and economic contexts (Chapter 4). The exploratory study identified the 26 barriers included in BTM; the comparative study acknowledged 20 and 21 barriers, out of the 26 included in BTM, to women's leadership within the Greek and Maltese healthcare settings, respectively. Both studies confirmed the varying degree of barriers' prevalence, whereas the manifestation and prevalence of barriers within the Greek and Maltese healthcare settings were found different.

In Part III research turned to gender equality policy agenda at the EU and Member States level. Two studies were undertaken: the first study assessed the priorities and challenges of sustainable development policy agenda against the actual social reality as experienced by Member States' citizens (Chapter 5); the second study explored the transformative capacity of the available gender mainstreaming toolkits towards achieving organizational and social change (Chapter 6).

In particular, the European Union's sustainable development thinking (EU-SDG5 - Achieve gender equality and empower all women and girls) was considered in relation to the relevance of EUSDG5 themes and indicators and the prioriization of policy objectives to actual social reality across Member States. Findings identified inconsistencies in application of TFEU articles for gender equality binding for both EU and Member States posing thus questions about the reasons of the misplaced priorities and unmet gendered challenges. The findings underscored the need for EU's proactive leadership, underpinned by academia and civil society, and for enhanced technical and gender expertise support to the Member States to revisit their national policies and develop evidenceinformed policies. Moving to the policy implementation aspect, the transformative capacity of gender mainstreaming toolkits towards achieving organizational change was assessed focusing on unpacking the complexity among toolkits, organizational context and outcomes. The findings unveiled a potential internal contradiction in toolkits' character, possibly inherent from the duality of EU's gender mainstreaming strategy; furthermore, the insufficient organizational capabilities for 
change and the lack of informed organizational leadership were also identified as the missing key drivers to bring about organizational and social change towards achieving gender equality.

The dissertation concludes that a barrier comprehensive and prevalence approach in addressing women's underrepresentation in top leading positions and, in a broader note, towards achieving gender equality is required. The contextuality in barriers' manifestation points to the need for evidence-informed, country specific gender policies. The research findings on Greece and Malta indicate each country's uniqueness in relation to interactions among gender, leadership and socio-cultural contexts. In that line, although gender equality has been an overarching policy objective in EU, gendered barriers have been persistent and compromised any progress made. Thereby, both EU and Member States policy actors and decision makers are held responsible to comply with legal and policy commitments made and work effectively towards achieving egalitarian social order, social cohesion and sustainable future for the EU citizens and the generations to come. 


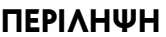

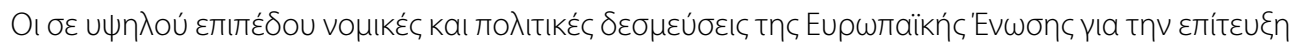

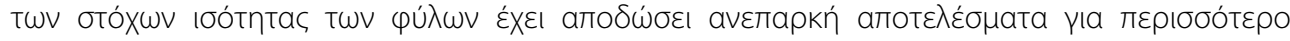

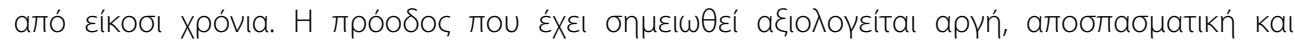

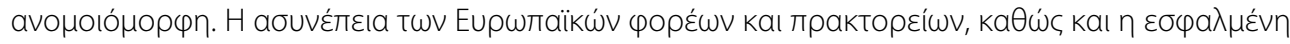

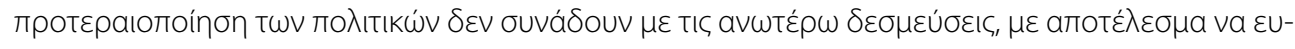

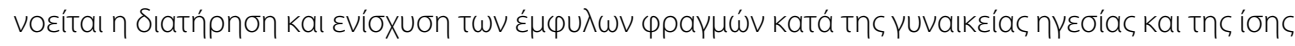

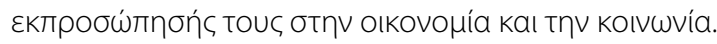

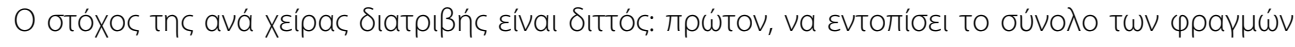

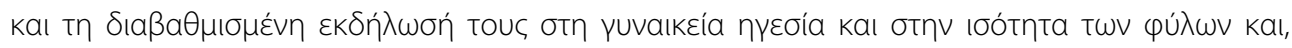

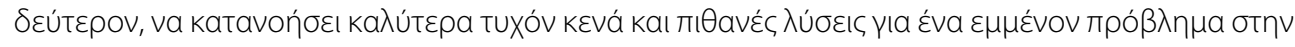

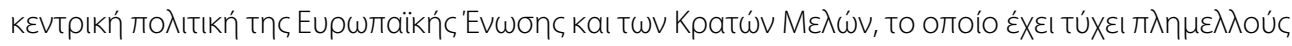

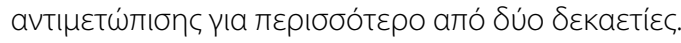

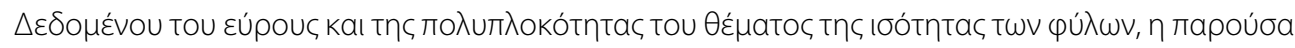

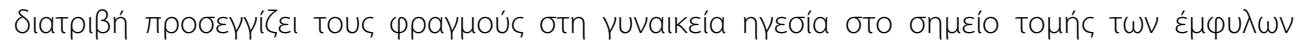

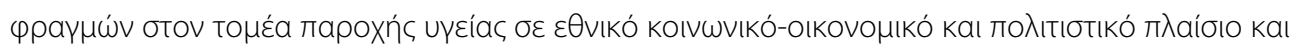

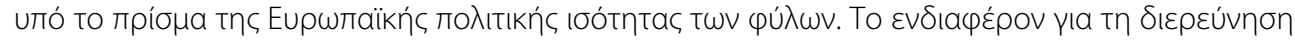

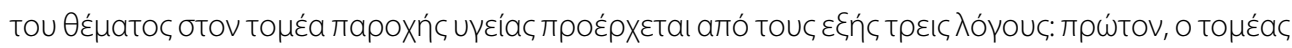

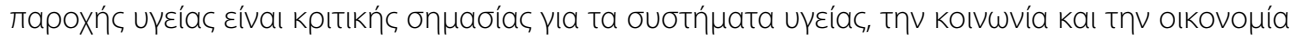

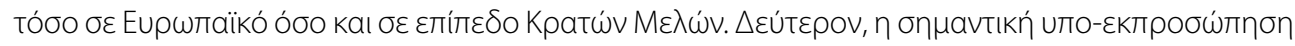

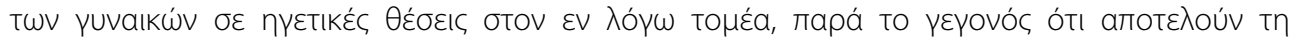

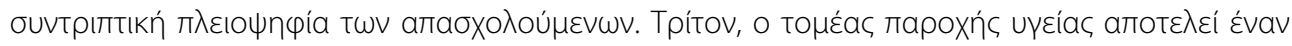

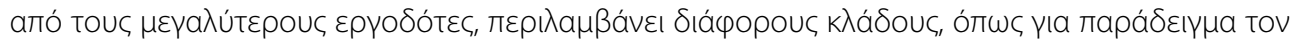

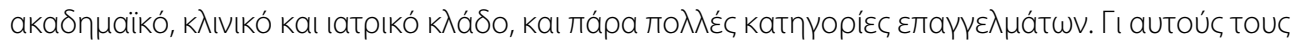

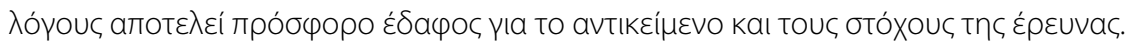

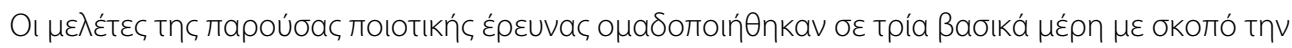

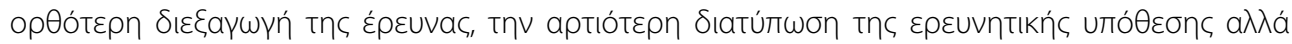

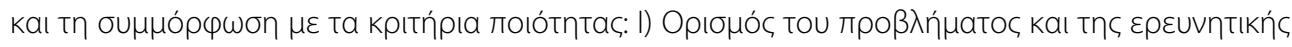

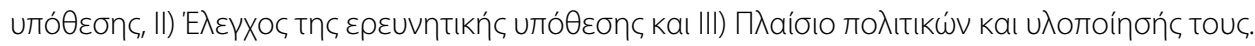

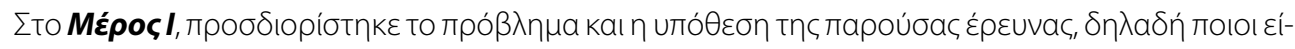

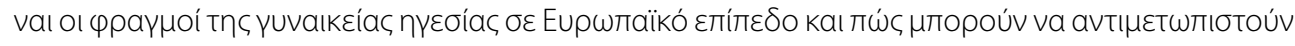

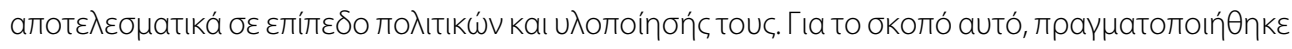

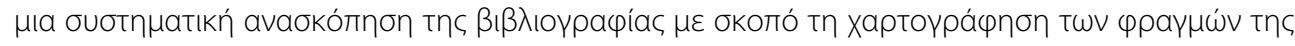

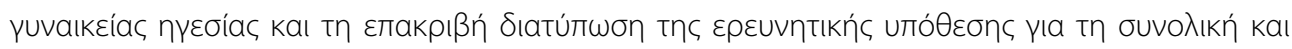

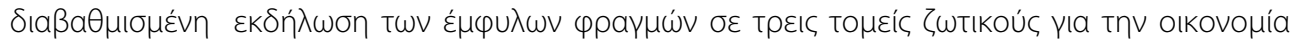

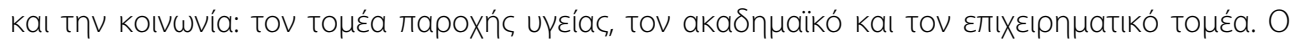




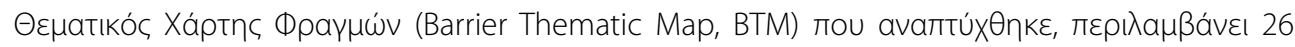

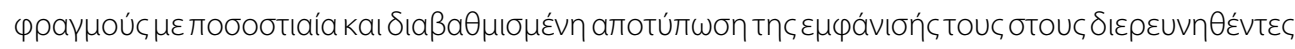

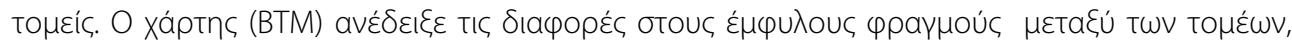

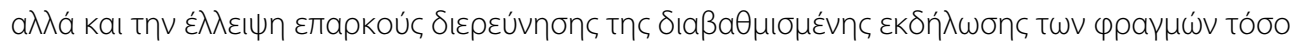

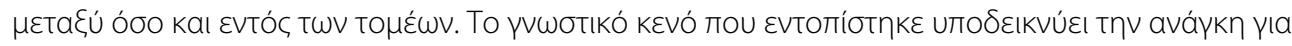

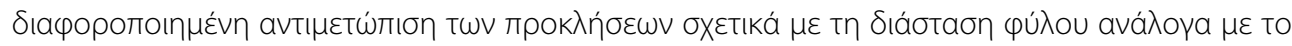

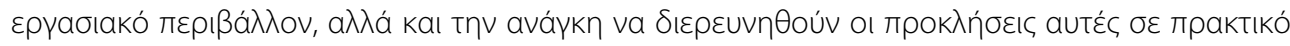

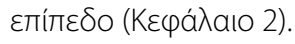

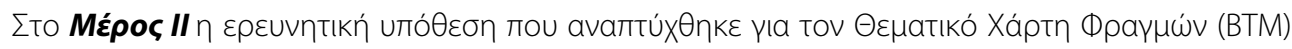

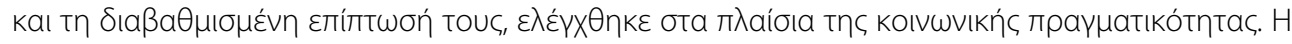

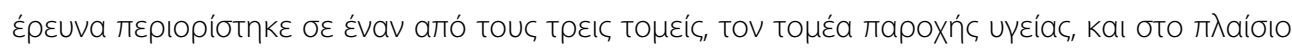

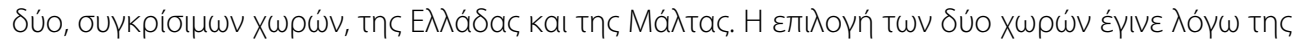

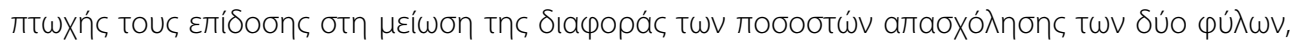

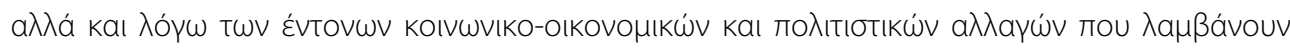

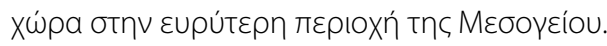

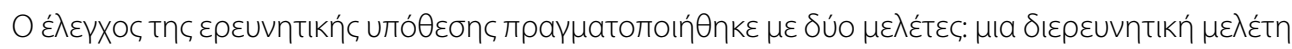

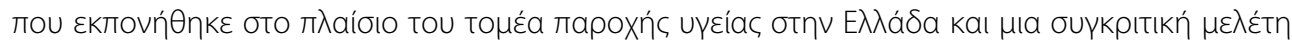

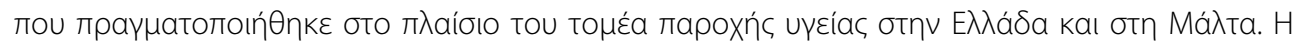

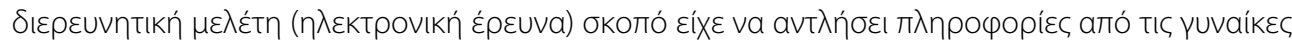

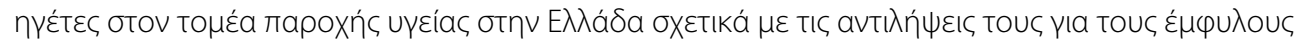

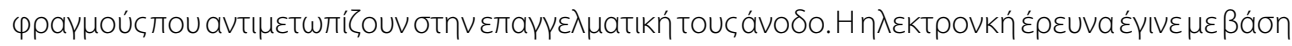

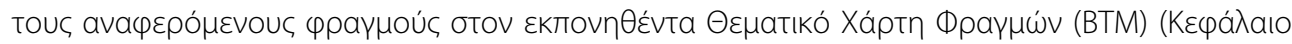

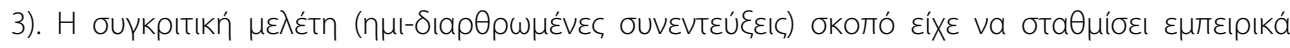

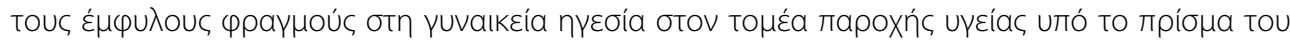

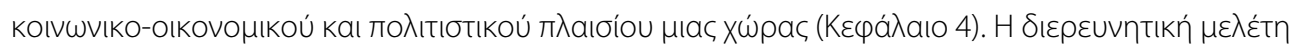

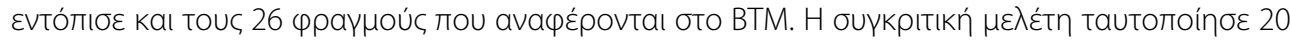

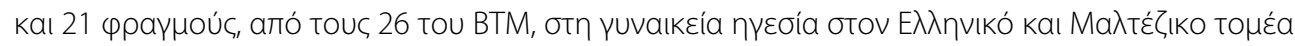

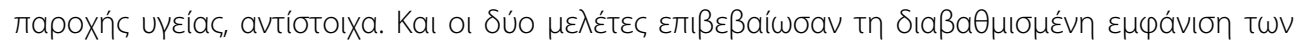

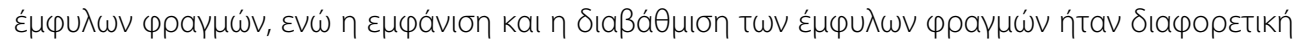

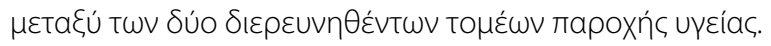

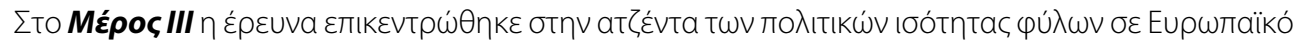

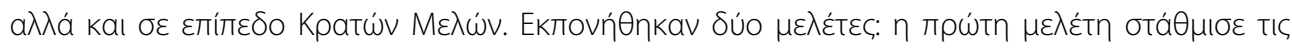

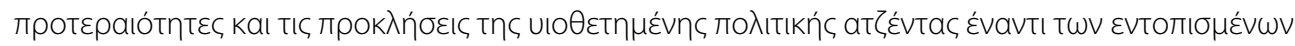

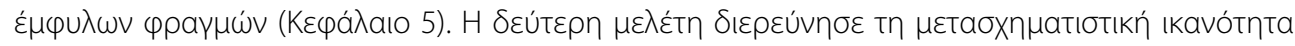

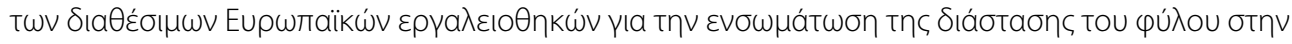

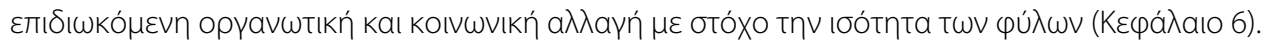

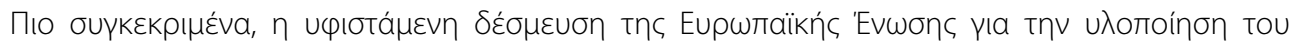




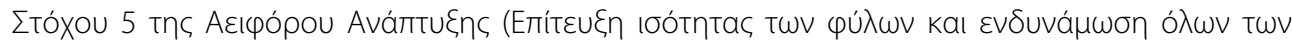

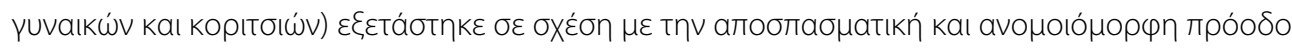

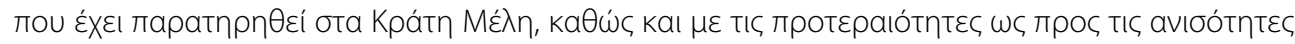

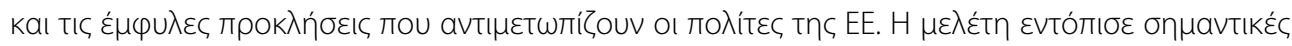

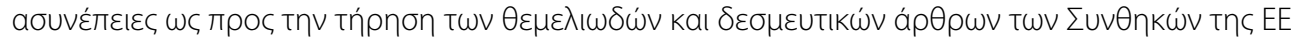

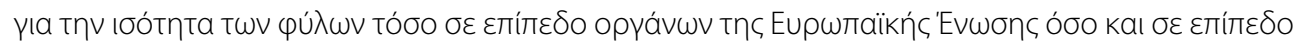

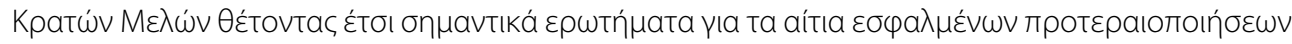

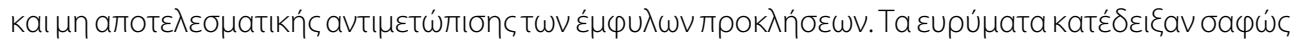

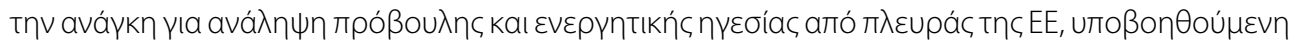

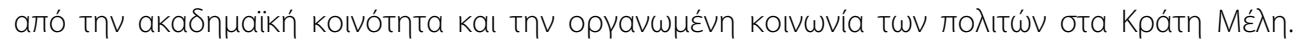

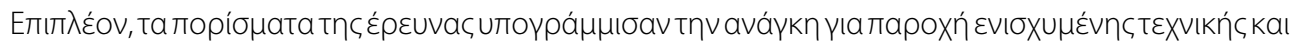

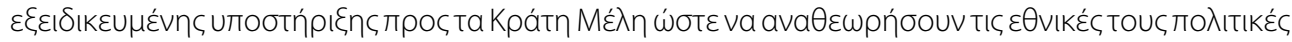

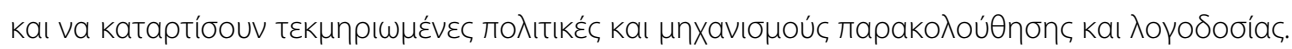

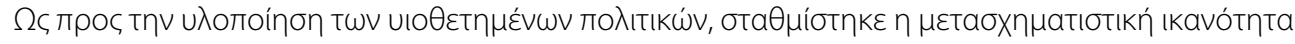

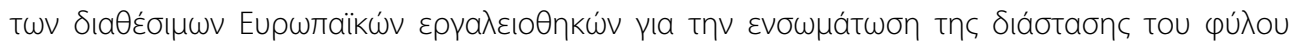

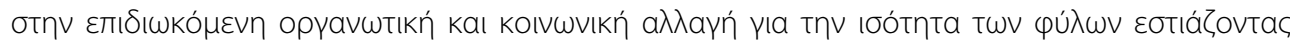

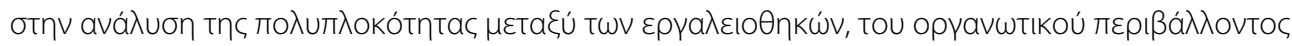

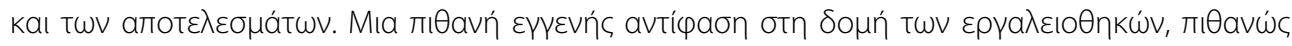

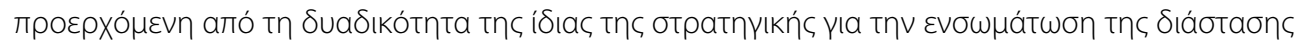

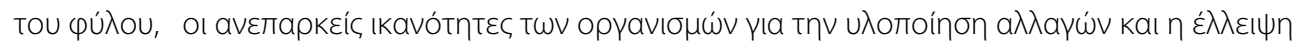

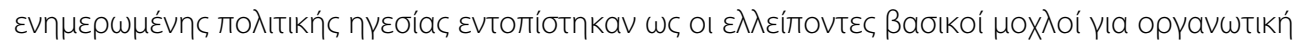

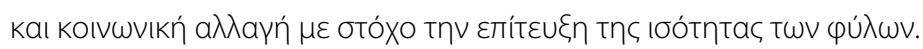

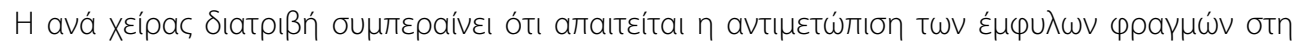

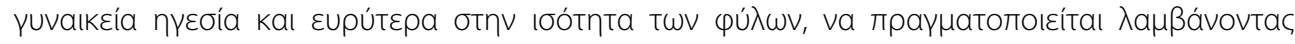

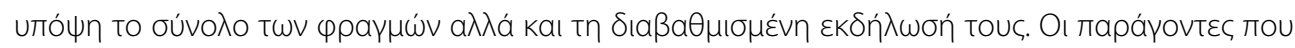

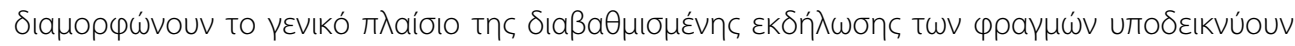

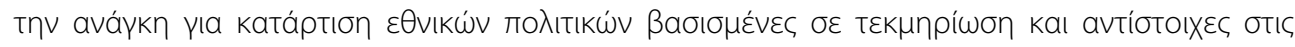

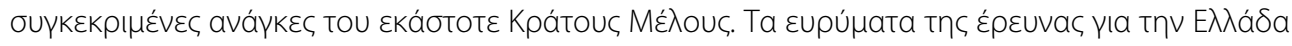

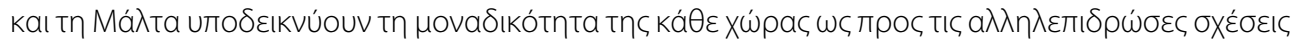

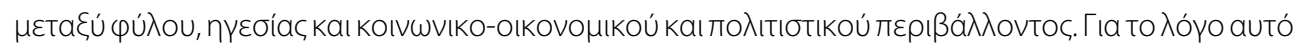

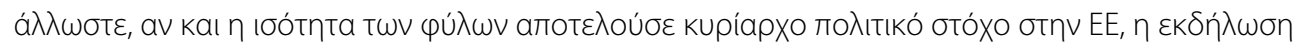

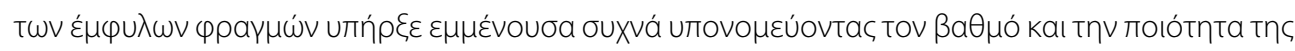

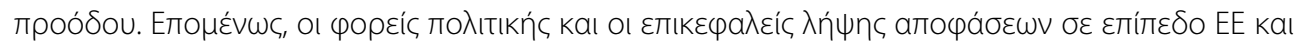

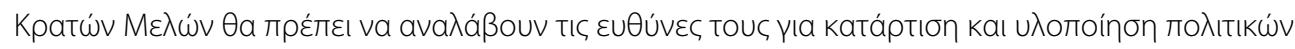

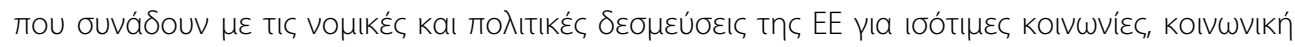

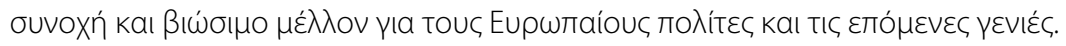






\section{Acknowledgments}

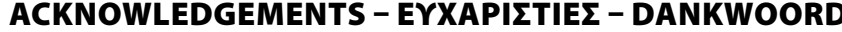

During my PhD journey, I have had the opportunity to learn and grow both as a researcher and as an individual. This endeavor could not have possible been accomplished without the valuable effort and support of many people to whom I wish to extend my gratitude and sincerest thanks.

First and foremost, I am truly grateful to my promotor Prof. D. Helmut Brand for providing me the opportunity to collaborate with the Department of International Health and bring this PhD to fruition under his supervision, guidance and critical reflections. Special thanks to the Associate Professor Dr habil. Katarzyna Czabanowska, my co-promotor and mentor, who inspired me to delve into the gender aspect of leadership in healthcare following the LePHIE training. I am thankful for the transformational leadership she demonstrated, her guidance and commitment all along the way. She has been supportive and encouraging, pushing me to challenge my limits, step outside my comfort zone, to develop a deeper and more nuanced understanding of the research questions propelling, thus, research to a higher level. Her backing, patience, confidence and faith shown in me have been valuable drivers during this PhD journey, especially when I felt distressed and questioned my own capabilities.

In that spirit, I would like to convey my thanks and appreciation to the members of the assessment committee for their time reading critically through this dissertation and taking the effort to discuss it with me during the defense. I would also like to give a sincere word of thanks, respect and acknowledgement to the co-authors of the various papers for their valuable contribution, reviewing my drafts and keeping fingers crossed once papers were submitted. I am also grateful to the interviewees for the insightful and illuminating deliberations we had and the precious time they sacrificed to contribute to this study. Special thanks to Anita Creusen who has been a consistent, valuable practical support, especially during these final months of administrative hurdles.

Lastly, but definitely most importantly, I would like to thank my family and friends. I wish to express my grateful and heartfelt thanks to my beloved daughters, Marilena and Nikoleta, the light in my life, for always supporting me in my personal development trajectory, keeping me going forward and providing me the time, peace and tranquility for writing, oftentimes assuming my own obligations. I owe my sincerest thanks and appreciation to Sue, Julia, Viktoria, Kostas, Ruth, Yiannis, Natasha, Giorgos, Elena, Genc and Panayiotis for supporting me in any possible way and on various instances, oftentimes listening patiently to my grumblings.

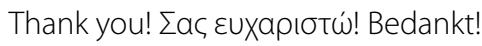





\section{Curriculum Vitae}

\section{CURRICULUM VITAE}

Stavroula (Valia) Kalaitzi was born on 31 May 1965 in Nea lonia, Athens, Greece. She studied Philology, with a major in Ancient Greek Literature (1988), at the National Kapodistrian University of Athens, Greece followed by a two-year professional training in translation at the Institut de Traducteurs, d'Interprètes et de Relations Internationales, Université de Strasbourg, France (1991). Valia holds a Master degree in International Management, University of Liverpool, United Kingdom [Master thesis "Analyzing the women's leadership labyrinth and its influence on career development"(2013)]. In 2014 She received training on leadership, focusing on leadership in public health, within the framework of LePHIE program (Leadership for Public Health in Europe), CAPHRI (Care and Public Health Research Institute), Maastricht University, Netherlands.

She started her professional career as a medical/health translator from 1994 - 2007 in Greece. She continued to work as a medical/health publisher in Greece and some Balkan countries until 2017. She also assumed professional roles as consultant in EU funded projects focusing on women's leadership and empowerment in Balkan countries since 2008 and up to date (capacity building programs, management/consultancy roles, supervision, consortium building). Since 2015 she joined the expert evaluators task force on H2020 program, at European Commission with areas of expertise on gender, eHealth, mHealth, innovation and SMEs.

In 2015 she started her PhD trajectory. The focus of her PhD has been the barriers to women's leadership and gender equality across sectors with a special interest in healthcare and the gender equality policies at EU and Member States level. Throughout her PhD track, Valia has embarked on additional training, including the training on tutoring/mentoring skills and the UTQ training at the Maastricht University. Furthermore, she has taken on various teaching roles in the Bachelor European Public Health and the Master in Governance and Leadership in European Public Health. Valia has been involved in several research projects exploring women's representation in decision making and policy in health workforce, tools to facilitate gender equality plans, as well as the intersections on gender, age, disability, ethnicity at social and economic level. She enjoys membership in EUPHA Working Group on Public Health Leadership and on Health Workforce Research, Foundation of King Jan Kazimierz (Poland), UN Women Organization, Women in Global Health, Euro gender and AGE. She serves as reviewer in scientific journals and chairs the Gender Equality in Healthcare WG, International Network for Health Workforce Education. 



\section{List of publications}

\section{LIST OF PUBLICATIONS}

Kalaitzi S. (2016). The mark of women's leadership on solutions to global health problems. South Eastern European Journal of Public Health, 7(1). (editorial) doi/org/10.4119/UNIBI/SEEJPH-2016-131

Kalaitzi S, Czabanowska K, Fowler-Davis S, Brand H, (2017) "Women leadership barriers in healthcare, academia and business", Equality, Diversity and Inclusion: An International Journal, Vol. 36 Issue: 5, pp.457-474. doi.org/10.1108/EDI-03-2017-0058

Czabanowska K., Domagała A., Kalaitzi S., Krogulec A., Burazeri G., \& Babich S. (2017). Exploring the Added Value of Women Health Care Managers in Poland. Materia socio-medica, 29(4), 280. doi. org/10.5455/msm.2017.29.280-285

Kalaitzi S., Czabanowska, K., Azzopardi-Muscat, N., Cuschieri, L., Petelos, E., Papadakaki, M., \& Babich, S. (2019). Women, healthcare leadership and societal culture: a qualitative study. Journal of healthcare leadership, 11, 43. doi/org/10.2147/JHL.S194733

Kalaitzi S., Cheung, K. L., Hiligsmann, M., Babich, S., \& Czabanowska, K. (2019). Exploring Women Healthcare Leaders' Perceptions on Barriers to Leadership in Greek Context. Frontiers in public health, 7. doi/org/10.3389/fpubh.2019.00068

Kalaitzi S., Czabanowska K., Petelos E., Brand H. (2019)

The sustainable development thinking in gender equality policy in EU: misplaced priorities and unmet challenges. - submitted on September $11^{\text {th }}, 2019$

Kalaitzi S. Czabanowska, K., Brand, H (2019)

Gender mainstreaming toolkits towards achieving organizational change: a qualitative analysis. - submitted on June $3^{\text {rd }} 2019$ 


\section{ABSTRACTS}

Kalaitzi S. \& Czabanowska K. (2015). The complexities of female leadership in healthcare: Stavroula Kalaitzi. The European Journal of Public Health, 25(suppl_3), ckv174-020.

Kalaitzi S. \& Czabanowska K. (2016). Women's leadership in healthcare-the three-faceted quest: Valia Kalaitzi. The European Journal of Public Health, 26(suppl_1), ckw166-018.

Kalaitzi S. \& Czabanowska K. (2017). Barriers Thematic Map (BTM) to Gender Equality in Healthcare Valia Kalaitzi. European Journal of Public Health, 27(suppl_3).

Kalaitzi S., Czabanowska K., \& Petelos E. (2018). Developing the BTM instrument to address gendered challenges in health work settings: Valia Kalaitzi. European Journal of Public Health, 28 (suppl_4), cky218-116.

A Odone, S. Kalaitzi, D Zeegers, K Czabanowska, N Azzopardi Muscat (2018) Public health in Europe: the contribution of women leaders, European Journal of Public Health, Volume 28, Issue suppl_4, 1 November 2018, cky213.620, https://doi.org/10.1093/eurpub/cky213.620

Czabanowska K., Myrup A. C., \& Aleksandrova O. (2018). Women leadership for public health: The added value and needs of women driving public health system reform in Ukraine. South Eastern European Journal of Public Health, 10. (Acknowledgments) 
CONFERENCE PRESENTATIONS

Leaders in Healthcare 2019

4-6 November 2019, Birmingham, United Kingdom

Kalaitzi S.: "Toolkits towards achieving gender equality: creating added value in healthcare organizations"

The 17th World Congress of Medical and Health Informatics

25-30 August 2019, Lyon, France

"Women in Health Informatics: perspectives, leadership and mentoring for diversity"

Anne Moen, Catherine Chronaki, Inge Madsen, Elena Petelos, Stavroula Kalaitzi, Suzanne Bakken

European Public Health Conference

28 November - 1 December 2018, Ljubliana, Slovenia

Kalaitzi S.: "Developing the BTM instrument to address gendered challenges in health work settings"

Women in Global Health Research Initiative

24 April 24 2018, Cornell University, New York, USA

Kalaitzi S.: "Developing the BTM instrument to identify and evaluate barriers and their prevalence to women leadership in global health settings"

European Conference of Health Education and Research: Leadership, Communication \& Intercultural Training

24-25 May 2018, Athens Greece

Kalaitzi S.: "Gender barriers to health workforce sustainability" (Chair of session)

1st Annual International Symposium on Human Rights in Patient Care

10-11 November 2017, Berlin, Germany

Kalaitzi S.: "Barriers to women leaders in Long Term Care"

European Public Health Conference

1-4 November 2017, Stockholm, Sweden

Kalaitzi S., Czabanowska K.: "Barriers Thematic Map (BTM) to Gender Equality in Healthcare"

International Congress of Health Workforce Education Future Education in Healthcare

27-29 June 2017, Porto, Portugal

Kalaitzi S.: «Mind the gap: toward gender inclusion strategies in health workforce sustainabi-lity" 
European Public Health Conference

9-12 November 2016, Vienna, Austria

Kalaitzi S.: "The three-faceted quest in Women's Leadership in Healthcare"; part of the Work-shop: "The Facets of Public Health Leadership in 21st century and its translational outreach", EUPHA Working Group on Public Health Leadership

10th Annual Conference on Scientific Hospital Management: Human Resources as a success factor in hospital running

13-14 June 2016, Athens, Greece

Kalaitzi S.: "Female leadership: the neglected opportunity to progress in healthcare"

Global Health Forum

1-2 November 2015, Tai Pei, Taiwan

Kalaitzi S.: "Contribution of female leaders in building capacity for NGO within the framework of public health leadership"

European Public Health Conference

14-17 October 2015, Milan, Italy

Kalaitzi S.: "The Complexities on Female Leadership in Healthcare" part of the Round table: "Whiter shades of pale » public health leadership: policy, research, education and practice", EUPHA Working Group on Public Health Leadership

1st Annual Conference on Women's Leadership in Healthcare 8 June 2015, Dubai - UAE

Kalaitzi S.: "The art and science in women's leadership in healthcare" 
